\title{
Democracies Under Fire: How Targets and Allies Respond to Coercive Threats
}

\author{
Matt Koji Scroggs \\ Seattle, Washington
}

A.M., University of Chicago, 2010

B.A., University of Washington, 2008

A Dissertation presented to the Graduate Faculty of the University of Virginia in Candidacy for the Degree of Doctor of Philosophy

Department of Politics

University of Virginia

May, 2017 
Abstract: When do states concede to coercive threats? While the majority of research has focused on the states initiating these challenges, comparatively little attention has been given to the targets, the states that actually face the choice of whether to stand firm or back down. My project examines the role that a target's regime-type, broadly construed as democratic versus non-democratic states, plays in the decision-making process, arguing that democracies are more likely to concede when threatened due to the higher costs they pay for foreign policy failure and the relative ease that challengers have in identifying whether democracies are vulnerable to coercion. Further, my argument also extends to the role of democratic allies, who are less reliable when threats of violence are employed against their protégés. I employ statistical evidence with data from the Militarized Compellent Threat (MCT) and Threat and Imposition of Economic Sanctions (TIES) datasets to show the broad validity of my claims, as well as in-depth case studies, namely the Munich and Suez Crises, to demonstrate how my theory works in practice. 


\section{Acknowledgements}

I owe a great deal of thanks to many people who have helped shape this dissertation. My first and greatest debt belongs to Todd Sechser, the chair of my dissertation committee. Todd has been an excellent advisor, helping me along when I had only the faintest ideas of what my project would be about. I had always been fascinated with coercion since the first time I read Thomas Schelling's Arms and Influence, so to find that Todd similarly loved Schelling's work was when I knew he would be a superb chair for my committee. His insights and advice throughout my time at the University of Virginia played a critical role shaping me into the scholar I am today, and I am only better for it.

The first class I took in international relations at UVA was with John Owen, who I quickly learned was not only a brilliant advisor but also one of the kindest people that I have been fortunate enough to meet in academia. I came to John early on in my third year with vague ideas of how I wanted to approach my dissertation, and he played a critical role in helping me piece together what eventually became the main thesis. Always able to make time for a meeting with me, no matter when I happened to be in town or for how long, I will always appreciate the impact that he had on shaping not my research but my view of international relations theory; I came in as a pretty hardcore realist, and I like to think that John played a large role in tempering that inclination (for better or for worse).

When I first arrived at the University of Virginia, I was luck enough to have Dale Copeland as my advisor. I rapidly came to appreciate Dale's deep respect and love for history, which became invaluable as I thought through the case studies for my dissertation. His emphasis on how politics change over time helped a great deal as I considered the potential for learning in my own argument. And his joy at just sitting back and talking theory and history was always a welcome (not to mention useful) use of an office visit.

Philip Potter and Allan Stam each came to UVA, and onto my committee, a little later when they each made their way from the University of Michigan, an immense gain for 
UVA and for the quality of this dissertation. Phil was kind enough to read my theory chapter for the Politics Department's Graduate Student Conference, not only providing me with some incredibly useful and incisive comments, but also what became the title of the dissertation. And beyond his feedback on the project itself, he was willing to take time out of his Thanksgiving break to talk about the job market and handling the two body problem, at a time when it was most needed.

Al's move to UVA to take the reins of the Batten School of Public Policy was a complete surprise when I found out about it; I ended up reading about it in the school newspaper of all places. Bringing him on board the committee as my outside reader may have been a bit of a cheat, since he is a distinguished political scientist in addition to a great dean at Batten. But his advice on writing the dissertation, thinking about alternative explanations and additional implications of the argument, as well as his breadth of knowledge on fields outside of political science, has only served to make the dissertation stronger and will make an even greater impact as I work to turn it into a book manuscript.

In addition to my committee members, I benefit from being able to take courses with and learn from a number of exceptional members of the University of Virginia faculty. In particular, I want to thank David Waldner for his dogged approach to causal inference, which has really pushed me to think long and hard about my beliefs about research design and how to best maximize the benefits of a multi-method approach. Jonathan Kropko managed to convince me that learning about statistical analysis could be an engaging experience, one that has carried over to my work in ways that I could never have imagined when I first arrived at UVA. And Jeffrey Legro taught me most acutely the need for critical thinking, skepticism, and doing research that grabs the reader's attention.

Apart from the faculty, I have been able to work with some fantastic colleagues in my graduate program at the University of Virginia. Michael Poznansky turned out to be not only one of the best colleagues I could have hoped for, having already co-authored with him on one 
project and with plans for more, but also a wonderful friend. My other international relations colleagues, Roger Herbert, April Herlevi, Carl Huang, Min-Gyu Paik, Aycan Katitas, Abigail Post, Chen Wang, Yaping Wang, and Yu Jin Woo, have all been wonderful during my time at UVA, both academically and socially. And I would be remiss if I left out my other colleagues, who have helped keep me on track during the dissertation process, with special thanks to Sarah Andrews, Andrew Clarke, Carrie Coberly, Harrison Frye, Andrew Gates, Chelsea Goforth, Geoff Gordon, Thomas Gray, Boris Heersink, Colin Kielty, Kenneth Lowande, Daniel Medeiros, Sam Plapinger, William Sbach, Paromita Sen, Jennifer Simons, Daniel Smith, Anthony Sparacino, Charlee Tidrick, and Theo Yakah.

I have been fortunate enough to present my work in a variety of conferences, the feedback from which has been invaluable to getting the dissertation to where it is today. Parts of the dissertation have been presented at the annual meetings of APSA, ISA, MPSA, ISAC-ISSS, and the Peace Science Society (International), all of which have given different and unique insights on the project, and for which I am very grateful. In particular, I would like to thank Robert Art, Christopher Darnton, Han Dorussen, Phil Haun, Joel Hillson, Alexandra Homolar, Ashley Leeds, Patrick McDonald, Roseanne McManus, Remi Piet, Kenneth Schultz, Douglas Stewart, and Clayton Webb for their advice and feedback at these conferences over the years.

I have also found myself with the opportunity to present my work at a couple of workshops, which has lead to some excellent and focused feedback from some wonderful scholars. I want to thank Michael Reese for inviting me to speak at the University of Chicago's Program on International Politics, Economics, and Security (PIPES), Kevin Weng for discussing my paper, and Yubing Sheng for coordinating my visit. And I want to thank Allan Dafoe for inviting me to present at Yale University's International Relations Seminar, and Jiyoung Ko for being a wonderful coordinator.

In addition to my time at the University of Virginia, I have had the opportunity to 
spend a good portion of my graduate career at two other institutions, Yale University and Dartmouth College. My time at the latter has been thanks to my fellowship through the University of Virginia's Miller Center, and I owe a great debt to Brian Balough, the chair of the program. Each insitutional has been exceptionally wonderful, providing great places to work and the chance to interact with some truly fantastic scholars and people.

In particular, I want to thank Jason Lyall for his generosity during my time at Yale, welcoming me into his group of graduate students, allowing me to present some of my dissertation work during his workshop with his students, and providing me with space in his FieldLab. I also owe my thanks to his two lab managers during my time there, Nicole Pflug and Prakhar Sharma. And I count myself fortunate to have made a number of great friends during my time at Yale, including Consuelo Amat, Nick Anderson, Vivek Ashok, Natalia Bueno, Charles Decker, Nathan Grubman, Josh Goodman, Jiyoung Ko, Lizzie Krontiris, Niloufer Siddiqui, Shikhar Singh, Anurag Sinha, Guadalupe Tunon, and Louis Wassar.

At Dartmouth, my greatest thanks are owed to William Wohlforth, my Miller Center mentor, who has provided me with feedback and advice on the entirety of my dissertation and related projects. I could not imagine a better mentor during my fellowship year. I also have been fortunate enough to spend my time with a fantastic group of postdoctoral fellows at the Dickey Center, who have integrated me in as if I was one of them. Getting to know them has made the year at Dartmouth all the better, so I want to thank Noel Anderson, Mary Barton, Sean Fear, Eric Hundman, Sabrina Karim, and David Wight for allowing me to be a part of that experience.

My love for political science, and international relations in particular, first came about during my undergraduate years at the University of Washington, and I would be remiss if I did not thank a few people there who were most critical to that experience. Elizabeth Kier became my informal advisor, providing me with guidance and advice not only while I worked on my undergraduate degree, but also during my applications to graduate programs. 
Jonathan Mercer helped cement my love for the study of coercion, introducing me to Thomas Schelling's work and making me think about how rational people truly are. Much of my research relies on rational approaches to political science, but his emphasis on psychology ingrained in me the need to always this a little harder about whether people act the way that I anticipate they should.

I am blessed to have a wonderful family who has been supportive throughout my entire career as a student, from my undergraduate days at the University of Washington, to my master's degree at the University of Chicago, through my doctorate at the University of Virginia. I especially want to thank my mother, Anne, who is the strongest person that I know, who despite hardships has remained the rock not only in my life but that of her entire family. I would never have completed this dissertation without her love and encouragement.

And finally, I want to thank my partner, Suparna Chaudhry. From when we first met during our master's program, to her moving to the states to start her doctoral program the same time as I, to sitting and talking through the very first iteration of my project after finishing comprehensive exams, to the final draft of the dissertation, she has been with me the entire way. That we have been fortunate enough to live together for the past three years despite being in programs that are stationed over 400 miles apart has been a not-so-small miracle, which has helped our bonds grow all the stronger, and I know we will maintain them despite all that academia can throw at us. When I started with a love for political science so many years ago, I would never have guessed that I would also find the love of my life. 


\section{Contents}

1 Introduction $\quad 1$

2 Theory $\quad 9$

3 Militarized Threats $\quad 47$

4 Economic Threats $\quad 85$

5 Case Studies: The Munich and Suez Crises 113

6 Conclusion $\quad 163$

$\begin{array}{ll}\text { A Militarized Threats Appendix } & 171\end{array}$

B Economic Sanctions Appendix 183

C Case Studies Appendix 195 


\section{List of Figures}

2.1 Target Logic . . . . . . . . . . . . . . . . . . . . . . . . . . 20

2.2 Ally $\operatorname{Logic} \ldots \ldots \ldots 22$

2.3 Alliance Logic - Economic . . . . . . . . . . . . . . . . . . . . 23

2.4 Target Model . . . . . . . . . . . . . . . . . . . . . . . . . . . . . 31

2.5 Alliance Model . . . . . . . . . . . . . . . . . . . . . . . . . . . 33

3.1 Dichotomous Measures of Targets - MCT . . . . . . . . . . . . . 67

3.2 Ally Measures w/Dichotomous Targets - MCT . . . . . . . . . . . . 68

3.3 Combined Target and Ally Measures - MCT . . . . . . . . . . . . 72

3.4 Dyadic Measures of Democracy - MCT . . . . . . . . . . . . . 77

3.5 Ally Measures w/Dyadic Target and Initiator - MCT _ . . . . . . . . 78

4.1 BMR Target Measures - TIES . . . . . . . . . . . . . . . . . . 101

4.2 Polity Target Measures - TIES . . . . . . . . . . . . . . . . . . . . 102

4.3 Full Models, All Measures - TIES . . . . . . . . . . . . . . . . . . 106

4.4 High Cost Models, All Measures - TIES . . . . . . . . . . . . . . . . . 107

B.1 CGV Target Measures - TIES . . . . . . . . . . . . . . . . . . . 189 


\section{List of Tables}

2.1 Summary of the Theory's Predictions _ . . . . . . . . . . . . . 25

2.2 Pure Strategy Payoffs for Target Model . . . . . . . . . . . . . . . . . . . 35

2.3 Initiator's Expected Utility for War Mapped onto Outcomes, Target Model . . . . . . . . . . . . . . . . . . . . 36

2.4 Pure Strategy Payoffs for Ally Model $\left(1-p-\omega_{T}>0\right) \ldots \ldots$

2.5 Pure Strategy Payoffs for Ally Model $\left(1-p-\omega_{T}<0\right) \ldots \ldots 37$

3.1 BMR Democracy - MCT Targets . . . . . . . . . . . . . . 58

3.2 Polity - MCT Targets . . . . . . . . . . . . . . . . . . . . 58

3.3 BRM Democracy - MCT Allies . . . . . . . . . . . . . . . . . . . 59

3.4 Polity - MCT Allies . . . . . . . . . . . . . . . . . . . . . . . . . 59

3.5 BMR Democracy - MCT Targets and Allies . . . . . . . . . . . . . 60

3.6 Polity - MCT Targets and Allies . . . . . . . . . . . . . . . . . 60

3.7 Dichotomous Measures of Democracy- MCT . . . . . . . . . . . . . 66

3.8 Predicted Probabilities for Target (Dichotomous) - MCT . . . . . . . . 67

3.9 Predicted Probabilities for Ally - MCT _ . . . . . . . . . . . . . 68

3.10 Dichotomous Measures, Non-Democratic Ally Baseline - MCT . . . . . . . . 69

3.11 Target/Ally Combination, Democratic Target and Ally Baseline - MCT . . . 71

3.12 Target/Ally Combination Predicted Probabilities - MCT _ . . . . . . . . 72

3.13 MCT Initiator/Target Distribution _ . . . . . . . . . . . . . 74 
3.14 Dyadic Measures of Democracy- MCT . . . . . . . . . . . . . 76

3.15 Predicted Probabilities for Targets (Dyadic) - MCT . . . . . . . . . . 77

3.16 Predicted Probabilities for Ally - MCT . . . . . . . . . . . . . . 78

3.17 Dyadic Measures, Non-Democratic Ally Baseline - MCT . . . . . . . . . . 79

3.18 Threat Types by Target $-\mathrm{MCT} \ldots \ldots \ldots 79$

3.19 Compliance by Threat Type and Target - MCT . . . . . . . . . . . . 80

4.1 BMR Democracy - TIES Targets . . . . . . . . . . . . . . . . . . 92

4.2 Polity Democracy - TIES Targets . . . . . . . . . . . . . . . . 93

4.3 BMR Dichotomous Measure - TIES . . . . . . . . . . . . . . . . . . . . . 99

4.4 Polity Dichotomous Measure - TIES . . . . . . . . . . . . . . . . . . 100

4.5 BMR Predicted Probabilities - TIES _ . . . . . . . . . . . . . 101

4.6 Polity Predicted Probabilities - TIES … . . . . . . . . . . . . 102

4.7 BMR Democracy - TIES Dyadic . . . . . . . . . . . . . . . . . . 103

4.8 Polity Democracy - TIES Dyad . . . . . . . . . . . . . . . . . . . 104

4.9 Dyadic Measures of Democracy, All Obs - TIES . . . . . . . . . . . . 105

4.10 Dyadic Measures of Democracy, High Target Cost Obs - TIES . . . . . . . . 105

4.11 Threat Types by Target - TIES _ . . . . . . . . . . . . . . . . . 108

4.12 Hard Issue Compliance Rate - TIES . . . . . . . . . . . . . . . . . . 108

A.1 Schultz (2001a) Replication via Downes and Sechser (2012) - MIDS . . . . 174

A.2 MIDS Replication with Table 3.7 Variables . . . . . . . . . . . . . . 175

A.3 Dichotomous Measures of Democracy- MCT (3.7) . . . . . . . . . . 177

A.4 Dichotomous Measures, Non-Democratic Ally Baseline - MCT (3.10) . . . 178

A.5 Target/Ally Combination, Democratic Target and Ally Baseline - MCT (3.11) 179

A.6 Dyadic Measures of Democracy- MCT (3.14) . . . . . . . . . . . . . 180

A.7 Dyadic Measures, Non-Democratic Ally Baseline - MCT (3.17) . . . . . . . 181 
B.1 CGV Democracy - TIES Targets . . . . . . . . . . . . . . . 187

B.2 CGV Dichotomous Measure - TIES . . . . . . . . . . . . . 188

B.3 CGV Predicted Probabilities - TIES _ . . . . . . . . . . . . . 189

B.4 CGV Democracy - TIES Dyad . . . . . . . . . . . . . . . . . . 190

B.5 BMR Dichotomous Measure - TIES (4.3) . . . . . . . . . . . . . 191

B.6 Polity Dichotomous Measure - TIES (4.4) _ . . . . . . . . . . . . . . 192

B.7 Dyadic Measures of Democracy, All Obs - TIES (4.9) _ . . . . . . . . . 193

B.8 Dyadic Measures of Democracy, High Target Cost Obs - TIES (4.10) . . . . 194

C.1 Democratic Target Residuals: All Positive Cases . . . . . . . . . . . . . . . 197

C.2 Democratic Ally Residuals: All Positive Cases . . . . . . . . . . . . . . . 198

C.3 All Positive Cases of Democratic Target and Ally, Chronological Order . . . 199 


\section{Chapter 1}

\section{Introduction}

"Democracies are exceptional." This notion undergirds much of American foreign policy, with policymakers buying into the belief that the more democracies exist in the world, the better off the United States will be. And there are multiple facets to this idea. Normatively, democracies are an attractive form of government, responsive to the citizens of the state, and representative of its peoples, at least in theory. With millions of dollars poured into democracy promotion on a yearly basis, this is no minor issue.

Practically speaking, there are numerous advantages to being a democracy. Scholars have claimed that democracies are effective fighters, winning the wars they are involved in more often than other types of regimes, regardless of whether they started the fighting. ${ }^{1}$ They might also have some important advantages in coercive diplomacy, with some arguing that democratic threats are more credible, allowing democracies to avoid fighting through success threats. $^{2}$

As allies, it has been argued that democracies are more "reliable partners," making

\footnotetext{
${ }^{1}$ For a variety of arguments for democratic exceptionalism in war, see Bueno de Mesquita, Morrow, Siverson and Smith (1999); Lake (1992); Rasler and Thompson (1999); Reiter and Stam (1998, 2002); Werner and Lemke (1997).

${ }^{2}$ For more on democratic credibility, see Fearon (1994); Schultz (2001a). For a counter-argument, see Downes and Sechser (2012).
} 
credible pacts and promises capable of outlasting the presence of a given administration. ${ }^{3}$ Still others point to democracies coming to one another's aid as a potential benefit, with the notion that "birds of a feather flock together," protecting each other if one is attacked or threatened. ${ }^{4}$ More broadly, there is of course the notion of democratic peace, which relies on the idea that more democracies will create an ever-expanding "zone of peace" amongst these fortunate members. ${ }^{5}$

The conclusion of the Cold War and the "end of history," along with the subsequent spread of liberal democracy throughout the world, have cemented this perspective, and underpin the liberal strain of international relations theory. ${ }^{6}$ Democratic exceptionalism, this belief that democracies hold such varied and distinct advantages, has become the standard perspective of how democracies fit into world politics.

Empirically, however, there are puzzling occurrences that require our attention. While perhaps not that unusual in and of itself, the case of Czechoslovakia wilting in the face of Nazi Germany's demands over the fate of the Sudetenland in 1938 is a very well-known and important example. The Czechoslovakian government as well the British and French knew that their defenses would be gutted by conceding the Sudetenland, making it incredibly vulnerable to future German aggressions. And yet, the British and French still chose to avoid hostilities, leading to the Czechoslovakian government conceding to the demands of the Nazis. While one could argue that this is a simple case of power politics, the fact that democracies failed to act in the face of such active coercion, it is worth asking if material factors along were decisive.

Alternatively, following their invasion of Egypt in 1956, the United Kingdom and France ultimately caved to the demands of the Soviet Union during the Suez Crisis, withdrawing

\footnotetext{
${ }^{3}$ Lipson (2003).

${ }^{4}$ Reiter and Stam (2002), Chapter 4, provides a summary (and critique) of this perspective.

${ }^{5}$ Levy (1989). For alternative takes, see Gartzke (2007) on capitalist peace; Waltz (2000) and Rauchhaus (2009) on nuclear weapons; and Brooks and Wohlforth (2008) and Gowa (2011) on unipolarity.

${ }^{6}$ Fukuyama (1992).
} 
their forces in humiliation. Why would these two powerful countries, closely tied to the United States, choose to yield to Soviet threats rather than standing their ground when they had the capability to do so? Was the threat of nuclear warfare so credible that the British and French had no choice but to back down, abandoning their excursion in the face of nuclear annihilation?

Or what about the United Kingdom capitulating to demands from Iceland during the "Cod Wars" in 1973 and 1975? Withholding comment on the fact that these events featured one democracy threatening another, how could the United Kingdom, spending billions of dollars on military expenditures, ${ }^{7}$ a military of 375,000 soldiers, and incalculably more influence on the world stage, end up conceding to Iceland, a country which, for all intents and purposes, was spending nothing on its military? Everything about this case indicates that the British should have come out on top, and yet they submit to Icelandic threats.

More recently, the Russian acquisition of Crimea from Ukraine has raised a different but related question: how has Russia been able to effectively coerce Ukraine into ceding Crimea, despite having the weight of the U.S. acting as a guarantor of Ukrainian security and independence? One would think that if any circumstance would bring about the full might of U.S. influence and persuasion, it would be in the case of Russian threats which undermine Ukrainian sovereignty and territorial integrity. And yet, Russia got what it wanted while the U.S. failed to take any meaningful action.

While each case is a unique situation unto itself, they are connected by an overarching the question: if democracies are as "tough and smart" as the overview presented above tells us, why do we observe such prominent (and less prominent) cases of democracies being victimized, and/or party to another's victimization, in coercive diplomacy?

As far back as Tocqueville, some have argued that democracies contend with important

\footnotetext{
$7 \$ 7.493$ billion in current dollars. Source: State Department World Military Expenditures and Arms Transfers, 1970-1979. http://www.state.gov/documents/organization/185663.pdf
} 
limitations, particularly when it comes to foreign policy. He thought "democratic governments... decidedly inferior to others" when it came to dealing with the state's foreign goals, with democracies prone to changing their behavior and interests along with the whims of the public (de Tocqueville 2009, 369). Wright (1965) argued that democracies actually operate at a disadvantage, with the participation of the public slowing down action, and making it difficult for democracies to hide their intentions (842). Kennan (1984) also believed that the role of the public was problematic, capable of influencing leaders into actions that might be in the public's demand but not in their interests (93).

One goal of this dissertation is to revive and revise these more pessimistic views of democracies in international relations. By focusing on how and when coercion is more likely to be effective, this project brings to bear significant evidence suggesting that the democratic triumphalist perspective has critical limitations that have heretofore been underappreciated. While war remains an important area of foreign policy and can always benefit from further study, the examination of how democracies fare in coercive diplomacy provided by this dissertation shows that democracies can indeed be hamstrung in important ways, adding nuance and reshaping the common understanding of democratic exceptionalism to the study of international relations.

What is coercion? In this context, I mean an attempt by one state to get some concessions from another state by threatening to do something that the latter would rather avoid. For the aggressor, they obtain some good that they did not have previously, while not having to resort to taking action in order to sway the target's behavior. For the target, they are able to avoid some sort of costly punishment being inflicted upon them, though at the cost of having to revise the status quo in favor of the aggressor.

Why are democracies at a disadvantage in coercive diplomacy? I argue that leaders in democracies simultaneously pay higher costs for erring in the foreign policy realm, and can be more readily identified as vulnerable to coercive threats. This combination of factors 
leads to democratic targets conceding more readily to a variety of different demands, while targets that are reliant upon democratic allies for their security give in to threats of violence more often. While it may be the case that democracies have some intrinsic advantages in certain regards, I contend that this is not the case as coercive targets and allies.

In particular, I identify public opinion as the mechanism that leads to higher concessions. Democracies are simultaneously less likely to prevent public gatherings and displays of displeasure regarding foreign affairs decisions, as well as more beholden to the members of the public for maintaining office. This combination makes for clear and credible signals from democracies, either in the direct form of protests and riots or indirectly through observable actions taken by the democratic government to prevent such public disobedience from occurring in the first place. Given that these events can be seen by other states, potential initiators are able to more readily select themselves into situations where the target and/or ally is seen as particularly vulnerable, thus maximizing the chances for the threat to succeed. Thus, while we cannot say for certain that any randomly chosen democracy would be more likely to concede to a coercive threat than a randomly chosen non-democracy, the selection mechanism leads to those democracies that are threatened to be more likely to give in to the initiator's demands.

This project also has a larger goal: to shed light on the importance of coercive targets. While there has been a recent reinvigorated interest in coercive diplomacy, the results have been primarily focused on the initiators of threats. This is inherently of interest, as we might want to better understand how democracies as the initiators of action make decisions. But understanding how they act as recipients of action is also crucial. This project shifts this emphasis to the latter by studying democratic targets of threats, an area of study which has been largely ignored. Subsequently, international relations scholars have left aside questions about factors indigenous to the recipient of the demands and how they might influence the decision-making process. As such, this project will investigate different factors related to 
coercive targets in an effort to better understand why some states choose to acquiesce to threatening demands while others risk war by standing firm.

\section{Contribution}

This project makes a two-fold contribution, both to the literature of democratic exceptionalism and inter-state coercion. As noted above, the story of democratic exceptionalism has been overwhelmingly focused on how democracies perform in war compared to other regimetypes. In so doing, the field has made a number of interesting and important observations, but ultimately they are limited purely to the realm of war. On the other hand, to the extent that we can say there are agreed upon "truths" when it comes to democracies as allies, they are primarily limited to conclusions on formal agreements and their fulfillment.

This project is able to expand on democratic exceptionalism by shifting the dependent variable from war to coercion and by emphasizing the informal sides of alliance politics in addition to the formal. By contributing to a small but young literature on compellent threats, this project seeks to gain new insights into how democracy matters in ways that have been heretofore understudied. Similarly, in examining alliance politics of democracies in a broader scope than has been previously realized, this project generates new conclusions that go beyond the arguments that focus purely on the formal aspect of alliance agreements, as has been often been the case in the past.

Moving to the realm of inter-state coercion, by expanding the analysis beyond merely looking at the initiators to actively theorize about the actions of targets, we can gain a more complete and comprehensive vision of how compellent threats function, starting with the decision by the initiator to make the threat and going through the choice of the target

to concede or stand firm. This undoing of the "black box" of the target and investigating how particular factors, such as the democratic / non-democratic split and alliance politics, 
provides a richer and fuller understanding of why targets make the decisions they do.

\section{Roadmap for the Dissertation}

This dissertation is divided into two main parts, with the first section outlining the theory of the dissertation while the second provides empirical tests of the theory. Chapter 2 develops the theoretical argument, starting first with the general logic, before transitioning to two formal models, one demonstrating the behavior of coercive targets while the second examines how alliance partners behave. If we think about the interplay between the challenger and target as the former considers whether or not to issue a demand, it becomes clear that there are important strategic interactions to consider, as these threats are not randomly distributed. This allows me to clearly identify observable implications of the selection process which I can then test using the available data, both quantitatively and qualitatively.

Chapter 3 applies the logic of the theory to the realm of militarized threats, i.e. those involving demands backed with threats of force. This chapter provides statistical evidence in line with the expectations of the theory, showing how both democratic targets and allies are correlated with higher rates of concessions. Chapter 4 performs a similar task, with the emphasis shifted toward threats of economic sanctions and arguing only that democratic targets be tied to higher concession probabilities. For both of these chapters, I provide multiple robustness tests and address potential threats to validity, in terms of monadic versus dyadic effects and the types of threats that democracies contend with in contrast to non-democracies.

Chapters 5 provides two major case studies where states faced militarized threats. Following Weller and Barnes (2014), I use statistical analysis to identify those cases where my variables of interest most contributed to the outcome and avoiding selection bias with case selection, using a mix of cases that fit the expectations of my theory as well as a few that do 
not. In addition, I use different case studies to get variation in both the targets and allies, thus demonstrating the effect that each has separately and in conjunction with one another. I first examine the Munich Crisis, utilizing captured Nazi documents to trace through the process by which Adolph Hitler chose to threaten Czechoslovakia, despite their alliances with the British and the French. My second case study covers the Suez Crisis, focusing on the decision-making processes that the British and the American faced following the invasion of Suez and through the British decision to back down following Soviet threats to attack both the British homeland as well as the soldiers deployed in Egypt.

Chapter 6 concludes the dissertation, summarizes the theory and the evidence I have provided to validate my claims. Further, it considers other implications of my argument and the relevance of my findings to policymakers. Finally, I discuss areas of future research, particularly considering the relaxation of key assumptions, such as the hard division between democratic and non-democratic regimes as Weeks (2012) and Weiss (2013) suggest. 


\section{Chapter 2}

\section{Theory}

How does being a democracy influence the likelihood of coercive success? I argue that democratic targets and allies simultaneously pay higher costs for foreign policy failures and their vulnerability to coercive demands can be more readily identified. This chapter will draw out the theory introduced in the previous chapter, employing formal models to demonstrate how the inclusion of democratic trappings changes the behavior of targets and their allies, building on the mechanisms that cause these variations. This chapter will begin by first briefly outlining my argument, then describing how democratic features interact with coercive diplomacy, establishing both why democratic leaders are more likely to be removed from office following a blunder on the international stage and why their vulnerability is easier to discern. I then formalize my argument, demonstrating how targets and allies indicate their

resolve, emphasizing the importance of selection effects and costly signals. I then conclude by summarizing the argument and the findings of the model. 


\section{Argument}

The two main claims that I put forward in this dissertation are that a) democratic targets are more likely to make concessions when threatened, and b) state that have democratic allies are also more likely to comply when facing coercion. Coercion and threats in this context mean an attempt by one state to bring about a change in the status quo vis-à-vis another state's position, and can cover a range of different issues, such as territorial demands, leadership changes, or policy stances, among others. What the precise threat involves can vary, but always involve some punishment being inflicted upon the target, which may then have consequences for the target's allies as well. The most prominent type of threat involves the use of force, with one state pressuring the other with the specter of war or an attack, though states have many avenues by which they can attempt to change the behavior of others.

My argument rests on two primary assumptions. First, when foreign policy mistakes are made, democratic leaders can have a higher probability of being removed from office than do non-democratic leaders. This is not to say that the punishment is worse, since nondemocratic leaders have to worry about being killed or exiled, nor that the overall expected utility for democratic leaders is lower than it is for non-democratic leaders; merely that, all else being equal, leaders in democracies are more likely to be removed due to predictable mechanisms by which the public can oust the leader. Nor is this to argue that the democratic public is inherently knowledgeable about foreign policy events. Instead, I contend that the very nature of a crisis brings the leader's decisions and actions to the attention of the public, which can make punishment for errors more likely.

Second, I assume that democracies that face elevated costs to the incumbent regime can be more readily identified. At any given point of time, leaders of any state face varying levels of domestic resistance, which, if properly exploited, can contribute to the ouster of the 
leader. In democracies, some of these signals are much more observable to outside actors, such as protests or demonstrations, to name some extreme cases. While non-democratic regimes can also contend with these sorts of disruptions, they are also much more likely to be repressed before they reach a suitably critical mass, thus denying outside observers an indicator of the regime's weakness. As I elaborate in below in the target and ally logics, this mechanism provides important information to states that might want to try coercing the democracy, allowing for the use of threats in situations where success is more likely.

In the case of targets specifically, I argue that in the pre-threat stages of a dispute, democratic targets are more likely to signal, often inadvertently, their vulnerability to coercion compared to non-democratic targets. Whereas non-democratic states are more likely to stifle domestic dissent and discontent, the open and transparent nature of democratic regimes allows for these types of disputes to be aired. On the lower end of the spectrum, this dissatisfaction may take the form of newspaper articles or television shows which are criticizing the incumbent regimes, perhaps some minor public demonstrations indicating that some members of the public are unhappy with how the leadership is acting. In more extreme cases, this can escalate to massive demonstrations, large portions of the public marching in the streets. That this behavior is taking place openly is critical, as it allows foreign actors to observe that the democratic leader faces genuine domestic pressure, and thus is vulnerable to coercion.

Democratic allies deal with many of the same vulnerabilities as their target counterparts. Just as domestic upheaval can indicate that democratic targets are susceptible to threats, their allies also have the potential to unwillingly signal that they face challenges at home which make them less amenable to interventions abroad on behalf of their protégé. What complicates matters further for allies is that they face no direct threat themselves, and thus are unlikely to experience any rallying effect where the public comes to support the government's position following the threat being issued. In contrast, since the target is the 
one being threatened, there is at least some chance of a backlash against the challenger, making resistance more likely. Instead, the ally has to weigh its interest in avoiding conflict with not wanting to appear as if it is abandoning the protégé, a difficult balancing act. I suggest that allies strike this balance by actually pressure the target to make concessions, thus preventing any escalation of the conflict while not violating the letter of the alliance agreement.

In both of these cases, the leader of the democratic target or ally can anticipate a higher likelihood that they will be punished by the voting public if they fail to act in accordance with the interests of the people. This constraint can then directly shape the behavior of the democratic leader, making them behave in a more conciliatory manner, even if the leader wanted to act more aggressively. It is worth noting, however, that the circumstances where we can expect to see these different effects take place are not perfectly aligned. While the target will always face some costs for not conceding, this is not true of the ally. For example, if the ally is called to help the protégé in a war, the ally can reasonably be expected to pay some costs for involvement. On the other hand, if the target faces sanctions, the ally might not suffer any pains and could even benefit. Therefore, we should only expect to see the ally mechanism be activated in cases where the democratic ally has a reasonable expectation of harm or costs should the threat be enacted.

For the potential challenger, there are then two different ways in which they can observe signals from democratic leaders which can be used to update their beliefs about the likelihood that coercion will be successful, both directly (from the democratic leader's behavior) and indirectly (from the general public). When the challenger sees these signals, they can easily tell that a threat is more likely to succeed, as no state or leader would willingly send or allow the sending of signals that betray their own weakness. Therefore, the challenger will be more likely to issue a demand and subsequently have a higher probability of success.

In short, democratic targets and allies are more likely to signal that they are capable of 
being coerced, due to the nature of their regimes and the manner in which they allow domestic discontent to publicly emerge without repression. This dissatisfaction serves to both directly indicate vulnerability to potential challengers, and indirectly through constraints placed upon the democratic leaders. By using this information to update their beliefs, challengers can make threats that more selective and ultimately more effective.

\section{Theorizing Responses to Coercion}

How do democracies differ in systematic ways from non-democracies in the context of coercive threats, both as targets and allies? I make a two-fold argument, that when democratic leaders err in the foreign policy arena, they are more likely to be removed from office than are nondemocratic leaders, and that they can be more likely identified as susceptible to threats by potential challengers. This combination makes democratic targets and those states that are reliant upon powerful, democratic allies more likely to make concessions when they are threatened. I will begin by outlining my theory as it applies to targets of coercive threats and their allies, contrasting it with the argument raised by Schultz (2001a). I will then address potential confounders, such as the ability for leaders to use conflict to improve their domestic standing and potentially endogenous relationship between democratic leaders and public opinion.

There is a great deal of disagreement over whether democracies suffer higher costs than their non-democratic counterparts for foreign policy mishaps. ${ }^{1}$ In its most simple form, this argument boils down to democratic leaders being held responsible by the general public of their state, while non-democratic leaders are reliant upon a small portion of the populace, or selectorate, for maintaining office. ${ }^{2}$ The particular mechanism can vary a great deal,

\footnotetext{
${ }^{1}$ For arguments in favor of this perspective, see Downs and Rocke (1994); Hess and Orphanides (1995). For an argument against, see Chiozza and Goemans (2003).

${ }^{2}$ While the portion of the general public that supports the democratic leader is also a selectorate, for the purposes of this section I use the term to refer specifically to the non-democratic leader's supporters.
} 
and I will posit three of the most prominent ones here in order to demonstrate why it is plausible that democratic leaders pay higher costs when they err. First, Bueno de Mesquita, Morrow, Siverson and Smith (2002) argue that democratic leaders have to employ public goods to keep the general public happy, while non-democratic leaders are able to pay off their selectorate with private goods. This distinction is critical, as it is much less expensive to provide side payments to the smaller, non-democratic selectorate following a foreign policy failure, whereas the democratic leader has to try and assuage a much larger number of people without the ability to discriminate between supporters and non-supporters. The end result is democratic leaders having a more difficult time trying to maintain office compared to non-democratic leaders following a major blunder.

A second mechanism focuses on the ability for leaders to mitigate the costs that they face, particularly audience costs. According to this set of arguments, leaders can, under some circumstances, mitigate or largely avoid costs associated with backing down during a crisis. Trager and Vavreck (2011) focus specifically on the President of the United States and find that factors such as how the president's party acts, the type of rhetoric being employed, and whether the opposition party supports backing down can help signal to voters whether they should punish the President. Relatedly, Levendusky and Horowitz (2012) find that factors connected to partisanship, how other elites react, and whether the President frames backing down in the context of new information can help lessen punishment. But by focusing solely on democratic leaders, both of these arguments miss the broader applicability of these mechanisms. While democratic leaders can utilize these avenues to try and circumvent audience costs, there is reason to believe that they can be employed more effectively by nondemocratic leaders. While democratic presidents and prime ministers have to transmit this information through indirect means to the public, primarily through speeches on television or radio, non-democratic leaders have a smaller selectorate whose members can be informed in a direct manner, thus removing possible confusion or ambiguities. By being able to directly 
lobby their selectorate, non-democratic leaders have a distinct advantage over democratic leaders when it comes to convincing them to hold back punishment.

Finally, a third mechanism contends that foreign policy failures act as a signal to the public or selectorate that a leader is incompetent and should be removed from office. This is particularly valuable for the general public in democratic states, as they have relatively little information on whether their leader is doing an effective job. Therefore, when they observe that the leader makes some error in foreign policy, they take this noisy signal as an indication that the leader is broadly incapable of handling the job, and should be removed from office at the most proximate opportunity. (Guisinger and Smith 2002) But the selectorate in a nondemocracy rarely has to rely solely on such signals to be able to tell whether their leader is incompetent. Indeed, they often have a great deal of information about the leader compared to the general public, and would have a much better sense of whether the foreign policy faux pas is truly indicative of the leader's abilities. Therefore, while this argument would imply that the probability of a democratic leader being removed from power will always increase following such an error, this is not necessarily the case in a non-democracy.

Taken together, these three mechanisms lend significant credence to the idea that leaders in democratic states can pay higher costs for foreign policy failures than do leaders in nondemocracies, but not that they necessarily do in all circumstances. As Baum and Potter (2015) persuasively argue, there is a great deal of evidence to suggest that voters are typically ignorant and inattentive when it comes to foreign policy (19-20). If this is accurate, it means the likelihood voters will punish leaders for any given error is much lower than we have been lead to believe. For Baum and Potter, the public can and will punish leaders under some circumstances, but only if the public is aware of what is happening, which requires both an opposition with enough political clout to call the incumbent leader or party on a mistake, as well as sufficient media institutions such that the public can become aware of the failure.

I suggest an alternative logic which relies on the public's awareness of events but does 
not explicitly require the two factors raised by Baum and Potter. Instead, I contend that the public can become aware of events during early stages of a crisis, before a threat emerges. Crises are, by definition, a time of exceptionally high public salience, such that people are aware generally of how events are transpiring due to the open nature of democratic regimes as well as the availability of the media. While the opposition might act as a whistleblower in these circumstances, this is not a necessity; rather, it could very well be the opposite, with the opposition (or even members of the incumbent party) reacting to public opinion by taking a stance critical of the leader. In these circumstances, should the leader continue to take actions that are unpopular with the public, it is reasonable to expect that there is a higher likelihood that the leader would be removed from office. ${ }^{3}$ In turn, democratic leaders should act to avoid these costs. Rather than attempting bluffs or trying to misrepresent the state's resolve, the democratic leader should act in more risk-averse ways.

In addition to being more susceptible to such costs under the circumstances I outlined above, I also propose that democracies are also more easily identified as being vulnerable due to the transparent nature of the system. While Schultz (2001a) focuses on how opposition parties reinforce or undermine signals of resolve, I instead concentrate on how observable actions by the public can reveal instability and constraint to other states that might threaten the democratic target. When a public demonstration occurs in a democracy, it is a relatively simple task to trace how these indicators of displeasure could influence the regime: if the unhappiness of the public is deep and widespread enough, when the next election occurs, the leadership can be voted out of power. For a non-democracy and its inner cadre, those who the regime is reliant upon for maintaining power, this is much less clear. One could argue that this mostly comes down to an issue of coordination: any single member of the

\footnotetext{
${ }^{3}$ It is possible that this effect could be mitigated by the leader's erroneous actions leading to a good outcome, with the public weighing the results as being worth the poor process. But this also requires a leader who is willing to make such a gamble, rather than playing it relatively safe by sticking with public opinion and undercutting the opposition's critique.
} 
regime's inner circle would want to avoid making public statements that indicate wavering resolve, for fear that they could be eliminated, whereas if all or most of the members acted simultaneously, it could force the leader to act. In any case, if we are focusing on those who the non-democratic leader is most directly reliant upon for maintaining power, it is rare to see public statements or disputes which would indicate waning resolve.

This is not to say that public protests or rallies cannot occur in a non-democracy. Indeed, Weiss (2013) has argued that rallies and protests in China can be taken as a credible signal that ties the hands of the leadership, arguing that the Communist Party's willingness to risk instability and a possible revolution signals resolve over a particular issue, as it becomes more difficult to crack down on these protests as they continue to gain more inertia. While I have no disagreements with this mechanism in the context of crises broadly speaking, I am less convinced of its relevance as relates to selecting into threats. Though it is possible in theory for such protests to take place prior to a threat being issued, and thus at lower levels of escalation within a crisis, there are two reasons why this seems unlikely. First, given that the burgeoning conflict is still at a relatively low level, it is unclear why the non-democratic regime would want to use such a high-risk mechanism. Even if the issue at hand is one of great importance to the regime, jumping right to state-sponsored protests and movements seems unnecessarily dangerous. Second, the cases that Weiss employs only seem to involve public demonstrations after a highly salient event has taken place, such as a bombing or a plane crash. While this does not mean such a catalyst is necessary for the the non-democracy to utilize costly protests, it does seem to at least make it much more feasible. If this is accurate, then pre-threat or pre-crisis protests, meant to deter threats by allowing potential challengers to gauge the target's level of resolve, are unlikely to emerge.

However, for the sake of argument, let us say that such protests are possible and that the non-democracy can initiate them prior to the crisis escalating to the point of explicit threats or demands. The signals that a non-democracy will send are still fundamentally different 
from those that come from a democracy as only the latter would ever signal weakness, precisely because it has no way of preventing it. While non-democracies might be capable of signaling resolve, this is a less useful barometer in many ways, as it only tells a potential initiator when they should not issue a demand. In contrast, democracies actually indicate that they are ripe targets, that the initiator can issue a threat and get some benefit on the cheap. This readily leads to initiators being able to select themselves into conflicts that reward them, while the signals from non-democracies only tell when they should be expressly avoided. Therefore, even in the most generous situation, it seems unlikely that non-democracies can employ public signals in the same manner as democracies.

Another important distinction to make here is between my conception of a crisis compared to that of Fearon (1994). Whereas Fearon's model has the crisis beginning with the threat by one state against the other, I do not think that this is necessarily the case. While the issuing of a threat represents a high degree of escalation, there are many events that can take place between the start of a crisis and the threat emerging which are worth emphasizing. For instance, there can be some disputed good over which the parties are bargaining, feeling out one another's preferences and constraints, eventually leading to an ultimatum. In such a situation, this pre-threat signaling actually allows for the decision to issue a threat or not to be made.

Of course, democratic publics are not necessarily submissive in all cases. Indeed, recent research would seem to indicate that the general public is more bellicose than members of the academy, even after accounting for the disparity between liberal and conservatives distributions between the two groups. ${ }^{4}$ While it should be mentioned that there are important differences between support for conflict in the abstract versus backing an actual war, it is still worth noting that the public can be willing to support conflict. This, in and of itself, should not be surprising; it is very reasonable to believe that the public will be willing and

\footnotetext{
${ }^{4}$ See Horowitz and Salehyan (2015) for more analysis.
} 
able to support a dispute should the need arise.

The critical factor to consider is that the public may be more or less in favor of a fight under different circumstances, and that their willingness is observable. This is important for the initiating state, as it allows a window into the democratic target's decision-making process: by being able to tell that the public is or is not in favor of a conflict, and roughly to what degree, the initiator has a greater ability to select into threats that are more likely to succeed. These selected conflicts, where the public is actively opposed to participating in a dispute, would be where the initiator has a higher chance of getting what it wants without needing to resort to violence.

This also means that there are cases where the public would support conflict, where if the initiator chose to get involved when the public was feeling particularly bellicose, it would make the democratic target less likely to concede to the initiator's demands. However, this event is less likely to happen precisely because the initiator can observe the public's level of support, and thus avoid making a threat when it is certain to fail. The simplified logic of the argument can be seen in Figure 2.1 below.

But the preceding argument is primarily framed in the context of democratic and nondemocratic targets, while my theory extends to alliance partners, when examining disputes that threaten the ally as well. In the case of democratic allies, the above argument becomes even more pronounced, as the ally was not directly threatened, thus limiting their stake in the conflict. While it may be possible that a direct, militarized threat could invoke nationalist sentiments or create a backlash against the threatener, this is not the case with allies, especially democratic ones. Indeed, because these democratic allies are even more risk averse, I argue that we should expect to see them actively aiming to undermine their allies in an attempt to avoid having the conflict reach a stage where the ally needs to intervene.

For a stylized example of how an ally can be influenced by a threat, imagine a situation with three states, the initiator (State I), the target (State T), and the target's democratic 


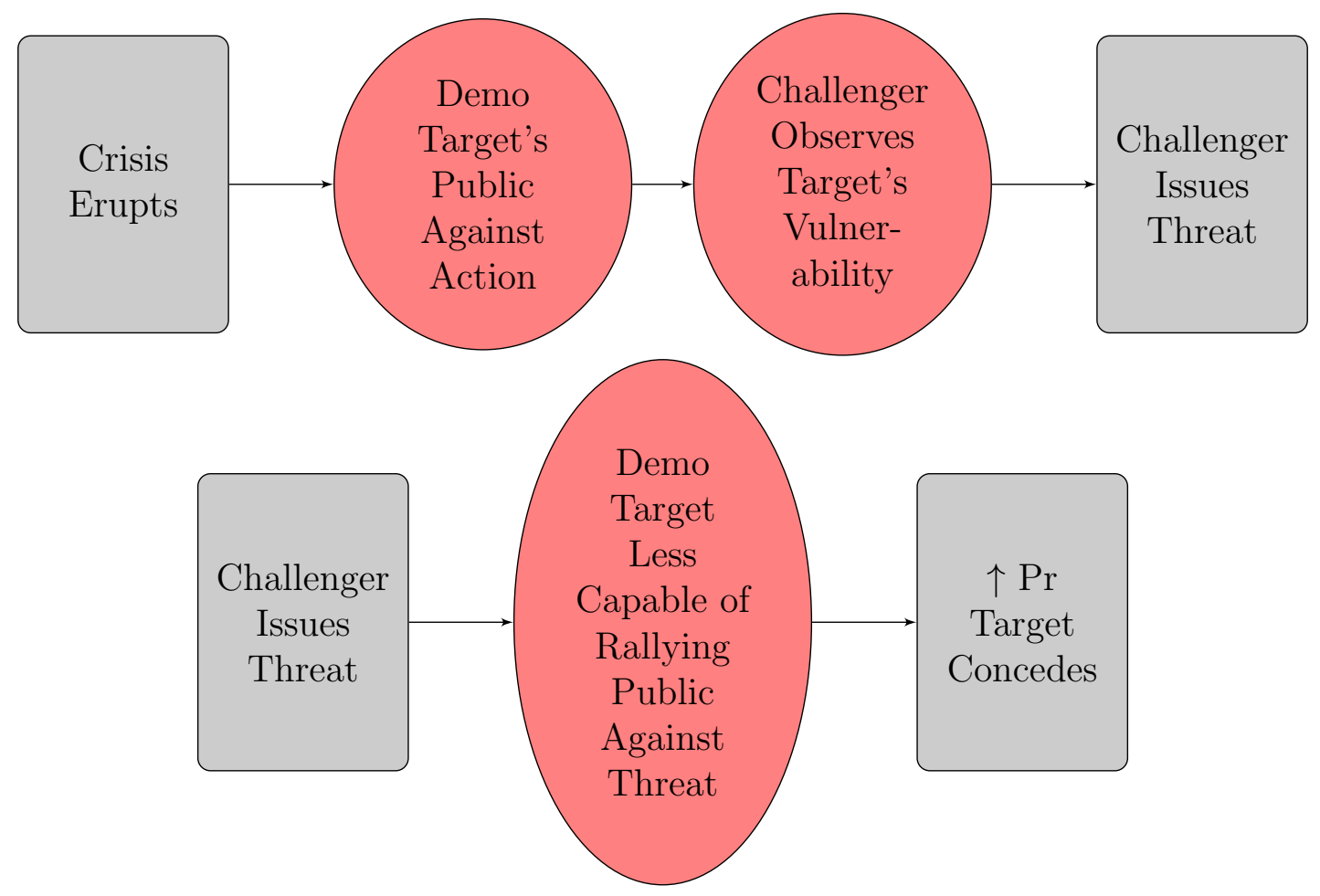

Figure 2.1: Target Logic

ally (State A), where State I has threatened State $\mathrm{T}$ over a parcel of land and State A is considering how to respond. In making this decision, State A is weighing two opposing interests. on the one hand, if they come to the aid of State T, State A's public will be unhappy that they are embroiled in a dispute that could escalate to war, where the citizens of State A would have to fight and die over an issue that does not directly involved them. On the other hand, if State A were to abandon State T, it could damage State A's reputation in the international arena and call into question the other commitments that State A has made to its allies. Neither of these outcomes is ideal for State A, but fortunately there is a third alternative: coerce or pressure State T into making concessions. This can take place through positive inducements, such as promising military and financial aid to build State $\mathrm{T}$ up in an effort to deter future acts of aggression. Or, if the stick became necessary, State A could threaten to cut aid or actively employ levers of diplomatic and economic coercion to 
get State $\mathrm{T}$ to back down.

Based on the above argument, we should expect to find those targeted states with democratic allies should be more likely to concede. But for non-democratic allies, there are cross-cutting effects to consider. On the one hand, the non-democratic nature of the ally means that the ally should be comparatively more risk acceptant for the same reason that they should pay lower costs for foreign policy failures as targets, and thus more willing to get involved with the chance that conflict could erupt. It follows then that, all else equal, we should see lower levels of concessions from targets with non-democratic allies. On the other hand, the fact that the ally was not directly targeted and thus has less incentive to get involved would seem to indicate that those allies would not be reliable, which would lead to higher levels of concessions from the targets.

I argue that the risk-avoidant nature of alliance partners outweighs the risk-acceptant characteristics of non-democratic states. Ultimately, fighting in wars and getting involved in conflicts that are not directly relevant to the non-democratic ally is a costly behavior for it to undertake, even for states that would be willing to get involved in similar conflicts if they were the targets of the threat themselves. Therefore, I would expect to see those states that do not have any major allies to be the most likely to stand firm in the face of threat, while those with autocratic allies would be slightly less likely to resist, and targets with democratic allies would be the most likely to make concessions. In other words, directly comparing those states with non-democratic allies with those that have democratic allies, the latter should be more likely to concede. This logic is summarized in Figure 2.2.

This is not to say that democracies are better or worse allies when it comes to war. ${ }^{5}$ Given that actualized war and coercion are such different types of events, it could very well be the case that how states act in one circumstance will have little bearing on what happens

\footnotetext{
${ }^{5}$ See Lipson (2003) for an argument that democracies are reliable allies that will honor their commitments, and Gartzke and Gleditsch (2004) for a counterargument.
} 


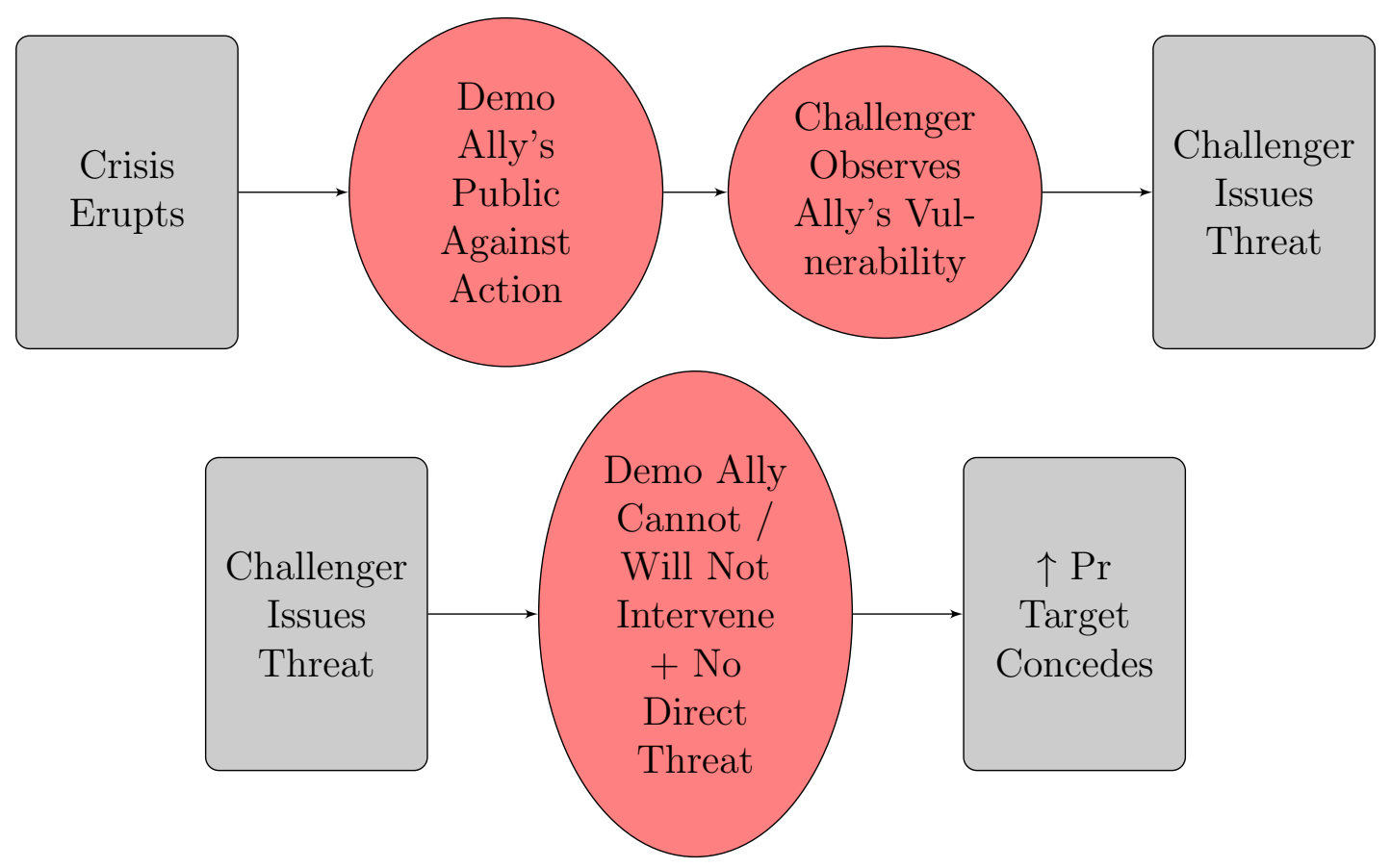

Figure 2.2: Ally Logic

in the other. Or, it could be that my argument simply has the effect of influencing which threats escalate up to war, and thus could fit in with one side or the other. I only contend that my argument neither undermines nor validates the conclusions about wartime behavior, just as previous research does not speak directly to the process of coercive diplomacy.

It is also important to note that this alliance logic should not extend to all coercive attempts. While an ally has powerful incentives to intervene prior to a threat involving military force escalating to actualized violence, for example, there are many other cases where this logic would be unlikely to hold. For instance, another major diplomatic tool that state have at their disposal is economic sanctions, and there are many cases where states or groups of states threaten to employ sanctions prior to actually utilizing them. In this case, it is much less clear how any ally would choose to intervene, if it would at all, since any direct impact the ally feels from the sanctions would likely be minimal. Unlike the hypothetical threat above, it is rare for an alliance to have explicit stipulations about 


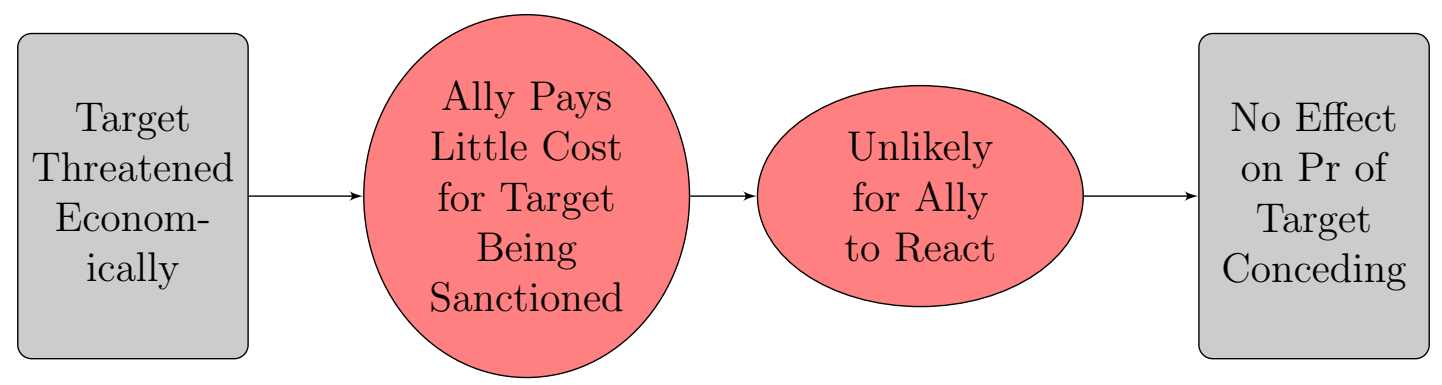

Figure 2.3: Alliance Logic - Economic

coming to a partners' aid when threatened with sanctions, or even if sanctions are imposed. Further, from a self-interested standpoint, there is little for the ally to gain for intervening on the target's behalf, and it may actually be the case that the target could become more reliant on the ally, thus providing benefits to sanctions being enforced. Therefore, while I argue that allies matter in the context of coercive threats with the backing of military force, I am not claiming that they extend far beyond that. In short, whereas having a democratic ally will lead to higher levels of concessions when the target faces a coercive threat with military backing, alliance partners should not matter in cases where the threat is economic in nature. This general logic is summarized in Figure 2.3.

The other major contrast that needs to be drawn here is with Schultz (2001b). On the surface, our predictions appear to be very similar, at least as regards democracies as targets of coercive threats: my theory predicts that democracies are more likely to concede, while he argued that "[d]emocratic targets are (weakly) less likely to resist threats than are non-democratic targets." (122) They key difference comes from his caveat about the target regime's influence, namely that "the regime type of the target influences the game under a more limited set of conditions than does the regime type of the challenger because the latter has greater strategic flexibility. Thus, this relationship, and all others dealing with democracy in the target, is predicted to hold only weakly." (121) In other words, the target's regime type only has limited sway according to his formal model.

Schultz's caveat makes a great deal of sense in the context of his argument. His emphasis 
is primarily on how the regime type of the initiator, and the subsequent presence of an opposition within democracies, provides a credible signal of resolve or lack thereof to the target. As such, what emerges are initiators (typically) selecting themselves into conflicts where the opposition will back the threat and selecting out of those where the opposition will not. However, Schultz notes that these findings are not limited only to initiators, though he concludes that targets often have less leeway to bluff and that challengers can initiate threats conditional upon what they observe from the target's reaction. (99)

I argue otherwise. Due to the initiator's ability to observe aspects of the target's resolve prior to the choice of issuing a threat or not, there should be two effects. The first effect is one of selection, with the initiator being capable of observing signals from the democratic target and/or ally indicating the level of resolve, and therefore the probability of concessions. The second effect, given that the initiator has chosen targets signaling irresolution, is that the target will be more likely to make those concessions. Therefore, whereas Schultz's argument only implies that democratic targets should be weakly more likely to make concessions (and to be targeted in the first place) due to the strategic limitations placed on those states responding to threats, my theory predicts that both of these effects should be clearly observable.

It is important to reiterate here just how critical selection effects are on this overall argument. As will be emphasized in the models below, what generates these outcomes are not just the costs and benefits that the targets and allies have to consider when debating whether to fight or not. Just as important are the signals that those states send, indicating the degree to which they care about the issue at hand. As demonstrated below, the addition of costs particular to democracies changes the behavior we should expect to see from targets and allies, leading to different signals which allow the initiators to select themselves into threats that are more likely to succeed. Rather than downplaying or ignoring the possibility of democracies being selected into conflicts differently than non-democracies, I instead integrate 
it into my theory.

The preceding argument, as well as the models I employ, makes a very strong but important assumption, namely that non-democracies can readily send duplicitous signals of their resolve, which have no effect on the costs that they do or do not pay when it comes to responding to coercive threats. This is a very strong assumption, and like all strong assumptions does not perfectly comport with reality. As Weeks $(2008,2012)$ and Weiss (2013, 2014) have demonstrated, there is variation amongst how different types of non-democratic regimes can interact in crises and conflicts, which should not be discounted. Indeed, future research should relax this assumption, examining how different autocratic states vary in their ability to issue credible threats and respond to them. ${ }^{6}$

To summarize what I would expect to see if my theory is correct, Table 2.1 provides a breakdown of my predictions below. These predictions are parsed based on whether the actor of interest is the target or the target's ally, and whether the threat is militarized or non-militarized.

\begin{tabular}{|l|l|l|}
\hline & Militarized Threat & Non-Militarized Threat \\
\hline Democratic Target & Higher Pr of Concessions & Higher Pr of Concessions \\
\hline Democratic Ally & Much Higher Pr of Concession & No Effect on Pr of Concessions \\
\hline
\end{tabular}

Table 2.1: Summary of the Theory's Predictions

Before moving on, it is worth considering some related arguments, particularly those that could act as confounders to the theory. In particular, there is some division in the literature as to whether getting involved with conflict is something that a) can help democratic leaders retain office, or b) if the democratic public actively constrains bellicose behavior. On the first point, focusing primarily on cases of military force for the time being, there is a long debate about the effect of events bolstering a leader's popularity, the so-called "rally 'round

\footnotetext{
${ }^{6}$ Preliminary analysis I have performed indicates there is some validity to the arguments made by Weeks (2008) and Weeks (2012). However, there are severe data limitations due to the underlying data on authoritarian regimes only goes back to 1945, thus excluding approximately half of the observations from the Sechser (2011) dataset.
} 
the flag" effect. Mueller (1970) made the original argument that leaders of democracies (in this case the President of the United States) can find their standing improve through a war, where the president leads the country into conflict, or a crisis. ${ }^{7}$ He predicted that such an event would galvanize the country around the President, leading to increased popularity and approval ratings. If such a mechanism does in fact work, then democratic leaders could use crises and conflicts as means of improving their domestic standing, even if they did not start the conflict initially. Indeed, one could argue the effect might be even stronger if the democratic leadership is able to portray themselves as the victim, fighting against injustice.

Empirically, however, this effect is less dramatic. For instance, Lian and Oneal (1993) argue that across 102 cases where the U.S. employing major uses of force, the average change in the president's approval rating was $0 \%$, that even in the most "well-publicized uses of force" only provided a small return on investment, to the tune of $2-3 \%$. Baker and Oneal (2001) provide slightly different findings, concluding that in cases where the conflict is particularly large and prominent, and when the U.S. was both the initiator of the dispute and had revisionist intentions. Further, framing of the conflict seems to matter a great deal, with those with greater media coverage, support across party lines, and effective "spin" from the White House being those that led to the greatest payoffs.

Another important point to consider are the conditions under which rallying effects occur in the first place. If we consider threats leading to war as occurring over multiple stages, one interpretation might be that they start with the threat itself, followed by the resistance of the target, then concluding with war. However, it is unclear at which stage rallying effects begin to take place, or, assuming that they accumulate across these stages, where the gains

\footnotetext{
${ }^{7}$ This is also closely related to the logic of diversionary war, where conflict is actively sought in order to improve the leader's prospects for maintaining power, though Mueller's argument emphasizes the rallying effect. For more on the diversionary war literature, see Chiozza and Goemans (2004), Clark (2003), DeRouen (2000), Levy (1989), Meernik and Waterman (1996), Morgan and Anderson (1999), Oakes (2006), Tarar (2006), Tir and Jasinski (2008) and Tir (2010). Also ee Aldrich, Gelpi, Feaver, Reifler and Sharp (2006), Berinsky (2007), Gartner (2008), Gelpi, Feaver and Reifler (2006), Gelpi (2010), and Grieco, Gelpi, Reifler and Feaver (2011) for the relationship between casualties and sustained public opinion.
} 
are highest. In other words, the timing of rallying effects is not clearly delineated in the literature, leaving it an open question how they would fit into my explanation of coercive threats.

Whether the public constrains democratic leaders from getting involved in conflicts, especially where war is involved, is also debated. In Perpetual Peace, Kant (1932) made the argument that the general public would always be opposed to conflict on the most basic level, due to the understanding that they would be the ones that would end up fighting and dying in order for the state to win. This fundamental opposition would then make the leaders of democracies more reluctant to wage war, for fear that they would be replaced by a public that did not seek to get involved in the first place. Leblang and Chan (2003), however, make an important observation: while it is argued that the public is against war, "this attribution of pacifism to a mass electorate tends to be more assumed than demonstrated, with scant reference to survey research on public opinion." (387) Ultimately, they appear to be correct, as this seems to be a theoretical issue with little by way of empirics to back it up.

Part of the problem is that this broad-stroke theory assumes that the public is consistently against war, and thus provides little nuance. For instance, Gartner (1998) find that public support for war, at least within the United States is heavily contingent on the level of casualties that U.S. forces are enduring; as those costs increase, the willingness of the public to go along with the conflict quickly erodes. Reiter and Tillman (2002) explore how domestic institutions influence the likelihood that states will initiate conflict, using different indicators from Polity to parse out the specific effects each has on outcomes. They conclude that the strongest evidence rests with political participation, that higher levels are correlated with states initiating disputes less often, which could be interpreted as a more important role for public opinion, that leaders who are more vulnerable and concerned about holding onto power through the participation of the public are more constrained in their actions. Baum (2004) notes the cross-cutting impact that public opinion has, both making commitments 
by democratic leaders more credible, but also constraining their ability to use force in the first place.

Overall, there is a great deal of disagreement about the circumstances under which public opinion is able to constrain democratic leaders from going to war, whether as initiators of conflict or as the targets thereof. Therefore, I take it as an empirical question that this project can at least partially answer, providing some understanding of whether and how the constraints of public opinion are able to prevent democracies from standing firm in the face of coercive threats. Hopefully, this will further provide a springboard for a broader and deeper understanding of how public opinion influences conflicts with democracies, even by moving the ball forward only slightly.

This section has sought to provide a theory for why democratic targets and allies lead to higher likelihoods of concessions. This is not to say make a deterministic argument, that having these factors will guarantee concessions, nor does it seek to argue that democratic targets and allies are less effective in other forms of coercive diplomacy or conflict. But it does emphasize the costs that democratic leaders pay for going against the wishes of the

public, for misrepresenting the interests of the general will. It is this point that I will carry over to the models of coercive threats, and demonstrate how the inclusion of costs associated with displeasing the public has on the way that democratic targets and allies will signal their resolve.

\section{Formalizing the Logic: Coercive Threat Structure}

Where the above section lays out the logic of theory, the task now becomes putting it in the context of a formal model, beginning with the broad question: If we focus on coercive threats as the unit of analysis, when will we see threats succeed? In order to understand this, it is useful to first consider what the context of a threat looks like. There are an unlimited 
number of ways this could be performed. In his study of coercive diplomacy, Schultz (2001a) conceived of threats in the guise of an extensive form game, with three moves: the initiator choosing whether to challenge the status quo or not; if a threat was issued, the target deciding whether to resist or not; and if the target resisted, whether the initiator stood firm or backed down. (27) In contrast, Sechser (forthcoming) frames it in the context of an ultimatum game, where two actors are bargaining over a good, with the coercer making a "take it or leave it" demand that the target either accepts or rejects, thus avoiding or starting war, respectively. Neither of these models are inherently better or worse than the other, only different ways of approaching a similar issue.

Since this project is interested in the role that both targets and allies play in responding to coercive threats, this chapter will present two variants of a single game. I will first outline the model emphasizing the role of the target, then demonstrate the alliance version. As conceived of here, the decision to make and the decision to respond to a coercive threat are akin to a simple signaling game, with two actors, the initiator and the target, the latter of which controls the good. Prior to the actual decision to make the threat, the initiator and the target have had some degree of communication over the good in dispute, whether that means through public or secret talks, bilateral or multilateral negotiations, or merely observing the degree to which the other has made public statements regarding the good. During the course of these discussions, the target decides whether to send a costly signal of high resolve or not. I treat this costly signal as one of sunk costs, associated with actions that the target has to take in order for these signals to have meaning. Regardless of whether the target is resolved or irresolute or if a challenge is issued or not, the target that signals high resolve must incur these costs.

Following the observed signal of resolve, the initiator has a decision to make: should they issue a threat or not? While the initiator has some idea of whether the target is resolved to fight, there is likely some degree of uncertainty about how the target would react to having 
a threat issued. To simplify matters, I assume here that a target that has a high degree of resolve will always fight if a threat is issued, whereas a target with low resolve will concede the issue rather than risk a costly fight over something they do not care a sufficient amount to defend. ${ }^{8}$ However, as alluded to above, resolved targets need not send signals of high resolve, nor irresolute targets indicating low resolve; rather, each type can misrepresent their level of resolve, most importantly for irresolute targets pretending to care greatly about the issue at hand.

With this conception of bargaining in mind, the baseline version of the model is set up as follows:

- There are two actors, the target state $(T)$ and the initiator state $(I)$, bargaining over some good with a value normalized to 1.

- Further, there are two types of $T$, those that are resolved $(R)$ and those that are irresolute $(\sim R)$, which is determined by nature with a distribution of $q$ irresolute to $1-q$ resolved.

- $T$ sends a signal of resolve, either high $(H)$ or low $(L)$.

- I responds by either challenging $T$ ( $C h$ in response to $H$, ch for $L$ ) or not challenging $(\sim C h$ in response to $H, \sim c h$ for $L)$.

- If $I$ challenges a resolute $T$, then the result is conflict where $I$ has $p$ probability of winning while suffering $\omega_{I}$ costs of fighting and $T$ has $(1-p)$ probability of winning while suffering $\omega_{T}$ costs of fighting.

- If $I$ challenges an irresolute $T$, then $I$ gets the good and $T$ gets nothing.

- If no challenge occurs, then $T$ retains the good and $I$ gets nothing.

- Regardless of outcome or type, any $H$ signal will impose a cost of $c$ onto the target.

A slightly different version of the model includes options for the target to concede or stand firm after being threatened, and the initiator given the choice of fighting or not following the target standing firm. For the sake of simplicity, I have chosen to prune the tree back some, and imposed the assumption that resolved types will always fight if challenged and

\footnotetext{
${ }^{8}$ It should be noted that while I separate types into those willing to fight and those not willing to fight, this is also indicative of a willingness to be intransigent in the face of a threat. As such, the logic applies not just to war.
} 


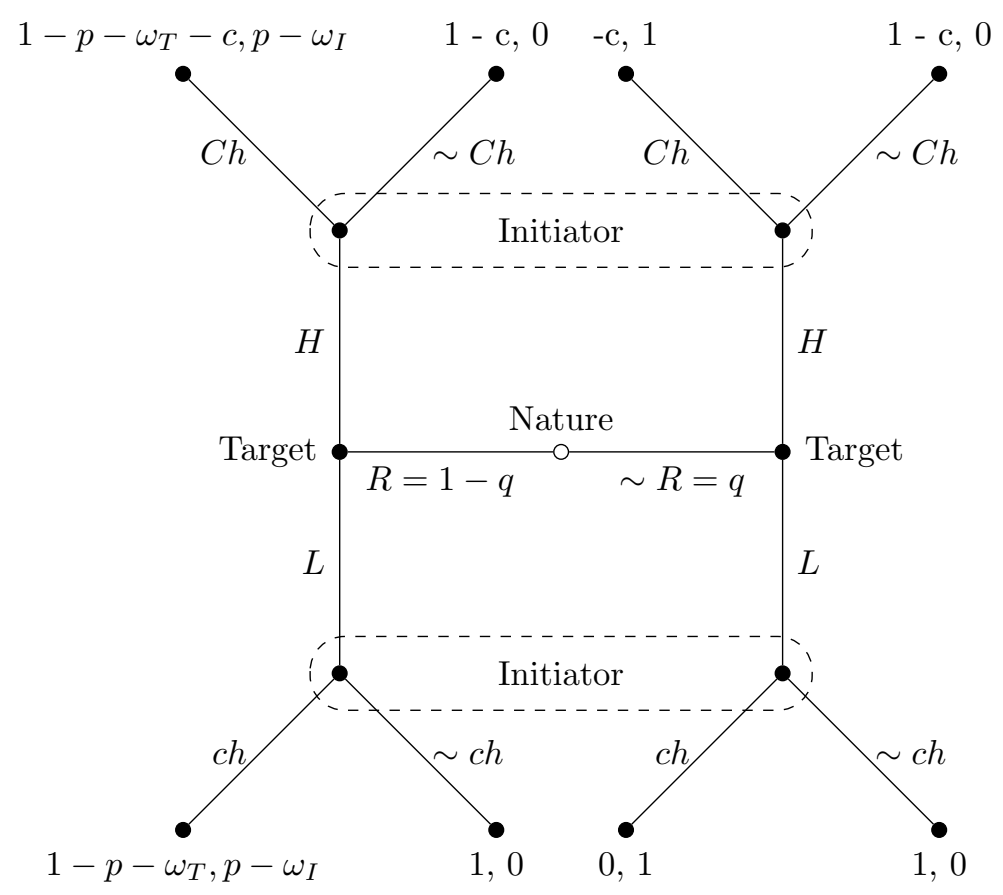

Figure 2.4: Target Model

irresolute types will not. This could also be interpreted as saying that resolved targets have an expected value for war that is greater than 0 , while irresolute types have a value less than 0 .

While it may be possible that under some circumstances coercive threats can approximate games of complete information, it is unlikely that this occurs very often. Rather, it is much more likely that the interplay between the initiator and target resembles a game of incomplete information, where the initiator is uncertain of whether the target is resolved or not, in which case the signal being sent could be a useful indicator of the target's type. As such, this section only include models with an incomplete information restriction.

This first model, focusing on coercive targets and with the payoffs listed in order of $T$ then $I$, is shown in Figure 2.4.

Along similar lines, I also construct a model that changes the first mover from the target to the target's ally, who signals resolve and willingness to stand by the target. The target 
still is an actor within the model; however, it is mostly passive, and only has the ability to decide whether to fight or back down when the ally refuses to come to its aid. The model breaks down as follows:

- There are three actors, the ally $(A)$, the initiator $(I)$, and the target $(T)$. The initiator and the target are disputing over a good with a value normalized to 1 . In addition, $A$ gets some benefit from the status quo, $S Q$.

- There are two types of $A$, those that are resolved $(R)$ and those that are irresolute $(\sim$ $R$ ), which is determined by nature with a distribution of $r$ irresolute to $1-r$ resolved.

- A sends a signal of resolve, either high $(H)$ or low $(L)$.

- I responds by either issuing a challenge ( $C h$ in response to $H$, $c h$ for $L$ ) or not challenging ( $\sim C h$ in response to $H, \sim \operatorname{ch}$ for $L)$.

- If $I$ challenges a resolute $A$, then the result is conflict where $A$ provides some additional probability of victory, $q$. Therefore, $I$ has $p-q$ probability of winning while suffering $\omega_{I}$ costs of war, while $A$ and $T$ have $(1-p+q)$ probability of winning while suffering $\omega_{A}$ and $\omega_{T}$ costs of fighting, respectively. If $A$ wins, it gets $S Q$, but it gets 0 if loses.

- If $I$ challenges an irresolute $A$, then $T$ decides whether to stand firm or back down. If $T$ decides to stand firm, it has a $1-p$ chance of winning while incurring $\omega_{T}$ costs of fighting. As such, $A$ also has a $1-p$ probability of retaining $S Q$ while avoiding any costs for fighting, and $I$ has a $p$ chance of winning while suffering $\omega_{I}$ costs for fighting. If $T$ chooses instead to back down, $I$ gets the good and both $A$ and $T$ get nothing.

- If no challenge occurs, then $A$ retains the status quo, $T$ keeps the good, and $I$ gets nothing.

- Regardless of outcome or type, any $H$ signal will impose a cost of $c$ onto the ally.

In addition to these factors, I also impose some limitations on the parameters of the model. Since $p$ and $q$ are meant to be some probability of success, I limit each of them to be between 0 and 1 , such that $p=[0,1]$ and $p+q=[0,1]$. I also limit the cost parameter, $c$, to be between 0 and 1 , not because costs cannot be greater than the value of the good in question (which they can be, under some circumstances), but because the game is only interesting in so far as the good is at least marginally valuable after sunk costs are imposed.

The model, with the payoffs in the order of $A, I$, and $T$, can be found in Figure 2.5. 


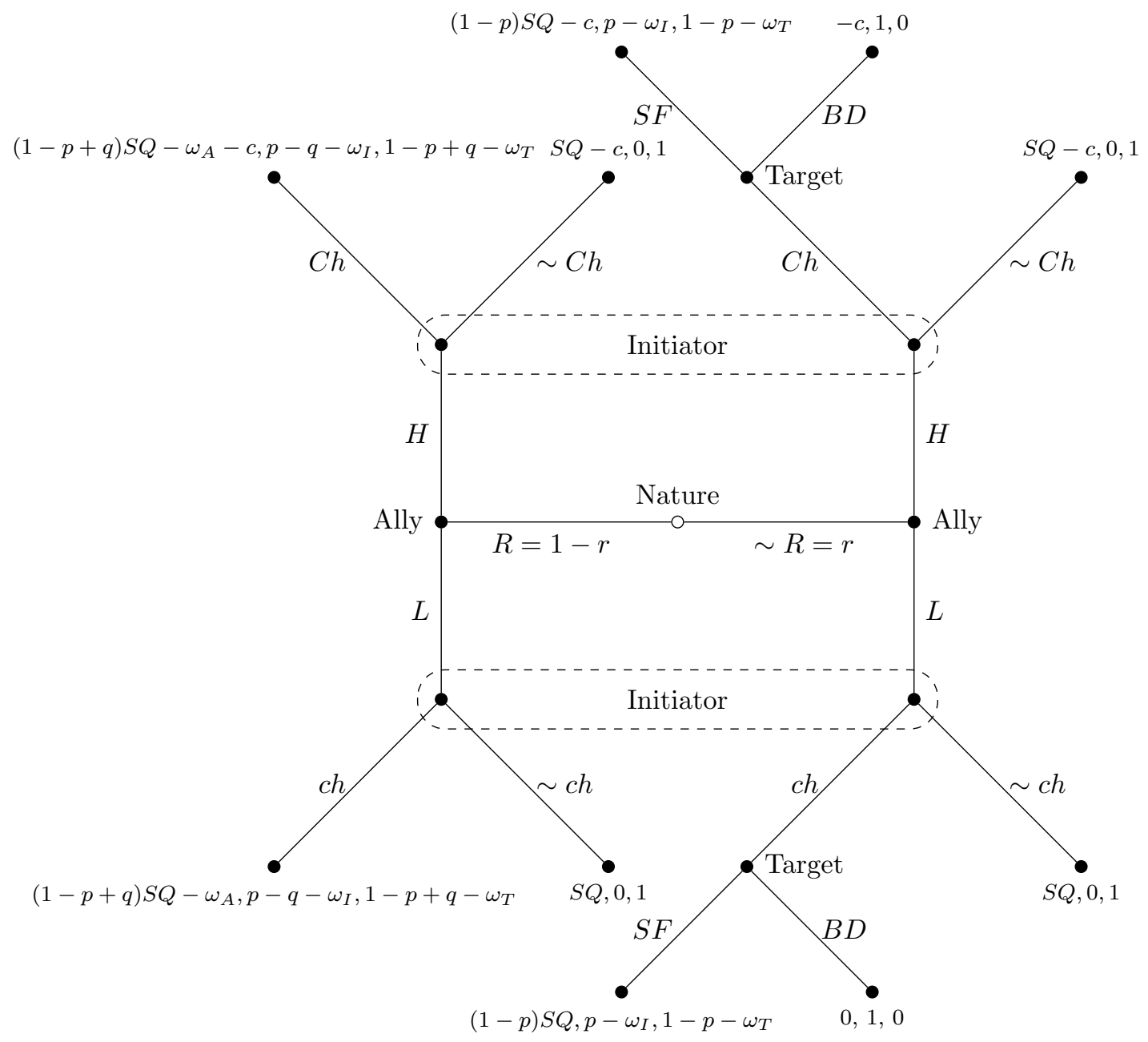

Figure 2.5: Alliance Model 
In examining these two models, there is an important observation to be made: neither model has anything explicitly about democracy in them, or at least the term does not arise in the description provided above. Rather than having the model include democracy/nondemocracy as a branch or solving different versions of the game using variations in regimes, the impact of a target or ally being a democracy or non-democracy is tied up in the cost parameter noted above. The contention here is that all states face costs when they send high signals, but that those costs are systematically higher for democracies.

As noted in the preceding section, there is reason to believe that the public in democracies is concerned with the possibility of conflict occurring, either in the militarized or economic sense, and thus worries about the costs that they will have to pay if things go poorly. Costs of military mobilization, risks of future war, and other factors that directly impact the public are in this context able to be passed on to the leadership, making democratic leaders have to take these costs into account.

In contrast, while the public certainly suffers costs in an autocracy as well, they do not have the capability to pass those costs on to the autocratic leadership in the same capacity. Therefore, we would expect that these costs are lower across the board for autocracies, even if they are sending the same type of signal as the democracy. Indeed, one way of modeling an autocratic target or ally would be to drop the cost term entirely, assuming the extreme example that sending a high signal is completely costless to the autocracy. ${ }^{9}$

Another important distinction to draw would be in contrast with models where the target's public either has an interest in removing leaders that are damaging the reputation of the state, or demand that the leader act in a manner that is consistent with the preferences of the public, regardless of the consequences. Guisinger and Smith (2002) provide two models, one where reputation rests within the leader and the other where it exists in the state itself,

\footnotetext{
${ }^{9}$ Such a model, while not included here, is predictably unenlightening: because the target or ally pays no costs for acting resolved, the result is pooling behavior between the resolved and irresolute types.
} 
in order to demonstrate how leaders that bluff and misrepresent the interests of the state can incentivize the public to remove them as a means of improving the state's reputation. As noted above, it may be the case that the public chooses to punish the leader for having accepted these sunk costs through bluffing, but it does not directly say anything about reputation in general. Though an iterated version of the game may indicate that the public has an incentive to remove leaders that bluff to prevent future bluffs, that is not an argument that I am proposing here.

Similarly, one could make an argument that the public prefers a leader who simply acts in accordance with what the public wants, no matter the aftermath. In such a model, we would expect that irresolute types pay costs for acting as if they were resolved, while the resolved types would be punished for signaling they were irresolute. While this is again plausible, I contend that the public is much more outcome-oriented than process in the real world, and thus would not typically choose to punish the leader if they like the result.

\section{Calculating Pure Strategy Equilibia}

Using the information available from the models, I begin by building a table of payoffs for the players involved, in order to determine whether any pure-strategy equilibrium are present in the game, starting first with the target model. To facilitate this, I assume that the targets are equally disposed to being resolved and irresolute, setting $q$ at .5. This results in the following payoffs shown in Table 2.2 .

Table 2.2: Pure Strategy Payoffs for Target Model

\begin{tabular}{|l|l|l|l|l|}
\hline & Ch, ch & Ch, ch & $\sim$ Ch, ch & $\sim$ Ch, ch \\
\hline H, H (T) & $.5\left(1-p-\omega_{T}\right)-c$ & $.5\left(1-p-\omega_{T}\right)-c$ & $1-c$ & $1-c$ \\
H, H (I) & $.5\left(1+p-\omega_{I}\right)$ & $.5\left(1+p-\omega_{I}\right)$ & 0 & 0 \\
\hline H, L (T) & $.5\left(1-p-\omega_{T}-c\right)$ & $.5\left(1-p-\omega_{T}-c\right)$ & $.5(1-c)$ & $.5(2-c)$ \\
H, L (I) & $.5\left(1+p-\omega_{I}\right)$ & $.5\left(1+p-\omega_{I}\right)$ & .5 & 0 \\
\hline L, H (T) & $.5\left(1-p-\omega_{T}-c\right)$ & $.5(1-c)$ & $.5\left(2-p-\omega_{T}-c\right)$ & $.5(2-c)$ \\
L, H (I) & $.5\left(1+p-\omega_{I}\right)$ & .5 & $.5\left(p-\omega_{I}\right)$ & 0 \\
\hline L, L (T) & $.5\left(1-p-\omega_{T}\right)$ & 1 & $.5\left(1-p-\omega_{T}\right)$ & 1 \\
L, L (I) & $.5\left(1+p-\omega_{I}\right)$ & 0 & $.5\left(1+p-\omega_{I}\right)$ & 0 \\
\hline
\end{tabular}


We can see that there are some circumstances under which pure strategy equilibria emerge. Starting first with the initiator, imposing certain restrictions on the expected utility for conflict leads to three sets of outcomes: the initiator always challenges, the initiator never challenges, and the initiator mixes challenging and not challenging. These circumstances are broken down in Table 2.3, which again assumes a 50/50 split of resolved and irresolute targets.

Table 2.3: Initiator's Expected Utility for War Mapped onto Outcomes, Target Model

\begin{tabular}{|l|l|l|l|}
\hline & $p-\omega_{I}>0$ & $0>p-\omega_{I}>-1$ & $-1>p-\omega_{I}$ \\
\hline Irresolute Target Action & Always Low & Mix High, Low & Always Low \\
\hline Initiator Action & Always Challenge & Mix Challenge, No Challenge & Never Challenge \\
\hline
\end{tabular}

What emerges from this table is a straightforward notion: because the target is often trying to avoid the sunk costs associated with high signals, low signals will always be sent when the initiator has a unilaterally best strategy, whether that is when the initiator will always challenge or never challenge. It is only when the initiator will challenge irresolute targets and not challenge resolved targets that the high signals come in, as a means of targets indicating their level of resolve. This, however, is also contingent on c's magnitude: if $c$ is too small, the signal loses meaning; and if $c$ is too large, the resolved target will be better off just sending a low signal and fighting, even if that means absorbing the costs of conflict.

A similar conclusion is reached when we examine the alliance model. I again begin by calculating the payoffs for pure-strategy outcomes, with the outcomes divided across two tables: one where the target is resolved to fight if the ally does not come to its aid (Table 2.4), and the other where it is not resolved (Table 2.5). Just as above, I once again assume that an ally is just as likely to be resolved as irresolute.

Attempting to draw any conclusions from these ally tables is an even more complicated process than the one for the target model, due to the inclusion of additional variables. While it is imposed that $q=1-p$, given that $p$ can range from 0 to 1 , determining if the initiator's 
Table 2.4: Pure Strategy Payoffs for Ally Model $\left(1-p-\omega_{T}>0\right)$

\begin{tabular}{|l|l|l|l|l|}
\hline & Ch, ch & Ch, ch & $\sim$ Ch, ch & $\sim$ Ch, ch \\
\hline H, H (A) & $S Q\left(1-p+\frac{1}{2} q\right)-\frac{1}{2}\left(\omega_{A}+c\right)$ & $S Q\left(1-p+\frac{1}{2} q\right)-\frac{1}{2}\left(\omega_{A}\right)-c$ & $S Q-c$ & $S Q-c$ \\
H, H (I) & $p-\frac{1}{2} q-\omega_{I}$ & $p-\frac{1}{2} q-\omega_{I}$ & 0 & 0 \\
\hline H, L (A) & $S Q\left(1-p+\frac{1}{2} q\right)-\frac{1}{2}\left(\omega_{A}+c\right)$ & $S Q\left[1-\frac{1}{2}(p+q)\right]-\omega_{A}-c$ & $S Q\left(1-\frac{1}{2} p\right)-\frac{1}{2} c$ & $S Q-\frac{1}{2} c$ \\
H, L (I) & $p-\frac{1}{2} q-\omega_{I}$ & $\frac{1}{2}\left(p-q-\omega_{I}\right)$ & $\frac{1}{2}\left(p-\omega_{I}\right)$ & 0 \\
\hline L, H (A) & $S Q\left(1-p+\frac{1}{2} q\right)-\frac{1}{2}\left(\omega_{A}+c\right)$ & $S Q\left(1-\frac{1}{2} p\right)-\frac{1}{2} c$ & $S Q\left(1-\frac{1}{2} p+\frac{1}{2} q\right)-\frac{1}{2}\left(\omega_{A}+c\right)$ & $S Q-\frac{1}{2} c$ \\
L, H (I) & $p-\frac{1}{2} q-\omega_{I}$ & $\frac{1}{2}\left(p-\omega_{I}\right)$ & $\frac{1}{2}\left(p-q-\omega_{I}\right)$ & 0 \\
\hline L, L (A) & $S Q\left(1-p+\frac{1}{2} q\right)-\frac{1}{2}\left(\omega_{A}\right)$ & $S Q$ & $S Q\left(1-p+\frac{1}{2} q\right)-\frac{1}{2}\left(\omega_{A}\right)$ & $S Q$ \\
L, L (I) & $p-\frac{1}{2} q-\omega_{I}$ & 0 & $p-\frac{1}{2} q-\omega_{I}$ & 0 \\
\hline
\end{tabular}

Table 2.5: Pure Strategy Payoffs for Ally Model $\left(1-p-\omega_{T}<0\right)$

\begin{tabular}{|l|l|l|l|l|}
\hline & Ch, ch & Ch, ch & $\sim$ Ch, ch & $\sim$ Ch, ch \\
\hline H, H (A) & $\frac{1}{2}\left[(1-p+q) S Q-\omega_{A}\right]-c$ & $\frac{1}{2}\left[(1-p+q) S Q-\omega_{A}\right]-c$ & $S Q-c$ & $S Q-c$ \\
H, H (I) & $\frac{1}{2}\left(1+p-q-\omega_{I}\right)$ & $\frac{1}{2}\left(1+p-q-\omega_{I}\right)$ & 0 & 0 \\
\hline H, L (A) & $\frac{1}{2}\left[(1-p+q) S Q-\omega_{A}-c\right]$ & $S Q-\left[1-\frac{1}{2}\left(p-q+\omega_{A}+c\right)\right]$ & $\frac{1}{2}(S Q-c)$ & $S Q-\frac{1}{2} c$ \\
H, L (I) & $\frac{1}{2}\left(1+p-q-\omega_{I}\right)$ & $\frac{1}{2}\left(p-q-\omega_{I}\right)$ & $\frac{1}{2}$ & 0 \\
\hline L, H (A) & $\frac{1}{2}\left[(1-p+q) S Q-\omega_{A}-c\right]$ & $\frac{1}{2}(S Q-c)$ & $\frac{1}{2}\left(p-q-\omega_{I}\right)$ & $\left.S-\frac{1}{2}(p+q)-\frac{1}{2}\left(\omega_{A}+c\right)\right]$ \\
L, H (I) & $\frac{1}{2}\left(1+p-q-\omega_{I}\right)$ & $\frac{1}{2}$ & $\frac{1}{2}\left[(1-p+q) S Q-\omega_{A}\right]$ & 0 \\
\hline L, L (A) & $\frac{1}{2}\left[(1-p+q) S Q-\omega_{A}\right]$ & $S Q$ & $\frac{1}{2}\left(1+p-q-\omega_{I}\right)$ & $S Q$ \\
L, L (I) & $\frac{1}{2}\left(1+p-q-\omega_{I}\right)$ & 0 & & 0 \\
\hline
\end{tabular}

payoff is greater or less than 0 becomes contingent on three variables, making it plausible that it could be either positive or negative. And with $S Q$ only being evaluated as a positive integer, it is hard to say the circumstances under which the ally will have a unilateral, pure strategy. $^{10}$

\section{Calculating Mixed Strategy Equilibria - Target Model}

As the above section indicates, pure strategy equilibria are unlikely to emerge except under very specific circumstances, which usually means the initiator having a strategy of unilaterally acting in a single manner. Therefore, I now turn to how mixed-strategy equilibria, particularly ones that act as semi-separating outcomes, can come about. I begin first with the target model, due to its comparative simplicity.

Since there are many different mixed strategy equilibria that can be supported under different circumstances, the first step is to identify what equilibria makes the most sense

\footnotetext{
${ }^{10} \mathrm{I}$ also will be including graphs demonstrating how the likelihood of challenges and conflict changes based on the expected utility of conflict, but I was unable to put these together for this draft.
} 
to evaluate. For the purposes of this section, I have chosen to examine a mixed strategy equilibria where the resolved type uniformly sends high signals while the irresolute type mixes high and low signals. The intuition here is that the resolved type is always willing to pay the sunk costs, due to the degree that they care about the good in question, evidenced by their willingness to fight to maintain it. If they are willing to fight and suffer the costs associated with that option, it also makes sense that they would be willing to pay these sunk costs. In contrast, the irresolute type is much less willing to pay these costs, but will under some circumstances in an attempt to bluff their way around a potential challenge, with the understanding that if they get caught, they will just give up the good.

The first step is calculating the initiator's strategy that will make the irresolute type of target indifferent between sending a high or low signal, with initiator always challenging low signals:

$$
\begin{aligned}
& E U_{\sim R}: 0=p(-c)+(1-p)(1-c) \\
& p c=1-c-p+p c \\
& p=1-c
\end{aligned}
$$

Therefore, the initiator playing $C h$ with probability $p=1-c$ and $\sim C h$ with probability $1-p=c$ will make the irresolute target indifferent. Since $c$ was bounded $[0,1]$ at the outset of this model, this is not unreasonable; however, it would also make sense that if $c$ were greater than 1, then no matter if the initiator challenges or not, the irresolute target would always be better off sending a low signal, being challenged, and receiving a payoff of 0 .

Next, the posterior probability of the target being irresolute which makes the initiator indifferent between high signals coming from either a resolved or irresolute target, since a low signal always means the target is irresolute, needs to be calculated:

$$
\begin{aligned}
& E U_{I}(C h \mid H): 0=x(1)+(1-x)\left(p-\omega_{I}\right)=x+p-\omega_{I}-p x+x \omega_{I} \\
& p x-x \omega_{I}-x=p-\omega_{I} \\
& x\left(p-\omega_{I}-1\right)=p-\omega_{I}
\end{aligned}
$$




$$
x=\frac{p-\omega_{I}}{p-\omega_{I}-1}
$$

Finally, using the posterior probability from above, I employ Bayes' rule to get the target's mixed strategy that would make the initiator indifferent between high and low signals. However, I use this as an opportunity to move away from the strong assumption of a 50/50 split of types, and again parameterize the distribution along the lines of $\sim R=$ $r, R=1-r$. The results are as follows:

$$
\begin{aligned}
& P(\sim R \mid H): \frac{p-\omega_{I}}{p-\omega_{I}-1}=\frac{r(x)}{r(x)-(1-r)(1)} \\
& p r x-p r+p-r \omega_{I} x+r \omega_{I}-\omega_{I}=p r x-r \omega_{I} x-r x \\
& -p r+p+r \omega_{I}-\omega_{I}=-r x \\
& x=p-\frac{p}{r}-\omega_{I}+\frac{\omega_{I}}{r}
\end{aligned}
$$

Thus, we have the complete equilibrium where $r$ is parameterized:

- Resolved Targets will play $H$ uniformly.

- Irresolute Targets will play $H$ with probability $p-\frac{p}{r}-\omega_{I}+\frac{\omega_{I}}{r}$ and $L$ with probability $1-\left(p-\frac{p}{r}-\omega_{I}+\frac{\omega_{I}}{r}\right)$.

- Initiators will challenge all $L$ signals, and challenge $H$ signals with probability $1-c$.

- The belief that sustains the initiator challenging $L$ uniformly is that the target is irresolute with probability $=1$.

- The belief that sustains the initiator challenging $H$ with probability $1-c$ is that the target is irresolute with probability $x=\frac{p-\omega_{I}}{p-\omega_{I}-1}$.

From this, we have a few observations:

- As the level of $c$ increases, initiators will challenge high signals less often.

- As the level of $r$ increases, irresolute targets will mix more heavily towards $L$.

- As noted above, the game is only interesting when $p-\omega_{I}$ is less than 0 ; otherwise, the initiator and irresolute target end up with unilateral strategies.

It is worth unpacking each of these statements to some extent, and getting at some big picture conclusions from the model. First, in regards to $c$, the sunk costs of the model, the finding is that higher costs will result in fewer signals of resolve. As such, as $c$ approaches 
1, we get closer to a separation of types with the resolved targets choosing to send a high signal while irresolute targets will send low signals.

Second, as $r$ increases and the distribution of types shifts more heavily towards irresolute, we should expect to see the irresolute types sending a higher proportion of low signals. The initiators, knowing that there are fewer resolute types, would respond by challenging high signals more often in an attempt to gain the good in dispute, which would result in more irresolute types having to pay costs for portraying themselves as resolved.

Finally, the initiator's expected utility for war has to be negative. This is a fairly straightforward point, but nonetheless needs to be emphasized: if the initiator has a positive expectation for war, then they will always challenge and be perfectly content with fighting should it come to that, as that positive outcome is better than getting nothing. But even in this case, the initiator would prefer to avoid fighting and just get the good by issuing a coercive threat, resulting in the target giving up without war. ${ }^{11}$

\section{Calculating Mixed Strategy Equilibria - Ally Model}

Just as with the target model, I want to elucidate the conditions under which the resolved ally will send high signals uniformly while the irresolute ally will mix different signals. The one complication with this model, as noted above, is that because the target can choose to stand firm or back down if it is facing the initiator alone, two different mixed strategy equilibria need to be derived. I begin first with the model where the target is resolved to fight alone, then I will return to the version where the target will always back down if abandoned by the ally. The first element to calculate is the initiator's strategy (represented by $q^{\prime}$ to differentiate from the $q$ employed in the alliance models) that makes the irresolute ally indifferent from sending a high or low signal, with the knowledge that low signals will

\footnotetext{
${ }^{11}$ This is demonstrated in the game, as the highest value that $p-\omega_{I}$ can take on is 1 , assuming that $p$ is 1 and $\omega_{I}$ is 0 . And even in that limited case, the initiator is indifferent between war and just getting the good.
} 
be met with challenges:

$$
\begin{aligned}
& E U_{\sim R}:(1-p) S Q=q^{\prime}[(1-p) S Q-c]+\left(1-q^{\prime}\right)(S Q-c) \\
& S Q-p S Q=q^{\prime}(S Q-p S Q-c)+S Q-c-q^{\prime} S Q+q^{\prime} c \\
& S Q-p S Q=q^{\prime} S Q-p q^{\prime} S Q-q^{\prime} c+S Q-c-q^{\prime} S Q+q^{\prime} c \\
& -p S Q=-p q^{\prime} S Q-c \\
& p q^{\prime} S Q=p S Q-c \\
& q^{\prime}=\frac{p S Q-c}{p S Q}
\end{aligned}
$$

This indicates that an initiator would need to play $C h$ with probability $q^{\prime}=\frac{p S Q-c}{p S Q}$ and $\sim C h$ with probability $1-q=\frac{c}{p S Q}$ to make the ally indifferent. As such, as $c$ approaches 0 , $q^{\prime}$ in turn nears 1 , while as $p S Q-c$ approaches $0, q^{\prime}$ converges on 0 . Next is calculating the posterior probability of the ally being irresolute which would make the initiator indifferent between high signals coming from either a resolved or irresolute ally.

$$
\begin{aligned}
& E U_{I}(C h \mid H): 0=x\left(p-\omega_{I}\right)+(1-x)\left(p-q-\omega_{I}\right) \\
& 0=x p-x \omega_{I}+p-q-\omega_{I}-x p+x q+x \omega_{I} \\
& 0=p-q-\omega_{I}+x q \\
& x q=q-p+\omega_{I} \\
& x=\frac{q-p+\omega_{I}}{q}=1-\frac{p-\omega_{I}}{q}
\end{aligned}
$$

Lastly, I parameterize the distribution of ally types, with $\sim R=r$ and $R=1-r$, and use Bayes' rule to find the ally's mixed strategy that makes the initiator indifferent between high and low signals.

$$
\begin{aligned}
& P(\sim R \mid H): \frac{q-p+\omega_{I}}{q}=\frac{r(x)}{r(x)-(1-r)(1)} \\
& q r x=\left(q-p+\omega_{I}\right)(r x+r-1) \\
& q r x=q r x+q r-q-p r x-p r+p+r x \omega_{I}+r \omega_{I}-\omega_{I} \\
& 0=p-q-\omega_{I}-p r+q r+r \omega_{I}-p r x+r x \omega_{I} \\
& p r x-r x \omega_{I}=p-q-\omega_{I}-p r+q r+r \omega_{I} \\
& x=\frac{p-q-\omega_{I}-p r+q r+r \omega_{I}}{p r-r \omega_{I}}
\end{aligned}
$$




$$
\begin{aligned}
& x=\frac{p-q+q r-\omega_{I}}{p r-r \omega_{I}}-\frac{p r-r \omega_{I}}{p r-r \omega_{I}} \\
& x=\frac{p-q+q r-\omega_{I}}{p r-r \omega_{I}}-1
\end{aligned}
$$

This results in the complete equilibrium:

- Targets will play $S F$ uniformly.

- Resolved Allies will play $H$ uniformly.

- Irresolute Allies will play $H$ with probability $x=\frac{p-q+q r-\omega_{I}}{p r-r \omega_{I}}-1$ and $L$ with probability $1-x=\frac{p-q+q r-\omega_{I}}{p r-r \omega_{I}}$.

- Initiators will challenge all $L$ signals, and challenge $H$ signals with probability $q^{\prime}=$ $\frac{p S Q-c}{p S Q}$.

- The belief that sustains the initiator challenging $L$ uniformly is that the ally is irresolute with probability $=1$, and that $p-\omega_{I}$ is greater than 0 .

- The belief that sustains the initiator challenging $H$ with probability $q^{\prime}=\frac{p S Q-c}{p S Q}$ is that the ally is irresolute with probability $x=1-\frac{p-\omega_{I}}{q}$.

Turning attention to the case where the target plays $B D$ instead of $S F$, we again start with the initiator's strategy that will make the irresolute ally indifferent between sending a high or low signal, with the understanding that low signals are always challenged:

$$
\begin{aligned}
& E U_{\sim R}: 0=q^{\prime}(-c)+\left(1-q^{\prime}\right)(S Q-c) \\
& 0=-q^{\prime} c+S Q--c-q^{\prime} S Q+q^{\prime} c \\
& q^{\prime} S Q=S Q-c \\
& q^{\prime}=\frac{S Q-c}{S Q}
\end{aligned}
$$

Therefore, we know that the initiator would have to play $C h$ with probability $q^{\prime}=\frac{S Q-c}{S Q}$ and $\sim C h$ with probability $1-q^{\prime}=\frac{c}{S Q}$ in order to make the ally indifferent. The posterior probability of the ally being irresolute which would make the initiator indifferent between high signals being sent from either a resolved or irresolute ally is solved as follows:

$$
\begin{aligned}
& E U_{I}(C h \mid H): 0=x(1)+(1-x)\left(p-q-\omega_{I}\right) \\
& 0=x-p+q-\omega_{I}-x p+x q+x \omega_{I} \\
& x p-x q-x \omega_{I}-x=p-q-\omega_{I}
\end{aligned}
$$




$$
\begin{aligned}
& x\left(p-q-\omega_{I}-1\right)=p-q-\omega_{I} \\
& x=\frac{p-q-\omega_{I}}{p-q-\omega_{I}-1}
\end{aligned}
$$

Then, we employ Bayes' rule to get the ally's mixed strategy to make the initiator indifferent between high and low signals:

$$
\begin{aligned}
& P(\sim R \mid H): \frac{p-q-\omega_{I}}{p-q-\omega_{I}-1}=\frac{r(x)}{r(x)-(1-r)(1)} \\
& \left(p-q-\omega_{I}\right)(r x+r-1)=\left(p-q-\omega_{I}-1\right)(r x) \\
& p r x-q r x-r x \omega_{I}+p r-q r-r \omega_{I}-p+q+\omega_{I}=p r x-q r x-r x \omega_{I}-r x \\
& p r-p q-r \omega_{I}-p+q+\omega_{I}=-r x \\
& r x=p-q-\omega_{I}-p r+p q+r \omega_{I} \\
& x=\frac{p-q-\omega_{I}}{r}-p+q+\omega_{I}
\end{aligned}
$$

And thus the complete equilibrium can be expressed as:

- Targets will play $B D$ uniformly.

- Resolved Allies will play $H$ uniformly.

- Irresolute Allies will play $H$ with probability $x=\frac{p-q-\omega_{I}}{r}-p+q+\omega_{I}$ and $L$ with probability $1-x=\frac{r-p-q-\omega_{I}}{r}-p+q+\omega_{I}$.

- Initiators will challenge all $L$ signals, and challenge $H$ signals with probability $q^{\prime}=$ $\frac{S Q-c}{S Q}$.

- The belief that sustains the initiators challenging $L$ uniformly is that the ally is irresolute with probability $=1$, and that $0>p-q-\omega_{I}>-1$.

- The belief that sustains the initiator challenging $H$ with probability $q^{\prime}=\frac{S Q-c}{S Q}$ is that the ally is irresolute with probability $x=\frac{p-q-\omega_{I}}{p-q-\omega_{I}-1}$.

Looking across both of these democratic alliance models, the most important point of emphasis is the same one that emerged from the democratic targets model, namely that as $c$ increases, initiators will be less likely to challenge $H$ signals. As these costs become larger, it becomes more difficult for the irresolute targets to justify risking being caught in a bluff, and therefore they will avoid sending signals of high resolve. 
Given the argument of this project, that democracies are more risk-averse and want to avoid committing themselves to costly endeavors, particularly those that the general public is strongly against, these models are useful demonstrations of how this logic works in a formal setting. Further, it provides us with important indicators to look for in both the statistical analysis as well as the case studies, to determine whether the argument works as predicted. These findings will be returned to in the subsequent chapters.

\section{Conclusion}

The purpose of this chapter was two-fold. First, I outlined an argument for why it is that democratic targets and democratic allies are systematically different from non-democracies, pointing to the costs that democracies pay from the public for misrepresenting their prefer-

ences and being caught doing so. Overall, I argue that democracies are much more risk-averse than their non-democratic counterparts, as they want to avoid having to pay these costs of misrepresentation which subsequently make it more difficult for the democratic leaders to maintain office.

Second, I employed two different models, one focused on targets of coercive threats and the other emphasizing those targets' allies, to demonstrate how the costs of indicating resolve influence the ability for states to signal their type, as either resolved to conflict or irresolute. The models indicate that as the sunk costs associated with signaling increase, we tend to see greater separation between these two types of states in how they act, with resolved states willing to take on these costs while irresolute states will attempt to avoid them.

Combined, these components make for both an argument in favor of democratic targets and democratic allies making for higher probabilities of concessions, as well as the indicators that would demonstrate whether the argument is correct. With this in mind, we move forward to the empirical part of the project, examining how patterns of democratic behavior 
differ from those of non-democracies, and identifying the causal mechanisms that are behind them. 


\section{Chapter 3}

\section{Militarized Threats}

This chapter provides evidence that democratic targets and allies lead to higher rates of concessions in response to coercive threats, focusing here on those of the militarized variety. Due to the nature of democratic processes, these targets and allies differ from their non-democratic counterparts in two important ways: they are able to create a situation that mimics perfect information for the state deciding whether to initiate a coercive threat, eliminating ambiguity (or at least severely curtailing it) as to how the target/ally will respond; or they have costs unique to themselves that help parse out their type via signals of resolve, such that irresolute types will reveal themselves. In each case, this information helps the initiator choose when they can effectively select into coercive threats that are more likely to succeed, resulting in more concessions than what we would expect from non-democratic targets and allies.

For the democratic targets, they find themselves constrained by the demands of their public, facing pressure within while contending with the external demands of the initiator. Though the target may get some degree of leeway or upwelling of support from the public in response being threatened, the fact that the initiator is able to identify a priori whether the target is resolved to fighting means that this backlash will often be insufficient to overcome 
the public's reticence to conflict, thus making concessions the most likely outcome. Though there may be countervailing impacts present here, ultimately I argue that the forces in favor of concessions will prevail.

In contrast, democratic allies often do not find themselves having to deal with the public demanding action. Indeed, it is often the opposite, with public opinion going against involvement where conflict has yet to emerge, particularly since their state was not directly threatened. While this desire to avoid conflict is powerful, the democratic ally also wants to deflect any criticisms of abandoning the target, and thus intervenes in such a way to bring about a peaceful end, even (and, perhaps, especially) if that means the target has to make concessions.

These two arguments are then tested using a dataset comprised entirely of coercive, militarized threats. The predictions of each theory are borne out to differing degrees, and are tested across a variety of models and with different specifications. The overall findings are as follows:

- When measured dichotomously, democratic targets are consistently shown to concede at higher rates than their non-democratic counterparts. If the examination is performed using dyadic data, democratic targets that are threatened by non-democracies concede at the highest rates.

- If all else is held constant, targets with democratic allies consistently concede at higher rates than those that have no allies at all while having a non-democratic ally cannot be distinguished from not having an ally. When directly contrasted with a non-democratic ally, the findings are much weaker and inconsistent.

- When the target and ally data are combined into a single measure, those pairings with both a democratic target and ally are generally found to be the most likely to concede. 


\section{Deriving Hypotheses from the Theoretical Models}

In this section, I refer back to the formal models of Chapter 2 to derive testable hypotheses for the behavior of coercive targets and their allies. There are two dimensions by which these predictions should be made, first by comparing the complete and incomplete versions of the models, and then by examining the target and alliance varieties separately, as each provides different intuitions even if the observable implications end up looking very similar.

Recall the distinction between states that can send costly signals and those that are incapable: I have argued in the previous chapter that democracies can more readily send them, due to the transparency of their political systems and the ability for individuals within the democratic society to display their discontent with the incumbent party. As such, democratic states can take positions in line with or contra to the observable preferences of the public, thus indicating a willingness or unwillingness to risk losing office over a foreign policy action.

Again, this is not to say that non-democratic leaders cannot lose power due to foreign policy errors, or that bluffing is a risk-less strategy overall for them. What is does indicate is that they cannot readily signal their constraints, preventing them from employing the same sort of costly signaling that is available ot their democratic counterparts. Therefore, when I refer to states that are capable of using costly signaling, I am in effect referring to democratic states.

Turning to the incomplete information model, costly signaling is a rational action for some types of states. Since the initiator no longer is able to determine with perfect precision the level of resolve on the part of the target or ally, signaling gains some value, though it remains an imperfect means of demonstrating the true preferences of the target or ally. In terms of particular actions we ought to observe, resolved targets and allies should always send signals of resolve, as they are willing to risk conflict in order to maintain possession of 
the good, leading to a uniformly dominant strategy.

In contrast, irresolute types will mix high and low signals, in an attempt to bluff their way to maintaining control over the good under some set of circumstances. Critically, this means that there will be some situations where the target or ally will readily "acknowledge" their irresolute nature, thus allowing the initiator to make cheap threats while getting what they want. This separation that emerges from the model results in predictions that those types of states that can credibly employ these costly signals will also sometimes choose to not use them, leading to concessions.

\section{Model Predictions}

To summarize, the incomplete information model indicates how the incentives for the target and ally influence their likelihood of indicating their true lack of resolve. Now, employing these high cost signals acts as a credible indicator of their willingness to fight to keep control over the good. In contrast, the irresolute actors will mix their signals, meaning that they will sometimes truthfully indicate their irresolute nature. As such, Hypothesis 2 states:

- $H_{\alpha}$ : Under a game of imperfect information, irresolute democratic targets or allies will signal low resolve at least some percentage of the time.

\section{Hypotheses for Testing}

I put forward here some more general predictions which follow from the model, but involve relaxing some assumptions of the model to build off of the general theory established earlier in Chapter 2. This move is particularly useful in being able to compare across situations where the model was not constructed to provide comparative statics, even if it means moving away from the strictly formal predictions the models provide.

Starting first with the contrast of democratic and non-democratic targets, both the model 
and my general theory predict that democracies will be more likely to give in to threats, as they are more easily identified as vulnerable and subsequently selected by initiators. Therefore, Hypothesis 1 states:

- $H_{1}$ : Democratic targets concede to militarized threats at higher rates than nondemocratic targets.

Shifting focus to the alliance predictions, both the models and my theory suggest that those targets that have democratic allies will be more likely to make concessions in contrast to those that have non-democratic allies. However, looking beyond the model and emphasizing the logic of the general theory, I would also predict that those same targets will be more likely to make concessions that those that have no allies whatsoever, and that arguably these pairings should go in order of least likely to most likely like so: no ally, non-democratic ally, democratic ally. Hypotheses 2a, 2b, and 2c are therefore framed as:

- $H_{2 a}$ : Targets with democratic allies are more likely to concede than targets with nondemocratic allies.

- $H_{2 b}$ : Targets with democratic allies are more likely to concede than targets with no allies at all.

- $H_{2 c}$ : Targets with non-democratic allies are more likely to concede than those with no allies at all.

Finally, there is one final predictions which emerges from the combination of these different hypotheses, one which focuses on the conjunction of the target and alliance types. Namely, if these arguments are accurate, we should see that those targets which are democracies and are also allied with fellow democracies should be the most likely of any pairing to make concessions. Hypothesis 3 thus predicts: 
- $H_{3}$ : Democratic targets paired with democratic allies will be the combination most likely to concede to militarized threats.

\section{Data on Democratic Responses to Militarized Threats}

To test how democratic targets and allies respond to threats involving the use of force, I utilize the Militarized Compellent Threats (MCT) dataset as the basis of my analysis. As described in (Sechser 2011), this dataset collects information on all known instances of compellent threats involving threats of force, wherein the target faces a decision to either concede the contested good or to contend with an attack. In contrast to other sources of information, such as the Militarized Interstate Dispute (MID) or International Crisis Behavior (ICB) datasets which include many different types of events, with varying levels of conflict, the MCT dataset is comparatively homogenous as it focuses purely on not only coercive acts of the compellent variety, but also its emphasis on threats.

\section{Dependent Variable: Compliance with Threats}

Per the MCT dataset, each observation involves one state making a threat against another, including clear demands which need to be met to avoid military conflict. These threats can cover a wide range of different issue areas: changes in policy, territorial demands, attempts at making the leader step down from office, etc. In addition, these threats can involve multiple demands, such as combinations of the above examples.

In the original coding of the dataset, responses are broken down into three categories: noncompliance, partial compliance, and full compliance. The first and last of these are the most straightforward, as the target either refuses to comply whatsoever or willingly concedes to any and all demands that are made by the threatening state. Partial compliance is slightly more complicated, as it indicates that the target gave way on one or more issues, 
but remained intransigent on at least one of the demands. However, it is unclear from the dataset what this partial compliance looks like, how many demands were made versus the number that were complied with, or any qualitative understanding of which demands were more important than others. Therefore, it is difficult to say if the target was making significant concessions or minor ones, which could complicate our interpretation of what partial compliance looks like. ${ }^{1}$

In an effort to get around this issue, I group all instances of partial compliance with noncompliance, turning the trichotomous outcome into a dichotomous one, where the target either conceded completely or did not. This avoids instances where the target might make some token concessions to the threatener, which are then accepted as a means of saving face while avoiding military conflict. While this does not deal with the possibility of the target meeting many or even most of the substantive demands, given that the concern with false positives is often greater than that of false negatives, this decision seems to be the most conservative approach and acts as a hard test of my theory.

\section{Independent Variable: Democracies vs. Non-Democracies}

Given that the theory put forward in the previous chapter argues that democracies act in different ways from non-democracies, a reliable indicator for whether a state qualifies is needed. However, there is a great deal of disagreement over the best way to quantify these differences. While some scholars recommend a dichotomous measure, where a state needs to meet certain minimum thresholds in order to count as a democracy, others employ something closer to a continuous measure, quantifying multiple aspects of the state's regime and combining them together to create a scale of "democraticness."

Each approach has strengths and weaknesses. As Skaaning, Gerring and Bartusevicius

\footnotetext{
${ }^{1}$ It could also be the other way around, however: the initiator makes multiple demands in order to trade less important ones for a few that are of great interest, creating a wider bargaining range in the process. However, given that there is no easy way to identify key or primary goals, I do not pursue this logic further.
} 
(2015) note, binary measures are ultimately reductionist, becoming a blunt tool as "[a]ll features of a regime must be reduced to a single coding decision, producing binary sets that are highly heterogeneous and borderline cases that may not fit neatly into either category." (2) As for continuous measures, since multiple variables can be combined together to create the index, two cases that have the same index value might have very divergent limitations and different parts of the index might not be relevant to the theory being tested. ${ }^{2}$

Since no singular means of measurement is ideal, I have chosen to include one of each type in my analysis. If the results are robust to the inclusion of either type of measurement, that would appear to be strong evidence of my argument and a clear demonstration that they are not being driven by a strategic choice to include or exclude a particular variable that is knowingly problematic.

Starting with the dichotomous measure of democracy, there are two primary options available. The first comes originally from Alvarez, Cheibub, Limongi and Przeworski (1996) and was expanded in Cheibub, Gandhi and Vreeland (2010), who which identifies states as either "democratic" or "autocratic," with four rules defining the former: the chief executive must be chosen in popular elections; the legislature (at least the lower house) is popularly elected; there must be more than one party; and there must have been an alternation in power (19-28). The second is derived by Boix, Miller and Rosato (2012), (hereafter, BMR) who define democracies as states where there is a minimum level of suffrage (majority of the male population can vote); there are free and fair voting procedures which decide the legislature; and the executive is either directly or indirectly elected in popular elections as well as accountable to either the voters or the legislature (9).

While there are theoretical arguments for or against either measure, I have chosen to employ the latter's due to a practical limitation: whereas the BMR variable covers the

\footnotetext{
${ }^{2}$ For a humorous take on this in the realm of political violence, see Vreeland (N.d.)'s "The Return of Goldilocks in... Civil War and The Three Regimes!"
} 
period from 1800 to 2007, the updated Cheibub et. al. measure only begins in 1950. Given that would prevent me from utilizing over half of the observations (112 out of 210), I believe that this decision is eminently defensible on pragmatic grounds if nothing else.

In addition, I include the most popular continuous index of democracy in the form of Polity IV, which ranges from -10 to +10 . However, my theory does not argue that increasing or decreasing levels of democratization should influence the probability of concessions: I also claim that those which meet the minimum thresholds will act in ways distinct from those that do not. Therefore, in accordance with the standards in the international relations literature, I employ a cutoff: if a state gets a Polity score of +7 or higher, it is counted as a democracy, and if it gets a +6 or lower, it is given a non-democratic designation.

Given these operationalizations for democracy, I then utilize two different ways of getting at the role of democratic/non-democratic regimes for the target as well as the initiator. The first is a pair of dichotomous measures, one for the target and one for the initiator, where each is assigned either a 0 (non-democracy) or 1 (democracy). The benefit of this is to specify the particular impact of the target and initiator separately, thus isolating the two from each other.

The other method I employ is a dyadic measure, which covers the four different possible pairings of initiator and target. Given that one argument is that democracies being threatened by other democracies are unlikely to occur due to constraints along the lines of the democratic peace, it makes sense to look at different pairs of states to see how they compare with one another. With this measure, two non-democracies are assigned a 0 , a democratic initiator with a non-democratic target is given a 1, a non-democratic initiator and a democratic target is designated with a 2 , and a pair of democracies are denoted with a 3 . 


\section{Identifying Allies}

While the coercive targets are easily identified in the MCT dataset, thus allowing for the application of the Polity and BMR democratic measures, this is not so with the target's allies. The first major question to be raised is: who counts as an ally? There are two major datasets on alliances that are often used, the Correlates of War version, created first by Singer and Small (1966) and with the most recent version updated by Gibler, and the Alliance Treaty Obligations and Provisions (ATOP) version, created by Leeds, Ritter, Mitchell and Long (2002). Each dataset focuses on slightly different things: the former emphasizes four types of state partnerships, namely defense pacts, neutrality agreements, non-aggression pacts, and ententes, while the latter breaks down along the lines of offensive, defensive, neutrality, non-aggression, and consultation compacts. Further, even in areas where there is overlap in the type of alliance, there are periodic disagreements between the datasets.

Rather than choosing one over the other, I decided to incorporate the information from both the COW and ATOP datasets, though only focusing on those alliances that were defensive in nature, since those would be the only ones where the target could reasonably expect the ally to come to their aid. Of the 132 cases of defensive alliances being in place, 69 of them were found in both datasets, 50 only in COW, and 13 only in ATOP.

While this addresses the sourcing of the alliances, it does not consider how to incorporate this information into the analysis. In the majority of cases, targets have multiple allies, but it becomes complicated trying to include information on all of them, if not counterproductive. While it may be the cases that each ally has some degree of influence on the target, I make the assumption that the ally of greatest interest in the analysis is the most powerful one, using Composite Indicator of National Capacity (CINC) scores to identify the strongest.(Singer 1987) CINC provides a measure of state strength, including multiple indicators such as "military expenditures, military personnel, energy consumption, iron and steel production, urban population, and total population," per the Correlates of War website, which is scaled 
proportional to all the other states in the system. While this inevitably excludes many other alliance partners, the trade-off for simplicity is a defensible one, as it allows for the interpretation of how much influence do factors intrinsic to the target's most powerful ally have on the likelihood fo the target conceding.

The final step that I take is to narrow down the scope of allies even further. While my first cut at the alliance partners includes all of the most powerful ones, regardless of their absolute level of military might, this can be very misleading. Indeed, in many cases the ally is actually incredibly weak, holding far less than $1 \%$ of the actual and/or potential power of the system. While they may matter in some instances, the fact that they are so insubstantial leads me to exclude them from the analysis, with a CINC score of $1 \%$ acting as the threshold. This leads to the exclusion of 36 allies in total. ${ }^{3}$

\section{Analysis}

With the data of interest identified, the process of analyzing it is broken down into two different parts. First, I provide some simple cross-tabulations of the data, to demonstrate observable patterns that exist without resorting to rigorous statistical analysis. Second, I incorporate logistic regression along with the array of independent variables listed above to establish the particular relationships of interest, as well as predicted probabilities for the key variables of democratic targets and allies.

\section{Preliminary Observations}

The first major division of interest comes from the targets of coercive threats, based on the democratic/non-democratic split and compliance with demands. Table 3.1 shows the divisions with the use of BMR's measure of democracy, while Table 3.2 employs Polity.

\footnotetext{
${ }^{3}$ In order of frequency: Egypt (11), Saudi Arabia (8), Iraq (4), Iran (3), and Afghanistan, Angola, Bosnia
} 
Table 3.1: BMR Democracy - MCT Targets

\begin{tabular}{|l|c|c|c|}
\hline & Democracy & Non-Democracy & \\
\hline Compliance & $34(62 \%)$ & $51(34 \%)$ & $85(41 \%)$ \\
\hline Non-Compliance & $21(38 \%)$ & $101(66 \%)$ & $122(59 \%)$ \\
\hline & 55 & 152 & 207 \\
\hline
\end{tabular}

Pearson $\chi^{2}=13.2104 ; \operatorname{Pr}=0.000$

Table 3.2: Polity - MCT Targets

\begin{tabular}{|l|c|c|c|}
\hline & Democracy & Non-Democracy & \\
\hline Compliance & $29(73 \%)$ & $55(34 \%)$ & $84(41 \%)$ \\
\hline Non-Compliance & $11(27 \%)$ & $109(66 \%)$ & $120(59 \%)$ \\
\hline & 40 & 152 & 204 \\
\hline
\end{tabular}

Pearson $\chi^{2}=20.1285 ; \operatorname{Pr}=0.000$

The two tables tell a similar story: while democracies tend to be threatened less often overall, they concede at higher rates. With the BMR measure, there are only 55 cases of a democracy being threatened, while Polity finds even fewer with 40. However, in each instance, the democratic targets are giving in to those threats much more often, being 24 and $46 \%$ compared to non-democratic targets. This is potentially evidence of democracies being chosen more selectively than non-democracies, though it could also be the case that there simply are fewer possibilities for democracies to be threatened. In order to distinguish between the two, examining the universe of possible threats would need to occur.

Moving on to the case of allies, the data is again broken down along democratic and non-democratic lines, with the addition of "no ally" cases where the target either had no alliance partners at all, or the ones that they did have were too weak $(\mathrm{CINC}<0.01)$. Table 3.3 again uses the BMR measure of democracy while Table 3.4 has Polity.

The most noticeable observation that jumps out from these tables are the large number of targets that do not have any allies: fully two-thirds of those threatened are without any and Herzegovina, Congo, Ethiopia, Ivory Coast, Nigeria, Portugal, Tanzania, and Turkey (1 each). 
Table 3.3: BRM Democracy - MCT Allies

\begin{tabular}{|l|c|c|c|c|}
\hline & Democratic Ally & Non-Democratic Ally & No Ally & \\
\hline Compliance & $27(68 \%)$ & $15(50 \%)$ & $44(31 \%)$ & $86(41 \%)$ \\
\hline Non-Compliance & $13(32 \%)$ & $15(50 \%)$ & $96(69 \%)$ & $124(59 \%)$ \\
\hline & 40 & 30 & 140 & 210 \\
\hline
\end{tabular}

Pearson $\chi^{2}=17.8759 ; \operatorname{Pr}=0.000$

Table 3.4: Polity - MCT Allies

\begin{tabular}{|l|c|c|c|c|}
\hline & Democratic Ally & Non-Democratic Ally & No Ally & \\
\hline Compliance & $27(69 \%)$ & $15(48 \%)$ & $44(31 \%)$ & $86(41 \%)$ \\
\hline Non-Compliance & $12(31 \%)$ & $16(52 \%)$ & $96(69 \%)$ & $124(59 \%)$ \\
\hline & 39 & 31 & 140 & 210 \\
\hline
\end{tabular}

Pearson $\chi^{2}=18.8235 ; \operatorname{Pr}=0.000$

allies that hold at least $1 \%$ of the military capabilities in the system. This is not necessarily surprising, in and of itself: it would make sense that such targets would appear ripe for coercion, as they have no one to call for help. What is surprising, however, is that those states are the least likely to make concessions, giving in less than one out of every three times.

If we limit our comparisons only to those states that do have a powerful ally, we find that democratic allies are more strongly correlated with concessions, giving in to more than two out of every three threats they face. In contrast, states with non-democratic allies concede about half of the time.

Finally, I present two tables that combine the information about the nature of the targets and allies, along with the percentage of the time that each combination conceded to threats. Table 3.5 provides the breakdown for the BMR dataset, while Table 3.6 has the same for Polity.

In each case, the combination of a democratic target with a democratic ally led to the highest percentage of concessions, between 94 and 95\%, with only one case in each coding 
Table 3.5: BMR Democracy - MCT Targets and Allies

\begin{tabular}{|l|c|c|c|}
\hline & Democratic Target & Non-Democratic Target & \\
\hline Democratic Ally & $20(95 \%)$ & $20(67 \%)$ & 40 \\
\hline Non-Democratic Ally & $5(40 \%)$ & $25(48 \%)$ & 30 \\
\hline No Ally & $30(43 \%)$ & $107(39 \%)$ & 137 \\
\hline & 55 & 152 & 207 \\
\hline
\end{tabular}

Table 3.6: Polity - MCT Targets and Allies

\begin{tabular}{|l|c|c|c|}
\hline & Democratic Target & Non-Democratic Target & \\
\hline Democratic Ally & $17(94 \%)$ & $21(52 \%)$ & 38 \\
\hline Non-Democratic Ally & $6(33 \%)$ & $25(52 \%)$ & 31 \\
\hline No Ally & $17(65 \%)$ & $118(26 \%)$ & 135 \\
\hline & 40 & 164 & 204 \\
\hline
\end{tabular}

actually standing firm. ${ }^{4}$ For either measure, going from a democratic target to a nondemocratic one has a fairly significant effect on the likelihood of concessions, with a $28 \%$ drop with the BMR measure, while Polity shows a $42 \%$ decrease.

Surprisingly, democratic targets with non-democratic allies appear to actually be less likely to concede than those targets that are non-democratic, though the margin is much smaller here, between 8 and 18\% depending on the measure employed. However, it should be noted that there is an extremely small sample size for cases of democratic targets with non-democratic allies, with only five according to BMR and six for Polity, which could be influencing the results. ${ }^{5}$ Nonetheless, there is an interesting reversal here that should be examined in greater detail.

When we turn our attention to those cases where no powerful allies are present, we see that the vast majority of them occur with non-democratic targets, between 78 to $87 \%$ of all observations. In comparing democratic vs. non-democratic targets, we again see democracies

\footnotetext{
${ }^{4}$ This case is the threat by Nicaragua against Costa Rica in 1978, when the U.S. was Costa Rica's most powerful ally.

${ }^{5}$ These cases are (threatener/target/compliance[Y/N] year): Turkey/France/Y 1936, Germany/UK/N 1939, Germany/France/N 1939, Japan/UK/Y 1939 Iraq/UK/N 1941, Turkey/Armenia/N in 1992. Interestingly, the most powerful ally in all of these cases was Russia / the Soviet Union, which BMR codes as a democracy in 1992 while Polity does not.
} 
conceding at higher rates, though there is a great deal of variation in terms of the margin. Whereas BMR only indicates a marginal difference of 4\%, Polity shows a large gap of $39 \%$ which is second only to the difference between democratic targets vs. non-democratic targets with democratic allies, also with the Polity measure.

In sum, the preliminary observations are somewhat mixed: when looked at individually, the target and ally information matches up with my predictions, as democratic targets concede at higher rates than non-democracies while those states that have democratic allies concede higher rates compared to either those with non-democratic allies or no allies, though the gap is quite small between democratic versus non-democratic allies. However, when the data is split into groupings of along target and ally lines, the divisions become less obvious, as the pairing of democratic targets and allies do concede at the highest rates, though democratic targets with non-democratic allies are shown to concede less often than nondemocratic targets with the same types of allies.

\section{Logistic Regression}

As noted above, I have coded my outcome variable using a dichotomous measure, where either the targeted state concedes fully to the demands it faces, or it does not. Therefore, my primary statistical model is a logistic regression, which allows for a dichotomous dependent variable. Similarly, my independent variables of interest are coded in either a dichotomous or trichotomous fashion, for targets and alliance partners respectively, along the lines outlined above. However, for the analysis to function properly, an appropriate array of control variables needs to be included as well along a number of dimensions, such as power and preferences, in order to avoid biasing the results. 


\section{Control Variables}

The first and broadest category of interest, as alluded to previously, is power. Given the difficulties of measuring power, I provide three different proxies that get at material capabilities in a variety of ways. The initial and arguably most nuanced tool comes from CINC measures, described in reference to how allies are identified. I take the CINC scores for the initiator and target, and divide the former by the latter, creating a power ratio with a larger number indicating a greater advantage for the initiator.

Another, less subtle tool, is the designation of a state as a "major" or "minor" power. As used by Schultz (2001a) among others, this variable goes beyond measuring the overall, indexed power of a state, and uses the "consensus among analysts taking into account power, reputation, and involvement in international affairs" to identify those states who hold a distinct advantage in international politics (264). The benefit of using this measurement in addition to the CINC scores listed above is that it gets to the idea that some states may hold material advantages above and beyond what is indicated purely by CINC, such as power projection via naval and air forces. This data also comes from the Correlates of War project, and identifies the U.S., Great Britain, France, Germany, Austria-Hungary (before its dissolution), Italy (prior to 1944), Russia / the Soviet Union (before 1917 and after 1921), China (after 1949), and Japan (before 1946 and after 1990) as great powers. (Correlates of War Project 2008)

The final power-related measure I include in my analysis involves nuclear weapons. Just as the major power indicator is attempting to quantify something that is above and beyond simple measures of strength, nuclear weapons are often considered to be qualitatively different tools of war and should be treated as such in our analyses. To account for this, I have created two different sets of variables, one of which is dichotomous for the target and initiator while the other is dyadic, not unlike the democratic measures. Though such tools do not get at more nuanced differences between the nuclear capabilities of the two states, 
such as what Kroenig (2013) incorporates in his analysis, this nonetheless acts as a useful first cut at controlling for the role of nuclear weapons.

Beyond these power-related measures, I also incorporate a number of other control variables that could plausibly be said to influence coercive threat outcomes. The first of them relate to the relative locations of the initiating state and the target, contiguity. There are two different ways to consider the relative proximity that contiguity proxies. First, states that geographically closer are capable of making more credible threats due to less power projection capabilities being necessary. Alternatively, as Sechser (2017) argues, it could be that states are most likely to resist threats from neighbors, for fear that by conceding they will open themselves up to future demands, at which point it will be more difficult to credibly convince the threatener that resistance will follow. In either case, it is important to control for distance between states in some capacity, for which contiguity is an effective tool.

Another argument claims that there needs to be some consideration for the similarity of foreign policy positions, with those targeted states with interests that are more diametrically opposed to those of the threatener being most likely to try and stand firm, rather than give in on an issue to a belligerent that takes hostile foreign policy positions, relative to the target. There is, however, disagreement about the best way to measure this concept. Bueno de Mesquita (1975) employed a measure, tau-b, that looks at alliance commitments, but has since been challenged by Signorino and Ritter (1999), who believe that tau-b is an inappropriate device for getting at the similarity of foreign policy positions. Instead, they argue for a spatial indicator, $S$, that deals more explicitly with association between states and not just similarity, which includes not just alliance portfolios but also United Nations voting patterns. Signorino and Ritter's $S$ variable has multiple versions, weighted and unweighted, regional and global. For the purposes of this paper, I employ the weighted, global version of $S$, but the results are largely unchanged with other measures, both within different versions of $S$ as well as Bueno de Mesquita's tau-b, which also comes in regional and global versions. 
It should be noted Bailey, Strezhnev and Voeten (N.d.) argue that $S$-scores are problematic due to the assumption of "straightforward relationship between how often two states vote together and preference similarity..." (4), and they therefore do not act as an ideal means of measuring shared preferences. Instead, they recommend employing an ideal point estimation based on United Nations voting data, which more accurately depicts the similarity or dissimilarity of preferences. While I am sympathetic to this approach, as it currently stands there has been no attempt to rework their recommended ideal points into larger framework of the $S$-score formula, which goes beyond simply looking at the United Nations. As such, while their measure may be more accurate, it would limit my analysis to the post-World War II environment and eliminate more than half of my observations.

There are also factors that are specific to the threat that could conceivably influence the likelihood of a peaceful resolution. In particular, the issues being bargained over could vary in how difficult they are to resolve. For example, Miller and Gibler (2011) have argued that territorial issues can be very complicated and hard to deal with peacefully, and that democracies tend to have them resolved prior to their democratic transitions, thus providing them with fewer thorny issues to contend with later on. Beyond land, an issue area that could lead to greater intransigence by the target might be demands for the leader to step down, with non-democratic leaders fearing for their post-rule survival while democratic regimes growing concerned with threats to popularly elected officials. In his MCT dataset, Sechser (2011) codes for the issue area or areas of the threat, including the aforementioned "hard" issues, which are then included as separate dummy variables.

Lastly, it is plausible that threats that are issued by the ally itself could be particularly difficult for the target to overcome. It is one thing for the ally to avoid getting involved, and thus the target not being able to rely on the ally in repelling the threat; while not a great situation, the target only has lost the ally's power and influence. But if the ally is issuing the threat, not only is that gravitas missing on the target's side, but it is actively working 
against the target, which could be a major blow. Therefore, I include a dummy variable for whether the initiating state and the target's most powerful ally are one and the same.

\section{Results}

The first series of results are presented in Table 3.7 below, starting with dichotomous measures of democracy for the target and trichotomous measures for the ally, utilizing both the BMR and Polity indicators. However, due to limited space, I have excluded certain nonsubstantive control variables from these tables. ${ }^{6}$ In addition to utilizing a standard logistic regression model, I have also clustered the standard errors at the level of the dyad, in order to account for instances where the same dyad had multiple threats being issued over time. According to the hypotheses listed at the beginning of this chapter, we ought to see:

- Democratic targets being correlated with compliance.

- Democratic allies being correlated with compliance.

The results provided here are in line with the predictions of the theory, as having a democratic target or ally is correlated with a higher probability of concessions, even after controlling for a wide array of other variables. While the target democracy outputs are able to match standard levels of statistical significance $(\mathrm{p}<0.05)$, the democratic ally values are even stronger $(\mathrm{p}<0.01)$ in contrast with the baseline of no ally at all. We can also compare the outcomes for having a non-democratic ally versus a democratic one, where we see that the results are very weak and statistically insignificant with either measure of democracy. As such, this is useful evidence in favor of both the primary hypotheses.

While this is a useful first cut, it provides very little by way of interpretable outputs, as the coefficients for a logistic regression do not have an simple translation. ${ }^{7}$ Therefore, in an

\footnotetext{
${ }^{6}$ In particular, I do not include contiguity, $S$-scores, and the ally threat variables. These full tables are available in Appendix A.

${ }^{7} \mathrm{~A}$ direct interpretation would be that a one-unit increase in the independent variable $k$ is associated with a $\beta_{k}$ change in the log-odds, on average, after controlling for the other independent variables.
} 
Table 3.7: Dichotomous Measures of Democracy- MCT

\begin{tabular}{lcc}
\hline & $(1)$ & $(2)$ \\
VARIABLES & BMR & Polity \\
\hline \multirow{2}{*}{ Target Democracy } & $0.805^{* *}$ & $1.046^{* *}$ \\
& $(0.405)$ & $(0.520)$ \\
Democratic Ally & $1.340^{* * *}$ & $1.389^{* * *}$ \\
& $(0.462)$ & $(0.518)$ \\
Non-Democratic Ally & 0.119 & -0.154 \\
& $(0.772)$ & $(0.785)$ \\
Initiator Democracy & -0.329 & -0.410 \\
& $(0.428)$ & $(0.383)$ \\
CINC Ratio & 0.00147 & 0.00170 \\
& $(0.00122)$ & $(0.00224)$ \\
Major Initiator & -0.579 & -0.576 \\
& $(0.434)$ & $(0.465)$ \\
Major Target & $1.190^{* *}$ & $1.226^{* *}$ \\
& $(0.479)$ & $(0.549)$ \\
Nuclear Initiator & $-1.361^{*}$ & $-1.281^{*}$ \\
& $(0.699)$ & $(0.707)$ \\
Nuclear Target & $1.554^{*}$ & 1.431 \\
& $(0.891)$ & $(0.990)$ \\
Territory & -0.481 & -0.473 \\
& $(0.392)$ & $(0.404)$ \\
Leadership & $2.327^{* * *}$ & $2.232^{* * *}$ \\
& $(0.681)$ & $(0.668)$ \\
Constant & 0.0578 & 0.0484 \\
& $(0.742)$ & $(0.799)$ \\
& 201 & 197 \\
Observations & \multicolumn{2}{c}{201} \\
\hline Robust standard errors in parentheses \\
$* * *$ p $<0.01, * *$ & $\mathrm{p}<0.05, * \mathrm{p}<0.1$ \\
& &
\end{tabular}

attempt to make these results more interpretable, I provide predicted probabilities graphs for the relevant variables. Figure ?? shows the outputs for the target, Figures 3.2 has the ally measures, while Tables 3.8 and 3.9 provide the point estimates displayed in the graphs for targets and allies, respectively.

Before delving into the results, it is worth a moment to properly discuss how to interpret the graphs. While the confidence intervals for the measures overlap in each case, that does not mean that the results are statistically indistinguishable. Rather, one has to determine what the likelihood that the true values of non-democracy and democracy are simultaneously 
Figure 3.1: Dichotomous Measures of Targets - MCT

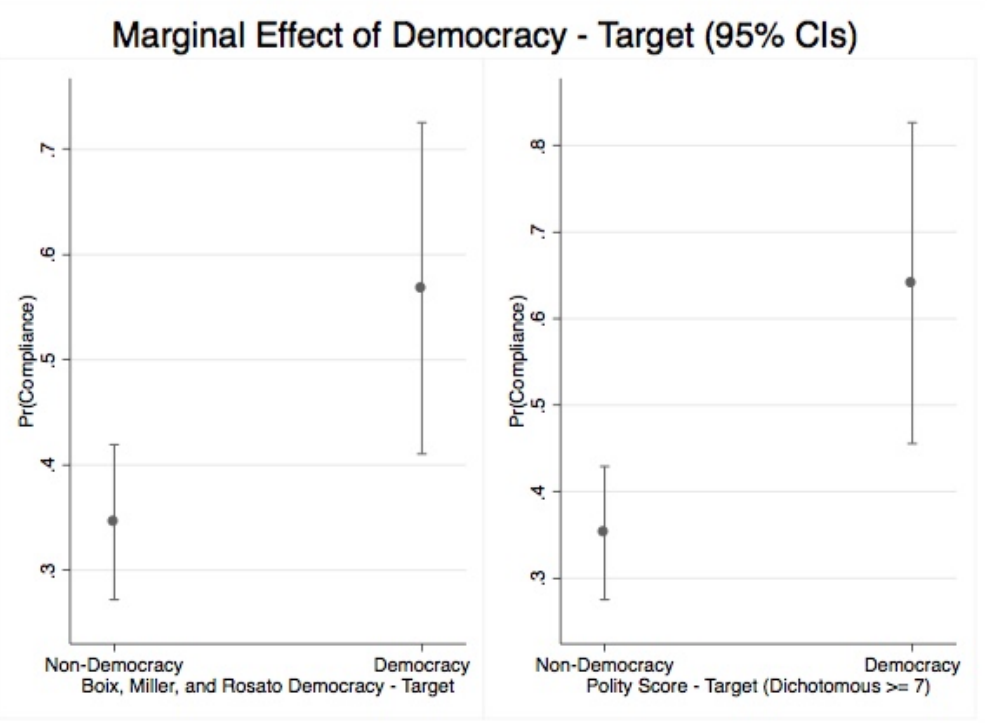

Table 3.8: Predicted Probabilities for Target (Dichotomous) - MCT

\begin{tabular}{|l|c|c|}
\hline & Democratic Target & Non-Democratic Target \\
\hline BMR & .514 & .365 \\
\hline Polity & .555 & .372 \\
\hline
\end{tabular}

in the overlapping tails. This can be performed by a post-estimation test, comparing the results for the different categories. Where appropriate, I provide these tests here. Therefore, while I refer to the point estimates of the predicted probabilities graphs, I also compare them to the level of statistical significance that emerges from the logistic regression that those graphs are based on.

Starting first with the results from the target data, there is a clear and substantial difference between the outputs for non-democratic targets compared to those that are democratic. More precisely, the dichotomous models indicate that a democratic target is $14.9 \%$ more likely to fully concede, per the BMR measure, while the Polity variable shows a $18.3 \%$ uptick in the likelihood that a democratic target would concede to a militarized coercive threat than a non-democratic target. Contrasting the dyadic measures, the results are more mixed, though more or less as predicted: a democratic target facing a threat from a non- 
democratic initiator is between 19.3 and $20 \%$ more likely to concede than a non-democratic target, according to the BMR and Polity indicators, respectively. However, it should be noted that the results for Polity are only weakly significant, though BMR's is robust. In comparison, a democratic target facing a democratic threat is no more likely to concede than a non-democratic target, according to BMR, or 11.5\% more likely with Polity, with neither of those results being statistically differentiable.

Figure 3.2: Ally Measures w/Dichotomous Targets - MCT

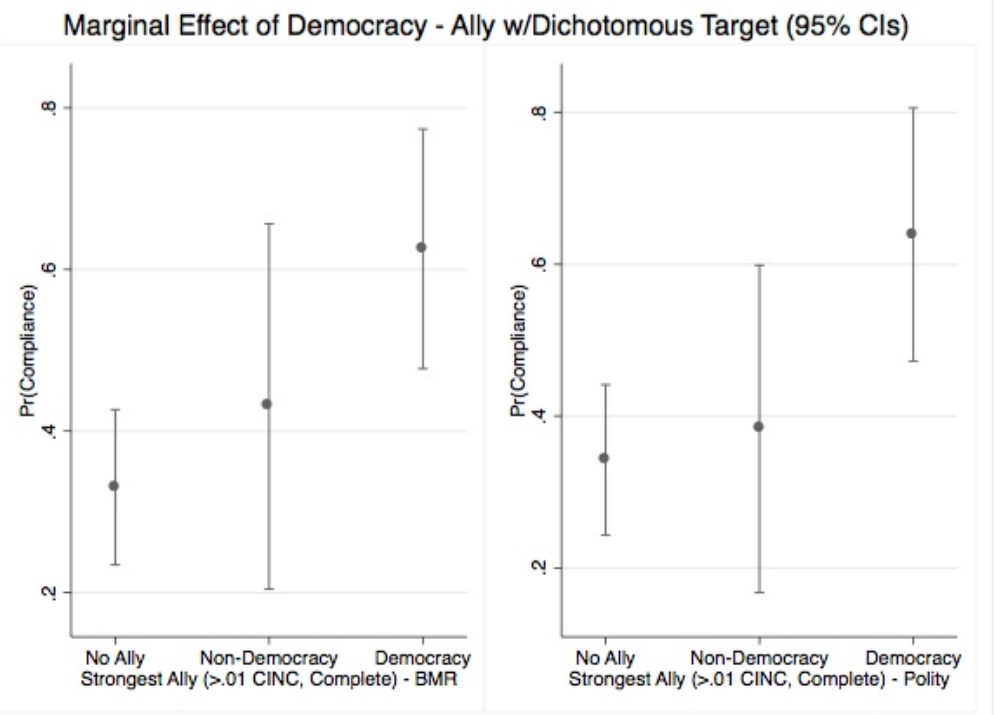

Table 3.9: Predicted Probabilities for Ally - MCT

\begin{tabular}{|l|c|c|c|}
\hline & Democratic Ally & Non-Democratic Ally & No Ally \\
\hline BMR (Dichotomous) & .608 & .372 & .351 \\
\hline Polity (Dichotomous) & .611 & .414 & .340 \\
\hline
\end{tabular}

For the ally measure, there are three comparisons that need to be made: democratic versus non-democratic, democratic versus no ally, and non-democratic versus no ally. Starting at the end, the predicted probabilities tend to show little to no difference between a target that has a non-democratic ally compared to one that has no ally at all: the smallest difference comes out at a $2 \%$ increase while the largest is $7.4 \%$, and none of them are statistically 
distinguishable. In contrast, a target with a democratic ally appears far more likely to make concessions when put against one with no ally, as the smallest increase has a $25.7 \%$ jump and the largest goes all the way up to $28.5 \%$, all of which are statistically significant. Therefore, at least when it comes to comparing against cases where there are no major allies involved, targets that have a democratic ally appear far more likely to concede while those with a non-democratic ally cannot be distinguished.

In order to compare democratic allies with non-democratic allies, however, the predicted probabilities graphs need to be put into greater perspective. To do so, I have re-run the results of the previous tables and changed the baseline alliance category from "no ally" to "non-democratic ally." This allows for a more direct comparison of the two types of alliances that are of most direct interest here. Table 3.10 provides these results, excluding all control variables as they are unaffected by the baseline change.

Table 3.10: Dichotomous Measures, Non-Democratic Ally Baseline - MCT

\begin{tabular}{lcc}
\hline \multirow{2}{*}{ VARIABLES } & $(1)$ & $(2)$ \\
No Ally & BMR & Polity \\
\hline \multirow{2}{*}{ Democratic Ally } & -0.119 & 0.154 \\
& $(0.772)$ & $(0.785)$ \\
Target Democracy & $(0.770)$ & $(0.794)$ \\
& $\left(0.405^{* *}\right.$ & $1.046^{* *}$ \\
Initiator Democracy & -0.329 & $(0.520)$ \\
& $(0.428)$ & $(0.410$ \\
Observations & 201 & 197 \\
\hline Robust standard errors in parentheses \\
$* * *$ p $<0.01, * *$ p $<0.05, *$ p $<0.1$
\end{tabular}

As expected, there is no distinguishable difference between having a non-democratic ally and having no ally at all. However, the results for comparing the two realized forms of alliances are much more problematic: while the democratic ally coefficients are always very 
large, they never reach traditional levels of statistical significance, and actually only achieve weak significance twice. Therefore, while the predicted probabilities graphs indicate that targets with democratic allies are more likely to make concessions than those with nondemocratic allies, and by a margin between 19.7 and 26.5\%, these results must be taken with a healthy degree of skepticism.

Finally, there is one last way in which the data can be parsed: by combining the information on the target and the ally together into a single measure. This allows for a more direct comparison across different groups, to see how the predicted probability for one pairing of target and ally stacks up with another. For this particular model, I have chosen to use the combination of a democratic target and democratic ally as the baseline, given that the cross-tab earlier in the chapter noted how this grouping appeared to be far and away the most likely to result in concessions. Table 3.11 shows the logistic regression outputs for both the BMR and Polity measures.

Overall, our expectations generally match up very well. Every single coefficient related to the target/ally pairings is negative, demonstrating that they all are less likely to make concessions compared to a paring of a democratic target and ally. And of the ten possible comparisons, eight are statistically significant at standard levels $(\mathrm{p}<0.05)$ or better, while a ninth is weakly significant $(\mathrm{p}<0.1)$ and the tenth is just barely misses weak significance as well $(\mathrm{p}<0.104)$. When taken together, this is strong evidence that, at the very least, democratic targets with democratic allies are more likely than any other grouping to concede to threats.

From here, I once again turn to the use of predicted probabilities outputs to demonstrate the results across groups other than democratic target and ally pairings. Figure 3.3 provides a visualization along with confidence intervals while Table 3.12 shows the point predictions for each pairing.

There are two ways in which to perform these comparisons: holding the allies constant and allowing comparisons across different target types, and holding the targets constant to get at 
Table 3.11: Target/Ally Combination, Democratic Target and Ally Baseline - MCT

\begin{tabular}{|c|c|c|}
\hline VARIABLES & $\begin{array}{c}(1) \\
\text { BMR } \\
\end{array}$ & $\begin{array}{c}(2) \\
\text { Polity } \\
\end{array}$ \\
\hline Non-Demo, No Ally & $\begin{array}{c}-3.775^{* * *} \\
(1.205)\end{array}$ & $\begin{array}{c}-3.508^{* * *} \\
(1.235)\end{array}$ \\
\hline Demo, No Ally & $\begin{array}{c}-3.508^{* * *} \\
(1.200)\end{array}$ & $\begin{array}{c}-2.058 \\
(1.267)\end{array}$ \\
\hline Non-Demo, Non-Demo Ally & $\begin{array}{c}-3.346^{* *} \\
(1.345)\end{array}$ & $\begin{array}{c}-2.775^{* *} \\
(1.335)\end{array}$ \\
\hline Demo, Non-Demo Ally & $\begin{array}{c}-4.926^{* * *} \\
(1.402)\end{array}$ & $\begin{array}{c}-4.470 * * * \\
(1.350)\end{array}$ \\
\hline Non-Demo, Demo Ally & $\begin{array}{c}-3.462^{\text {*** }} \\
(1.199)\end{array}$ & $\begin{array}{c}-2.347^{*} \\
(1.249)\end{array}$ \\
\hline Initiator Democracy & $\begin{array}{l}-0.269 \\
(0.485)\end{array}$ & $\begin{array}{l}-0.418 \\
(0.412)\end{array}$ \\
\hline CINC Ratio & $\begin{array}{c}0.00214 \\
(0.00318)\end{array}$ & $\begin{array}{c}0.00155 \\
(0.00126)\end{array}$ \\
\hline Major Initiator & $\begin{array}{l}-0.420 \\
(0.472)\end{array}$ & $\begin{array}{l}-0.530 \\
(0.477)\end{array}$ \\
\hline Major Target & $\begin{array}{c}1.777^{* * *} \\
(0.588)\end{array}$ & $\begin{array}{c}1.587^{* * *} \\
(0.556)\end{array}$ \\
\hline Nuclear Initiator & $\begin{array}{c}-1.560^{* *} \\
(0.770)\end{array}$ & $\begin{array}{c}-1.444^{*} \\
(0.745)\end{array}$ \\
\hline Nuclear Target & $\begin{array}{c}1.134 \\
(1.108)\end{array}$ & $\begin{array}{c}0.938 \\
(1.015)\end{array}$ \\
\hline Constant & $\begin{array}{c}3.760^{* *} \\
(1.543)\end{array}$ & $\begin{array}{c}3.575^{* *} \\
(1.410)\end{array}$ \\
\hline Observations & 201 & 197 \\
\hline
\end{tabular}

differences between alliance formations. For the ease of simplicity, I will begin with targets before moving to allies. Starting from the left and moving rightward, we will first begin by focusing on cases of states which have no allies at all. The evidence here is, once again, mixed. On the one hand, there is only a meager difference $(4.7 \%)$ between the probability of a democratic target with no ally making concessions compared to a non-democratic target according to the BMR measure, which turns out to be statistically insignificant. In contrast, the Polity measure shows a much larger gap (28.1\%), which is demonstrated to be statistically differentiable. Therefore, there is at least some evidence of a credible difference between 
Figure 3.3: Combined Target and Ally Measures - MCT

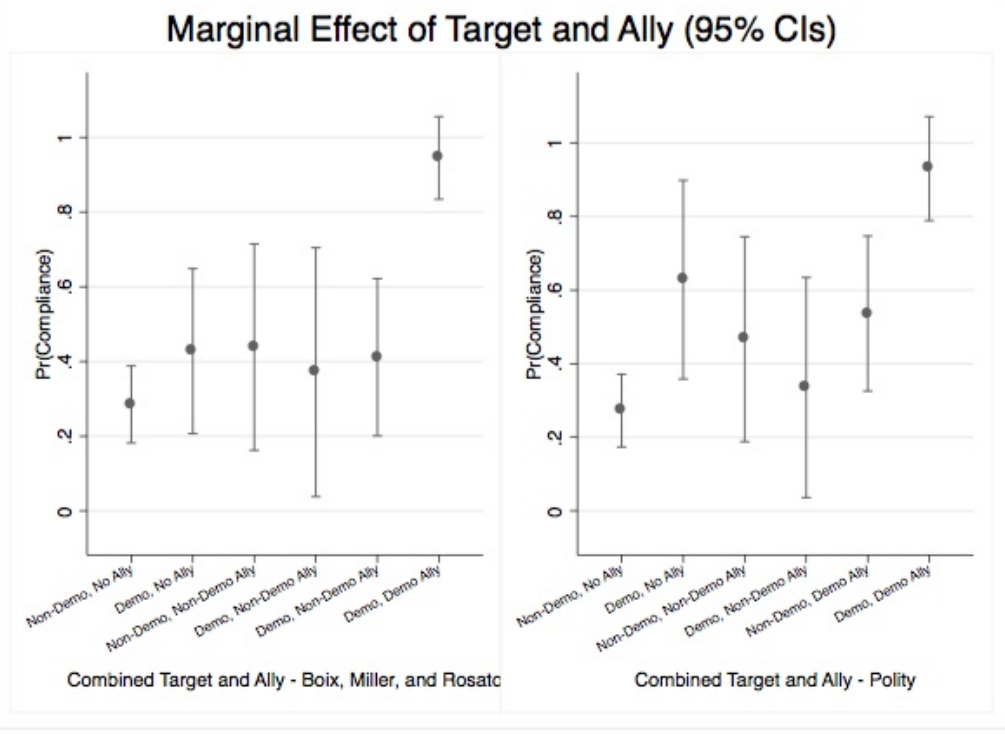

Table 3.12: Target/Ally Combination Predicted Probabilities - MCT

\begin{tabular}{|l|c|c|}
\hline & BMR & Polity \\
\hline Non-Demo, No Ally & .338 & .309 \\
\hline Demo, No Ally & .385 & .590 \\
\hline Non-Demo, Non-Demo Ally & .415 & .445 \\
\hline Demo, Non-Demo Ally & .174 & .172 \\
\hline Non-Demo, Demo Ally & .393 & .531 \\
\hline Demo, Demo Ally & .927 & .898 \\
\hline
\end{tabular}

targets alone when there is no ally to speak of.

Shifting to comparisons of states with non-democratic allies, the point estimates for both BMR and Polity show a very distinct difference, with democratic targets being much less likely to make concessions, by $24.1 \%$ and $27.3 \%$ respectively. However, neither of these results are statistically significant, due to the large standard errors around each of these categories, making it difficult to say that there is any meaningful change in the probability of concessions from shifting to a democratic target from a non-democratic one while holding a non-democratic ally constant.

Lastly, there are the cases of states with democratic allies. We again see a very wide 
gulf between democratic targets and non-democratic ones: per BMR, the former are $59.4 \%$ more likely to fully concede, while Polity shows the difference being $36.7 \%$, both of which are the widest bar a decent margin. In terms of statistical significance, the BMR measure is distinctly significant $(\mathrm{p}<0.01)$ and very strong evidence for the difference between democratic and non-democratic targets. While the Polity measure is not nearly as strong $(\mathrm{p}<0.1)$, it does manage to reach minimal levels of statistical significance.

Moving on to comparisons of allies, we start with targets that are non-democratic. While the point estimates of the predicted probabilities graph using the BMR measure of democracy indicates having a non-democratic ally leads to the highest probability of concessions (41.5\%), followed by a democratic ally (39.3\%), and lastly no ally at all (33.8\%), none of these differences are statistically distinct. In contrast, the Polity measure shows having a democratic ally has the highest probability of concessions (53.1\%), then a non-democratic ally $(44.5 \%)$, and lastly no ally period (30.9\%), of which there is a statistically meaningful difference between the democratic ally compared to no ally. Therefore, what little we can say that is statistically differentiable from these models does appear to comport with the predictions of the theory.

Turning our attention to cases of democratic targets, the results are much stronger overall. Once again, the cases that are most likely to result in concessions come from pairings with the democratic ally, regardless of which measure of democracy is being employed, with BMR showing $92.7 \%$ and Polity weighing in at $89.8 \%$. Further, these outputs can be statistically distinguished from both of the cases with non-democratic pairings, at $17.4 \%$ with BMR and $17.2 \%$ for Polity, as well as BMR's "no ally" output of $38.5 \%$. Indeed, the only measure where a different alliance pairing could not be differentiated while holding the target constant as a democracy was with Polity's "no ally" variety (59.0\%). In directly contrasting the results of the no ally and non-democratic ally categories, there is the interesting results where they can be differentiated when using the Polity measure, but could not with BMR's. 


\section{Dyadic Measures}

One possible critique of this perspective is that nature of the target alone is not actually driving these results, but that it is instead about the combination of the initiator and target. If this view is accurate, then the best approach would not be to utilize dichotomous measures of the target and the initiator, but instead a single variable that covers all four possible combinations. To account for this possibility, this section will utilize a dyadic measure of the initiator and target regimes. Table 3.13 provides a cross-tabulation of the initiator and target combinations for both the BMR and Polity measures, along with the rates at which the targets concede.

Table 3.13: MCT Initiator/Target Distribution

\begin{tabular}{|l|c|c|}
\hline Initiator/Target & BMR Democracy & Polity \\
\hline$\sim$ Demo/ Demo & $102(32 \%)$ & $112(34 \%)$ \\
\hline Demo/ Demo & $49(37 \%$ & $52(33 \%)$ \\
\hline$\sim$ Demo/Demo & $41(66 \%)$ & $31(74 \%)$ \\
\hline Demo/Demo & $14(50 \%)$ & $6(66 \%)$ \\
\hline
\end{tabular}

Just as with the previous tables, the cross-tabulations appear to clearly indicate that democratic targets are conceding at higher rates than non-democracies, regardless of what type of initiator is involved. However, there is an important divergence that occurs with democratic/democratic threats: they are much less common. Per the BMR measure, there are only fourteen cases of inter-democratic threats being issued, while Polity only identifies six such cases, both of which are much less frequent than any other combination. This is in line with the argument of Poznansky and Scroggs (2016), who claim that the logic of democratic peace extends to the realm of militarized coercive diplomacy, where democracies cannot or will not threaten one another with force to achieve diplomatic goals.

However, the consequences of this are more complicated for this analysis. Due to the small number of observations, it can be difficult to extract any meaningful results within that set of outcomes. While they were grouped together with the non-democratic/democratic threat 
dyads for the analysis utilizing dichotomous measures of democracy, they will be separated out with the dyadic measures and it is likely that the standard errors will be very large. Subsequently, it will be hard to compare and contrast the results of democratic/democratic threats versus other types of dyads.

That being said, it is worth noting that regardless of these small samples, any pairing that has a democratic target has a higher probability of concessions than any pairing which has a non-democratic target, at least within the same coding scheme. This provides some confirmation of the expectations of the theory, though we should be very cautious about reading much into the results for the small samples provided by inter-democratic threats.

Having established the basic breakdown of the data, the next step is to employ statistical analysis to actively control for confounding influences. Table 3.14 takes the same model as was employed in the dichotomous version, Table 3.7, simply replacing the initiator and target variables with a single variable that takes on one of four values: 0 for a non-democratic initiator and target; 1 for a democratic initiator and non-democratic target; 2 for a nondemocratic initiator and democratic target; and 3 for a democratic initiator and target. From these combinations, this model employs the non-democratic initiator and target as the baseline. These results are then followed by the predicted probabilities graphs and table, Figure 3.4 and Table 3.15, respectively.

Again, we see outcomes that are largely in line with the predictions of the theory given the limitations of the data. Democratic targets threatened by non-democratic initiators are noticeably more likely to make concessions compared to a combined non-democratic initiator and target. This is particularly true with the BMR measure of democracy $(\mathrm{p}<0.05)$, though the Polity measure also retains weak statistical significance $(\mathrm{p}<0.1)$. In contrast, we once again see a powerful and very significant effect from democratic allies $(\mathrm{p}<0.01)$, regardless of the specification of democracy being employed.

Contrasting this dyadic model with those of the analogous dichotomous model in Table 
Table 3.14: Dyadic Measures of Democracy- MCT

\begin{tabular}{|c|c|c|}
\hline VARIABLES & $\begin{array}{c}(1) \\
\text { BMR }\end{array}$ & $\begin{array}{c}(2) \\
\text { Polity } \\
\end{array}$ \\
\hline Demo/ Demo & $\begin{array}{c}-0.0259 \\
(0.532)\end{array}$ & $\begin{array}{l}-0.337 \\
(0.426)\end{array}$ \\
\hline$\sim$ Demo/Demo & $\begin{array}{l}1.082^{* *} \\
(0.511)\end{array}$ & $\begin{array}{l}1.131^{*} \\
(0.596)\end{array}$ \\
\hline Demo/Demo & $\begin{array}{c}-0.0147 \\
(0.668)\end{array}$ & $\begin{array}{c}0.333 \\
(0.890)\end{array}$ \\
\hline Non-Democratic Ally & $\begin{array}{c}0.140 \\
(0.788)\end{array}$ & $\begin{array}{l}-0.138 \\
(0.793)\end{array}$ \\
\hline Democratic Ally & $\begin{array}{c}1.337^{* * *} \\
(0.460)\end{array}$ & $\begin{array}{c}1.382^{* * *} \\
(0.517)\end{array}$ \\
\hline CINC Ratio & $\begin{array}{c}0.00132 \\
(0.000831)\end{array}$ & $\begin{array}{c}0.00170 \\
(0.00231)\end{array}$ \\
\hline Major Initiator & $\begin{array}{l}-0.486 \\
(0.443)\end{array}$ & $\begin{array}{l}-0.588 \\
(0.465)\end{array}$ \\
\hline Major Target & $\begin{array}{l}1.104^{* *} \\
(0.472)\end{array}$ & $\begin{array}{l}1.203^{* *} \\
(0.554)\end{array}$ \\
\hline Nuclear Initiator & $\begin{array}{c}-1.502^{* *} \\
(0.704)\end{array}$ & $\begin{array}{l}-1.294^{*} \\
(0.705)\end{array}$ \\
\hline Nuclear Target & $\begin{array}{c}1.683^{* *} \\
(0.846)\end{array}$ & $\begin{array}{c}1.428 \\
(0.976)\end{array}$ \\
\hline Territory & $\begin{array}{l}-0.517 \\
(0.408)\end{array}$ & $\begin{array}{l}-0.463 \\
(0.403)\end{array}$ \\
\hline Leadership & $\begin{array}{c}2.314^{* * *} \\
(0.665)\end{array}$ & $\begin{array}{c}2.238^{* * *} \\
(0.668)\end{array}$ \\
\hline Constant & $\begin{array}{l}-0.175 \\
(0.792)\end{array}$ & $\begin{array}{c}-0.00387 \\
(0.814)\end{array}$ \\
\hline Observations & 201 & 197 \\
\hline
\end{tabular}

3.7, the results are more mixed, though more or less as predicted: a democratic target facing a threat from a non-democratic initiator is between 19.3 and $20 \%$ more likely to concede than a non-democratic target, according to the BMR and Polity indicators, respectively. However, it should be noted that the results for Polity are only weakly significant, though BMR are robust. In comparison, a democratic target facing a democratic threat is no more likely to concede than a non-democratic target, according to BMR, or $11.5 \%$ more likely with Polity, with neither of those results being statistically differentiable. 
Figure 3.4: Dyadic Measures of Democracy - MCT

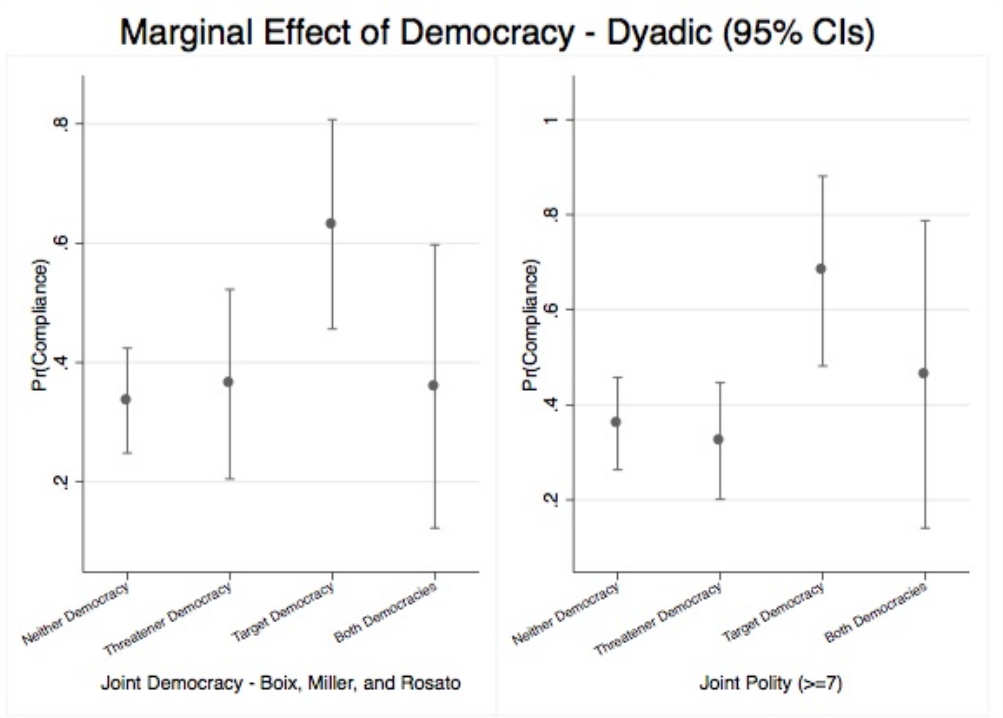

Table 3.15: Predicted Probabilities for Targets (Dyadic) - MCT

\begin{tabular}{|l|c|c|}
\hline & Democratic Target & Non-Democratic Target \\
\hline BRM ( Dem Initiator) & .562 & .369 \\
\hline BRM (Dem Initiator) & .352 & .352 \\
\hline Polity ( Dem Initiator) & .592 & .392 \\
\hline Polity (Dem Initiator) & .430 & .315 \\
\hline
\end{tabular}

The transition from dichotomous to dyadic indicators for the initiator and target, shown in Table 3.5 does little to impact the results for the alliance measures. Just as with the previous findings, targets with democratic allies are the most likely to make concessions, at around $63 \%$, the results of which are distinct from those that have no allies but not so compared to targets with non-democratic allies, as demonstrated in Table 3.16. This comes across more clearly when the baseline category is changed from no ally to a non-democratic ally, as provided in Table 3.17 below. 
Figure 3.5: Ally Measures w/Dyadic Target and Initiator - MCT
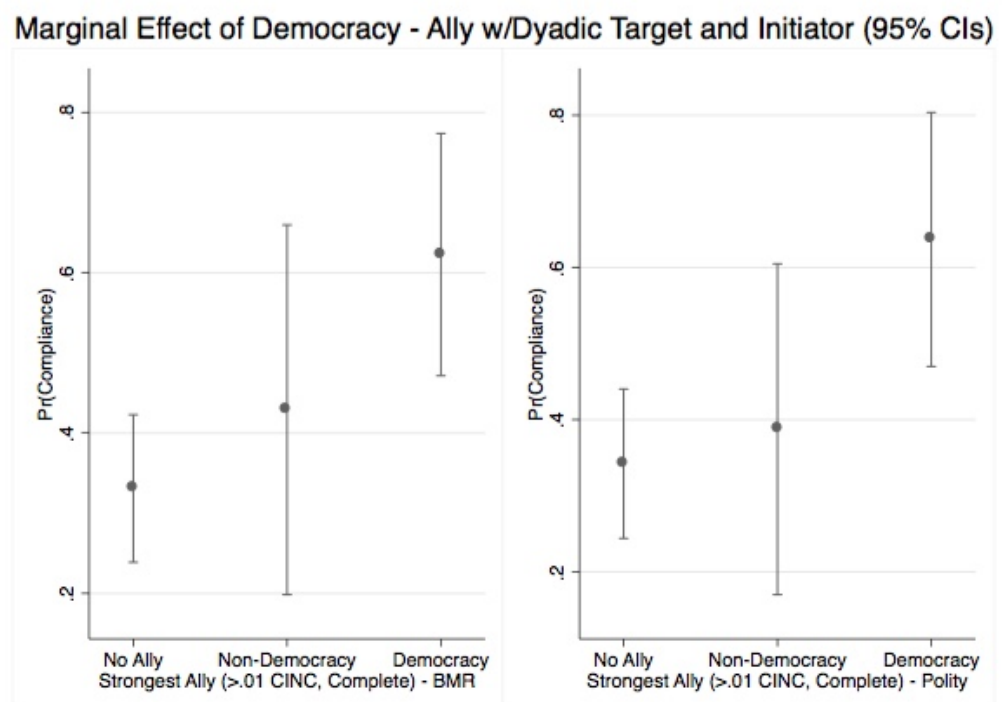

Table 3.16: Predicted Probabilities for Ally - MCT

\begin{tabular}{|l|c|c|c|}
\hline & Democratic Ally & Non-Democratic Ally & No Ally \\
\hline BMR (Dyadic) & .634 & .369 & .349 \\
\hline Polity (Dyadic) & .633 & .372 & .349 \\
\hline
\end{tabular}

\section{Types of Threats}

Another possible critique of this analysis is that democratic and non-democratic targets face different types of threats, and that, control variables for territory and leadership in the logistic regression notwithstanding, this could subsequently lead to differing levels of compliance. In particular, if democracies tend to face threats that are less thorny than what non-democracies have to contend with, that could actually be what is causing the divergence in concession rates. As noted above, this is particularly plausible in the realm of territorial issues: according to Mitchell and Prins (1999), democracies tend to have resolved territorial issues earlier on in their history, before their democratic transition, making conflict with one another less likely. Given that territorial issues should be among the thornier problems states have to contend with, if they are removed from the subset of threats that democracies 
Table 3.17: Dyadic Measures, Non-Democratic Ally Baseline - MCT

\begin{tabular}{|c|c|c|}
\hline VARIABLES & $\begin{array}{c}(1) \\
\text { BMR }\end{array}$ & $\begin{array}{c}(2) \\
\text { Polity }\end{array}$ \\
\hline No Ally & $\begin{array}{l}-0.140 \\
(0.788)\end{array}$ & $\begin{array}{c}0.138 \\
(0.793)\end{array}$ \\
\hline Democratic Ally & $\begin{array}{c}1.197 \\
(0.786)\end{array}$ & $\begin{array}{l}1.520^{*} \\
(0.803)\end{array}$ \\
\hline Demo/ Demo & $\begin{array}{c}-0.0259 \\
(0.532)\end{array}$ & $\begin{array}{l}-0.337 \\
(0.426)\end{array}$ \\
\hline$\sim$ Demo/Demo & $\begin{array}{c}1.082^{* *} \\
(0.511)\end{array}$ & $\begin{array}{l}1.131^{*} \\
(0.596)\end{array}$ \\
\hline Demo/Demo & $\begin{array}{r}-0.0147 \\
(0.668)\end{array}$ & $\begin{array}{c}0.333 \\
(0.890)\end{array}$ \\
\hline Observations & 201 & 197 \\
\hline
\end{tabular}

face, this could lead to a higher overall willingness to make concessions. Alternatively, in the realm of leadership, it might be the case that initiators avoid issuing such threats against democracies, for fear of causing a backlash among the public by challenging a foundational aspect of the state's identity, through demanding the removal of a democratically elected leader.

To address this possibility, I first created a cross-tabulation that featured both whether the target was democratic or not, as well as how many of the threats that they faced involved territorial or leadership disputes. Table 3.18 has the breakdown of the data below, with counts for both the BMR and Polity datasets. Further down, I also include a summary of the responses to these threats in Table 3.19.

Table 3.18: Threat Types by Target - MCT

\begin{tabular}{|l|c|c|c|c|}
\hline & Territorial & Non-Territorial & Leadership & Non-Leadership \\
\hline Democracy (BMR/Polity) & $41 / 31$ & $14 / 9$ & $4 / 5$ & $51 / 35$ \\
\hline Non-Democracy (BMR/Polity) & $79 / 86$ & $73 / 78$ & $18 / 17$ & $134 / 147$ \\
\hline
\end{tabular}

Though not directly contradicting Mitchell and Prins (1999), the results do indicate that 
Table 3.19: Compliance by Threat Type and Target - MCT

\begin{tabular}{|l|c|c|}
\hline & Territorial Concessions & Leadership Concessions \\
\hline Democracy (BMR/Polity) & $68 / 68$ & $100 / 100$ \\
\hline Non-Democracy (BMR/Polity) & $25 / 30$ & $78 / 76$ \\
\hline
\end{tabular}

the threats democratic targets have to contend with overwhelmingly have at least a territorial aspect to them, even if in conjunction with some other demand. In the case of the BMR measure, every threat that does not have to do with territory is met with almost three that do not, while that ratio is actually exceeded with Polity. In contrast, it is much closer to a one-to-one ratio for non-democratic targets, with only a few more threats emerging involving territory compared to those that do not.

Threats involving leadership are more in line with what we might have predicted, as there are very few cases of democracies facing such threats, four in the case of BMR and five with Polity. That being said, there are not a significantly larger number of such demands made of non-democracies, such that the ratio of leadership threats versus non-leadership threats are fairly close between democracies and non-democracies. Indeed, while between 7 and $12 \%$ of threats directed as democracies involve at least an aspect of leadership, non-democratic targets only have between 10 and $12 \%$ of their threats involving leadership demands.

Upon further examination of these "hard" issues, however, something very interesting emerges: democracies comply more readily in both issue areas than non-democracies. With territorial issues, democracies concede more than twice as often than non-democracies do, while in the realm of leadership, democracies actually give in to every threat they face.

What can explain this pattern of behavior? According to my theory, democratic states should be threatened more selectively than non-democracies, particularly when the costs of conflict or war are very high. If we believe that territory or leadership are goods that the target would only concede if it had very few other options, this selectivity argument makes a great deal of sense: the initiators in these cases knew that they had a high probability of 
success, even if the demands were very costly. Therefore, examining costly cases not only fails to weaken my argument, it actually provides further evidence in line with the expectations of my theory.

\section{Conclusion}

What takeaways can we extract from these results? When it comes to the issue of targets, the findings are firmly in line with the expectations of the theory, providing strong evidence for $H_{1}$. Starting first with the dichotomous measures, the results are very strong and consistent, demonstrating that democratic targets are certainly correlated with higher probabilities of concessions. The dyadic measures are more complicated, due to the distinction between threats that are issued by democracies compared to those that come from non-democracies, and the small number of inter-democratic threats. However, we once again see that there is a correlation between democratic targets threatened by non-democracies and a higher likelihood of concessions, with strong results when using the BMR measure and weakly significant findings from Polity.

For democratic allies on the other hand, the results are much more mixed. When contrasted against cases where the target has no ally, or at least none that are particularly powerful, the results consistently indicate that democracies are significantly more likely to make concessions. At the same time, targets with non-democratic allies are not noticeably different in their behavior. However, the results comparing democratic allies with no ally are incredibly robust, as they hold at very high levels of statistical significance across every model, lending credence to $H_{2 b}$.

In contrast, when the baseline category transitioned to non-democratic allies, the results became much weaker. Even though the predicted probabilities graphs indicated a wide gap between democratic and non-democratic allies in terms of point estimates, the best results 
only were able to achieve weak levels of statistical significance. Therefore, the degree of certainty that targets with democratic allies concede at higher rates than those with nondemocratic allies is not nearly as strong as the other results that have been derived in this section, making support for $H_{2 a}$ less clear.

These findings are further complicated when the data was parsed in combined target/ally categories. On the one hand, democratic target/ally combinations were typically found to be most likely to make concessions, with the results being very strong in eight of the ten comparisons across both pairings and measures of democracy. Similarly, we see that holding alliance partners constant and switching the target from a non-democracy to a democracy provides some evidence in line with the predictions of the theory. On the other hand, holding the target constant and changing up the ally provides much more mixed evidence, due to the large uncertainty that exists with cases involving non-democratic allies, though nothing that directly contradicts the argument. In sum, while $H_{3}$ appears to be quite likely, with democratic targets and allies being the combination with the highest probability of concessions, there is some uncertainty about the degree to which this is accurate.

Overall, however, the observable implications of the theory have generally been proven accurate, at least in the context of militarized coercive threats. The next step with this data will be to identify particular cases of interest and examine how the democratic (or non-democratic) nature of the target as well as the presence and/or democratic-ness of the ally matter in those specific case studies.

Before moving on to those cases, I will first turn to another source of data, the Threat and Imposition of Economic Sanctions (TIES) dataset, to evaluate whether my theory applies in realms other than that involving militarized force. Though the logic works in a slightly different manner, if the predictions of the theory are found to carry over to such a very different set of cases, it would provide powerful evidence in favor of my argument. Therefore, we will return to the substance of the militarized cases in the fifth chapter, when both the 
Munich and Suez Crises will be examined in much greater detail. 


\section{Chapter 4}

\section{Economic Threats}

This chapter continues to evaluate how democracies respond to coercive threats, with the focus shifting from demands backed by violence to those involving economic sanctions. Just as in the case of militarized threats, I argue that democratic targets can involuntarily signal their weakness or instability to potential initiators, by either mimicking a game of perfect information (i.e. making it clear whether they are resolved or irresolute) or through costly signaling which acts to partially separate out some irresolute states. In both cases, the key is that the initiator is once again are provided with information about the target's "type," thus allowing the initiator to select into situations where concessions are more likely to occur.

However, the scope conditions for this application of the theory differ significantly from those of militarized threats. Whereas there are strong reasons to believe that allies will at least need to entertain intervening on behalf of their allied targets, such priors are much weaker in the context of economic sanctions. Though being allied with a target that is sanctioned certainly could impose some costs on the ally, the gap in terms of how significant these are for the ally are different by orders of magnitude. Indeed, it may even be possible for the ally to benefit from the target being sanctioned, as it could lead the to the target becoming more dependent on the ally in order to replace the goods or markets that could 
be lost should the sanctions be imposed, preventing the ally from intervening at all. With this logic in mind, this chapter leaves out any analysis related to their allies, though my reasoning will be expanded in greater detail below.

This leaves the target logic to stand on its own. While sanctions do not offer the same degree of costs that fighting or war entail, they nonetheless offer a promise to the target: change their behavior in line with the initiator's demands, or face the imposition of sanctions. Given that economic sanctions can vary a great deal from case-to-case, with some being performed through multilateral institutions while others are unilateral, some having high costs for the target and/or the sender while others do not, and so on, some threats are certainly going to be more effective than others. Indeed, we should expect to see much lower levels of compliance as the targets find themselves having stronger incentives to maintain their behavior. With these sources of variance in the background, it is worth testing to determine if democracies remain more likely to concede under these circumstances.

This argument is tested via a dataset consisting of both threats and imposition of economic sanctions, though only the former is germane to this project. The results from the statistical analysis are found to be consistent with the theory's predictions, even as three different measures of the dependent variable are employed. The overall findings are as follows:

- Democratic targets are more likely to concede to threats of economic sanctions that are non-democratic targets, at about a two to one ratio.

- These results are also found to be even more extreme in cases where the target would be expected to pay very high costs should the sanctions be imposed, with one measure indicating a five to one difference in concessions by democracies compared to nondemocracies. These results are strongest with the BMR measure of democracy, whereas the Polity measure shows little difference from the models including both high and low 
costs of sanctions.

\section{Deriving Hypotheses from the Formal Model}

To derive testable hypotheses for my statistical analysis in this chapter, I once again refer

back to the formal models of Chapter 2. However, when applying these models to the case of economic sanctions, it is important to note what the key variables of interest mean in such a context, and how they should be interpreted. The costs of war are, after all, distinctly different from those brought about by economic sanctions, and should be noted as such. Further, as we think about broader patterns of behavior, especially among and between democracies, it is worth considering not only how the targets should respond but how the initiators would threaten.

Similar to the previous chapter, there are two primary dimensions upon which these models should be analyzed, namely targets / allies and complete / incomplete information. While the distinction between the target and ally logic is a critical one for this chapter, the takeaways for complete and incomplete information are essentially the same as the conclusions reached in the previous chapter. I follow this by relaxing assumptions of the model to consider how democracies will or will not interact differently with one another in the context of sanction threats, and outlining specific hypotheses that can then be tested in the statistical analysis.

\section{Targets vs. Allies}

For targets, the general logic of the model applies very well: when facing a threat of sanctions, the target must weigh the benefits of maintaining control of the good versus the costs of being sanctioned, thus leading to their "type" as either resolved (willing to suffer the sanctions) or irresolute (preferring concessions). As there are at least some groups within the target's 
society that will suffer for having these sanctions being imposed on them, there is some ability on the part of the initiator to determine whether the target is vulnerable to threat, and would thus back down, or if the threat is unlikely to succeed, resulting in the sanctions being enforced.

Where this logic differs from the context of militarized threats are the type of costs that are being considered. Though sanctions certainly imply costs for both the initiator and target states, they are typically much lower than what we would expect to find in war, especially for the initiator. This decrease in costs of "conflict" for initiators $\left(\omega_{I}\right)$ makes initiators more willing to threaten and follow through on those threats, even if the likelihood of success is low. Therefore, we should expect to see initiators being more willing to threaten and subsequently impose sanctions. In a similar manner, since the costs of "conflict" for the targets $\left(\omega_{T}\right)$ are more likely to be much lower than the value of the good, we should also expect to see more intransigence in the face of threats.

- $H_{\beta}$ : Threats of economic sanctions should be more common than threats of military force.

- $H_{\gamma}$ : Threats of economic sanctions should fail more often than threats of military force.

However, while this logic makes reasonable sense in the context of targets, it is less plausible for alliance partners. Typically speaking, there is no reason to believe that alliance partners will pay a heavy price for their allied targets having sanctions placed on them. Indeed, if we think about how sanctions cause disruptions to economic relationships, particularly between the sanctioning and sanctioned states, it may actually be the case that the ally may benefit from having target being sanctioned, as the ally could act as an alternative market for goods.

More broadly, alliances are rarely built purely on economic grounds, and I can find no instance of an agreement where one state explicitly agreed to come to another's aid should 
they be sanctioned. Defensive alliances exist with the goal of providing protection from military threat, violence, or conquest, not economic sanction, and thus we have little reason to believe that they should have any influence on the sanctioning process. As such, this

chapter will focus exclusively on targets and how they respond to threats of sanctions, while leaving out alliance partners.

\section{Hypotheses for Testing}

As alluded to in the above sections, we ought to find that those targets that have systematically higher costs should be able to signal their "type" more readily than those that do not. Given that those states, per my theory, are democracies, we should see that some portion of irresolute democratic targets will signal their true nature, thus leading to a higher rate of concessions. Therefore, Hypothesis 1 is as follows:

- $H_{1}$ : Democratic targets concede to threats of sanction at higher rates than nondemocratic targets.

In addition to the systemic costs that democracies face, we can also consider the caseby-case costs. If there is a way to measure how much the target would expect to "pay" for having sanctions imposed, that would provide a different means of testing the theory. Assuming that there is such a measurement available, the model predicts that higher costs will lead to a great probability of concessions, which leads to Hypothesis 2:

- $H_{2}$ : Democratic targets concede to threats of sanction at higher rates than nondemocratic targets when the target costs of sanctions are high. 


\section{Data on Democratic Responses to Threats of Economic}

\section{Sanction}

To test how democratic targets respond to threats involving economic sanctions, I employ the Threat and Imposition of Economic Sanctions (TIES) dataset. Whereas previous datasets have primarily focused on collecting all observations of sanctions being employed, Morgan, Bapat and Kobayashi (2014) have instead started with the issuance of threats of sanction, followed by the target's response. Building on arguments made by Smith (1996) and Drezner (2003), they note the potential selection issues that may emerge from states which concede to threats of sanction compared to those that actually contend with sanctions being imposed, using this logic as the motivation for creating such a dataset.

\section{Dependent Variable: Compliance with Threats}

According to the TIES dataset, there are eleven possible outcomes following a threat of economic sanction, varying from the target fully conceding at the threat stage to "total acquiescence" following the imposition of sanctions, with a great deal of variety in-between. ${ }^{1}$ Of those different outcomes, there are only two that are of potential interest for this project: where the target partially concedes following the threat of sanctions, and where the target completely concedes after sanctions are threatened. In terms of coding, these categories appear to match up very well with the rules established by Sechser (2011) for militarized threats, as partial capitulation similarly requires that the target only give way on some issues while standing firm on others and full compliance necessitates that the target agree to all of the initiator's (or "sender's," in the TIES parlance) demands.

\footnotetext{
${ }^{1}$ They are, in order: 1) partial acquiescence by target at threat stage; 2 ) total acquiescence by target at threat stage; 3) acquiescence by sender at threat stage; 4) stalemate at threat stage; 5) negotiated settlement; 6) partial acquiescence of target after sanction imposition; 7) total acquiescence of target after sanction imposition; 8) acquiescence by sender after imposing sanctions; 9) stalemate after santion imposition; 10) negotiated settlement after sanction imposition; and 11) unknown.
} 
Just as with militarized threats, there are potential concerns that the target choosing to partially concede might lead to situations where the initiator is only provided with a "token" victory, as the target gives way on a minor issue in order to allow the initiator to save face. Therefore, I once again code compliance as a "hard test" for my theory, by making it such that the target either conceded completely to the initiator's demands, or did not.

\section{Independent Variable: Democracies vs. Non-Democracies}

Similar to the previous chapter, the (non-)democratic nature of the coercive targets is the primary independent variable of interest. However, there is one critical divergence from how this chapter's analysis is constructed that are worth focusing on. As noted above, my theory does not predict that the alliance partner would have any major influence on the likelihood of concessions. Therefore, measures related to the target's alliance partners are excluded. And second, due to the time-frame of the TIES dataset, I am able to employ a third measure of democracy from Cheibub, Gandhi and Vreeland (2010) to test my theory, though these results are relegated to Appendix B for the sake of brevity.

On the first point, targets have to weigh potentially important costs and benefits as they decide whether to stand firm or back down in the face of sanctions. In the case of allies, this is not really the case. While it is possible that sanctions being enforced on the target will have a ripple effect on the ally's economy or that failing to prevent the enforcement of sanctions will harm their relationship in some capacity, ultimately the stakes are much lower for the ally in those circumstances. In general, they simply do not face the same sort of consequences if the sanctions are imposed, which means there should be no expectation of action by the ally.

To put this in the language of the formal model, I believe that this has a direct influence on the $r$ value, which speaks to the probability that the ally is "resolved" to stand firm with the target if sanctions are imposed. Whereas there is some probability of the ally being 
resolved to intervene in the case of a militarized conflict, thus making $r$ a positive value, I argue that probability is effectively zero across the board. With this assumption, the ally model becomes meaningless. Therefore, this chapter will focus solely on the target.

\section{Analysis}

With some basic information about the data laid out, I again process it in two stages. First, I employ cross-tabulations on the relationship between democracy and compliance with sanction threats, to not only give a basic sense of what the data looks like but also to contrast the results with what was observed in the MCT dataset. Second, I utilize logistic regression, after identifying the relevant control variables I include in the analysis, to demonstrate the outcomes of interest as well as the predicted probabilities for democratic targets.

\section{Preliminary Observations}

This section includes six tables, showing the compliance rates for democracies compared to non-democracies across each of the measures I employ in this chapter. The first three will show the results for dichotomous measures of democracy while the last three will have dyadic structures. I will begin first with Table 4.1, which utilizes the BMR measure of democracy.

Table 4.1: BMR Democracy - TIES Targets

\begin{tabular}{|l|l|l|l|}
\hline & Democracy & Non-Democracy & \\
\hline Compliance & $90(10.6 \%)$ & $48(10.1 \%)$ & $138(10.4 \%)$ \\
\hline Non-Compliance & $756(89.4 \%)$ & $429(89.9 \%)$ & $1185(89.6 \%)$ \\
\hline & 846 & 477 & 1323 \\
\hline
\end{tabular}

Pearson $\chi^{2}=0.6804 ; \operatorname{Pr}=0.409$

The first distinction to draw between these results and those of the MCT dataset are 
the shift in compliance probabilities. While MCT demonstrated a clear and distinct difference in the likelihood that a democratic target would comply with a threat compared to a non-democratic target, that gap is comparatively minuscule here. Democratic targets were $28 \%$ more likely to give in to militarized threats compared to non-democracies, while these results only show a $.5 \%$ difference. Unsurprisingly, the probability that these values are independent comes in at $40.9 \%$, which falls very far short of statistical significance. In addition, democracies are targeted more often than non-democracies, by nearly a two to one ratio, which fits with the predictions of the theory as costs of conflict decrease for the initiator. Finally, there are many more economic threats issued than militarized ones: whereas only 210 unique observations found from 1918 to 2001 in the MCT dataset, there are over 1300 for the period from 1945 to 2001, which is in line with the costs expectation from the model.

Table 4.2: Polity Democracy - TIES Targets

\begin{tabular}{|l|l|l|l|}
\hline & Democracy & Non-Democracy & \\
\hline Compliance & $60(8.3 \%)$ & $56(9.8 \%)$ & $116(9.0 \%)$ \\
\hline Non-Compliance & $662(91.7 \%)$ & $515(90.2 \%)$ & $1177(91.0 \%)$ \\
\hline & 722 & 571 & 1293 \\
\hline
\end{tabular}

Pearson $\chi^{2}=0.8709 ; \operatorname{Pr}=0.351$

The results for Polity in Table 4.2 are generally comparable to the BMR. Democracies are found to comply slightly less often, both when contrasted to non-democracies and across different measures, but the frequency of compliance is roughly the same. ${ }^{2}$ These results are the most likely to be independent based on the Pearson chi-squared test, but even here the results are quite weak.

In summary, there are no clear divisions in how democratic targets respond to threats of economic sanction in the way that was observed with militarized threats. Indeed, in the case of Polity's measure, democratic targets actually concede less often than non-democracies,

\footnotetext{
${ }^{2}$ I do lose the largest number of observations here due to micro-states not being identified in the Polity dataset.
} 
though none of the cross-tabulations demonstrate independence. Therefore, there is little by way of obvious evidence in favor of my theory, and attention must be turned to the statistical analysis where confounding variables can be controlled in order to determine if there is anything to my explanation.

\section{Logistical Regression}

While there is a great deal of overlap in how I perform my statistical analysis from the previous chapter to this one, there are also a number of important differences. For the most part, these come from the choices of control variables that are included in the sanctions models that were not incorporated in the militarized models and vice versa. Therefore, the next section describes the control variables that are utilized in this model, paying particular attention to those that were not in the prior models, before moving on to the actual results from the logistic regressions.

\section{Control Variables}

The TIES dataset provides a number of relevant variables for each observation which likely have some degree of influence on the likelihood of success. ${ }^{3}$ The first of these that I include is whether the sanction threat was conducted under the auspices of an international institution. While each observation identifies who the primary initiator was, it is important to note whether the threat has the backing of multiple collaborators, which is implied by the institutional setting. In particular, it is plausible to believe that multilateral threats are more likely to be successful as they provide the target with fewer means of substitution, such as alternative markets or sources of revenue. Therefore, I include a dichotomous measure for

\footnotetext{
${ }^{3}$ There is one other variable that I coded for this analysis from the TIES dataset but I did not end up using, as it was a perfect predictor of success. It was diplomatic sanctions, which identified whether the threat involved sanctions on a diplomatic level, such as the expulsion of an ambassador or ending diplomatic contact.
} 
whether the threat was embedded in an institution.

Next is an indicator of the type of issue with which the dispute is related. The TIES dataset identifies fifteen different types of issues, with some being more complicated or harder to deal with than others. ${ }^{4}$ Of those identified by the authors, I single out five particular issues as being more likely to face resistance: containing military behavior, regime change, the release of citizens/property/material, territorial disputes, and ending weapons or material proliferation. Due to the large number of issues that could be considered particularly thorny, I combine them into a single dichotomous variable, where the threat involved a "hard issue" or did not. ${ }^{5}$

Another variable that the TIES dataset codes for is the level of commitment from the threatening state. According to the coding scheme, the threat can take on four levels: weak, moderate, strong, or no threat. First, I drop all instances where no threat was observed, in order to focus purely on cases where some sort of threat was involved. I then create a dichotomous variable where either the threat involved at least a moderate level of commitment from the initiator state or did not.

I also include a measure which indicates whether the initiator, in addition to threatening punishment, also offered "carrots," or benefits, to the target. It could be the case that states which are given some sort of side payment in order to change their behavior would be more likely to deviate from their current actions, and it would be worthwhile to include a measure which captures this. TIES includes a variety of different benefits that have been offered, such as straightforward payments and/or aid, concessions in trade, and political concessions.

\footnotetext{
${ }^{4}$ The entire list includes, verbatim: 1) contain political influence; 2) contain military behavior; 3) destabilize regime; 4) release citizens, property, or material; 5) solve territorial dispute; 6) deny strategic materials; 7) retaliate for alliance or alignment choice; 8) improve human rights; 9) end weapons/material proliferation; 10) terminate support of non-state actors; 11) deter or punish drug trafficking practices; 12) improve environmental policies; 13) trade practices; 14) implement economic reforms; and 15) other.

${ }^{5}$ Of course, one can reasonably argue what constitutes an issue that is difficult to resolve, especially in the context of economic sanctions. The results for my analysis do not change either if this variable is dropped from the models, or is substituted for a series of dichotomous variables covering each individual issue type.
} 
While there may be some degree of variance for which carrots are more successful, I simply include a dichotomous measure for whether any carrots are being offered.

Two related variables that I coded for were the anticipated costs of imposed sanctions for both the target and the sender. For the target, the logic is straightforward: if the costs are high enough in comparison to the benefit of maintaining course, it should prevent the target from acting in a resilient manner. The sender logic is slightly more complicated, but just as important: it may be the case that by threatening to damage oneself through the imposition of the sanctions, it can send a credible signal to the target that the initiator is highly resolved, to the point of being willing to incur high costs by following through on the threat. For both of these measures, TIES identifies whether the costs are predicted to be unknown, minor, major, or severe, which I turned into a dichotomous measure where the anticipated costs are major or higher. ${ }^{6}$

The specificity of the threat is also included in the TIES dataset, identifying whether the demands of the initiator are clear or not. While the target may wish to comply with the initiator's demands, it may not be obvious what needs to be done in order to avoid having the sanctions imposed, thus leading to the threat ultimately failing. Per TIES, all threats are either identified as ambiguous or clear, which I again turn into a dichotomous measure.

Moving beyond variables that are collected in the TIES dataset, I have included a variety of measures that cover a number of other related issues. First, I incorporate a measure of preference similarity between the initiator and the target. As Bailey, Strezhnev and Voeten (N.d.) demonstrate, previous formulations of preferences have been flawed, which has resulted in inappropriate measurements. They correct this problem by creating a ideal point estimation based on United Nations voting to evaluate how close or far apart two states are in their preferences.

\footnotetext{
${ }^{6}$ The TIES dataset also includes a prediction of economic costs for the initiator and target. However, due to both issues of missing data and different types of currencies involved, they were not included in the analysis.
} 
Next is a measure of economic interdependence between the sender and the target. Given that it is not clear whether threats directed by a more dependent state toward the less dependent state are more credible due to the damage, I utilize either joint measures of dependence or the lowest level of dependence between the two states. The former measure comes from Barbieri and Peters (2003), and is calculated:

$$
T S A L=\sqrt{\frac{\text { TotalTrade }}{\text { Target'sShareofTrade }} * \frac{\text { TotalTrade }}{\text { Initiator'sShareofTrade }}}
$$

The alternative measure, which identifies the lowest level of dependence between the target and initiator, comes from Oneal and Russett (1997) and is calculated by first taking the total amount of trade between the two states and dividing it by the total gross domestic product of each state separately. Whichever value is lower is then taken as the lowest level of interdependence. ${ }^{7}$

Finally, I include two variables described in the previous chapter, contiguity and CINC ratio, to get at proximity and power dyanamics, respectively. For contiguity, it may be the case that states that are close together expect to interact many times going into the future, and thus are more or less likely to make concessions as a means of preventing future threats from being issued. With power dynamics, while the threat is being posed as an economic one per this analysis, it may also be the case that the target is considering the power differential between itself and the initiator, particularly if conflict is on the horizon should the target choose not to concede.

\section{Results}

For each of the three measures of democracy, I provide below four separate models. The variance comes along the dimensions of the costs for the target and the type of interdepen-

\footnotetext{
${ }^{7}$ I also attempted to include the lowest measure of contract intensive economy for the dyad, per Mousseau (2013). However, this caused the indicator of initiator's democracy to drop out of the models and lose observations. While the results still remain quite favorable to my explanation, I have excluded these models from the main body of the paper. Theese results can be found in Appendix B.
} 
dence being measured. In the case of the former, I run the models either including the target costs as a variable or only looking at those observations where the target costs $\left(T_{\text {Cost }}\right)$ are expected to be high. The reason for the latter is that we might expect the results to only hold in cases where the targets are highly concerned about the costs that they have to pay; otherwise, it might not register as something that needs to be dealt with, particularly by the domestic groups that will be punished by the sanctions. For interdependence, this is simply to account for the different measures that I employ in the analysis, both TSAL and low dependence.

In addition, and just as in the previous chapter, I have clustered the standard errors at the dyad level to account for the same initiator and target having repeated threats. Table 4.3 provides the results from the BMR measure of democracy, with non-substantive control variables excised for space. ${ }^{8}$

As the theory would predict, democracies are correlated with concessions across all four of these models $(\mathrm{p}<0.05)$. Also of note, both sender and target costs are found to be statistically significant, as high sender costs make the target less likely to concede while high target costs lead to more concessions, conclusions that are in line with the findings of Bapat, Heinrich, Kobayashi and Morgan (2013). This would seem to suggest that targets are motivated to avoid costs that impose high costs while risking threats that hurt the sender, perhaps indicating that those demands are less credible. In addition, threats are institutional in nature are more likely to succeed, possibly due to those threats involving more cooperation among sanctioning states.

In contrast, there is much more division occurring in the Polity results shown in Table 4.4. Here we see that only two of the four models reach traditional levels of significance

\footnotetext{
${ }^{8}$ See Appendix B for the complete tables, as well as the results for the CGV measure of democracy. Furthermore, as my theory does not predict that there should be any meaningful difference in dyadic measures, apart from those involving democratic targets being more likely to concede, I do not provide the results in the main body of the dissertation. However, they are also available in Appendix B, following the complete, main tables.
} 
Table 4.3: BMR Dichotomous Measure - TIES

\begin{tabular}{|c|c|c|c|c|}
\hline VARIABLES & $\begin{array}{c}(1) \\
\text { TSAL } \\
\text { All Obs }\end{array}$ & $\begin{array}{c}(2) \\
\text { Low Depend } \\
\text { All Obs }\end{array}$ & $\begin{array}{c}(3) \\
\text { TSAL } \\
\text { High } T_{\text {Cost }}\end{array}$ & $\begin{array}{c}(4) \\
\text { Low Depend } \\
\text { High } T_{\text {Cost }}\end{array}$ \\
\hline Target Democracy & $\begin{array}{c}0.881^{* *} \\
(0.418)\end{array}$ & $\begin{array}{c}0.844^{* *} \\
(0.409)\end{array}$ & $\begin{array}{c}1.906^{* *} \\
(0.785)\end{array}$ & $\begin{array}{c}1.716^{* *} \\
(0.747)\end{array}$ \\
\hline Initiator Democracy & $\begin{array}{c}0.453 \\
(0.801)\end{array}$ & $\begin{array}{c}0.241 \\
(0.794)\end{array}$ & $\begin{array}{c}0.464 \\
(0.934)\end{array}$ & $\begin{array}{c}0.196 \\
(0.942)\end{array}$ \\
\hline Carrots & $\begin{array}{l}-0.537 \\
(0.930)\end{array}$ & $\begin{array}{l}-0.318 \\
(0.940)\end{array}$ & $\begin{array}{l}-0.638 \\
(0.786)\end{array}$ & $\begin{array}{l}-0.440 \\
(0.783)\end{array}$ \\
\hline Commitment & $\begin{array}{c}0.245 \\
(0.498)\end{array}$ & $\begin{array}{c}0.556 \\
(0.586)\end{array}$ & $\begin{array}{l}-1.071 \\
(0.779)\end{array}$ & $\begin{array}{l}-0.711 \\
(0.906)\end{array}$ \\
\hline Specificity & $\begin{array}{c}2.226^{* * *} \\
(0.664)\end{array}$ & $\begin{array}{c}2.217^{* * *} * \\
(0.642)\end{array}$ & $\begin{array}{l}1.678 \\
(1.157)\end{array}$ & $\begin{array}{l}1.595 \\
(1.168)\end{array}$ \\
\hline Institution & $\begin{array}{c}1.128^{* * *} \\
(0.422)\end{array}$ & $\begin{array}{l}1.055^{* *} \\
(0.455)\end{array}$ & $\begin{array}{c}2.191^{* * *} \\
(0.640)\end{array}$ & $\begin{array}{c}2.089^{* * *} \\
(0.723)\end{array}$ \\
\hline Interdependence & $\begin{array}{l}-1.630 \\
(2.199)\end{array}$ & $\begin{array}{l}-0.0796 \\
(16.35)\end{array}$ & $\begin{array}{l}-5.041 \\
(3.962)\end{array}$ & $\begin{array}{l}-33.21 \\
(31.63)\end{array}$ \\
\hline Sender Costs & $\begin{array}{c}-1.938^{* * *} \\
(0.452)\end{array}$ & $\begin{array}{c}-2.044^{* * *} \\
(0.468)\end{array}$ & $\begin{array}{c}-2.004^{* * *} \\
(0.474)\end{array}$ & $\begin{array}{c}-2.082^{* * * *} \\
(0.475)\end{array}$ \\
\hline Target Costs & $\begin{array}{c}1.027^{* *} \\
(0.411)\end{array}$ & $\begin{array}{l}1.065^{* *} \\
(0.418)\end{array}$ & & \\
\hline Constant & $\begin{array}{c}-5.661^{* * *} \\
(1.122)\end{array}$ & $\begin{array}{c}-5.818^{* * *} \\
(1.165)\end{array}$ & $\begin{array}{c}-3.565^{* *} \\
(1.560)\end{array}$ & $\begin{array}{c}-3.389^{* *} \\
(1.527)\end{array}$ \\
\hline Observations & 754 & 743 & 357 & 345 \\
\hline
\end{tabular}

for the target democracy indicator while the other two achieve weak significance. However, whereas the weakest models had previously been included all observations, this is not the case here, as the two that fail to reach standard levels of significance are of the abrogated observations where the target costs are high. On top of those findings, the same pattern holds as from the previous tables, with sender and target costs as well as institutional threats emerging as significant.

Moving away from logistic regression outputs and towards more readily interpretable results, ?? provides the predicted probabilities graphs for the four BMR models from 4.3. In addition, 4.5 has the point estimates from those graphs to allow more direct comparisons of the results. 
Table 4.4: Polity Dichotomous Measure - TIES

\begin{tabular}{|c|c|c|c|c|}
\hline VARIABLES & $\begin{array}{c}(1) \\
\text { TSAL } \\
\text { All Obs }\end{array}$ & $\begin{array}{c}(2) \\
\text { Low Depend } \\
\text { All Obs }\end{array}$ & $\begin{array}{c}(3) \\
\text { TSAL } \\
\text { High } T_{\text {Cost }}\end{array}$ & $\begin{array}{c}(4) \\
\text { Low Depend } \\
\text { High } T_{\text {Cost }}\end{array}$ \\
\hline Target Democracy & $\begin{array}{c}0.756^{* *} \\
(0.329)\end{array}$ & $\begin{array}{c}0.726^{* *} \\
(0.319)\end{array}$ & $\begin{array}{l}1.251^{*} \\
(0.645)\end{array}$ & $\begin{array}{l}1.095^{*} \\
(0.617)\end{array}$ \\
\hline Initiator Democracy & $\begin{array}{c}0.543 \\
(0.760)\end{array}$ & $\begin{array}{c}0.348 \\
(0.741)\end{array}$ & $\begin{array}{c}0.294 \\
(0.838)\end{array}$ & $\begin{array}{c}0.0487 \\
(0.822)\end{array}$ \\
\hline Carrots & $\begin{array}{l}-0.374 \\
(0.910)\end{array}$ & $\begin{array}{l}-0.143 \\
(0.925)\end{array}$ & $\begin{array}{l}-0.495 \\
(0.824)\end{array}$ & $\begin{array}{l}-0.290 \\
(0.801)\end{array}$ \\
\hline Commitment & $\begin{array}{c}0.357 \\
(0.666)\end{array}$ & $\begin{array}{c}0.716 \\
(0.844)\end{array}$ & $\begin{array}{l}-1.120 \\
(0.777)\end{array}$ & $\begin{array}{l}-0.816 \\
(0.894)\end{array}$ \\
\hline Specificity & $\begin{array}{c}2.012^{* * *} \\
(0.686)\end{array}$ & $\begin{array}{c}2.036^{* * *} \\
(0.692)\end{array}$ & $\begin{array}{c}1.532 \\
(1.178)\end{array}$ & $\begin{array}{c}1.383 \\
(1.179)\end{array}$ \\
\hline Institution & $\begin{array}{c}1.167^{* * *} \\
(0.434)\end{array}$ & $\begin{array}{l}1.042^{* *} \\
(0.474)\end{array}$ & $\begin{array}{c}2.131^{* * *} \\
(0.604)\end{array}$ & $\begin{array}{c}2.015^{* * *} \\
(0.678)\end{array}$ \\
\hline Interdependence & $\begin{array}{l}-0.402 \\
(2.170)\end{array}$ & $\begin{array}{c}8.853 \\
(16.13)\end{array}$ & $\begin{array}{l}-3.192 \\
(3.872)\end{array}$ & $\begin{array}{l}-17.01 \\
(30.63)\end{array}$ \\
\hline Sender Costs & $\begin{array}{c}-1.799^{* * *} \\
(0.489)\end{array}$ & $\begin{array}{c}-1.884^{* * *} \\
(0.507)\end{array}$ & $\begin{array}{c}-1.754^{* * *} \\
(0.530)\end{array}$ & $\begin{array}{c}-1.805^{* * *} \\
(0.519)\end{array}$ \\
\hline Target Costs & $\begin{array}{l}1.053^{* *} \\
(0.437)\end{array}$ & $\begin{array}{l}1.063^{* *} \\
(0.451)\end{array}$ & & \\
\hline Constant & $\begin{array}{c}-5.682^{* * *} \\
(1.134)\end{array}$ & $\begin{array}{c}-5.927^{* * *} \\
(1.249)\end{array}$ & $\begin{array}{c}-2.914^{* *} \\
(1.442)\end{array}$ & $\begin{array}{c}-2.734^{* *} \\
(1.394)\end{array}$ \\
\hline Observations & 749 & 737 & 354 & 342 \\
\hline
\end{tabular}

The results are quite powerful: starting with the full models, going from a non-democracy to a democracy makes it about twice as likely that the target will end up making concessions following merely the threat of economic sanctions, with a post-estimation test confirming that the results are distinct $(\mathrm{p}<0.05)$. While the overall levels are low $(\sim 11 \% \mathrm{v} . \sim 5 \%)$, especially when compared to the results from the militarized section, there is nonetheless a solid difference, though the results are only significant with the TSAL model. However, shifting to the models where the threats only involve high costs to the target, the split becomes even more distinct, as democratic targets become three to four times as likely to make concessions. Post-estimation tests again confirm that these probabilities are distinct $(\mathrm{p}<0.01)$. 
Figure 4.1: BMR Target Measures - TIES

\section{Marginal Effect of Democracy - BMR}
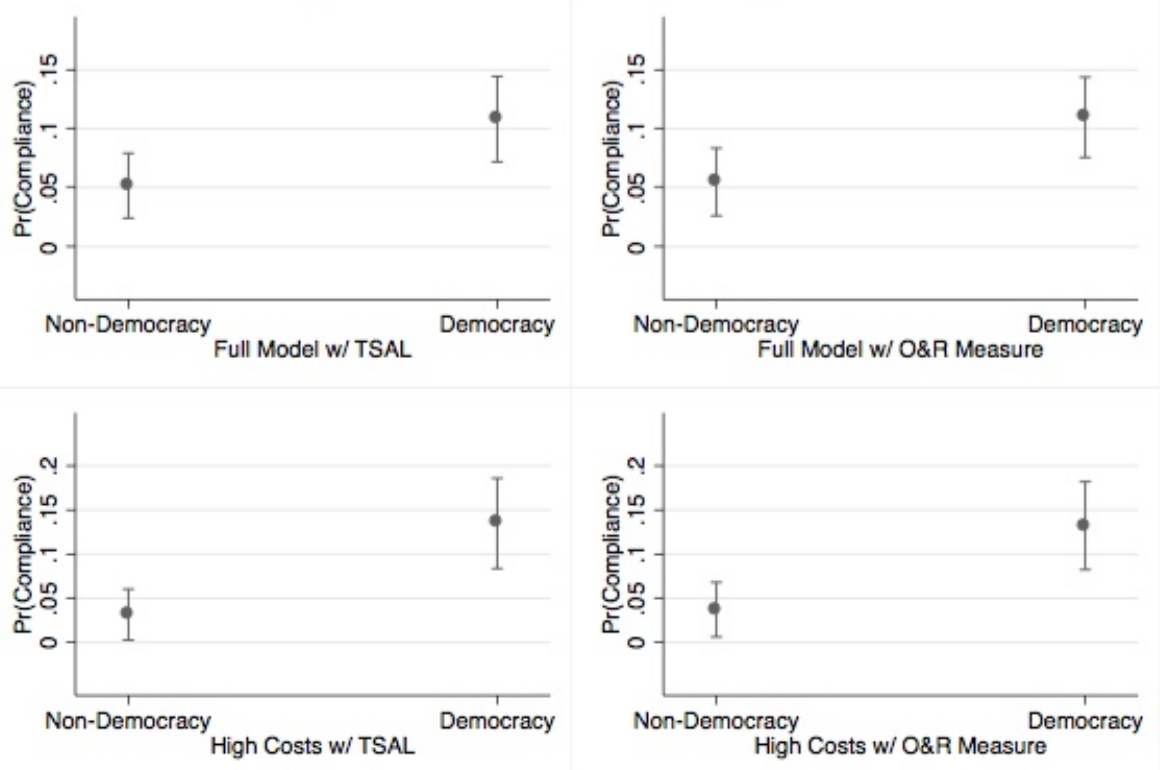

Table 4.5: BMR Predicted Probabilities - TIES

\begin{tabular}{|l|c|c|}
\hline & Democracy & Non-Democracy \\
\hline Full w/TSAL & 10.8 & 5.2 \\
\hline Full w/Low Depend & 11.0 & 5.5 \\
\hline High Cost w/TSAL & 13.5 & 3.2 \\
\hline High Cost w/ Low Depend & 13.2 & 3.7 \\
\hline
\end{tabular}

The results from Polity, in comparison, are relatively weak, as shown in Figure 4.2 and Table 4.6, though they still provide evidence in favor of my theory. Further, compared to the BMR results, there are some important similarities and differences which are worth expanding on. While the full Polity models are very similar to what BMR demonstrated, with about a $10.5 \%$ probability of a democracy conceding compared to $6 \%$ for a non-democracy, the wider gaps of the high cost models are not replicated to nearly the same extent. As the graphs and table show, the probability of a democracy conceding ticks up slightly but there is no noticeable change with how non-democracies react. Unlike the BMR model, the post-estimation tests only demonstrate standard levels of independence in the first three 
Figure 4.2: Polity Target Measures - TIES
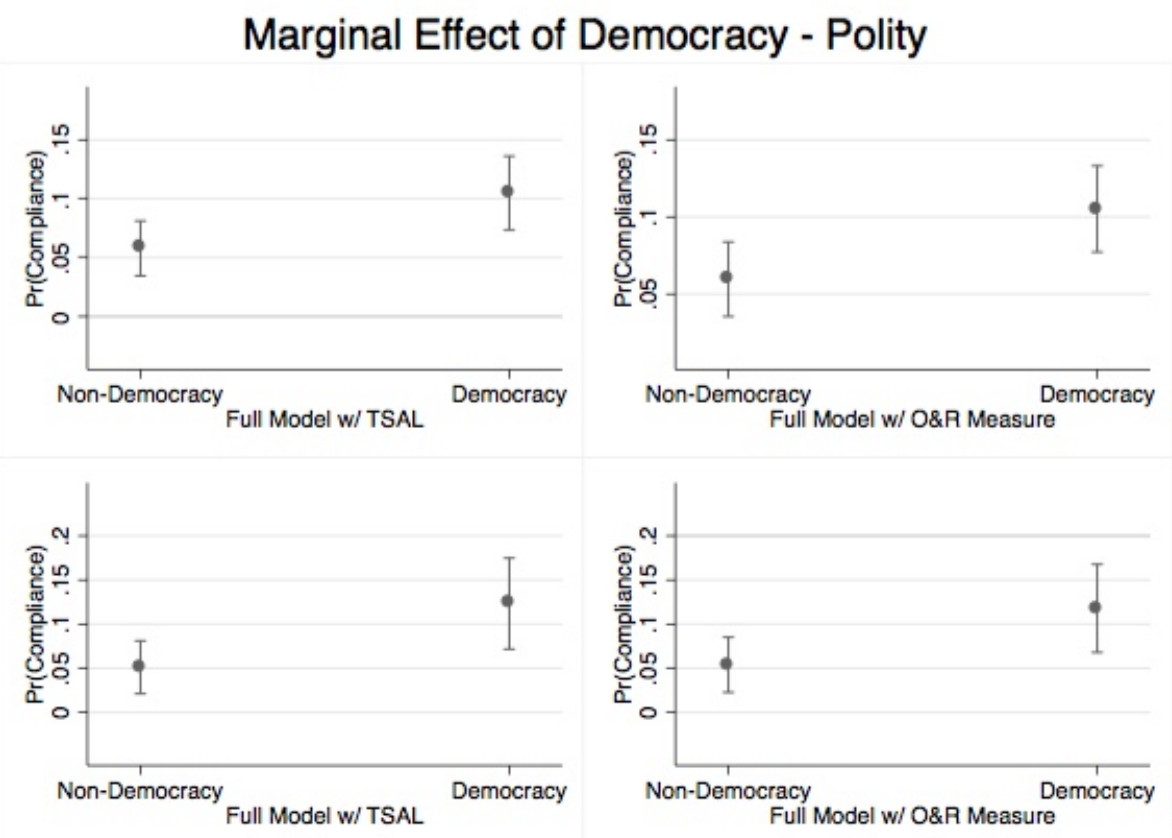

Table 4.6: Polity Predicted Probabilities - TIES

\begin{tabular}{|l|c|c|}
\hline & Democracy & Non-Democracy \\
\hline Full w/TSAL & 10.5 & 5.8 \\
\hline Full w/Low Depend & 10.5 & 6.0 \\
\hline High Cost w/TSAL & 12.3 & 5.1 \\
\hline High Cost w/ Low Depend & 11.8 & 5.4 \\
\hline
\end{tabular}

models $(\mathrm{p}<0.05)$, while the final one is only weakly distinct $(\mathrm{p}<0.1)$.

In summary, the full models, across all three measures of democracy appear to tell a similar story: democratic targets concede more readily than non-democratic targets, at about a 2:1 rate. In contrast, while the BMR and CGV measures show a widening gap between democracies and non-democracies when the scope is narrowed to cases where the target expects to pay high costs for being sanctioned, the Polity measure held relatively steady, with democracies being slightly more likely to concede compared to all threats while there was little change in the response rates of the non-democracies. While it is worth recognizing that threats of economic sanctions are generally much less likely to succeed that 
those involving military force, these findings are still squarely in line with the predictions of my theory.

\section{Dyadic Measures}

Though the dichotomous results indicate that there is a strong relationship between democratic targets and concessions, it is possible that there is something about threats from particular kinds of initiators which are driving these results. As Cox and Drury (2006) and Lektzian and Souva (2007) argue, democratic peace holds in the context of the imposition of economic sanctions, but this tells us very little about whether threats are being issued between democracies and how this might bias the results.

In order to evaluate whether there is something to this concern, this section recodes the individual initiator and target variables into a single indicator for the dyad. I will begin by first progressing through the distribution of dyad types along with the concession rates for each pairing. 4.7 below provides the results from the BMR measure of democracy.

Table 4.7: BMR Democracy - TIES Dyadic

\begin{tabular}{|l|c|c|c|c|c|}
\hline & $\sim$ Demo/ Demo & Demo/ Demo & $\sim$ Demo/Demo & Demo/Demo & \\
\hline Compliance & $5(9.3 \%)$ & $25(7.3 \%)$ & $5(4.1 \%)$ & $58(9.7 \%)$ & $93(8.3 \%)$ \\
\hline Non-Compliance & $49(90.7 \%)$ & $316(92.7 \%)$ & $116(95.9 \%)$ & $540(90.3 \%)$ & $1021(91.7 \%)$ \\
\hline & 54 & 341 & 121 & 598 & 1114 \\
\hline
\end{tabular}

Pearson $\chi^{2}=5.2986 ; \operatorname{Pr}=0.151$

The first thing to note is the differences in how threats of economic sanctions are employed by democracies compared to non-democracies, regardless of the target's type, as they make up $84.3 \%$ of observed threats. This is not particularly surprising, as it has been argued by others that democracies view economic sanctions as a particularly useful tool of statecraft that does not require significant expenditure of blood and treasure. ${ }^{9}$ And of all types of

\footnotetext{
${ }^{9}$ Lenway (1988), for example, notes the implicit nature of this argument from the works of Baldwin (1985) and Hufbauer, Schott and Elliott (1990).
} 
threats, the most successful ones come from democracies against fellow democracies, at 9.7\%. But overall, there are no major differences that jump out from these groupings.

Table 4.8: Polity Democracy - TIES Dyad

\begin{tabular}{|l|c|c|c|c|c|}
\hline & $\sim$ Demo/ Demo & Demo/ Demo & $\sim$ Demo/Demo & Demo/Demo & \\
\hline Compliance & $8(10 \%)$ & $34(8.5 \%)$ & $2(1.6 \%)$ & $46(9.1 \%)$ & $90(8.1 \%)$ \\
\hline Non-Compliance & $72(90 \%)$ & $366(91.5 \%)$ & $127(98.4 \%)$ & $457(90.9 \%)$ & $1022(91.9 \%)$ \\
\hline & 80 & 400 & 129 & 503 & 1112 \\
\hline
\end{tabular}

Pearson $\chi^{2}=12.0316 ; \operatorname{Pr}=0.007$

We once again see that democracies issue the most threats, $81.2 \%$ according to the Polity measure in Table 4.8. Here, it appears that non-democratic threats against non-democratic targets are the most successful, followed closely by inter-democratic threats, and democratic demands directed toward non-democracies. While each of these categories are roughly comparable, threats by non-democracies against democracies are noticeably unsuccessful, with only $1.6 \%$ of such threats ultimately leading to concessions.

Looking across both measures, there are no clear divisions in concession rates in the manner observed with militarized threats. However, these results do cast some doubt on the findings of Cox and Drury (2006), as democracies often threaten to sanction one another, though any theorizing for why this disjuncture appears is beyond the scope of this project. But there does not appear to be any obvious pattern which could explain why we see democracies concede at higher rates, at least with the preliminary cross-tabulations.

While a useful first cut, the next step is to analyze the dyadic data in conjunction with other variables to control for confounding influences. Table 4.9 combines the results for all three measures of democracy with all cases of economic sanction threats, while Table 4.10 is limited only to cases where the target was expected to pay high costs should the sanctions be imposed. In addition, Figures 4.4 and 4.5 provide the predicted probabilities for the full and high cost models, respectively. Due to the small number of cases where non-democracies threaten one another with economic sanctions, the democratic/democratic dyad is used as 
the baseline category for these tables, while for reasons of space, I am only providing the logistic regression outputs for the dyadic categories. ${ }^{10}$

Table 4.9: Dyadic Measures of Democracy, All Obs - TIES

\begin{tabular}{ccccc}
\hline \multirow{2}{*}{ VARIABLES } & $(1)$ & $(2)$ & $(3)$ & $(4)$ \\
& TSAL & O\&R & TSAL & O\&R \\
& BMR & BMR & Polity & Polity \\
\hline \multirow{4}{*}{ Demo/ Demo } & -0.0428 & 0.0664 & 0.253 & 0.307 \\
& $(1.137)$ & $(1.176)$ & $(0.782)$ & $(0.789)$ \\
Demo/ Demo & $-0.987^{* *}$ & $-0.940^{* *}$ & $-0.988^{* * *}$ & $-0.951^{* * *}$ \\
& $(0.429)$ & $(0.419)$ & $(0.345)$ & $(0.337)$ \\
$\sim$ Demo/Demo & -1.053 & -0.805 & - & - \\
& $(1.107)$ & $(1.103)$ & & 710 \\
Observations & 754 & 743 & 720 & \\
\hline \multicolumn{5}{c}{ Robust standard errors in parentheses } \\
$* * *$ & $\mathrm{p}<0.01, * *$ p $<0.05, *$ p $<0.1$ &
\end{tabular}

Table 4.10: Dyadic Measures of Democracy, High Target Cost Obs - TIES

\begin{tabular}{|c|c|c|c|c|}
\hline VARIABLES & $\begin{array}{c}(1) \\
\text { TSAL } \\
\text { BMR }\end{array}$ & $\begin{array}{c}(2) \\
\text { O\&R } \\
\text { BMR }\end{array}$ & $\begin{array}{c}\text { (3) } \\
\text { TSAL } \\
\text { Polity }\end{array}$ & $\begin{array}{c}\text { (4) } \\
\text { O\&R } \\
\text { Polity }\end{array}$ \\
\hline$\sim$ Demo/ Demo & $\begin{array}{l}-0.710 \\
(1.292)\end{array}$ & $\begin{array}{c}-0.593 \\
(1.309)\end{array}$ & $\begin{array}{c}0.199 \\
(0.862)\end{array}$ & $\begin{array}{c}0.245 \\
(0.857)\end{array}$ \\
\hline Demo/ Demo & $\begin{array}{c}-2.256^{* * *} \\
(0.832)\end{array}$ & $\begin{array}{c}-2.022^{* *} \\
(0.797)\end{array}$ & $\begin{array}{c}-1.987^{* * *} \\
(0.746)\end{array}$ & $\begin{array}{r}-1.763^{* *} \\
(0.721)\end{array}$ \\
\hline$\sim$ Demo/Demo & $\begin{array}{l}-1.287 \\
(1.308)\end{array}$ & $\begin{array}{c}-0.957 \\
(1.346)\end{array}$ & - & - \\
\hline Observations & 357 & 345 & 333 & 323 \\
\hline
\end{tabular}

Starting with the results from the tables, the only category that is noticeably different than the paired democratic dyad is that of the democratic initiator with non-democratic target, which is always less likely to concede across all twelve models, both with all observations and only high target cost observations. ${ }^{11}$ In other words, we can hold the initiator

\footnotetext{
${ }^{10}$ The full model has the carrots, commitment, specificity, sender and target costs, institution, and "hard issue" dichotomous variables, in addition to UN ideal point estimates, CINC ratios, and interdependence measures. The full models are available in Appendix B.

${ }^{11}$ It should be noted that the Polity indicator of a non-democratic initiator threatening a democratic target predicts failure perfectly both Table 4.13 and 4.14 , which is why those spaces are left blank.
} 
constant as a democracy, vary the target between a democracy and a non-democracy, and find evidence that the former is more likely to result in concessions than the latter.

Figure 4.3: Full Models, All Measures - TIES

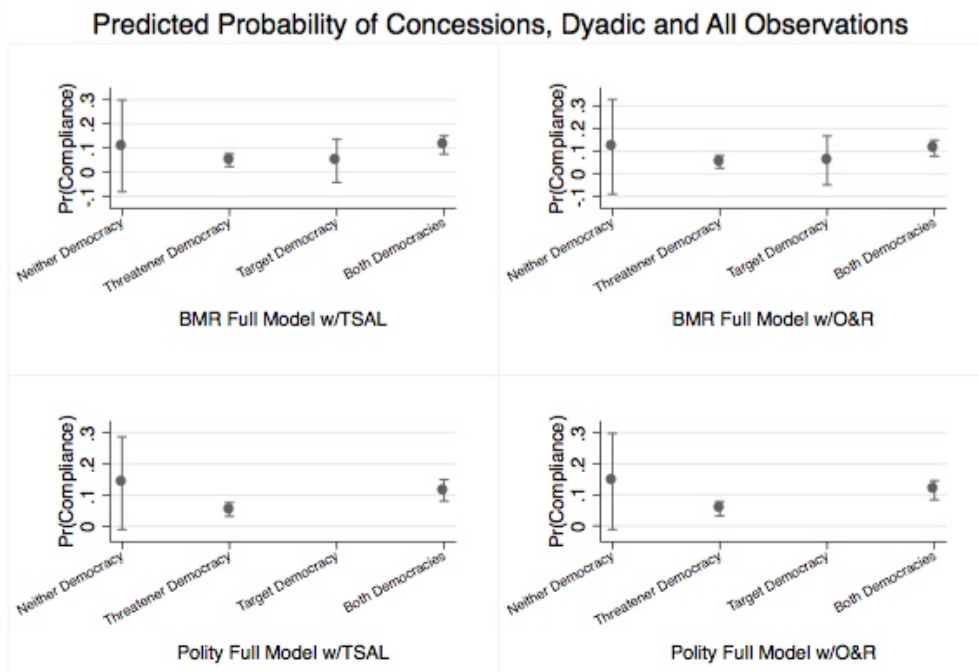

These findings also come across in the predicted probabilities graphs of Figures 4.3 and 4.4. While the confidence intervals around the observations with non-democratic initiators are comparatively very large, and thus making it difficult to say much about how they compare with the dyads that have democratic initiators, the narrow intervals around the democratic/non-democratic and democratic/democratic pairings allow for a more direct comparison. Similar to the dichotomous results, the democratic/non-democratic dyads concede with a probability that is roughly half that of the democratic/democratic dyads, which is approximately what was found in the dichotomous measures and very different than the cross-tabulations. These findings once again provide evidence in line with the expectations of the theory.

Though the evidence from dyads involving threats from non-democratic initiators is problematic, what emerges from the democratic initiator categories is very clear: democratic targets concede at higher rates than non-democratic targets, while holding constant a demo- 
Figure 4.4: High Cost Models, All Measures - TIES

Predicted Probability of Concessions, Dyadic and High Cost Observations
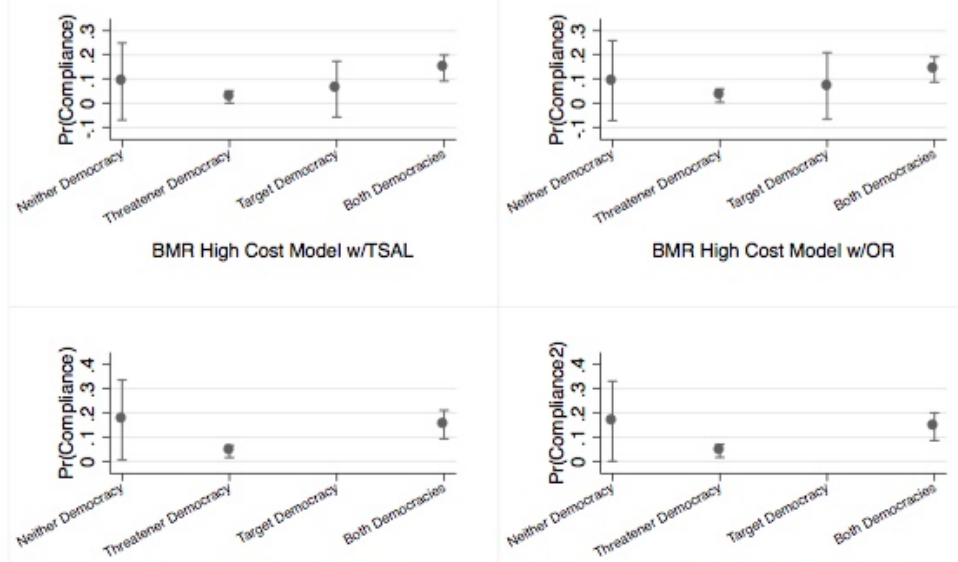

Polity High Cost Model w/TSAL

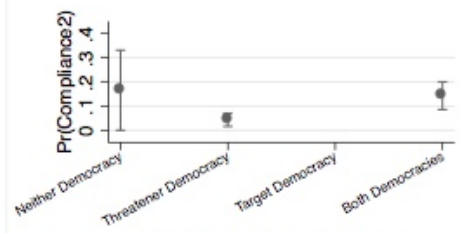

Polity High Cost Model w/O\&R

cratic initiator. While this evidence is limited only to cases of democratic initiators, it is nonetheless further confirmation that my theory appears to be validated.

\section{Types of Threats}

Another potential limitation of this analysis comes from the types of threats that democracies have to face compared to those from non-democracies. While the logistic regression includes a variable for the numerous types of hard issues that may be at the heart of a sanction threat, that might not get at a larger selection issue which could bias the results. In particular, if democracies face more difficult issues significantly less often than non-democracies do, this could be what is driving the observation that democracies concede more readily to threats, rather than anything related to democracies themselves.

To address this possibility, I have broken down the types of threats that democracies and non-democracies face into those which are "hard" and those that are "easy," based on the coding scheme listed in the Control Variables section above. For the sake of completion, I provide these comparisons for each of the measures of democracy, first with BMR, then with 
Polity. These results are available in 4.11 .

Table 4.11: Threat Types by Target - TIES

\begin{tabular}{|l|c|c|}
\hline & BMR: Hard/Easy & Polity: Hard/Easy \\
\hline Democracy & $82 / 764$ & $73 / 649$ \\
\hline Non-Democracy & $150 / 327$ & $163 / 408$ \\
\hline
\end{tabular}

What this indicates is that democracies do, indeed, appear to face difficult threats much less often than non-democracies: whereas approximately one out of every three threats qualify as "hard" issues for non-democracies, this is closer to one out of every ten for democracies. This does raise questions of potential bias within the main analysis, assuming that democracies are responding to these difficult threats at significantly lower rates. However, this is an issue for analysis in its own right, and Table 4.12 below shows the concession rates to threats that meet the "hard" issue metric.

Table 4.12: Hard Issue Compliance Rate - TIES

\begin{tabular}{|l|l|l|}
\hline & BMR & Polity \\
\hline Democracy & $7.3 \%$ & $4.1 \%$ \\
\hline Non-Democracy & $4.6 \%$ & $6.1 \%$ \\
\hline
\end{tabular}

These results are very mixed. While the BMR indicator shows democracies conceding more readily to threats involving difficult issues, the Polity measurement shows the opposite. Combined with the findings of the previous table, this means that while democracies have to contend with threats over thornier issues less often, whether they concede more or less often is questionable. In essence, there is nothing to definitively say that democracies act significantly more differently than non-democracies do in the context of threats over more difficult issues.

A separate issue to consider from all of these results, however, is what the goal of the sanctions, if imposed, would be. Per Pape (1997), economic sanctions do not necessarily have the goal of causing the target to change their behavior; rather, they can be imposed 
with the goal of weakening the target so that they can be defeated in a military conflict more easily. ${ }^{12}$ If this is true, this could explain why we observe non-democracies being threatened as often as we do: the initiators, often democracies, seek to utilize economic sanctions to undermine the target's military power, and never intend for the threat of economic sanction to work on its own. Given these additional strategic considerations, greater caution should be considered in reading too much into these results, given that we cannot speak to the broader intentions of the threatening parties.

\section{Conclusion}

Just as with militarized threats, the results of the economic sanctions data provide evidence that democracies concede to threats more readily than non-democracies. These findings do not extend to dyadic relations, which comes as a mild surprise, given that both Cox and Drury (2006) and Lektzian and Souva (2007) have argued that democracies are less willing to impose sanctions on one another. Though outside of the scope of this project to examine why this is the case, future work will expand on this observation and theorize about the disconnect between these findings. ${ }^{13}$ Once the focus shifts purely to the targets alone, the results stack up well with those of the militarized variety.

Starting first with the models that included all observations, it was consistently observed that democratic targets concede more readily than non-democracies, with the former backing down just over $10 \%$ of the time while the latter caved to between 5 and $6 \%$ of the threats they faced. The level of statistical significance for these findings varied to a minimal extent, with four of the six achieving standard levels $(\mathrm{p}<0.05)$ while the remaining two only reached weak significance $(\mathrm{p}<0.1)$. In general, this provides strong evidence in favor of my first

\footnotetext{
${ }^{12}$ An alternative view on this could also be that once the target has been sufficiently weakened, they become a more viable target for threats of military force, rather than only its use.

${ }^{13}$ See Scroggs and Poznansky (2017) for more details on how democracies and non-democracies initiate threats of sanction.
} 
hypothesis.

The results from the second set of models, looking only at cases where the target faced high costs if they would ultimately be sanctioned, were generally quite comparable, as democracies once again were found to be conceding at higher rates. This was most powerfully demonstrated with the BMR measure of democracy, where democracies conceded $13.3 \%$ of the time in comparison to $2.8 \%$ for non-democracies, nearly a five to one ratio, and all of them reaching standard levels of significance $(\mathrm{p}<0.05)$. The results were not nearly as generous with the Polity measure, however, as both models only featured a mild uptick in the probability of a democratic target conceding and a small decrease in the likelihood of non-democratic concessions. Further, these findings were only weakly significant $(\mathrm{p}<0.1)$. Overall, however, these conclusions are very much in line with the predictions of my second hypothesis, and are generally a validation of the first as well.

Admittedly, threats of economic sanction are a very different type of event than one involving military force, as they involve very different costs for both the initiating state and the target. Nonetheless, they share very important similarities insofar as they involve demands being issued by one side against the other, typically with a clear ultimatum that tells the target what they must do to avoid punishment. They also can provide opportunities for the target to send costly signals of resolve, as a means of indicating to the initiator that they are willing to suffer the costs of having the sanctions imposed. And, I argue, it is more readily possible for the initiator to observe the level of discontent on the part of the domestic groups that will suffer the most within a democracy than a non-democracy, and that when those costs are particularly high, the target is more likely to concede.

The statistical evidence provided in this chapter is in line with the expectations of my theory. Democratic targets are, all else being equal, more likely to concede to threats of sanction that are non-democratic targets. Further, this gulf seems to only widen when the costs for the target are particularly acute. While not performed in this project, case studies 
that process trace the relationship between the democratic/non-democratic nature of the target with the probability of concessions would be a valuable next step, to identify the particular mechanisms driving why we see democracies giving in so much more often than their non-democratic counterparts.

While the next section of this dissertation will examine the processes that drive democratic concessions in the case of militarized threats, future research on sanction case studies are a natural next step for those interested in the particulars of prominent threats of economic sanctions. Since most research has tended to focus only on cases where sanctions were applied, taking a step back and finding out what happens when threats are effective is an avenue of research ripe for study. 


\section{Chapter 5}

\section{Case Studies: The Munich and Suez}

\section{Crises}

In this chapter, I employ two case studies, that of the Munich and Suez Crises, to demonstrate how my theory works in major, historical events involving threats of military force. While the statistical evidence from Chapter 3 provides strong corroboration that democratic targets and those states with major democratic allies concede to militarized threats at higher rates than do others, these results do not speak to the specific mechanisms that are at play in these observations. Through in-depth process tracing of these case studies, I will show how limitations related to democratic states shape the outcome of these cases, highlighting the necessity of historical documentation, case studies, and qualitative methodology.

I will begin by first briefly outlining my approach to case study research and the importance of combining qualitative tools with quantitative methods. I will also touch on the issue of case selection criteria, and how the cases employed in this dissertation were chosen. With the groundwork laid, I will move on to the cases themselves, starting first with the Munich Crisis before proceeding to Suez. I then conclude by recapitulating my findings and connecting my qualitative results to my quantitative conclusions. 


\section{The Added Value of Case Studies}

What contributions can case studies make to our goals of causal inference? There are significant disagreements in political science as to what qualitative methods are capable of providing, a topic that I am not attempting to persuade on one way or the other. However, it is important that I specify what I am attempting to glean from my case studies, in order to manage expectations for this chapter and set benchmarks for what I hope to achieve.

There are extreme positions to be found on each side of the argument. For some, case studies are truly the only real means of causal inference, as it is only through in-depth tracing of a process of onset to conclusion that we say with certainty that a particular independent variable "caused" a specific outcome to take place. Without such an analysis, we are at best observing correlations, which tells us nothing of causality.

Alternatively, one could claim that case studies are merely isolated observations, and that anything we learn from those cases that we examine cannot be applied to other situations. Worse, given the fundamental problem of causal inference, while we are able to observe what happened in the case, our inability to see what took place in an alternative world where the independent variable was not present limits our confidence that there is truly a causal relationship. Taken to its logical conclusion, this perspective would contend that a case study can, at best, provide a convincing narrative for that specific case, but little else. Further, we must be careful to avoid overemphasizing what happens in positive cases, utilizing only case studies where we observe our outcome of interest and subsequently miss out on the "dogs that do not bark." As such, we must find some means of identifying broad patterns of behavior, so that we can both speak to what takes place across all of our observations while also avoiding any bias that might emerge from only focusing on a certain subset of cases that only have one outcome.

There are merits to each of these schools of thought. In the case of the former, getting at 
specific causal mechanisms is often a tricky proposition, especially in research that involves examining documentation from historical cases. While other types of work such as experiments allow for greater flexibility in terms of identifying and manipulating mechanisms by researchers directly, we have no such control with observational data. As such, I believe that case studies that carefully trace how a factor of interest influences or causes an outcome of interest provide incredible value to political scientists. On the other hand, we must be cognizant of the skeptical perspective, and question the external validity of the findings that emerge from any historical case work. As our colleagues in history departments would no doubt remind us, each case is a unique confluence of events, and attempting to claim that a single observation is reflective of the whole can be a tricky position to defend.

For the purposes of this project, I argue that my case studies demonstrate a direct connection between democracy (for coercive targets and allies) and successful threats. In each case, there is sufficient evidence present to demonstrate that there is more than simple correlation in place, but that there is a causal relationship that can be traced out. This is not to say that the case study findings have external validity in and of themselves; without any further corroboration, I would be hesitant to say that what happens in these two cases is also happening in the many other observations I do not applying process tracing to as well. But the case studies do not stand alone, as the statistical evidence presented in the previous two chapters provides clear proof that there is an externally valid pattern of behavior, while accounting for cases where concessions did occur and those where they did not. Between these two pieces of evidence, I feel confident claiming both that democratic targets and democratic allies concede at higher rates, and that it is occurring for the reasons that I have theorized. 


\section{Case Selection Criteria}

Apart from the main task of demonstrating how a mechanism functions in a real-world example, there are three aspects of a case study that are ideally balanced against one another. First, the case should be of interest to scholars, which typically means that it has been used as an example for other arguments or theories. This does not necessarily mean that only "big cases" should be used, especially if a lesser-known case is particularly illuminating, but it deals with any possible critiques about the theory's potential for explaining cases that we, as a field, collectively care about. Second, since we are interested in identifying why it is that actors behaved the way that they did, a good case study would ideally have primary documentation from all of the key actors. In practice, this can be a tricky task, as many countries have not made their internal documents publicly available, especially in the case of non-democratic states. But to the greatest extent possible, having access to the documents of policymakers can be the difference between demonstrating causation and inferring it from correlation.

Third, the mechanism should also have a great deal of sway over the outcome of interest. After all, if the mechanism did not actually cause the outcome of interest, there is little point in using the case study at all. In practice, the first two points are much more easily handled by researchers, as it is a much simpler task to evaluate how well-known a case is, how many other scholars have studied it in other works, and whether primary documentation is available. Determining the degree of influence that a particular variable has over outcomes, however, is a much more complicated issue, one that is difficult to evaluate in any systematic manner. In comparing two specific cases where, for example, the targets are both democracies, how can we compare the degree to which this mattered for the outcome of interest? While there are certainly examples where one could argue that a single factor outweighed all the others, these cases are rare and tell us little about the argument holds up under less "extreme" or 
"deviant" situations. ${ }^{1}$

To address this issue, Weller and Barnes (2014) recommend the application of statistical methods in order to identify relevant cases for further analysis. The basic intuition of their argument is straightforward: if the variable of interest truly matters, then it will be able to explain greater amounts of residual "noise" compared to a statistical model where the variable is absent. We can then compare the residuals for the specific observations / cases to identify which ones benefit the most from the addition of the variable of interest, thereby providing a clear and replicable means of case selection. ${ }^{2}$

For the purposes of case selection for this project, I utilize the baseline model from Chapter 3 with the Boix, Miller and Rosato (2012) measure of democracy. As such, the complete equation that serves as the full model is:

$$
\begin{gathered}
D V_{\text {Compliance }}=\beta_{0}+\beta_{1} \text { TargetDemocracy }+\beta_{2} \text { InitiatorDemocracy }+\beta_{3} \text { AllyDemocracy }+ \\
\beta_{4} \text { Contiguity }+\beta_{5} \text { CINC }+\beta_{6} \text { SScore }+\beta_{7} \text { NuclearTarget }+\beta_{8} \text { Nuclear Initiator }+ \\
\beta_{9} \text { Territory }+\beta_{10} \text { Leadership }+\beta_{11} \text { AllyThreat }+\epsilon
\end{gathered}
$$

After running this baseline model, I calculate the residuals for each of the observations,

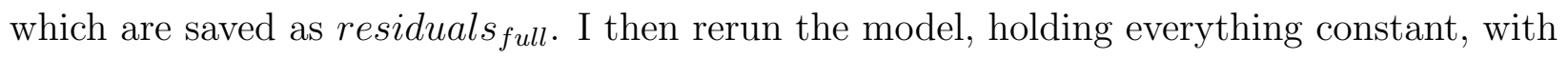
the exception of $\beta_{1}$ TargetDemocracy, which is withheld, and these residuals are also saved

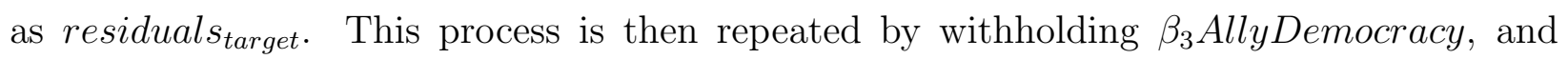
saving the residuals as residualsally. Finally, I take the absolute value of the residuals $s_{\text {target }}$ for each observation and subtract the absolute value of the residuals full $_{\text {in }}$ order to get the added value of including the indicator for the target being a democracy or not, and doing the

\footnotetext{
${ }^{1}$ For an example of such a model using a "deviant" case, among other types, see Gerring (2008).

${ }^{2}$ Appendix $\mathrm{C}$ provides a complete breakdown of this process, including the resulting residual comparisons for both the democratic target and ally models.
} 
same with the ally measure. The larger the number, the greater influence that the addition of the democratic target or ally variable had on accounting for the unexplained heterogeneity from the incomplete model to the full one. This also means that the addition of the variable of interest can have a detrimental effect on cases as well, introducing more noise than the incomplete model, which is fairly common in practice. ${ }^{3}$

Through this process, I am able to identify those cases where the target and/or ally being a democracy subsequently contributed to a more complete "explanation" for whether the target conceded. This method provides a more objective means of measuring the impact that democracy has on each observation, thus dodging some possible concerns tied to case selection, such as the representative nature of the cases and ensuring that the variables matter without referring to the conclusions from the cases themselves.

However, there are two possible concerns worth discussing. First, one interpretation of this process would be that it is similar to identifying "extreme" cases, since I am relying on higher values of the residual comparison to drive my case selection. (Seawright 2016) But such an interpretation misconstrues the method, and conflates high residuals with high values of the independent variable, which is how "extreme" case selection is meant to work. Given that my independent variables can only take on, at most, three values, they cannot realistically be viewed as extreme at all, thus limiting this concern.

Second, one could read this process as identifying "easy" cases for the theory to test, given that the cases with high residuals should have the most impact from the variable of interest. If accurate, then the case studies provide little value, since they are only showing the theory working in situations where the expectation is that it should. Given that we are interested in making sure that the theory is subjected to rigorous testing, this is a serious concern.

But interpreting high residuals as easy tests is an inaccurate reading of the method, just

\footnotetext{
${ }^{3}$ In the case of the targets model, over 70 observations have negative residuals.
} 
as taking low residuals as hard tests would be a mischaracterization. Given that high values and low values tell us about the extent to which the variables of interest are contributing to outcomes, this method is simply helping us identify which cases fit the broad expectations of the theory. By identifying those cases where democracy played an important role in the ultimate outcome, we can more readily narrow down our focus to meaningful cases, while also balancing influence with our interest in important and readily identifiable observations.

That being said, this second critique is a far more problematic one, and should be taken very seriously. In an attempt to assuage concerns that the cases are being drawn from the tails of the observations, I will be choosing one case that has among the highest residuals values for both democratic targets and allies, while the other case will be from more of the middle of the pack, though still positively associated with and contributing to the outcome of interest. While Appendix $\mathrm{C}$ has the complete breakdown of the residuals, the Munich Crisis has the 3rd highest value for targets and 3rd highest value for allies, making this a potential outlier, while the Suez Crisis only has the 26th highest residual among the targets and the 17th highest residual for allies, though both values still remain positive.

\section{Process Tracing: What to Look For}

With this discussion of case selection covered, I now move to the actual cases themselves. Ideally, a case study will include a detailed description of how a given threat unfolded, starting before the threat first emerged, continuing through the immediate response to the demands and into the decision-making process underlying the choice of whether to make concessions or stand firm, and covering the ultimate decision itself. In so doing, evidence from the target, ally, and the challenger should all be provided, in order to demonstrate how each actor saw the situation, evaluated their options, and decided on the final course of action. Getting this evidence from the challengers is often a tricky task, as they are usually 
non-democratic states, and therefore do not always provide thorough records of these events. But to the extent that this evidence can be procured, it will be evaluated here.

I will proceed by first providing a brief description of events taking place in the event of interest, outlining how things unfolded at the macro level. This will be followed by a more detailed description of the lead-up to the threat, covering how the target and ally were behaving, and what the challenger was able to observe. Next, the inception of the threat as well as its are examined, delving into the target and ally's reactions, the decision-making process, and how the final response was decided.

\section{The Munich Crisis}

\section{A (Very) Brief Overview}

While the precise beginning of the Munich Crisis is debatable, for the purposes of this analysis I will mark September 7th, 1938, as the starting point. On that day, a group of Sudeten German deputies aligned with Adolph Hitler's regime visited the town of Mährisch-Ostrau, where eighty-two members of the Sudeten German Party (SdP) were in custody. During this visit, violence broke out between the Sudeten Germans and Czech policemen, leading to the assault of one of the SdP deputies by a policeman.(Faber 2008, 244) The SdP used this incident to disrupt negotiations with the Czech government, eventually leading to their complete cessation. On the same day, an editorial in Britain's The Times intimated that "the advantages to Czechoslovakia of becoming a homogeneous State might conceivably outweigh the obvious disadvantages of losing the Sudeten German districts of the borderland...", an idea which "has found favour in some quarters." (Anonymous (1938) quoted in Faber (2008, 247)) Following these events, the SdP continued to promote demonstrations and acts of violence against the Czech government, in anticipation of Hitler's forthcoming speech at Munich. (Eubank 1963, 97) 
On September 12th, Hitler gave a speech at Nuremberg in front of a crowd of 30,000, declaring the status of Sudeten Germans unacceptable. Further, he called upon their "right of self-determination, denied by the Versailles Treaty," demanding their separation from Czechoslovakia and integration back into Germany. (Eubank 1963, 99) This speech was followed further protests and uprisings throughout the Sudeten regions of Czechoslovakia, predominately targeting "homes and business establishments with Jewish or Czech names," with violence reported in over seventy towns. (Ibid.)

In response to the growing turmoil, British Prime Minister Neville Chamberlain, whose country, it should be noted, did not have a formal alliance with Czechoslovakia, in contrast to the French or Soviets, went to meet with Hitler on September 15th, in an attempt to negotiate a peaceful resolution to the conflict. Chamberlain followed this meeting by discussing the situation on the 16th with his French counterpart, Prime Minister Édouard Daladier, where they agreed that all regions with majority German population in Czechoslovakia would be ceded to Germany, while Britain and France would guarantee the sovereignty of what remained of Czechoslovakia. (Faber 2008, 304-6) However, when Chamberlain returned to Germany on September 22nd, Hitler now found the agreed-upon plan unacceptable, and demanded the complete dismemberment of Czechoslovakia.

In a meeting on September 24th, Hitler provided his ultimatum to Chamberlain, of which the key demand involved the removal of all Czech government, military, and police from identified areas by September 28th. ${ }^{4}$ The ultimatum would be reinforced on the evening of the 26th, when Hitler gave a speech at the Berlin Sportpalast which was broadcast worldwide. In this speech, Hitler refused to back down from his position, placing "the choice between war and peace... in the hands of the Czechoslovak President." According to Robbins (1968),

\footnotetext{
${ }^{4}$ The other demands included that the territory and property remain undamaged, the removal of all Sudeten Germans from the Czech military, the freeing of German prisoners whose arrests were political in nature, and that other areas be identified for a plebiscite by November 25th. See Nogueres $(1965,170-1)$ for a translation of the memorandum.
} 
"As a result of this speech, it seemed impossible for Hitler to turn back. He would declare war unless he heard by 2 p.m. on 28 September that the Sudetenland would be evacuated by 1 October." (298)

Though the original deadline would eventually pass without an agreement, Hitler acceded to a twenty-four hour delay in the invasion through Italian Prime Minister Benito Mussolini, who acted as an intermediary. In the early morning of September 29th, an deal was put into place with the agreement of the British and French. With her allies abandoning her, Czechoslovakia had to decide between fighting against Germany alone or conceding to German demands, ultimately opting for the latter. While Chamberlain proclaimed that the agreement would guarantee "peace for our time," Hitler would quickly abandon his end of the bargain, enveloping the rest of Czechoslovakia by March 1939.

\section{Before the Threat}

In order to understand how the Czechoslovak case unfolded, understanding Hitler's focus on Austria and his planning in late 1937 provides some critical illumination. On November 5th, he met with his generals and foreign minister to discuss his views on military action and foreign policy. He argued that "Our first objective, in the event of our being embroiled in war, must be to overthrow Czechoslovakia and Austria simultaneously..." and that "Britain, and probably France as well, had already tacitly written off the Czechs and were reconciled to the fact that this question would be cleared up in due course by Germany." (Faber 2008,

15) As for why Hitler came to this conclusion, on the British side, he believed that they would be tied up with internal concerns regarding their empire, as well as fears of getting involved in another continental war. Hitler was also convinced that the French were likely to become involved in a war, "possibly allied to Britain and almost certainly against Italy... given the continuing tension in the Mediterranean over the civil war in Spain." (Ibid.)

Despite his two hour long harangue, Hitler failed to convince his audience of his plan. His 
War Minister, Field Marshall Werner von Blomberg, emphasized the qualitative differences in Czech versus German fortifications in the border area, while the commander-in-chief of the army, General Werner Freiherr von Fritsch, warned about the strength of the French military. (Ibid. 16) In addition, in a cable from November 6th, reports from the German Foreign Ministry indicated while Britain would be willing to help secure autonomy for the Sudeten Germans, in the event of an invasion, they would certainly support the French and the Czechs. (United States Government 1949a, No. 13, 30) Nonetheless, Hitler remained steadfast in his beliefs, convinced that Britain and France were not concerns, and he would move on with his plans, focusing first on Austria.

The choice of going after Austria was a natural one in many ways, especially in light of Hitler's emphasis on the "plight" of the Germans spread throughout the country. And given that it was his first target, the planning was far more slipshod than what would come in subsequent invasions, with Hitler finding himself surprised by actions taken by the Austrian government and his military forces unprepared to act. According to one source, over seventy percent of the tanks and trucks broke down during the invasion of Vienna, such was the state of the German military. (Bullock 1972, 233) Nonetheless, the Anschluss was ultimately a success, as Germany was able to annex Austria without resorting to a war with Britain and France. As Furnia (1960) notes, the end result was:

1) the German army was now in a position to outflank Czechoslovakia, 2) German troops were now on the Brenner to complete the ties within the Axis Alliance, 3) the Little Entente [Czechoslovakia, Romania, and Yugoslavia] and Poland were demoralized, 4) Anschluss further estranged the Soviets from the Entente [Britain, France, and the Soviet Union] and 5) Anschluss considerably widened the appreciable gulf which already existed between the Entente powers. (282)

The success of the Anschluss in "liberating" the ethnic Germans of Austria also encour- 
aged the Sudeten Germans in Czechoslovakia, as it "led to enthusiastic expectation in some sections of the Sudeten German Party that they themselves were now about to be taken into the Reich," to which "The Czechs felt confident to be able to deal with... by gestures of conciliation towards their German minority." (Kee 1988, 128) However, this hope would be quickly dashed, as "Within a day [of promising a statute codifying minority rights, in March 1938] the Czechs were confronted with an outright demand from the Sudeten Party for autonomy, a notion which they dismissed as incompatible with the integrity of the state." (Ibid.)

Coming back to the domestic dynamics, SdP was certainly encouraged and assisted by Hitler in Germany. At the same time, they were by no means completely under the control of the Nazis. Just prior to an election in the Sudentenland taking place in late May, Henlein broke off negotiations with the Czech government. (Faber 2008, 177-8) Shortly thereafter, during the actual elections, it was described as: "The local Sudeten situation continued to manifest its own dynamic... it hardly looked as if the Sudeten German Party were any longer much interested in remaining a constitutional component of the Czechoslovak state. There seemed a real danger that the Sudeten Germans might precipitate a crisis and force Hitler's hand." (Robbins 1968, 131) And indeed, a crisis did ensue, leading to the mobilization of 400,000 Czech soldiers to the German border, with Britain and France declaring their support to the Czech regime. (Lee 1970, xiii) But the resolution of the May Crisis, which saw the Czechs eventually back down, had a negative effect on Hitler, who had no intention of striking at Czechoslovakia at that time. Indeed, it convinced him that Czechoslovakia needed to be dealt with, as "It is my unalterable decision to smash Czechoslovakia by military action in the near future." (Kee 1988, 132) Rather than deterring Germany, the crisis had only served to spur further antagonism.

Meanwhile, Konrad Henlein, the leader of the SdP, was meeting Hitler in Germany, where he was ordered to make demands that would be unacceptable to the Czech government. On 
April 23, he announced eight specific demands which fit Hitler's orders, and were designed to make concessions difficult for Czech President Edvard Beneš, taking primary demand of autonomy and expanding his aims. These included:

Full equality of rights and of status between the German national group and the Czech people; recognition of the Sudeten German national group as a legal personality in guarantee of this status; determination and recognition of the German-inhabited territory; full autonomy; legal protection for those Germans living outside the territorial area; removal of injustices inflicted since 1918; the principle of German public officials in German territory; and finally recognition of the right to profess the National Socialist outlook. (Robbins 1968, 218-9)

Though couched in the language of self-determination and identity, there is little evidence that this approach persuaded any political leaders in Britain or France of the rightousness of the SdP. ${ }^{5}$ However, this notion of irresolvable political differences between the ethnic Germans and the Czech government would nonetheless remain salient throughout the run-up to the Munich crisis, with Hitler often referring to these divisions as his primary motivation behind intervening. That this severe disunion was in place incentivized Hitler's regime to push the Czechs, knowing that these internal divisions would only exacerbate problems for the Czech government and increase the looming threat to both the state and the region.

Around the same time, on March 19th, a message was sent from the German Foreign Ministry to German embassies throughout Europe, indicating that the French were attempting to get a joint declaration with the British on the territorial integrity of Czechoslovakia, with no success. The Germans believed "the British Government is likely meanwhile to reserve the right according to its former declaration to guarantee assistance to Czechoslovakia if she is attacked, only when this appears indicated in accordance with the provisions of the

\footnotetext{
${ }^{5}$ It was also a common theme in conversations between the German Foreign Ministry and members of the British and French diplomatic corps. See United States Government (1949a, Nos. 250, 259, and 465).
} 
League of Nations Covenant." (United States Government 1949a, No. 98, 182-3) (182-83) This careful circumscribing of how and when Britain would contribute to Czechoslovakia's defense would become a common theme in British foreign policy, with Czech Prime Minister Milan Hodža informing Ernst Eisenlohr, the German Minister in Czechoslovakia, on March 23rd that "he had no illusions regarding British guarantee to Czechoslovakia. British foreign policy would still be guided by the same considerations as in the past," (United States Government 1949a, No. 102, 185) namely the interests of Britain.

Only two days later, the German Chargè d'Affaires in Britain reinforced this belief, noting that according to Chamberlain's speech to the House of Commons, any "Guarantee to France to render immediate military aid, if in event of a German attack upon Czechoslovakia she fulfills her treaty obligations toward that country, or any preliminary declarations of military action to meet the case of any forcible interference with Czechoslovakia's independence and integrity, is expressly refused." (United States Government 1949a, No. 104, 192) At the same time, however, Chamberlain was publicly stating that an intervention might occur without juridical obligation, per the League of Nations. In so doing, the German Foreign Ministry interpreted this as an attempt to prevent any guarantee of intervention, while also warning Germany and providing a positive signal to France.

Given public polling data at the time, this ambiguity makes a great deal of sense. While Chamberlain sought to prevent conflict, the public was showing signs of discontent with the possibility of a military intervention. A poll issued in March asked members of the British public whether Britain should promise to help the Czechs if it appeared Germany sought a repeat of the Anschluss in Austria. 43\% responded "No," 33\% said "Yes," and 24\% replied they had no opinion, which often indicated they were ignorant of ongoing events. (Trueman 2015) It was in this context that Chamberlain was attempting to maintain the peace and keep Britain out of a continental war.

Meanwhile, France was having its own concerns and internal discord. According to a 
cable from the German Ambassador in France on April 8th, there was a belief that "France will hasten to the aid of Czechoslovakia with armed force if the latter is attacked by German." (United States Government 1949a, No. 120, 218) However, he also noted the sense among the French public "of being obliged to go to war for Czechoslovakia... is received with cold displeasure." (Ibid.) Beyond the practical concerns behind attempting to defend the Czechs from an invasion, the anti-government press was becoming increasingly hostile, with headlines such as "What do the Czechs matter to us?" "The invention of Czechoslovakia"; "Should the French let themselves be slaughtered for the Freemason Professor Benes?" (Ibid., 220) The Ambassador raised the possibility that these statements could be insightful for understanding the country's mood, saying "If one scans these press statements, which may be said to represent popular opinion, it might also appear as if the furtive hope were germinating in the French subconscious mind that France might be absolved from discharging her treaty obligations by developments inside Czechoslovakia." (Ibid., 221) And, while France was hopeful for British assistance and perhaps even some help from the Americans, "this policy finds little echo in public opinion, and cannot overcome the doubts as to whether intervention on behalf of Czechoslovakia is worth the risk involved for France in bringing about a general conflict." (Ibid., 222)

Following Heinlein and the Sudeten German Party issuing their eight demands to the Czech government, the French foreign minister, Georges-Étienne Bonnet, spoke with the German ambassador, begging for assistance in helping avoid a war. In particular, he stated that both Britain and France would

exert their utmost influence to induce the Prague Government to adopt an accommodating attitude up to the extreme bounds of possibility; for he considered any arrangement better than world war, in the event of which all Europe would perish, and both victor and vanquished would fall victims to world Communism. People in France and Britain were convinced that the Sudeten German problem 
must be solved, and saw in this very crisis an opportunity of reaching an understanding with Germany which would finally assure the peace of Europe. (United States Government 1949a, No. 144, 254)

Another meeting on May 6th, this time between the German ambassador to Great Britain, Herbert von Dirksen, and Comte de Brinon, an employee of the French prime minister and foreign minister, provided greater insights into French behavior. de Brinon claimed that, while France was honor bound to help the Czechs, both Bonnet and Daladier were keen on "steering clear of France's obligation to fight for Czechoslovakia," and that Bonnet felt "It would be too dreadful if the whole of Europe had to be plunged into war for the sake of the Czechoslovaks!" (United States Government 1949a, No. 147, 257-8) While the French believed that Germany did not want war to break out on the continent, it is clear from this conversation that they believed Germany was willing to risk fighting, particularly on the issue of Czechoslovakia (Ibid., 258), putting the French in a difficult position of preparing for a conflict they had little interest in fighting.

The British were similarly showing concern, and a willingness to pressure their Czech friends in order to prevent a war. According to a May 10th conversation with Ivone Kirkpatrick, the first secretary of the British embassy in Berlin, it became clear that the British were fearful of being blamed for any breakdown of negotiations by the Czechs. Indeed, the British sought to create a solution through negotiations with the Germans directly, and listened for advice on how British influence could be most effectively brought to bear on the Czech government. (United States Government 1949a, No. 151, 265) That the British not only were willing to try and influence or coerce the Czechs, but that they were actively seeking advice from Germany on how they could be most effective, matches up well with the predictions of the theory.

May 17th brought a conversation between Ribbentrop and the French ambassador to discuss the Sudeten problem. François-Poncet reiterated how the French and British govern- 
ments "would do everything to contribute to a settlement of the Sudeten German problem," (United States Government 1949a, No. 163, 284) clearly signaling once again a desire to avoid war regardless of the costs. Ribbentrop pushed the ambassador's position on Czechoslovakia, and ridiculed French willingness to fight on the Czech's behalf, arguing that "A war for the preservation of a state of affairs in which an unarmed majority in the Czechoslovak State was held subject by an armed minority would defy all the principles of democracy so highly prized in France." (Ibid., 285) This conversation demonstrates the British and French attempts to avoid conflict, on the one hand, while also showing the German belief that, though they might get involved in a war between Germany and Czechoslovakia, it would be done reluctantly with no core interests at stake.

Discussions were quickly overwhelmed by a miniature crisis which developed on May 22nd, when two Sudeten Germans were shot and killed by Czech police. ${ }^{6}$ The immediate response was two-fold. First, the Nazi regime began immediately discussing military action as a means of protecting the Sudeten Germans from further violence, which ignited renewed concern in France that an invasion would ensue. In this light, the French pinned their hopes on British action, and that they would be able to "restrain Germany from any intended military intervention." (United States Government 1949a, No. 190, 321)

At the same time, the French sought to reinforce their willingness to fight should Germany intervene. In a conversation on May 22nd with Lord Halifax, the British Foreign Secretary, the German Ambassador to Britain was reminded "that in the case of a German entry into Czechoslovakia, in whatever circumstances, even in the event of serious acts of provocation by the Czechs, the French would march against" Germany. (United States Government 1949a, No. 191, 322) In other words, the Western Powers would not allow Germany to use this incident in the Sudetenland as an excuse for invasion. This despite French displeasure with

\footnotetext{
${ }^{6}$ It is unclear whether they were members of the Sudeten German Party, or merely civilians, as the Czech account suggested the former while the German interpretation tells the latter.
} 
the situation they found themselves in. On May 23rd, the very next day, Daladier complained to the German Ambassador that he "had not made the alliance and was certainly not happy about it. It did, however, exist and, if [Germany] attacked Czechoslovakia, the French would have to fight if they did not wish to be dishonored." (United States Government 1949a, No. 194, 327)

June 8th and June 10th provide two of the most important cables for understanding German views of British popular opinion. In the first document, the German Ambassador to Britain sent a political report back to his superiors, examining Anglo-German relations in light of the Czech crisis. First, he notes how

The whole body of British public opinion in its attitude towards Germany is still influenced by the union of Austria with Germany. Due to the inability of the British to grasp Continental political affairs before they have become extremely urgent, the press and public assessed the Czechoslovak affair in the light of the German action in the Austrian question... The feeling, by no means overcome yet, of being made a fool of in that affair, grew up again, together with the determination not to allow, unchallenged, further alterations to the balance of power in Central Europe. (United States Government 1949a, No. 244, 390-1)

He continues on, blaming much of this on the May 20th-22nd crisis, as well as how those events were framed in Britain. However, he also notes that there remain many signs of conciliation and willingness to pressure Czechs into making important concessions. But among the public, there are serious fears about the possibility of war: "It cannot be said that the British public is preparing or is being directly prepared for a violent quarrel with Germany; good judges of British mentality describe this state of mind of the masses more as a fatalistic acceptance of an unalterable fact." (Ibid., 394) That the public has come to accept war as likely, however, does not mean that they wanted to fight, as that quote indicates. 
The British people had resigned themselves to a situation where war was inevitable, but had no desire to fight, a split which Germany would later be able to exploit.

The June 10th document, which served as a follow-up from the German Ambassador in Britain, observes that both the British Government and public were well-aware of the Sudeten issue, and that Britain would likely become embroiled in war if Germans invaded Czechoslovakia, per Chamberlain?s speech on March 24th in House of Commons. The Ambassador even reported on letters mailed to British newspapers, noting how many call for "granting the right of self-determinaiton to the Sudeten Germans," (United States Government $1949 a$, No. 250, 405) using it as a litmus test of sorts for public support. Based on these two reports, it appears likely that the German Ambassador believed strongly that while Britain was preparing for war, the public was not eager to fight and wanted a peaceful conclusion if possible. ${ }^{7}$

July also brought additional reports emphasizing the importance of public opinion in Britain, with the first sent on the 5th again from the German Ambassador to Britain. In it, he says that while the public is being prepared for the likelihood of war, it is not being framed as inevitable. Even more importantly, the Ambassador argues that Chamberlain is primarily concerned with ensuring the British people remain content, that "He will resist to the uttermost any attempt to destroy [British welfare] by a policy leading intentionally or unintentionally to war." (United States Government 1949a, No. 281, 472) His July 15th report emphasized the degree to which Britain sought to keep the peace, as "No one in Britain wanted war; Chamberlain and Halifax, who was in complete agreement with him, were working doggedly at the task of making the Czechs see reason and alter their policy." 8 In

\footnotetext{
${ }^{7}$ See also the June 23rd report from the German Ambassador to Britain, where he points to both the British public's concern over fighting a war over Czechoslovakia as well as fears about the imminent nature of such a conflict. (United States Government 1949a, No. 266, 433)

${ }^{8}$ See also the July 18th report from the German Ambassador to Britain, examining how Chamberlain has sought to make an Anglo-German settlement a priority for the government. Also views the public as more malleable for Britain, capable of being prepared for conflict. (United States Government 1949b, No. 793)
} 
addition, the report notes how the British Ambassador was becoming increasingly displeased with both Prague and Paris, making Britain's efforts more complicated. (United States Government 1949a, No. 292, 488-9)

As tensions began to ease prior to Hitler's speech at Nuremberg, the idea of war became an increasingly thorny issue for the British government, with the public pushing for peaceful solutions to the greatest extent possible. An example of this comes from the August 6th communication at a party held at the British Military Attaché's residence between the British Ambassador and the Chief of the German Secret Service. In this conversation, "Henderson repeatedly emphasized on this occasion that Great Britain would not think of risking even one sailor or airman for Czechoslovakia, and that any reasonable solution would be agreed to, so long as it were not attempted by force." (United States Government 1949a, No. 337, 536) That the definition of a "reasonable solution" was continually being stretched by this point in time helps drive home the point that the British government sought nearly any means to keep out of a war, continually communicating to members of the German government that Hitler could have most anything he wanted from Czechoslovakia, so long as he did not resort to war. ${ }^{9}$

For months ahead of Hitler's threats to Czechoslovakia and, therefore, the Western Powers, there were two key themes which were continually popping up in the reports being sent through the German Foreign Ministry. First, Britain and France both sought to try and maintain peace on the continent, regardless of the costs. While France did have a treaty in place that required them to come to the aid of Czechoslovakia in the event of an invasion, the French government was deeply unhappy being put in the position of having to help the

\footnotetext{
${ }^{9}$ The German Ambassador to Great Britain would be given a similar perspective from the British Prime Minister's Press Chief on August 24th: "The British Government were prepared to demand the most farreaching sacrifices from Czechoslovakia if only Germany would adhere to peaceful methods in settling the Czech question. The British Government and people had no interest whatsoever in Czechoslovakia, other than that the affair should not end in Germany?s using force." (United States Government 1949a, No. 389, $621)$
} 
Czechs in the face of German aggression. The British, who had no constraints of a formal alliance but were still nominally on Czechoslovakia's side of the conflict, had perhaps an even greater desire to prevent war. And each were eagerly signaling their willingness to force Czechoslovakia into making great sacrifices, if it meant neither of them would have to fight.

Second, much of Britain and France's behavior can be traced back to their respective public's desires to keep them out of another conflict so soon after the Great War had come to a close. While there is definite evidence that people were becoming convinced that such a fight might be unavoidable, this was not taken as a sign of encouragement; rather, the people looked forward to such a future with dread. Therefore, they would latch on to any signs indicating that peace might be possible, hoping against hope that the fragile status quo could be maintained. And the leaders of Britain and France, knowing this state of public opinion and that the people would, at best, fight reluctantly, worked to prevent the outbreak of war. With this information available through the German Foreign Ministry, Hitler was certainly aware of the weaknesses in the Western Powers.

\section{The German Threat: Why It Developed and the Response}

On September 12th, 1938, Hitler called for the right of self-determination for the Sudeten Germans, declaring the discrimination and violence they faced in Czechoslovakia to be unacceptable. In this speech at Nuremberg, he intimated that should his demands not be met and the Sudeten Germans not be allowed back into the fold, Germany would resort to violent ends in order to achieve his goals. This was reinforced the next day, as the German Chargé d'Affaires in the U.S. stated:

Hitler has indeed threatened to use force, but has not decided on any definite action. He has rejected idea of plebiscite; on the other hand, right of selfdetermination remains as subject of direct negotiations between Sudeten Ger- 
mans and Prague. Further British mediation now appears superfluous... Main conclusions: Hitler will achieve in due course what he is striving for, namely annexation of Sudeten Germany. (United States Government 1949a, No. 465, 750)

As noted in the previous section, Hitler's demands came about during a time where many countries were preparing for war, but none, save perhaps Germany itself, wanted to see fighting break out. The Czechs were the most willing apart from the Germans, but given that it was their country that was more proximately at risk, this is unsurprising. For the British and the French, on the other hand, war was the absolute last resort.

Over and over again, the documentary evidence has demonstrated that in the run-up to Hitler's threat of war, the British government in particular was constantly signaling its willingness to put immense pressure on the Czechs. That all was asked in return was that Germany avoid resorting to force demonstrates just how important maintaining the peace was, and the extent to which they would ultimately demand from Czechoslovakia.

This desire to avoid conflict is strongly associated with the public's desire to avoid war as well. During the course of the numerous smaller crises which contributed to the Munich Agreement, public opinion was always in favor of peace. This is not to say that war was unthinkable; as demonstrated above, it is quite clear that the people of Britain and France were at different points in time resigned to fighting in an unnecessary war. But it was the "unnecessary" nature of the conflict that resulted in the very obvious and open reactions from the masses when word of Chamberlain's first meeting with Hitler was announced. As the German Chargé d'Affaires in Britain wrote on September 15th:

Never have I witnessed such a sudden change in atmosphere as took place yesterday evening in the whole of Great Britain when Chamberlain?s visit to the Fuhrer was announced. Until evening the entire British population was sunk in 
deep depression called forth by the decision, no less serious, to take up arms under certain circumstances. Now things had taken a completely unexpected turn which offered the hope of a peaceful settlement... It is no exaggeration when the newspapers report that men and women wept for joy in the streets. (United States Government 1949a, No. 486, 785)

Another piece of evidence we can employ comes from monthly Gallup polling of Chamberlain's government. Though the polls only begins in October 1938, after the crisis has come to an end, they do demonstrate that healthy support of at least 50\%. (Dutton 2001, 45) And as noted above, a March Gallup poll examining support for the British intervention showed a plurality in favor of staying out. Chamberlain himself believed that he remained very popular and had the complete support of his party and the public. (Ibid. 47)

In France, the speech was received slightly differently, with less concern about war with Germany breaking out immediately. As the German Chargé d'Affaires in France noted on September 14th, "It is generally stressed as a reassuring factor in the speech that it does not contain an ultimatum, demand the severance of the Sudeten German regions, nor signify any breaking off of the negotiations now in progress..." and the "fact that door remains open for negotiations and that no irrevocable step has been taken... Idea of military invasion seems to be abandoned. Fuhrer will now attempt to undermine Czechoslovakia from within." (United States Government 1949a, No. 471, 755-6) For the French, the lack of any precise threat of violence (however implicit) was a positive sign, giving hope that war was not as inevitable as previously believed. In a follow-up note on the same day, the Chargé d'Affaires observed:

The desire to avoid a European war, which would also be unpopular with the people, is becoming more noticeable than ever. The readiness to make concessions has increased during recent days. This is partly due to the realization, brought about by the Fuhrer's speech and recent events in Czechoslovakia, that 
the continued existence of Sudeten Germans side by side with Czechs is no longer really possible. (United States Government 1949a, No. 479, 762)

Once again, there is a clear desire to avoid conflict, a feeling which has only become more powerful after Hitler's September 12th speech, even if that means making further concessions. In line with this, we see that the French became increasingly willing to sacrifice Czechoslovakia for peace, either concluding or convincing themselves that such a multi-ethnic state was doomed to failure regardless.

In conversation with their British counterparts, there is also evidence that the French were increasingly concerned for how the public would handle a conflict. The former French Premier Pierre Flandin, on September 24th, informed Halifax that the French peasant class was overwhelming against involvement, and that should war actually break out, "their hearts would not be in it." (British Government, September 24th, 509) In addition, it was not clear how votes for war would unfold in the Chamber and Senate, with most political parties divided on how to proceed. (Ibid., 510)

It should be noted that the Godesberg Memorandum of September 24th, where Hitler made additional demands after an agreement had more or less put into place, did have a profound negative effect on public opinion. Chamberlain noted as much in his negotiations with Hitler, due to it being "couched in the language of a conqueror who dictated his will to the conquered, laid down everything in precise terms, and left no time for discussions on measures of rate peaceful and orderly execution of the existing basic plans." (United States Government 1949a, No. 583, 904) This was, however, very short-lived; once Chamberlain announced his September 28th meeting with Hitler to try and avert war, the public once again reverted to its pacific tendencies. (Homer 1963, 14)

Though not covered in great detail in the previous section since the U.S. was not directly involved, it should also be noted that Franklin Delano Roosevelt had similar public opinion limitations in the United States at the time. He was severely hamstrung, unable to directly 
intervene in any overt way, due to the powerful isolationist tendencies in the U.S. at the time. However, Roosevelt also noted the changes in public opinion over time, becoming gradually more cognizant of the threat that Nazi Germany represented. Therefore, while the American public was unwilling to act decisively, he also believed that over time the public could be educated, with the hope the U.S. could provide future assistance. (Farnham 1997, 216)

In Czechoslovakia, on the other hand, the threat only served to embolden the Czech people and mobilize them against the German threat. An immediate response came from both the Czechs as well as the Sudeten Germans, with the former preparing for war while the latter marched and demonstrated in the streets. (United States Government 1949a, No. 457 and 461) On September 22nd, reports came in of numerous demonstrations taking place in Prague, at the same time that the Hodža government fell. This actually had the effect of temporarily calming the nerves of the Czech population, which been had mobilizing and preparing for war, though impact was short-lived. (United States Government 1949a, No. 568) This is not to say that the Czech government completely abandoned diplomacy; on September 26th, the Czech Foreign Ministry requested guarantees of the new frontiers, and provided promises that the Sudeten Germans would be transferred peacefully. They implored Hitler for some improvement of relations, stating that "A relaxation of the mental tension of the Czech people would be immediately realized if only the Fuhrer would utter a kindly word assuring them their independent existence and paying some regard to Czech requirements in the delimitation of the frontier and other arrangements." (United States Government 1949a, No. 617, 942) But in general, Czechoslovakia's readiness for war was much greater than any of its allies.

Following days of negotiations, an agreement was finally struck on September 29th and in the early hours of the 30th. Among the signatories were Hitler, Chamberlain, Mussolini, and Daladier; in contrast, no Czechoslovakian envoys were present or consulted. Instead, the Czechs faced a second ultimatum, this time from her presumed allies: either agree to 
the terms set out in the Munich agreement or face war with Germany alone, where the Western Powers would have said they tried to bring about peace and would not come to Czechoslovakia's aid due to its intransigence. With no assistance forthcoming, the Czech government had no choice but to concede to Hitler's demands and allow for the occupation and subsequent loss of the Sudetenland. In addition, this event served to let the rest of Europe know that Czechoslovakia was vulnerable to coercion, with subsequent threats emerging from Poland and Hungary, leading to the complete dismemberment of the country.

\section{Summarizing Munich}

The Munich Crisis is an important one, as it follows directly on the heels of the Anschluss, and precedes a number of subsequent threats made against the leftovers of the Czechoslovakian state as well as the failed coercive attempt against Poland which finally ignited the powderkeg of World War II. While it is debatable whether Hitler's threat to invade was necessary in order for the Sudetenland to return to Germany, the fact that it was issued at all clearly had a powerful effect on Britain and France in particular, leading to the immense application of pressure on Czechoslovakia in order to avoid war.

Czechoslovakia itself found itself in an unusual situation, with the Nazi regime able to utilize and manipulate the Sudeten Germans within Czechoslovakia as a tool against the Czech government. The SdP Party's ability to create uncertainty and discontent within the Sudetenland forced the Czechs to crack down on the Sudeten Germans, making it difficult for the Western Powers to readily defend Czech actions. While the non-German population was certainly willing to fight against Germany in order to protect the Czech state, the internal divisions within Czechoslovakia made it more difficult for them to resist the demands made by Germany.

The situation was only made worse by those who should have been defending the Czechs. Britain, France, the Soviet Union, and the United States all failed to come to her aid, 
and in the case of the democratic partners, the reasoning can often be attributed to the interests or demands of the public. In each of these three cases, we find evidence that the leaders were concerned about the outbreak of war and sought to avoid it, in line with the demands of the public to keep the peace. Public opinion data from Britain and the United States in particular show how overall trends in the masses, still so heavily scarred from the Great War that they had no interest in risking conflict, especially over Czechoslovakia. And while the use of threats and demands by Hitler did have the effect of making war more palatable temporarily, the evidence suggests that the impact was much more limited than we might have predicted otherwise, ultimately leading to the isolation and dismembering of Czechoslovakia.

We also see evidence that Hitler's regime was aware of the turmoil that these democratic states were contending with. Through the use of numerous documents captured by the Allies after World War II, this case demonstrates how the Nazi regime observed the actions and words of the Western Powers, interpreting their weaknesses and vulnerabilities over the course of the numerous crises which ultimately lead to the handover of the Sudetenland. While this still does not get directly at how Hitler ultimately resolved to use threats of violence to achieve his aims, these documents get us as close as we possible given the problems associated with Hitler and his decision-making.

To summarize, this case clearly demonstrates a number of key factors that are critical to my argument. First, we can readily observe how public opinion within Czechoslovakia's allies managed to constrain their responses to the crisis. That the general public, and much of the world, wanted to avoid a second World War is not in question. But significantly, we can see how the will of the public often influenced the choices of policymakers, particularly as they sought to keep the peace. Second, the impact of Czechoslovakia's domestic discontent also clearly played an important role in Germany's ability to coerce the Czech government. Though it was not public opinion that created this vulnerability, the democratic nature of 
the regime ultimately enabled the openness and transparency to allow protests and riots which helped undermine the state. Third, the German government was observing these factors and it appears that they contributed to the decision to pursue their militant policies. The use of primary documents from the Nazi regime helps illuminate the factors that key players in the German foreign policy apparatus emphasized, thus making it likely that Hitler himself also had this information available to him. These three factors are all in line with the expectations of the theory, and serve as strong confirmatory evidence.

\section{The Suez Crisis}

\section{A (Very) Brief Overview}

The Suez Crisis began on October 29th, 1956, with the Israeli invasion of Egypt's Suez Canal, though the British and French were involved with the planning of the initial raid. The assault had two primary goals. The first was to return control of the Suez Canal to British hands, as Egyptian President Gamal Abdel Nasser had nationalized the canal in July and subsequently limited access to the canal for Israeli ships. The second was to remove Nasser himself from power, for fear that leaving him untouched could threaten Europe's political and economic prospects, as well as undermine the stability of the Middle East and friendly Arab regimes.

This course of action was supported by the British and French, eventually leading to their provision of air support and troops to assist the Israelis. This was in spite of American concerns, which had clearly communicated that the canal should remain in Egyptian hands. In response, the Americans quickly began applying immense political and economic pressure in an attempt to get the British and French to abandon their enterprise.

Following the involvement of British and French ground troops on November 5th, the Soviet Premier, Nikolai Bulganin, sent notes to the leaders of Britain, France, and Israel. 
These notes included veiled threats of military and nuclear retaliation should the canal remain occupied, invoking images of rockets being rained down upon British, French, and Israeli cities. These notes were quickly made public, leading to a further escalation of tensions and ramping up the stakes of the conflict.

Under severe pressure from all sides, the British and French conceded, with Britain issuing a cease fire on November 6th, just over a week after the crisis began. The invading soldiers withdrew from Egypt shortly thereafter, though it would take a number of months for the canal to reopen, due to the Egyptians sinking a number of ships during the invasion in order to block the canal. This was a humiliating defeat, particularly for the British, as their failure signaled its exit from the club of great power states.

For the purposes of this case, I will be focusing predominantly on the decision-making processes of the British and Americans, as they were the primary players on the target side. While the French and Israelis were active participants in the Suez invasion, they generally played a secondary role after the British, who had the most to lose from no longer having access to her colonies through the Canal as well as concerns over falling to a second-rate status in global affairs. Simply put, the British were the lynchpin that drove the invasion forward, and it was pressure on them that resulted in an end to the crisis.

It should also be noted that while the coercive attempt against Britain had positive but not overwhelmingly large residual values, the threat against the French actually had the largest in the entire dataset for both target and ally. I would argue that this is due to France being pressured in a manner similar to the British, while also being reliant on them for ensuring that the invasion would move forward. ${ }^{10}$

\footnotetext{
${ }^{10}$ More details on this breakdown are available in the appendix. In addition, it should be noted that while France required Britain's assistance for the attack to proceed, it was not nearly as vulnerable to American economic coercion as the British. See Kunz (1991) for more on this disparity.
} 


\section{Before The Threat}

In order to understand the context in which the crisis unfolded and how the Soviet threat emerged, the nationalization of the Suez Canal is the natural starting point. On July 26th, 1956, Nassar announced the nationalization of the Canal. Meeting the next day, the British Cabinet expressed surprise at Nassar's actions, and immediately sought "to reach an understanding of the matter with the French, as our partners in the Canal enterprise, and with the United States government." (CM 54(56), 2) The Cabinet viewed the Canal as an "international asset," and sought to prevent the Egyptians from taking it for "purely international purpose." (ibid., 3)

Prime Minister Anthony Eden tried to persuade U.S. President Dwight Eisenhower directly, attempting to convince Eisenhower of the need to intervene in Egypt, even if that required military involvement. Avoiding legal arguments, Eden emphasized the importance of the Suez Canal, stating that it was "vital to the free world," there could be immediate ramifications to oil access for Western Europe, and that the Egyptians could not be "trusted to manage it with any sense of international obligation." (PRO PREM 11/1177) Further, members of the Cabinet expressed their desire to remove Nasser from power entirely, articulating this position directly to American diplomat Robert Murphy on July 31st, who subsequently forwarded these views to the U.S. Secretary of State, John Foster Dulles. (FRUS (C) 33, 60) Even members of the opposition were intimating that military force might be necessary, with Hugh Gaitskell, leader of the Labour party, calling for the involvement of the United Nations, comparing Nasser's actions to Mussolini and Hitler, and noting that "force cannot be excluded." (Frankland 1959, 137)

Despite these entreaties, support was not forthcoming from the Eisenhower administration. Eden received warnings directly from both Eisenhower and Dulles cautioning against military intervention. On July 31st, Eisenhower emphasized the need to employ and exhaust all diplomatic options before even considering kinetic action, concerned that while "initial 
military success might be easy but the eventual price might become far too heavy." (FRUS (C) 35, 71) Perhaps more tellingly, he also considered the prospective impact that an invasion would have on American and global public opinion, claiming that people "would be outraged should there be a failure to make [diplomatic] efforts." (Ibid., 71) The importance of U.S. public opinion was reiterated by Dulles on August 1st, telling Eden that there would be no forthcoming domestic support in the U.S. "to back a military venture by Britain and France which, at this stage, could be plausibly portrayed as motivated by imperialist and colonialist ambitions..." (FRUS (C) 42, 97-98) Dulles also reiterating how potential short-term military success would likely give way to long-term opposition, emphasizing the issues that Britain had with "the infiltration and assassination tactics of the Egyptians" even when they held the Canal, which would only become worse with Egypt becoming "much stronger militarily, and... getting moral and material support from the Soviet Union and Egypt's prestige and influence in the Arab World [being] much greater." (Ibid.)

Eisenhower would later reiterate his concerns to Eden on September 3rd, again emphasizing the importance of public opinion in the U.S. and abroad. In particular, he noted that military action would only take place if "public opinion in our several countries [were] overwhelming in its support. I must tell you frankly that American public opinion flatly rejects the thought of using force, particularly when it does not seem that every possible peaceful means of protecting interests has been exhausted without result." (PRO PREM 11/1100, 3 September 1956) While Eden had attempted to argue that removing Nasser from power would only benefit the U.S., Eisenhower strongly disagreed, concerned with losing access to oil and the consolidation of Soviet support among much of the third world if an invasion were to occur. (Ibid.) And on September 8th, in response to another letter from Eden asking for assistance, Eisenhower warns that military action could "cause a serious misunderstanding between our two countries because I must say frankly that there is as yet no public opinion in this country which is prepared to support such a move and the most significant public 
opinion that there is seems to think that the United Nations was formed to prevent this very thing." (PRO PREM 11/1100, 8 September 1956) Polling data appears to support the idea that American citizens wanted little to do with a potential conflict over Egypt, as a Gallup poll from September 28th found that $55 \%$ of respondents wanted the U.S. to avoid sending forces to the region if war were to erupt. (Kingseed 1995, 79)

While Eden sought to convince Eisenhower to see his side of events, Eden also began having to contend with divisions at home, foreshadowing the very public and divisive response to the invasion. On August 7th, two Labour MPs, Douglas Jay and Denis Healey, wrote a letter to The Times, indicating that any use of force "other than in self-defence, or in pursuance of our international obligations and the UN Charter" would be "in defiance of very large sections of opinion" in Britain (Lucas 1991, 165). This is in line with how the Labour Party's Gaitskell had initially come out in support of military action, but this backing had been predicated on the inclusion of American backing. During a session of Parliament on September 13th, Gaitskell directly asked Eden about the government's intentions, and whether Eden sought to "shoot their way through the Canal?", in response to public comments by Dulles that the United States had no intentions of going "into [the Canal] shooting" (Frankland 1959, 215) Eden pivoted, focusing on his government's agreement with the U.S. on how to proceed, an attempt to demonstrate unity that was, simply put, nonexistent. This attempt at masking the problem was unsatisfactory to the members of Parliament, who demanded that Eden answer the question directly, to no avail.

In addition to disagreements with Labour, the Conservative Government found its Cabinet members at odds. According to the summary of an August 28th Cabinet meeting, Sir Walter Monckton, the Minister of Defence, raised concerns over British public opinion if an invasion took place, arguing it would lead to a domestic split. He did not speak entirely against the use of force, but did see it as a "last resort," to be employed after "first exhaust[ing] all other means of curbing Colonel Nasser's ambitions and, in particular that 
we should let no opportunity pass of securing a settlement by agreement." (CM 62 (56), 5) Monckton again took a contrary position during a September 11th meeting, stating that "Any premature recourse to force, especially without the support and approval of the United States, was likely to precipitate disorder throughout the Middle East and to alienate a substantial body of public opinion in this country and elsewhere throughout the world." (CM $64(56), 7)$

While these divisions were apparent both within the Parliament as well as the government itself, the British public was also not strongly in favor of military action. Indeed, it is difficult to say that the public was ever really in support of intervention, with its high watermark coming in August 1956, as one poll had 33\% of the public backing the use of military force while $47 \%$ supported economic and political action. However, this would wane to $27 \%$ in support of military action and $64 \%$ needing United Nations approval by September. (Shaw 1996, 63) As such, even if the Opposition would back the use of force, it seemed likely that the public would not, though admittedly the endogenous relationship between the two makes this a messy claim to verify. But the critical point is that public support was not present, and would only deteriorate.

With U.S. support not forthcoming, the British colluded with the French and Israelis, finalizing a plan on October 24th, following a number of joint meetings, on how to proceed with an invasion of the Suez Canal. The Sèvres Protocol outlined a number of key points, starting with the Israeli invasion of Egypt on October 29th, and leading to the British and French governments demanding that both the Israelis and Egyptians cease their fighting, withdraw a minimum of ten miles from the Canal, and, in the case of the latter, to turn over control of the Canal to a joint Anglo-French force meant "to guarantee freedom of passage through the Canal by vessels of all nations until a final settlement." (Kyle 1991, 565) In addition, it was agreed that if the Egyptian government failed to comply with these demands, the British and French would begin their own invasion on the morning of October 
31st. However, this agreement was made in secret, and the British Cabinet was not informed of the plan's details; rather, on October 25th they "agreed in principle that, in the event of an Israeli attack on Egypt, the Government should join with the French government in calling on the two belligerents to stop hostilities...", effectively confirming British involvement contingent on an previously agreed-upon Israeli invasion. (PRO CAB 128/30 Pt II, October $25,1956)$

With all of this in mind, here is what we can say definitively: the British as well as the French and Israelis were primarily focused on the idea of using military force to oust Nasser from power, while the Americans sought to restrain their behavior. However, each had some degree of recognition that public opinion was going to be a major factor in the crisis. In the United Kingdom, there was the specter of division beginning to form early on, with the Labour Party only willing to go along with the Conservative Party's invasion plans if the United States was also on board, while the Cabinet was concerned that an attack would cause an uproar both at home and abroad. But this was not enough to deter Eden from pushing the invasion forward, nor is it necessarily clear based on the evidence available that it should have been. ${ }^{11}$ Meanwhile, Eisenhower was firmly entrenched against any sort of invasion, and had reason to believe that there was insufficient domestic support to take any sort of military action or even back anything initiated by the British. This made it very clear that there would not only be no support coming, but that the U.S. would actively try to undermine any attempts by the British and French to go off independently.

The crisis kicked off in earnest on October 29th, with the Israelis driving into Egypt towards the Canal. Following a message from a disappointed Eisenhower, warning Eden that the Soviets might intervene on Egypt's behalf with the backing of the United Nations if Israel were found to be the aggressor (PRO PREM 11/1105, 30 October 1956), the Cabinet met

\footnotetext{
${ }^{11}$ There is an argument here for psychological biases coming into play with Eden and his Cabinet as well, though it would have likely been a secondary issue for my argument. See Jervis (1968) for more on biases and misperception, as well as McDermott (1998) and Richardson (1993) for specific arguments on Suez.
} 
again on October 30th to discuss the forthcoming American response. During this meeting the Foreign Secretary noted that the American Ambassador did not appear convinced by arguments of Israeli self-defense against Egypt, and appeared to be pushing a United Nations resolution "condemning Israel as an aggressor." (PRO CAB 128/30 Pt II, CM 75 (56), 30 October 1956) There was some hope that, since the Israelis were not facing a great deal of resistance from the Egyptian military, the British and French might not need to make a statement as quickly as originally planned, thus providing time to bring the U.S. over to their view of the situation. In particular, it was noted that Britain "should do our utmost to reduce the offence to American public opinion which was liable to be caused by our notes to Egypt and Israel." Further, major concerns were raised about Britain's economic status following the invasion, foreshadowing American coercive diplomacy via economic leverage: "Our reserves of gold and dollars were still falling at a dangerously rapid rate; and, in view of the extent to which we might have to rely on American economic assistance we could not afford to alienate the United States government more than was absolutely necessary." (Ibid.)

The subsequent Parliamentary debates, discussing the invasion and Britain's contribution to Israel's actions, did little to help Eden and the Conservatives' position. By essentially lying to Gaitskell and Labour about the plans for invading the Suez Canal following the Israeli attack and putting forward a "blatantly transparent" ultimatum in the House of Commons on October 30th, any support from the Opposition was certainly not forthcoming. (Lucas 1991, 261) The next day, Gaitskell questioned Eden about whether the U.S. had been informed about the plan to get involved in Suez, with Eden failing to deny his "blackout" of the Americans and contending that "while the Canal was necessary to British survival, it was only a secondary concern for the Americans." (Ibid., 267-8) In the Press Gallery, a reporter described it as "quite the most shattering experience I've ever sat through... the divisions, the uproar, the emotion were much worse than at the time of Munich." (Kyle 1991, 388-9) Aneurin Bevan, the prominent Labour Party politician, stated "I am bound to say 
that I have not seen from the Prime Minister in the course of the last four or five months... any evidence of that sagacity and skill that he should have acquired in so many years in the Foreign Office. There is something the matter with him." (Ibid. 389) As Eden removed himself from the room, "the entire Labour front bench rose and called for his resignation. Accusations of 'murderers' were launched, and MPs nearly came to blows." (Lucas 1991, 283)

The public outcry was similarly robust. Following the direct involvement of British forces, a Gallup poll inquired into whether the use of military force was justified. 37\% of respondents said that they believed it was, while $44 \%$ disagreed and $19 \%$ had no firm opinion, indicating a clear division in the public's views. (Lucas 1991, 284) Members of the Conservative Party were similarly concerned of the public undercurrent against the government, with Oliver Poole, the Conservative Party Chairman claiming that "while a majority of Conservatives backed the Government, a 'liberal' element of the country was strongly opposed and mobilising itself under the slogan, 'Law, not War.'" (Ibid.)

The most visible indicator of this discontent, however, came on November 4th, when Aneurin Bevan of the Labour Party spoke before a crowd of anti-government protesters in Trafalgar Square. Estimates indicate that more than thirty thousand people were present, and while some portion of them were counter-protesters in favor of the Conservative government, they were in the clear minority. (Lucas 1991, 284) Observers at the time noted "the presence of people carrying pro-Eden signs and hecklers, but the police removed them from the square when they appeared to be in danger of being drawn and quartered by the angry crowd." (Cooper 1978, 187)

At the same time and in parallel, the Soviet Union had their own issues that were bubbling up, in the form of the Hungarian Revolution of 1956. Starting off as a student demonstration, the protests quickly exploded into a massive revolt following the death of a student protester, eventually leading to the collapse of the Hungarian government and 
demands by the protesters of free and fair elections. Though the movement had begun on October 23rd, by the end of the month, a new self-proclaimed Hungarian government was in place and negotiating with the Soviet Union, specifically asking for the removal of foreign troops and secession from the Soviet Union. This peace was short-lived, as the Soviets quickly changed tracks, sending in a massive invasion force on November 4th, which quickly crushed the protesters, ousted the government, and re-installed a Soviet-friendly regime.

As Borhi (1999) points out, these events are important not because they distracted U.S. policymakers from the events taking place in Egypt, but rather how they limited the response that the Americans could make. While Eisenhower was clearly dismayed by the events taking place, his ability to condemn Soviet actions was hamstrung by the behavior of his British, French, and Israeli allies, who were similarly undermining the sovereign actions of another state. As Vice President Richard Nixon put it later, "We couldn't on one hand, complain about the Soviets intervening in Hungary and, on the other hand, approve of the British and the French picking that particular time to intervene against Nasser." (Ibid., 105) Indeed, Dulles lamented the situation, saying that "Just when the Soviet orbit was crumbling and we could point to a contrast between the Western world and the Soviet, it now looked as though the West was producing a similar situation." (PRO PREM 11/1105, 31 October 1956) This acted as a further incentive for Eisenhower to push the British and French out of Suez: it would demonstrate U.S. leadership and control over it's allies, and re-establish the moral high ground for the United States vis-a-vis the Soviet Union.

The combination of the Hungarian uprising with the British/French/Israeli military action frustrated and angered American policymakers. The U.S. responded in two key ways, applying both political and economic pressure, particularly on the British. In the United Nations Security Council on October 30th, the U.S. submit a resolution condemning the Israeli attack which was subsequently vetoed by both the British and the French. (Kingseed 1995, 104) This forced the vote to move to the General Assembly, where the British and 
French could not employ their veto powers though the resolution was non-binding. Nonetheless, the Americans helped push through the vote, getting a victory with sixty-four countries voting in favor, five (the U.K., France, Israel, Australia, and New Zealand) against, and six abstaining. (Ibid. 110-1) That three belligerents were only able to bring two allies to their assistance with the General Assembly vote is indicative of just how unpopular their actions were, but also of how much the U.S. was attempting to push them into a corner. There were even inquiries by Dulles into whether the U.S.'s Sixth Fleet would be able to intercept the Anglo-French fleet as it moved towards Egypt, though it was concluded that only an attack would be able to prevent their arrival. (Lucas 1991, 266)

Economically, the U.S. was also applying immense pressure onto the British in particular. ${ }^{12}$ The onset of the crisis had taken a large toll on the British economy: between October 30th and November 2nd, the Bank of England had lost approximately $\$ 50$ million in U.S. dollars, with that increasing to $\$ 85$ million of Britain's foreign reserves by the end of the week, while the closing of the Canal had heavily impacted Britain's oil supply. (Lucas 1991, 292) With the economy damaged, Eden sought out means of trying to keep Britain afloat but was rebuffed at every turn.

First, a request for a loan was requested from the International Monetary Fund, which the U.S. initially denied; it was only in early December, long after the crisis had concluded that Britain was given access to funds it needed to help sustain the economy. (Lucas 1991, 318-9) According to Harold Macmillan, the Chancellor of the Exechequer, he had been told by the Americans that "only a cease-fire by midnight [of the 6th] would secure U.S. support for an International Monetary Fund loan to prop up the pound. (Horne 1989, 440) ${ }^{13}$ The Treasury

\footnotetext{
${ }^{12}$ The French and Israelis were also targeted, but with the former having preemptively shored up its borrowing prior to the crisis for protection, while the latter's actions were heavily dependent on the British and French. See Kunz (1991) for more details.

${ }^{13}$ There is debate about how credible this threat was, and whether Harold Macmillan, the Chancellor of the Exechequer, was overstating the situation. Regardless, it was believed credible at the time, which is most critical. See Love (1969) and Kunz (1991) for more on this argument.
} 
agreed with the dire nature of the situation, saying that "unless we can secure at least US support and a fairly unified Commonwealth then it is not possible to predict either the exact timing or the magnitude of the strains that are likely to come on our currency. At the worst, however, the strains might be so great that, whatever precautionary measures were taken we should be unable to maintain the value of the currency. (PRO T236/4188, 7 September 1956) Second, attempts to purchase oil from other states failed, as the U.S. partnered with Saudi Arabia to embargo Britain and France. This, combined with declarations from other members of NATO that they would not sell any of their oil reserves, hurt immensely. (Love 1969, 651) At the same time, the U.S. was preparing to sell British bonds on the market, which would have quickly devalued the pound and sent the British economy further into a tailspin. (Ibid. 464)

In the lead up to the threat, we see that there are many visible signals emerging from both Britain and the United States. In the case of the former, there are clear indications of domestic turmoil, between the very public disagreements that are taking place between the Conservative Government and Labour Opposition, the high levels of public discontent with the actions of the Conservative Government, and public demonstrations taking place involving tens of thousands of people. Domestically, Eden was facing pressure coming from every direction as he attempted to maintain his position and get an outcome in line with his goals.

Internationally, the situation was no better. The U.S. was making a great deal of effort to undermine British/French/Israeli triumvirate, utilizing a wide variety of levers of influence to prevent further escalation and bring the crisis to a conclusion. Politically, Eisenhower attempted to bring as much pressure to bear as possible at the United Nations, which amounted to a General Assembly resolution following the British and French veto over both U.S. and Soviet-sponsored resolutions condemning the Israeli attack. But more tangibly, the U.S. was also contributing to severe economic pains for Britain, preventing access to needed 
liquid funds and oil. And Eisenhower continually returned to the issue of public opinion, and how a military intervention by these American allies, would be and was unacceptable at home and abroad. It was in this context, with all of these ongoing problems, that the Soviet Union threatened to intervene.

\section{The Soviet Threat: Why It Developed and the Response}

On November 5th, the Soviets issued their threat, with Soviet Premier Bulganin warned the British, French, and Israelis that their behavior could lead to the start of a Third World War, declaring the invasion "an aggressive predatory war... against the Arab peoples with the object of destroying the national independence of the states of the Near and Middle East and of re-establishing the regime of colonial slavery rejected by the peoples..." and threatened "to crush the aggressors and restore peace in the East through the use of force." Bulganin went on to consider:

In what situation would Britain find herself if she were attacked by stronger states, possessing all types of modern destructive weapons and such countries could, at the present time, refrain from sending naval or air forces to the shores of Britain and use other means - for instance, rocket weapons. Were rocket weapons used against Britain and France you would, most probably, call this a barbarous action. But how does the inhuman attack launched by the armed forces of Britain and France against a practically defenceless Egypt differ from this? (Frankland 1959, 289)

The allusions to "rocket weapons," combined with reference to "all types of modern

destructive weapons," has been taken to mean that Bulganin was threatening the use of nuclear weapons in particular against the British, French, and Israelis, though it is questionable whether the Soviets could have actually followed through on such a threat. As Lucas 
(1991) contends, "No one, with the possible exception of Israeli leaders, believed that the Soviets would defend Egypt with nuclear weapons. The Air Ministry was assured by military intelligence that Soviet rockets could not reach Britain since the Soviets did not have launch sites in East Germany or Poland." On the other hand, "It was feared... that the Soviets would land equipment and 'volunteers' in Egypt via Syria." (290) In other words, while the threat of nuclear destruction was not especially credible, the idea that the Soviets might intercede militarily in Egypt was very plausible and concerning. ${ }^{14}$

Within twenty-four hours of the Soviet threat being issued, the British called for a unilateral ceasefire. Without the British providing their support, neither the French nor the Israelis could continue on with their plans, and thus they also backed down. Though foreign soldiers would remain in Egypt for some time longer, the crisis itself had come to an end with major conflict averted.

But why did the Soviets choose to issue a threat at that point in time? There were two major concerns that the Soviet leadership needed to consider when deciding to get directly involved. First, by making such a demand, there was the possibility that it could backfire, by increasing popular support for Eden and the Conservative government, and thus making it more likely that they would try to stick out the crisis. And to a certain extent this did actually occur, as the threat and subsequent Soviet actions motivated some portion of British and American public opinion in favor of intervention, even after the crisis came to a close. (Shaw 1996, 81-2, 194) This supports the idea that the threat itself might have had a counterproductive aspect, making it somewhat less likely that Britain would have conceded.

Second, there was the broader fear that it could have lead to further escalating the crisis regardless of popular opinion, as the Americans could have viewed the threat as raising the stakes of the conflict. Replying to the demand, the U.S. did warn the Soviets that nuclear attacks on either Britain or France would lead to a U.S. response in kind, with General Alfred

\footnotetext{
${ }^{14}$ See also Betts (1987) for a skeptical take on the nuclear aspect of the crisis.
} 
Gruenther, the supreme commander in Europe, stating that if such an attack occurred the Soviet Union would be destroyed "as surely as night follows day." (Prados 56, cited in Betts (1987), 63-4.) Further, Eisenhower ordered that the Sixth Fleet, stationed in Mediterranean, and the Atlantic Fleet be put on alert, though Betts (1987) notes that this also could have been related to the ongoing Hungarian revolution. (64)

In the end, neither of these fears prevented the conflict from coming to an end, as the ceasefire was quickly called by Britain. But this still leaves the question of why the Soviets chose to issue a threat in the first place, as well as the timing. Fukuyama (1980) observes that the peak of the crisis came on October 31st, with the expiration of the British and French ultimatum, and that "A Soviet threat at that point might have deterred the two European power from proceeding." (7) For Fukuyama, the threat's delay to November 5th is tied to the Soviet observation of

several reassuring signals that the Anglo-Franco-Israeli invasion would cease of its own accord: The United States had stated its unconditional opposition to its allies' actions in numerous public statements and its votes for U.N. ceasefire resolutions...; and British Prime Minister Anthony Eden had demonstrated his weakening resolve by agreeing in principle to a ceasefire and police action by U.N. forces. (7)

U.S. attempts to undermine the belligerents had a powerful effect on the British, to the point that these efforts were arguably the most important factor leading to the end of the conflict. According to Lucas (1991), though the British found themselves influenced by both U.S. and Soviet coercion, "the American position was the dominant influence, for US support would have removed all obstacles to continued Anglo-French action... The Soviets would have been deterred by an American warning against intervention, and the US, with her UN allies, could have delayed, if not prevented, the passage of Assembly resolutions." 
(295) This is perfectly in line with the argument put forward by Kunz (1991), arguing that "economic diplomacy defined the course of the Suez crisis from beginning to end," (2) describing British "struggle[s] against the double-barreled American blows of no aid for the pound, no oil for Western Europe... The battle was uneven, the outcome certain." (3) But she also notes the importance of significant divisions in Britain's domestic sphere, as "Eisenhower confessed that he was also puzzled by Eden's willingness to proceed with the invasion when the British people did not wholeheartedly back their government... Indeed, Eisenhower correctly emphasized the growing fissures in British society, the widest since Munich." (129) While the economic pressure was perhaps sufficient to drive Eden to back down, the domestic turmoil he faced was a major contributing factor which, if nothing else, made it that much more difficult to stand firm.

That being said, one must consider whether British domestic turmoil would have been sufficient on its own to cause Eden to back down in the face of a Soviet threat. While British newspapers and the public were certainly in an uproar, trying to disentangle their origins from American actions or the temperature of the Labour Party is a tricky prospect. However, by the time of the London Conference in the middle of August, long before the U.S. had come out publicly against Eden and even about a month before Gaitskell performed his about face, there was already "a solid, recognizable pro-UN, anti-war block [of newspapers], spearheaded by the Daily Herald, News Chronicle, Manchester Guardian, and Observer.", (Shaw 1996, 52) indicative of some identifiable public opposition against any use of force, which would soon expand to include other major newspapers, such as the Daily Mirror. If this sentiment is accurate, then the militarized actions which followed in October and November would have exacerbated these divisions in British public opinion regardless of American actions, and would have eventually put Eden and the Conservative Government in an untenable position.

In contrast, Rucker (2001) argues that the timing had less to do with factors related to 
the invading parties and more with the Soviet Union and Egypt. On the first point, he claims that the Soviet crushing of the Hungarian Revolution on November 4th freed up the Soviets to tackle the Suez Crisis more directly, allowing them to intervene on Egypt's behalf. (80) Second, Rucker points to a November 4th "delegation sent by Nasser to the Soviet embassy in Cairo stat[ing] that if the Soviet Union did not intervene, the regime would not be unable to hold out for longer than 24 hours." (Ibid.) Taken together, this would seem to indicate that the timing of the threat had nothing to do with the British and/or the Americans, and entirely with the Soviets and Egyptians.

However, this argument seems problematic. While the Soviets invaded Hungary on November 4th, the revolution was by no means eliminated by the end of that day. Indeed, the Hungarian Army continued to provide resistance against the Soviet invasion until November 9th, at which point the last vestiges of the resistance were effectively eliminated. Therefore, it is difficult to say that the Soviet leadership could be so sure of their victory so early in the conflict. On the other hand, if we take a prospective approach, given the overwhelming force that the Soviets sought to bring upon the Hungarians and the relative certainty that they could have of their victory, it is not immediately clear why the Soviets would wait until the invasion itself to come to Nasser's aid. Realistically, the only major difference between the 4th and the 5th was the declaration by János Kádár, the new Sovietsupported figurehead, that a new revolutionary government had been established on the morning of the 4 th.

One final piece of evidence to consider comes from a Soviet Staff Study drafted by the Central Intelligence Agency, written in January 1957 but only declassified in 2007. While attempting to understand Soviet goals and intentions towards the Middle East writ large, this document speaks specifically to the Suez Crisis, providing perhaps the best insights available to Soviet decision-making, given that we do not have access to any of their primary documentation. According to this assessment, the Soviets were initially uncertain of the split 
between the U.S. and its allies, with "[First Deputy Chairman of the Council of Ministers of the Soviet Union, Vyacheslav] Molotov attempted to sound out American intentions by suggesting to Ambassador [Charles] Bohlen at the 30 October reception that the United States could have prevented the Israeli attack, adding that of course the United States had acted in collusion with Britain and France.", a claim which Bohlen denied. (CAESAR V-A$56,10)$ By November 5th, however, the Soviets "received several reassuring signals that the Anglo-Franco-Israeli invasion would cease of its own accord," with the U.S.'s "unconditional opposition to its allies' actions in numerous public statements and by its votes for U.N. ceasefire resolutions between October 31st and November 4th" chief among them. (Ibid., 7) They had been "convinced apparently that the divergence between the United States and Britain and France was genuine and that the Nasr regime and its Soviet-equipped armed forces were threatened with destruction." (Ibid., 11) While this last point backs Rucker's claim about the imminent danger that Nasser faced, its emphasis on the split in the alliance is in line with my argument, as the publicly observable actions by the U.S. were finally enough to convince the Soviets that the support of the U.S. was genuinely being withheld.

\section{Summarizing Suez}

To start, it is worth discussing how the decision to back down had little to do with the threat from the Soviet Union itself, and much more with the situation that Eden found himself in at home and in his relationship with the United States. While there might have been some initial concerns about the validity of the Soviet threat, the majority of scholarly work indicates quite clearly that the British and French homelands in particular were never under serious threat. Though the Soviets were able to come away claiming that they brought an end to the conflict through their intervention, it seems much more likely that the threat itself was epiphenomenal to the observed concessions.

Rather, the evidence is strongly supportive of the idea that Britain in particular chose 
to end the crisis due to immense pressure from at home and the United States. And without Britain driving the conflict, France and Israel quickly agreed to a peaceful resolution. Domestically, Prime Minister Anthony Eden found himself facing a major groundswell of discontent, with public opinion turning against him and the Conservative Government. With the opposition able to harness the anger of tens of thousands of protesters marching in the streets, along with the media largely critiquing government actions, any attempts to push forward through the conflict quickly became untenable.

Also critical to ending the fighting was the coercive influence of the U.S. Bringing both political and economic pressure to bear, the U.S. made it incredibly difficult for the British to continue forth with their invasion plans. On the political side, the Americans went through great lengths to undermine the narrative of Israeli self-defense set forth by the British and her co-conspirators, and were able to collect an enormous coalition of supporters in the U.N. General Assembly to vote against the aggressive actions, even after attempts to do so in the Security Council were fruitless. Economically, the Americans spearheaded an effort to deny the British with critically needed economic aid through the IMF, as well as withhold the oil necessary for maintaining the British industrial machine.

But the decision by the Soviets to issue their threat appears intimately connected to signals that they received during the lead up to and early stages of the crisis. According to U.S. reports and secondary sources, Soviet policymakers eventually became convinced of the genuine rift between the Americans and her allies, making coercive diplomacy an attractive option. And much of this signaling was taking place in very public venues, not the least of which was the United Nations, as well as statements following the Israeli incursion and subsequent British and French invasion into Egypt.

While there is no direct evidence that Britain's domestic turmoil influenced the Soviet decision to intervene, the timing of events seems to suggest that it likely had some degree of impact. Within twenty-four hours of major protests in Trafalgar Square, involving tens 
of thousands of British protesters, the threat was issued. While the Labour Party had been railing against Eden's handling of the crisis for days ahead of time, it appears plausible that it required first the British and French being directly involved militarily in Suez and the subsequent public backlash for the Soviets to believe that the threat would avoid backfiring. But that these protests took place simultaneously with the second U.N. vote against the belligerents, a vote which the U.S. supported, makes it difficult to disentangle these effects.

Overall, however, there is ample evidence to indicate that the domestic upheaval faced by Britain and the American unwillingness to support her allies played a critical role in the threat emerging, as well as the subsequent decision to end the crisis. While we would, in an ideal world, be able to draw upon the Soviet primary documents to confirm these inferences, we can only rely on British and American primary documents to inform our conclusions. But even in the absence of such resources, we can still find that domestic politics in Britain and the United States stimulated events, with public opinion and the unpopularity of military action drove Eden first out of Egypt and eventually out of office and pushed Eisenhower to take a strong stand against his allies.

\section{Conclusion}

The goal of this chapter was to employ two case studies, the Munich and Suez Crises, to demonstrate how my theory of democratic vulnerability works from a historical perspective. Using the case selection criteria provided by Weller and Barnes (2014), I identified my cases as ones where the democratic nature of the target and its allies contributed to compliance, while avoiding both situations where it could have been an "easy" case for my theory as well as sticking with cases that are substantively of interest in their own right. I then discussed what happened in each crisis, what took place in the lead up to the threats being made and the responses to the demands, making use of both primary and secondary sources, while 
emphasizing the former wherever possible.

What we observe in each of these cases matches up very well with the expectations of the theory, particularly on the alliance side. In both crises, there is substantial evidence to show that public opinion played an important role in influencing how the leaders of democratic allies chose to intervene (or not) on behalf of their protégés, including numerous documents from Nazi Germany showing how they paid attention to the British and French publics in particular during Munich, and a declassified CIA document discussing the high likelihood that U.S. behavior, driven by fear of public backlash, led to the Soviet demands. In short, we first see signals of vulnerability coming from the allies, which are picked up by the revisionist states, and leads to the coercive attempts.

On the target side, things are more complex. This is partly because of the enormous impact that the allies had on their own, which makes it difficult to disentangle the separate effects of the targets and allies. In the stronger of the two cases, Suez, it is clear that Britain had enormous instability at home which made it difficult for them to remain in Suez, especially after the U.S. decided to stay out. And arguably, from a counterfactual perspective, Britain's domestic instability could have been sufficient to force them out of Egypt. But due to the impact of U.S. decision-making, we cannot say this for certain. As I will discuss in the conclusion chapter, future revisions will address this concern by bringing in cases where the target had no significant allies of note.

The other complication comes from the Munich case, where the democratic nature of Czechoslovakia did serve to cause complications, but not precisely in the manner that was predicted by the theory. Hitler's ability to manipulate the Sudeten Germans, thus creating discontent and vulnerability, is very much related to the argument of this project. It demonstrates a clear signal to other states that coercion has a higher chance of success, due to these divisions which threatened to tear the country apart. However, that this discord was purposefully created by Nazi Germany should not be discounted. 
In general, however, the results from these case studies largely conform to the expectations of the theory, and serve as useful demonstrations of the mechanisms. There still remains more work to be done in order to further elucidate these mechanisms, which, as noted above, will be involve the use of additional case studies. Nonetheless, these cases serve as a critical step, bridging the gap between the theory and what was derived from the statistical results, while examining both the selection process of threat development as well as how responses are managed by the targets and their allies. 


\section{Chapter 6}

\section{Conclusion}

This dissertation sought to demonstrate the influence that regime-type has on coercive success, focusing on targets and their allies. Threats do not occur randomly, and are often made strategically in an attempt to get concessions cheaply. In short, when one state observes a vulnerability in another, they use that opening to issue a threat with the hope of getting something without having to follow through. The more information that a potential challenger has available to them on the resolve of the target and its allies, the easier it is to identify when a threat is more likely to succeed.

Building on this logic, I argued that democratic targets and targets with democratic allies are more likely to make concessions when they are threatened, due to the higher costs that democratic leaders pay for foreign policy failures and the greater likelihood that these costs can be observed. While the idea that democratic leaders pay higher costs is well-grounded in international relations scholarship, I contend that the higher probability of paying those costs comes from the transparent nature of democratic regimes. Since they allow protests and demonstrations criticizing the regime to take place, democracies provide credible signals of their vulnerability which are inherently observable to outside actors. These internal disruptions allow potential challengers to update their beliefs of the regime's vulnerability, 
which allows for the use of targeted and ultimately more successful threats.

This relationship is even stronger with democratic allies. While targets may get some benefit from being threatened in the form of increased support for the regime, this is not the case with an ally who is not directly threatened. Further, given that the ally has to contend with its public not wanting to fight and die on behalf of another state, the ally faces powerful incentives to avoid conflict while not openly abandoning the target and inviting questions about other alliance commitments. This provides incentives for the ally to pressure the target into making concessions, as it prevents the challenger from following through on the threat and does not directly violate the terms of the alliance.

Chapter 2 covered the minutiae of the theory, walking through why democracies as targets and allies are more likely to be successfully coerced. This chapter called attention to the importance of events that take place prior to the initiation of the threat, but after the challenger and target have entered into a crisis. Threats rarely emerge out of nowhere, and it is in this pre-threat state of the crisis that the target and/or ally can send this important signals of vulnerability, thus providing an opening for the challenger to make demands.

This chapter also elaborated on precisely when we should expect to see the argument come into play. Particularly important, it laid out scope conditions for when democracies should be most vulnerable, arguing that whether the target or ally is democratic matters under different circumstances. For democratic targets, there are no restrictions, and we should expect to see that a wide variety of public threats should match up with the theory. On the other hand, it is a relatively narrow set of threats that would cause the alliance mechanism to kick into action, as there are comparatively few situations where the target being threatened would endanger the ally, such as militarized conflict. These logics are outlined in detail using formal models, demonstrating how democratic targets and allies should be more likely to make concessions.

Chapter 3 turned to the first set of statistical evidence for the argument, looking at 
threats involving military force. The Militarized Compellent Threat dataset, which includes all cases of explicit threats of militarized violence from 1918 to 2001, was utilized here to test how democratic targets and those states with democratic allies respond to such threats. For targets, the results were quite clear: across the board, in all of the models, democratic targets concede more readily than do non-democracies. In the case of democratic allies, the results are slightly more nuanced, as those states with democratic allies do concede compared to those that do not. However, once these results are broken down into comparisons with targets that have no allies and those with non-democratic allies, there is only a clear differentiation when compared to the former category. That being said, when measures of democracy for both the target and ally are combined, it is clear that democratic targets allied with fellow democracies are by far the most likely pairing to make concessions in the face of violent threats.

Chapter 4 followed a similar track, providing statistical evidence derived from the Threat and Imposition of Economic Sanctions dataset in order to demonstrate the validity of the theory. Unlike the previous chapter, however, these findings were only focused on the targets themselves, as they are the only actors that can be reasonably expected to pay significant costs for having sanctions imposed on them. In contrast, the target's allies should have no significant expectation that the target being sanctioned should harm them as well. While not as dramatic as the prior findings, this chapter nonetheless demonstrated that democratic states that are threatened with economic sanctions still concede at higher rates than do nondemocracies in all of the models, and regardless of whether low cost threats were included or excluded.

Moving away from broad findings to examine the mechanisms driving the results, Chapter 5's two case studies provided evidence that democratic targets and those allied with democracies are more vulnerable to coercion. The Munich Crisis focused on the decisionmaking process of the challenger, Germany, as Adolph Hitler weighed his options prior to 
threatening Czechoslovakia. Using evidence from the Nazi's Foreign Office, this case study shows how the weakness of the British in particular was known to the Germans, and that the public was noticeably against getting involved militarily on the continent. In addition, while the Czechs were prepared to fight, Hitler's knowledge of the Sudeten Germans' willingness to fight and the disruptions taking place in Czechoslovakia made the decision to issue the threat more likely.

In contrast, the Suez Crisis emphasizes the decision-making taking place in Britain and the United States in the lead-up to and aftermath of the Soviet "nuclear" threat. Drawing from evidence provided via British and American primary documents, this case study clearly shows how concerned leaders in both states were with the role of public opinion and how it influenced their ability to act. For the British, their fears quickly came to fruition as the crisis unfolded, with the social fabric of the state threatening to come apart by the time the threat was issued, leaving no option other than to stand down. For the Americans, domestic opinion being against any action clearly influenced Eisenhower's willingness to act on behalf of the British and French, leading to public statements and actions that undermined the latter's positions in Egypt. Put together, the democratic nature of the target and ally in this case made concessions inevitable.

\section{Implications for Theory}

On the theoretical side, this dissertation has touched wide swaths of the literature, further developing or expanding some arguments while providing important challenges to others. One of the greatest contributions is to the debate on democratic exceptionalism, joining works such as Downes (2009) in calling for a reevaluation of how "smart and tough" democracies truly are. By shifting the focus away from actualized conflict to coercive diplomacy writ large, this project goes beyond the argument of Downes and Sechser (2012) to say that not only might democracies be on a level playing field with non-democracies, but they actually 
might have critical disadvantages that should be better understood.

Similarly, much importance has been given to how the use of signaling, with the lion's share being directed at their positive impact. Even more recent work which contends that non-democratic states can credibly signal their intentions, such as Weeks (2012) and Weiss (2014), argue that these signals are able to help the state credibly indicate their preferences. In contrast, this dissertation points to the inherent vulnerability that these signals can transmit, and how this weakness is built in to democratic regimes in particular.

The addition of coercive diplomacy to the study of alliance politics also has great added value. Previous analysis has overwhelmingly focused on how alliances and alliance partners matter in the context of fighting, such as whether democracies make more credible commitments to one another or if they are more likely to come to one another's aid. While not explicitly agreeing with the conclusions reached by Gartzke and Gleditsch (2004) regarding war, this dissertation concurs that democratic allies are not necessarily inherently trustworthy and reliable, and might very well be less dependable than previous research has led us to believe.

\section{Implications for Policymakers}

An important question that policymakers must grapple with is how their state can effectively and credibly indicate resolve during a crisis. There is a vast literature on crisis signaling and how to signal resolve which is too large to effectively summarize here, ${ }^{1}$ but often the emphasis is placed on active choices that leaders can make to transmit information. Given the desire for individuals to shape or control events, this is not an unreasonable approach to take.

However, it misses out on involuntary information that cannot be avoided. The theory put forward in this dissertation claims that signals sent due to the role of a dissatisfied

\footnotetext{
${ }^{1}$ For examples, see
} 
public are credible, but can rarely be controlled. Indeed, it is the very fact that they can only serve to hurt or undermine the transmitting state that makes the signals credible. So, while policymakers can emphasize the importance of certain signals they can influence, they must also be keenly aware of those that they have no leverage over. By being aware of this vulnerability, it may be possible for policymakers in democratic states to either head off potential threats before they emerge, possibly by making lower-level concessions, or manage threats more properly in order to save face when they do materialize.

On the alliance side of things, policymakers should be aware of the potential risks that come along with entering into alliances and then subsequently failing to follow through on the agreement. More precisely, there is an important distinction between failing to commit to the letter of an alliance and the spirit of an alliance; though the latter is likely to be less damaging than the former, it nonetheless has consequences later down the line which should be studied in greater detail.

In some ways, the Trump administration could very well serve as an important litmus test for my alliance argument. President Trump has often professed a dislike and distrust of alliances, particularly NATO, claiming that they provide little benefit to the United States while imposing costs that are not borne fairly by the U.S.'s partners. If the Trump administration continues to use public displays of discontent towards U.S. allies and showing an unwillingness to intervene on their behalf, this could lead to future threats against those allies. This is especially true if the American public becomes increasingly unwilling to fight in foreign wars, perceiving them as someone else's problem. In addition, this effect could plausibly trickle down to other states where right-wing populism gains traction. If, as in the Munich case, it becomes possible for an outside actor to manipulate domestic divisions to create discontent and anger, this could provide opportunities for selective demands that the public is willing to comply with. 


\section{Future Research}

While this dissertation marks an important shift in how we think about coercive diplomacy and democracy, further work still needs to be done. Though the primary distinction here is between democratic and non-democratic states, recent work has emphasized the importance of disaggregating non-democratic states in a variety of ways. (Weeks 2008, 2012; Weiss 2013, 2014) Performing a similar examination in coercive diplomacy would certainly yield additional findings, and provide a richer analysis amongst the various different types of nondemocratic regimes. While I have already performed some preliminary estimations along these lines which has not been included here, future work will be developed along these lines.

Though the argument made here claims that democracies should be more likely to make concessions than non-democracies, this also obscures the way in which certain types of nondemocracies mimic democracies in terms of their transparency. ${ }^{2}$ As such, we should expect to observe that these types of "transparent" non-democracies should act in similar ways to democratic regimes. This would require a coding scheme which focuses exclusively on how transparent a state is, according to the characterization provided in Chapter 2, a task which I aim to perform in future research as well.

Moving beyond regime-type, there are other puzzling findings which should call for further analysis. In particular, it is interesting to note how powerful states are more likely to be successfully coerced. ${ }^{3}$ Regardless of the particular measure employed (i.e. major/minor power distinction, nuclear target), powerful states appear more likely to make concessions than do weaker states. Understanding why this dynamic is the case, and why stronger states ultimately concede more often, is a fascinating puzzle that should be developed in greater

\footnotetext{
${ }^{2}$ There are also arguments to be made about the variation among and between democracies. For example, Potter and Baum (2013) and Baum and Potter (2015) demonstrate how only democracies with a strong opposition party or parties in addition to strong, independent media sources are likely to generate audience costs and make threats that will not be reciprocated.

${ }^{3}$ In contrast, see Sechser $(2010,2017)$ on the difficulties of coercing weak states.
} 
detail.

Finally, though this project focuses on reciprocation of threats, more work needs to be performed on how and when threats emerge in the first place. Poznansky and Scroggs (2016) serves as an effective starting point, emphasizing the relationship between democratic peace and coercive diplomacy, but examining other factors that impact threat onset in militarized cases, as well as looking at other varieties of threats, is well worth the attention of scholars. 


\section{Appendix A}

\section{Militarized Threats Appendix}

This appendix includes material that is directly relevant to the results from Chapter 3, militarized threats. I will begin by first providing the full definitions for the variables included in the analysis, before moving a replication of Schultz (2001a) via Downes and Sechser (2012), utilizing the MIDS data instead of MCT, with the addition of an alliance variable, and closing with the extended tables from the chapter.

\section{Definitions}

Each table has a number of different variables related to the target, initiator, and ally's democratic nature. They are:

- Initiator and Target Regime-Type Variables: these variables, derived from the Boix, Miller, and Rosato, and Polity datasets, indicate whether the initiator and target are democratic or not. These are measured in one of two ways: dichotomously, with two indicators, one for the initiator and one for the target; and dyadically, with a single indicator combining the measure for the initiator and target.

- Ally's Regime-Type Variable: this trichotomous variable takes on a different value 
depending, first, on the presence of a major ally (defined as a state that has at least $1 \%$ of the CINC value for a given year) and, second, on whether it is a democracy or not.

In addition, each table shares the same set of control variables, which are presented in order:

- Contiguity: a dichotomous variable, given a 1 if the two states shared a border or were within 150 miles of one another by water.

- $S$-score: a continuous measure of shared foreign policy preferences, based on United Nations voting and alliance portfolios.

- CINC Ratio: the CINC score for the initiator divided by that of the target, to indicate how much of a material advantage the initiator held at the time of the threat.

- Major Initiator/Target: binary indicators telling whether the initiator and/or target qualified as a "major" power, per the Correlates of War dataset.

- Nuclear Initiator/Target: binary indicators telling whether the intiator and/or target had nuclear weapons at the time of the threat.

- Territory and Leadership: dichotomous measures indicating whether the threat involved demands for territory or the target's leadership.

- Ally Threat: a dichotomous measure for whether the threat also came from the target's most powerful ally.

\section{MIDS Replication}

One avenue of examination which requires its own section is an analysis of the Militarized Interstate Dispute (MID) data. While it has been argued above that there are serious 
limitations to the data, it is nonetheless worthwhile to see how the results contrast with the MCT data. ${ }^{1}$ In order to stick most closely to what other scholars have previously done, I first utilize a replication of Schultz (2001a) created by Downes and Sechser (2012) as a starting point, which I then added measures for the target's most powerful ally per my coding rules above. In addition, I rerun the models using the closest approximations of the variables from the main results in Chapter 3. The analysis of the first replication can be found in Table A.1, while the second is available in Table A.2.

To briefly summarize the findings, the democratic target indicators provide little useful information. In all four of the models, the coefficients point in the positive direction, but none begin to approach statistical significance. It is difficult to take away anything concrete from these results, apart from the failure to reject the null hypothesis that democratic targets are any more or less likely to reciprocate a dispute than are non-democratic targets.

In contrast, the democratic ally measures appear to be much more fruitful. While the results with the Boix, Miller, and Rosato measure of democracy are relatively poor, with the first replication showing no statistical significance and the second only reaching weak levels, this is not the case with Polity. In both models utilizing the Polity measure of democracy, states that have democratic allies are less likely to reciprocate a threat, as my theory would predict.

While we should be hesitant to take any of these results at their face due to the problems of data quality outlined above, the evidence is in favor of the alliance mechanism while failing to support the target mechanism. Ideally, these results will eventually be able to be tested against the reworked MIDS data per the suggestions of Gibler, Miller and Little (2016), as this would provide a much better test of the argument on its merits. For now, however,

\footnotetext{
${ }^{1}$ As an example of why caution should be employed with the MID data: according to Gibler, Miller and Little (2016), 251 of the more than 2000 cases should be dropped entirely, while another 234 disputes require major changes (e.g. year, fatality level, participants, etc.) and over 1000 need minor revisions (such as start and end dates). With these modifications, the authors find that many previous results disappear or even reverse. As of the time of this writing, this reworked MID data is not publicly available.
} 
Table A.1: Schultz (2001a) Replication via Downes and Sechser (2012) - MIDS

\begin{tabular}{|c|c|c|}
\hline VARIABLES & $\begin{array}{c}(1) \\
\text { BMR }\end{array}$ & $\begin{array}{c}(2) \\
\text { Polity }\end{array}$ \\
\hline Democratic Ally & $\begin{array}{c}-0.135 \\
(0.0897)\end{array}$ & $\begin{array}{c}-0.0129 * * \\
(0.00573)\end{array}$ \\
\hline Democratic Challenger & $\begin{array}{l}-0.137 \\
(0.163)\end{array}$ & $\begin{array}{l}-0.206 \\
(0.170)\end{array}$ \\
\hline Democratic Target & $\begin{array}{c}0.0627 \\
(0.149)\end{array}$ & $\begin{array}{c}0.00817 \\
(0.147)\end{array}$ \\
\hline Both Democratic & $\begin{array}{l}0.0851 \\
(0.297)\end{array}$ & $\begin{array}{c}0.132 \\
(0.307)\end{array}$ \\
\hline Major/Major & $\begin{array}{l}-0.132 \\
(0.323)\end{array}$ & $\begin{array}{r}-0.0975 \\
(0.273)\end{array}$ \\
\hline Major/Minor & $\begin{array}{l}-0.158 \\
(0.187)\end{array}$ & $\begin{array}{l}-0.140 \\
(0.183)\end{array}$ \\
\hline Minor/Minor & $\begin{array}{c}0.177 \\
(0.234)\end{array}$ & $\begin{array}{c}0.298 \\
(0.229)\end{array}$ \\
\hline Initiator's Capabilities & $\begin{array}{l}-0.118 \\
(0.222)\end{array}$ & $\begin{array}{c}-0.0459 \\
(0.223)\end{array}$ \\
\hline Contiguity & $\begin{array}{c}0.753^{* * *} \\
(0.139)\end{array}$ & $\begin{array}{c}0.649 * * * \\
(0.133)\end{array}$ \\
\hline Alliance Portfolio Similarity & $\begin{array}{l}-0.184 \\
(0.221)\end{array}$ & $\begin{array}{c}0.216 \\
(0.211)\end{array}$ \\
\hline Status Quo Evaluation of Initiator & $\begin{array}{l}-0.232 \\
(0.188)\end{array}$ & $\begin{array}{l}-0.120 \\
(0.182)\end{array}$ \\
\hline Status Quo Evaluation of Challenger & $\begin{array}{r}-0.0197 \\
(0.236)\end{array}$ & $\begin{array}{c}-0.0256 \\
(0.206)\end{array}$ \\
\hline Territory & $\begin{array}{l}0.301^{*} \\
(0.158)\end{array}$ & $\begin{array}{c}0.297^{*} \\
(0.157)\end{array}$ \\
\hline Government & $\begin{array}{c}0.435 \\
(0.332)\end{array}$ & $\begin{array}{c}0.127 \\
(0.339)\end{array}$ \\
\hline Policy & $\begin{array}{c}-0.976^{* * *} \\
(0.138)\end{array}$ & $\begin{array}{c}-1.215^{* * *} \\
(0.136)\end{array}$ \\
\hline Other & $\begin{array}{l}-0.615 \\
(0.550)\end{array}$ & $\begin{array}{l}-0.603 \\
(0.549)\end{array}$ \\
\hline Constant & $\begin{array}{c}0.0457 \\
(0.263)\end{array}$ & $\begin{array}{r}-0.0831 \\
(0.256)\end{array}$ \\
\hline Observations & 1,445 & 1,526 \\
\hline
\end{tabular}


Table A.2: MIDS Replication with Table 3.7 Variables

\begin{tabular}{|c|c|c|}
\hline VARIABLES & $\begin{array}{c}(1) \\
\text { BMR }\end{array}$ & $\begin{array}{c}(2) \\
\text { Polity }\end{array}$ \\
\hline Democratic Ally & $\begin{array}{l}-0.144^{*} \\
(0.0815)\end{array}$ & $\begin{array}{r}-0.0122^{* *} \\
(0.00550)\end{array}$ \\
\hline Target Democracy & $\begin{array}{c}0.0392 \\
(0.127)\end{array}$ & $\begin{array}{l}0.0449 \\
(0.124)\end{array}$ \\
\hline Initiator Democracy & $\begin{array}{c}-0.226 \\
(0.139)\end{array}$ & $\begin{array}{c}-0.217 \\
(0.139)\end{array}$ \\
\hline Contiguity & $\begin{array}{c}0.761^{* * *} \\
(0.137)\end{array}$ & $\begin{array}{c}0.642^{* * *} \\
(0.132)\end{array}$ \\
\hline CINC Ratio & $\begin{array}{l}-0.140 \\
(0.222)\end{array}$ & $\begin{array}{c}-0.0850 \\
(0.224)\end{array}$ \\
\hline$S$-Score & $\begin{array}{c}-0.114 \\
(0.217)\end{array}$ & $\begin{array}{c}0.287 \\
(0.212)\end{array}$ \\
\hline Major Initiator & $\begin{array}{l}-0.239 \\
(0.174)\end{array}$ & $\begin{array}{l}-0.204 \\
(0.175)\end{array}$ \\
\hline Major Target & $\begin{array}{l}0.0472 \\
(0.220)\end{array}$ & $\begin{array}{c}0.285 \\
(0.218)\end{array}$ \\
\hline Nuclear Initiator & $\begin{array}{c}0.334 \\
(0.259)\end{array}$ & $\begin{array}{l}0.0793 \\
(0.214)\end{array}$ \\
\hline Nuclear Target & $\begin{array}{c}0.270 \\
(0.267)\end{array}$ & $\begin{array}{l}-0.189 \\
(0.243)\end{array}$ \\
\hline Territory & $\begin{array}{c}0.308^{* *} \\
(0.157)\end{array}$ & $\begin{array}{l}0.295^{*} \\
(0.157)\end{array}$ \\
\hline Government & $\begin{array}{c}0.416 \\
(0.333)\end{array}$ & $\begin{array}{c}0.145 \\
(0.341)\end{array}$ \\
\hline Policy & $\begin{array}{c}-0.989^{* * *} \\
(0.139)\end{array}$ & $\begin{array}{c}-1.206^{* * *} \\
(0.136)\end{array}$ \\
\hline Other & $\begin{array}{l}-0.573 \\
(0.553)\end{array}$ & $\begin{array}{l}-0.534 \\
(0.552)\end{array}$ \\
\hline Ally Threat & $\begin{array}{c}-0.414 \\
(0.403)\end{array}$ & $\begin{array}{l}-0.531 \\
(0.395)\end{array}$ \\
\hline Constant & $\begin{array}{l}0.0310 \\
(0.249)\end{array}$ & $\begin{array}{c}-0.0946 \\
(0.245)\end{array}$ \\
\hline Observations & 1,445 & 1,526 \\
\hline
\end{tabular}


these replications serve as a useful comparison of the MCT and MIDS data, as well as a robustness check for my argument.

\section{Extended Chapter Tables}

The tables will proceed in order:

- Table 3.7: Dichotomous Measures of Democracy - MCT

- Table 3.10: Dichotomous Measures, Non-Democratic Ally Baseline - MCT

- Table 3.11: Target/Ally Combination, Democratic Target and Ally Baseline - MCT

- Table 3.14: Dyadic Measures of Democracy - MCT

- Table 3.17: Dyad Measures, Non-Democratic Ally Baseline - MCT 
Table A.3: Dichotomous Measures of Democracy- MCT (3.7)

\begin{tabular}{|c|c|c|}
\hline VARIABLES & $\begin{array}{c}(1) \\
\text { BMR }\end{array}$ & $\begin{array}{c}(2) \\
\text { Polity }\end{array}$ \\
\hline Target Democracy & $\begin{array}{c}0.805^{* *} \\
(0.405)\end{array}$ & $\begin{array}{c}1.046^{* *} \\
(0.520)\end{array}$ \\
\hline Democratic Ally & $\begin{array}{c}1.340^{* * *} \\
(0.462)\end{array}$ & $\begin{array}{c}1.389^{* * *} \\
(0.518)\end{array}$ \\
\hline Non-Democratic Ally & $\begin{array}{c}0.119 \\
(0.772)\end{array}$ & $\begin{array}{l}-0.154 \\
(0.785)\end{array}$ \\
\hline Initiator Democracy & $\begin{array}{l}-0.329 \\
(0.428)\end{array}$ & $\begin{array}{l}-0.410 \\
(0.383)\end{array}$ \\
\hline Contiguity & $\begin{array}{l}-0.332 \\
(0.411)\end{array}$ & $\begin{array}{l}-0.194 \\
(0.425)\end{array}$ \\
\hline CINC Ratio & $\begin{array}{c}0.00147 \\
(0.00122)\end{array}$ & $\begin{array}{c}0.00170 \\
(0.00224)\end{array}$ \\
\hline$S$-Score & $\begin{array}{l}-0.831 \\
(0.718)\end{array}$ & $\begin{array}{l}-0.836 \\
(0.758)\end{array}$ \\
\hline Major Initiator & $\begin{array}{l}-0.579 \\
(0.434)\end{array}$ & $\begin{array}{l}-0.576 \\
(0.465)\end{array}$ \\
\hline Major Target & $\begin{array}{l}1.190^{* *} \\
(0.479)\end{array}$ & $\begin{array}{l}1.226^{* *} \\
(0.549)\end{array}$ \\
\hline Nuclear Initiator & $\begin{array}{l}-1.361^{*} \\
(0.699)\end{array}$ & $\begin{array}{c}-1.281^{*} \\
(0.707)\end{array}$ \\
\hline Nuclear Target & $\begin{array}{l}1.554^{*} \\
(0.891)\end{array}$ & $\begin{array}{c}1.431 \\
(0.990)\end{array}$ \\
\hline Territory & $\begin{array}{l}-0.481 \\
(0.392)\end{array}$ & $\begin{array}{l}-0.473 \\
(0.404)\end{array}$ \\
\hline Leadership & $\begin{array}{c}2.327^{* * * *} \\
(0.681)\end{array}$ & $\begin{array}{c}2.232^{* * *} \\
(0.668)\end{array}$ \\
\hline Ally Threat & $\begin{array}{c}0.618 \\
(0.901)\end{array}$ & $\begin{array}{c}0.715 \\
(0.905)\end{array}$ \\
\hline Constant & $\begin{array}{l}0.0578 \\
(0.742)\end{array}$ & $\begin{array}{l}0.0484 \\
(0.799)\end{array}$ \\
\hline Observations & 201 & 197 \\
\hline
\end{tabular}


Table A.4: Dichotomous Measures, Non-Democratic Ally Baseline - MCT (3.10)

\begin{tabular}{|c|c|c|}
\hline VARIABLES & $\begin{array}{c}(1) \\
\text { BMR }\end{array}$ & $\begin{array}{c}(2) \\
\text { Polity }\end{array}$ \\
\hline No Ally & $\begin{array}{l}-0.119 \\
(0.772)\end{array}$ & $\begin{array}{c}0.154 \\
(0.785)\end{array}$ \\
\hline Democratic Ally & $\begin{array}{c}1.221 \\
(0.770)\end{array}$ & $\begin{array}{l}1.543^{*} \\
(0.794)\end{array}$ \\
\hline Target Democracy & $\begin{array}{c}0.805^{* *} \\
(0.405)\end{array}$ & $\begin{array}{c}1.046^{* *} \\
(0.520)\end{array}$ \\
\hline Initiator Democracy & $\begin{array}{l}-0.329 \\
(0.428)\end{array}$ & $\begin{array}{l}-0.410 \\
(0.383)\end{array}$ \\
\hline Contiguity & $\begin{array}{l}-0.332 \\
(0.411)\end{array}$ & $\begin{array}{l}-0.194 \\
(0.425)\end{array}$ \\
\hline CINC Ratio & $\begin{array}{c}0.00147 \\
(0.00122)\end{array}$ & $\begin{array}{c}0.00170 \\
(0.00224)\end{array}$ \\
\hline$S$-Score & $\begin{array}{l}-0.831 \\
(0.718)\end{array}$ & $\begin{array}{l}-0.836 \\
(0.758)\end{array}$ \\
\hline Major Initiator & $\begin{array}{l}-0.579 \\
(0.434)\end{array}$ & $\begin{array}{l}-0.576 \\
(0.465)\end{array}$ \\
\hline Major Target & $\begin{array}{c}1.190^{* *} \\
(0.479)\end{array}$ & $\begin{array}{l}1.226^{* *} \\
(0.549)\end{array}$ \\
\hline Nuclear Initiator & $\begin{array}{l}-1.361^{*} \\
(0.699)\end{array}$ & $\begin{array}{c}-1.281^{*} \\
(0.707)\end{array}$ \\
\hline Nuclear Target & $\begin{array}{l}1.554^{*} \\
(0.891)\end{array}$ & $\begin{array}{l}1.431 \\
(0.990)\end{array}$ \\
\hline Territory & $\begin{array}{l}-0.481 \\
(0.392)\end{array}$ & $\begin{array}{l}-0.473 \\
(0.404)\end{array}$ \\
\hline Leadership & $\begin{array}{c}2.327^{* * * *} \\
(0.681)\end{array}$ & $\begin{array}{c}2.232^{* * *} \\
(0.668)\end{array}$ \\
\hline Ally Threat & $\begin{array}{c}0.618 \\
(0.901)\end{array}$ & $\begin{array}{c}0.715 \\
(0.905)\end{array}$ \\
\hline Constant & $\begin{array}{c}0.176 \\
(1.052)\end{array}$ & $\begin{array}{c}-0.105 \\
(1.105)\end{array}$ \\
\hline Observations & 201 & 197 \\
\hline
\end{tabular}


Table A.5: Target/Ally Combination, Democratic Target and Ally Baseline - MCT (3.11)

\begin{tabular}{|c|c|c|}
\hline VARIABLES & $\begin{array}{c}(1) \\
\text { BMR }\end{array}$ & $\begin{array}{c}(2) \\
\text { Polity } \\
\end{array}$ \\
\hline Non-Demo, No Ally & $\begin{array}{c}-3.775^{* * *} \\
(1.205)\end{array}$ & $\begin{array}{c}-3.508^{* * *} \\
(1.235)\end{array}$ \\
\hline Demo, No Ally & $\begin{array}{c}-3.508^{* * *} \\
(1.200)\end{array}$ & $\begin{array}{l}-2.058 \\
(1.267)\end{array}$ \\
\hline Non-Demo, Non-Demo Ally & $\begin{array}{c}-3.346^{* *} \\
(1.345)\end{array}$ & $\begin{array}{c}-2.775^{* *} \\
(1.335)\end{array}$ \\
\hline Demo, Non-Demo Ally & $\begin{array}{c}-4.926^{* * *} \\
(1.402)\end{array}$ & $\begin{array}{c}-4.470^{* * *} \\
(1.350)\end{array}$ \\
\hline Non-Demo, Demo Ally & $\begin{array}{c}-3.462^{* * *} \\
(1.199)\end{array}$ & $\begin{array}{c}-2.347^{*} \\
(1.249)\end{array}$ \\
\hline Initiator Democracy & $\begin{array}{l}-0.269 \\
(0.485)\end{array}$ & $\begin{array}{l}-0.418 \\
(0.412)\end{array}$ \\
\hline Contiguity & $\begin{array}{l}-0.483 \\
(0.453)\end{array}$ & $\begin{array}{l}-0.418 \\
(0.392)\end{array}$ \\
\hline CINC Ratio & $\begin{array}{c}0.00214 \\
(0.00318)\end{array}$ & $\begin{array}{c}0.00155 \\
(0.00126)\end{array}$ \\
\hline$S$-Score & $\begin{array}{l}-0.569 \\
(0.782)\end{array}$ & $\begin{array}{l}-0.649 \\
(0.785)\end{array}$ \\
\hline Major Initiator & $\begin{array}{l}-0.420 \\
(0.472)\end{array}$ & $\begin{array}{l}-0.530 \\
(0.477)\end{array}$ \\
\hline Major Target & $\begin{array}{c}1.777^{* * *} \\
(0.588)\end{array}$ & $\begin{array}{c}1.587^{* * *} \\
(0.556)\end{array}$ \\
\hline Nuclear Initiator & $\begin{array}{c}-1.560^{* *} \\
(0.770)\end{array}$ & $\begin{array}{l}-1.444^{*} \\
(0.745)\end{array}$ \\
\hline Nuclear Target & $\begin{array}{c}1.134 \\
(1.108)\end{array}$ & $\begin{array}{c}0.938 \\
(1.015)\end{array}$ \\
\hline Territory & $\begin{array}{l}-0.460 \\
(0.420)\end{array}$ & $\begin{array}{l}-0.564 \\
(0.437)\end{array}$ \\
\hline Leadership & $\begin{array}{c}2.295^{* * *} \\
(0.721)\end{array}$ & $\begin{array}{c}2.268^{* * *} \\
(0.709)\end{array}$ \\
\hline Ally Threat & $\begin{array}{c}0.433 \\
(0.903)\end{array}$ & $\begin{array}{c}0.231 \\
(0.895)\end{array}$ \\
\hline Constant & $\begin{array}{c}3.760^{* *} \\
(1.543)\end{array}$ & $\begin{array}{c}3.575^{* *} \\
(1.410)\end{array}$ \\
\hline Observations & 201 & 197 \\
\hline
\end{tabular}


Table A.6: Dyadic Measures of Democracy- MCT (3.14)

\begin{tabular}{|c|c|c|}
\hline VARIABLES & $\begin{array}{c}(1) \\
\text { BMR }\end{array}$ & $\begin{array}{c}(2) \\
\text { Polity }\end{array}$ \\
\hline Demo/ Demo & $\begin{array}{r}-0.0259 \\
(0.532)\end{array}$ & $\begin{array}{l}-0.337 \\
(0.426)\end{array}$ \\
\hline$\sim$ Demo/Demo & $\begin{array}{l}1.082^{* *} \\
(0.511)\end{array}$ & $\begin{array}{l}1.131^{*} \\
(0.596)\end{array}$ \\
\hline Demo/Demo & $\begin{array}{r}-0.0147 \\
(0.668)\end{array}$ & $\begin{array}{c}0.333 \\
(0.890)\end{array}$ \\
\hline Non-Democratic Ally & $\begin{array}{c}0.140 \\
(0.788)\end{array}$ & $\begin{array}{l}-0.138 \\
(0.793)\end{array}$ \\
\hline Democratic Ally & $\begin{array}{c}1.337^{* * *} \\
(0.460)\end{array}$ & $\begin{array}{c}1.382^{* * * *} \\
(0.517)\end{array}$ \\
\hline Contiguity & $\begin{array}{l}-0.279 \\
(0.408)\end{array}$ & $\begin{array}{l}-0.161 \\
(0.433)\end{array}$ \\
\hline CINC Ratio & $\begin{array}{c}0.00132 \\
(0.000831)\end{array}$ & $\begin{array}{c}0.00170 \\
(0.00231)\end{array}$ \\
\hline$S$-Score & $\begin{array}{l}-0.681 \\
(0.740)\end{array}$ & $\begin{array}{l}-0.823 \\
(0.758)\end{array}$ \\
\hline Major Initiator & $\begin{array}{l}-0.486 \\
(0.443)\end{array}$ & $\begin{array}{l}-0.588 \\
(0.465)\end{array}$ \\
\hline Major Target & $\begin{array}{l}1.104^{* *} \\
(0.472)\end{array}$ & $\begin{array}{l}1.203^{* *} \\
(0.554)\end{array}$ \\
\hline Nuclear Initiator & $\begin{array}{c}-1.502^{* *} \\
(0.704)\end{array}$ & $\begin{array}{l}-1.294^{*} \\
(0.705)\end{array}$ \\
\hline Nuclear Target & $\begin{array}{l}1.683^{* *} \\
(0.846)\end{array}$ & $\begin{array}{l}1.428 \\
(0.976)\end{array}$ \\
\hline Territory & $\begin{array}{l}-0.517 \\
(0.408)\end{array}$ & $\begin{array}{l}-0.463 \\
(0.403)\end{array}$ \\
\hline Leadership & $\begin{array}{c}2.314^{* * *} \\
(0.665)\end{array}$ & $\begin{array}{c}2.238^{* * * *} \\
(0.668)\end{array}$ \\
\hline Ally Threat & $\begin{array}{l}0.666 \\
(0.927)\end{array}$ & $\begin{array}{c}0.723 \\
(0.904)\end{array}$ \\
\hline Constant & $\begin{array}{l}-0.175 \\
(0.792)\end{array}$ & $\begin{array}{r}-0.00387 \\
(0.814)\end{array}$ \\
\hline Observations & 201 & 197 \\
\hline
\end{tabular}

Robust standard errors in parentheses *** $\mathrm{p}<0.01,{ }^{* *} \mathrm{p}<0.05,{ }^{*} \mathrm{p}<0.1$ 
Table A.7: Dyadic Measures, Non-Democratic Ally Baseline - MCT (3.17)

\begin{tabular}{|c|c|c|}
\hline VARIABLES & $\begin{array}{c}(1) \\
\text { BMR }\end{array}$ & $\begin{array}{c}(2) \\
\text { Polity }\end{array}$ \\
\hline No Ally & $\begin{array}{l}-0.140 \\
(0.788)\end{array}$ & $\begin{array}{c}0.138 \\
(0.793)\end{array}$ \\
\hline Democratic Ally & $\begin{array}{c}1.197 \\
(0.786)\end{array}$ & $\begin{array}{l}1.520^{*} \\
(0.803)\end{array}$ \\
\hline Demo/ Demo & $\begin{array}{l}-0.0259 \\
(0.532)\end{array}$ & $\begin{array}{c}-0.337 \\
(0.426)\end{array}$ \\
\hline$\sim$ Demo/Demo & $\begin{array}{c}1.082^{* *} \\
(0.511)\end{array}$ & $\begin{array}{l}1.131^{*} \\
(0.596)\end{array}$ \\
\hline Demo/Demo & $\begin{array}{l}-0.0147 \\
(0.668)\end{array}$ & $\begin{array}{c}0.333 \\
(0.890)\end{array}$ \\
\hline Contiguity & $\begin{array}{l}-0.279 \\
(0.408)\end{array}$ & $\begin{array}{c}-0.161 \\
(0.433)\end{array}$ \\
\hline CINC Ratio & $\begin{array}{c}0.00132 \\
(0.000831)\end{array}$ & $\begin{array}{c}0.00170 \\
(0.00231)\end{array}$ \\
\hline$S$-Score & $\begin{array}{l}-0.681 \\
(0.740)\end{array}$ & $\begin{array}{l}-0.823 \\
(0.758)\end{array}$ \\
\hline Major Initiator & $\begin{array}{l}-0.486 \\
(0.443)\end{array}$ & $\begin{array}{l}-0.588 \\
(0.465)\end{array}$ \\
\hline Major Target & $\begin{array}{l}1.104^{* *} \\
(0.472)\end{array}$ & $\begin{array}{l}1.203^{* *} \\
(0.554)\end{array}$ \\
\hline Nuclear Initiator & $\begin{array}{c}-1.502^{* *} \\
(0.704)\end{array}$ & $\begin{array}{c}-1.294^{*} \\
(0.705)\end{array}$ \\
\hline Nuclear Target & $\begin{array}{c}1.683^{* *} \\
(0.846)\end{array}$ & $\begin{array}{c}1.428 \\
(0.976)\end{array}$ \\
\hline Territory & $\begin{array}{l}-0.517 \\
(0.408)\end{array}$ & $\begin{array}{l}-0.463 \\
(0.403)\end{array}$ \\
\hline Leadership & $\begin{array}{c}2.314^{* * * *} \\
(0.665)\end{array}$ & $\begin{array}{c}2.238^{* * *} \\
(0.668)\end{array}$ \\
\hline Ally Threat & $\begin{array}{c}0.666 \\
(0.927)\end{array}$ & $\begin{array}{c}0.723 \\
(0.904)\end{array}$ \\
\hline Constant & $\begin{array}{l}-0.175 \\
(0.792)\end{array}$ & $\begin{array}{c}-0.00387 \\
(0.814)\end{array}$ \\
\hline Observations & 201 & 197 \\
\hline
\end{tabular}




\section{Appendix B}

\section{Economic Sanctions Appendix}

This appendix includes material that is directly relevant to the results from Chapter 4, threats of economic sanction. The largest contribution of this appendix is to provide the full tables from the statistical analysis, which were truncated for reasons of space, as well as the results from the Cheibub, Gandhi and Vreeland (2010) measure of democracy. I will begin by first outlining the definitions for the variables employed in the analysis, before moving to the CGV measures, and concluding with the extended versions of the main tables with CGV measures added where appropriate.

\section{Definitions}

Each table has a number of different variables related to the target and initiator's democratic nature. They are:

- Initiator and Target Regime-Type Variables: these variables, derived from the Boix, Miller, and Rosato, Cheibub, Gandhi, and Vreeland, and Polity datasets, indicate whether the initiator and target are democratic or not. These are measured in one of two ways: dichotomously, with two indicators, one for the initiator and one for the 
target; and dyadically, with a single indicator combining the measure for the initiator and target.

Each table shares the same set of variables, which are presented in order:

- Carrots: a dichotomous measure from the TIES dataset, this variable indicates whether the initiator offered any positive inducements to the target in addition to the threat of economic sanction.

- Commitment: derived from a TIES variable as indicating whether the threatening state's level of resolve was weak, moderate, strong, or there was no threat, I identify all those threats with at least a moderate level of commitment with a 1 and a 0 otherwise.

- Specificity: this indicates the level of clarity to the initiator's demands. If the threat was clear, it received a 1 , and if it was ambiguous, it received a 0 .

- Institution: if the threat emerged from an institution, it is more likely that it was multilateral in nature, thus potentially cutting off substitute sources of goods or markets to the target. If it was institutional in nature, this variable was marked as 1 , and 0 otherwise.

- UN Ideal: this variable acts as a indicator of preference similarity between the two states, based on patterns of voting behavior in the United Nations, per Bailey, Strezhnev and Voeten (N.d.).

- Hard Issue: this variable identifies whether the threat involved specific issues that might be considered more difficult, and thus less likely to lead to concessions at the threat stage. These types of threats include containing military behavior, regime change, the release of citizens/property/material, territorial disputes, and ending weapons or material proliferation. 
- CINC Ratio: the CINC score for the initiator divided by that of the target, to indicate how much of a material advantage the initiator held at the time of the threat.

- Interdependence: I utilize two different measures of economic interdependence, one recommended by Barbieri and Peters (2003) while the other comes from Oneal and Russett (1997). The former emphasizes the joint nature of the interdependence of the two states, while the latter focuses on the less dependent of the trade partners.

- Sender Costs: from the TIES dataset, this variable indicates whether the sender would have been expected to suffer high costs should the sanctions be imposed.

- Target Costs: similar to the previous variable, this one indicates the level of costs that the target would expect to suffer should the sanctions be imposed.

\section{CGV Measure of Democracy}

As noted in chapter 3, there are multiple options for measuring democracy. However, due to temporal and data limitations of the Militarized Compellent Threat dataset, only two (BMR and Polity) are actually employed. No such constraints are in effect with the Threat and Imposition of Economic Sanctions. While the MCT dataset begins in 1918, TIES only starts in 1945. Fortunately, unlike MCT which only has about a hundred observations from 1945 on, TIES has well over a thousand, thus eliminating concerns over small sample sizes. This allows for the inclusion of the measure promoted by Cheibub, Gandhi and Vreeland (2010) (hereafter, CGV) in addition to the BMR and Polity indicators from the previous chapter.

To briefly recapitulate what was stated previously, the BMR measure is dichotomous in nature, where the state either is a democracy or is not, based on whether it meets the criteria put forward by Boix, Miller, and Rosato, namely: 1) the executive is directly or indirectly elected by popular vote, and is held accountable by the people or the legislature; 2) there 
are free and fair elections for the legislature (or executive, if there are direct elections for the position); and 3) the majority of adult males can vote. (1530) In contrast, Polity is on semicontinuous scale, from -10 to +10 , which comes from the addition of multiple component parts. These include, but are not limited to, constraints on the power of the executive, limits on where the executive can be recruited from, and the level of political competition. Following convention, I then set a cut-off at +7 , where all states that meet or exceed +7 count as a democracy and all those that do not are treated as a non-democracy.

The CGV measurement is much closer to BMR, in that it also is dichotomous. There are, however, some important differences in the coding schemes. For CGV, there are four criteria that must be met: 1) "The chief executive must be chosen by popular election or by a body that was itself popularly elected."; 2) "The legislature must be popularly elected."; 3) "There must be more than one party competing in the elections."; and 4) "An alternation in power under electoral rules identical to the ones that brought the incumbent to office must have taken place." (69) The first two points made by CGV match up with BMR's first requirement, but otherwise there are fairly important divergences. Whereas BMR emphasizes the need for "free and fair elections" and that at least half adult men are able to vote, CGV instead requires multiple parties being allowed to compete for office. This causes a potential problem, as it is possible for a non-democratic state to have a singular hegemonic party while allowing opposition parties to exist, either by enacting rules which ensure the opposition cannot win, having the opposition parties be puppets of the regime, or by simply cheating to prevent turnover, among other possibilities.

This is where CGV's fourth criteria comes into play, as it requires that there be at least one instance of an alternation in power with the same rules that got the incumbent into power in the first place. If this occurs, it would imply that there is no systematic way in which the incumbent party is able to hold on to power, and effectively making the system "free and fair." In a sense, this is beneficial, as identifying whether an election is, in fact, 
"free and fair" can be a complicated issue as there are multiple criteria by which one can claim that the process is either upheld or violated. But ultimately, the rules put forward by CGV act as a viable alternative to either the BMR or Polity measures.

Table B.1: CGV Democracy - TIES Targets

\begin{tabular}{|l|l|l|l|}
\hline & Democracy & Non-Democracy & \\
\hline Compliance & $92(10.8 \%)$ & $48(9.6 \%)$ & $140(10.3 \%)$ \\
\hline Non-Compliance & $762(89.2 \%)$ & $453(90.4 \%)$ & $1215(89.7 \%)$ \\
\hline & 854 & 501 & 1355 \\
\hline
\end{tabular}

Pearson $\chi^{2}=0.4889 ; \operatorname{Pr}=0.484$

The CGV results in Table B.1 tell a similar story to what was observed with the BMR and Polity measures, though they appear to be slightly more in favor of the theory. In comparison to non-democracies, democratic targets are 1.2\% more likely to make concessions following threats of economic sanction. However, these results are even less likely to be independent according to the chi squared test.

Interestingly, Table B.2 provides essentially an identical story to Table ??, as three of the four models reach standard levels of significance while one, with the Oneal and Russett measure of interdependence employed with all observations, only reaches weak significance. And, just as in Table 4.3, high sender costs are correlated with failed threats while high target costs are more successful, and threats of an institutional variety are more likely to lead to concessions.

The CGV measure of democracy ultimately provides a similar picture as the BMR measure, with the graphical representations provided in Figure B.1 and the point estimates found in Table B.3. Both of the full models show that democratic targets are roughly twice as likely to concede to threats of economic sanction as are the non-democracies, again at about $11 \%$ compared to $5 \%$, though the model with Low Dependence is not statistically significant. These results are found to be independent, per the post-estimation test $(\mathrm{p}<0.05)$. And, just 
Table B.2: CGV Dichotomous Measure - TIES

\begin{tabular}{|c|c|c|c|c|}
\hline VARIABLES & $\begin{array}{c}(1) \\
\text { TSAL } \\
\text { All Obs }\end{array}$ & $\begin{array}{c}(2) \\
\text { Low Depend } \\
\text { All Obs }\end{array}$ & $\begin{array}{c}(3) \\
\text { TSAL } \\
\text { High } T_{\text {Cost }} \\
\end{array}$ & $\begin{array}{c}(4) \\
\text { Low Depend } \\
\text { High } T_{\text {Cost }}\end{array}$ \\
\hline Target Democracy & $\begin{array}{c}0.947^{* *} \\
(0.421)\end{array}$ & $\begin{array}{c}0.789^{*} \\
(0.406)\end{array}$ & $\begin{array}{l}1.966^{* *} \\
(0.811)\end{array}$ & $\begin{array}{c}1.776^{* *} \\
(0.774)\end{array}$ \\
\hline Initiator Democracy & $\begin{array}{c}0.691 \\
(0.762)\end{array}$ & $\begin{array}{c}0.499 \\
(0.745)\end{array}$ & $\begin{array}{c}0.540 \\
(0.890)\end{array}$ & $\begin{array}{c}0.296 \\
(0.884)\end{array}$ \\
\hline Carrots & $\begin{array}{l}-0.581 \\
(0.903)\end{array}$ & $\begin{array}{l}-0.388 \\
(0.916)\end{array}$ & $\begin{array}{l}-0.682 \\
(0.766)\end{array}$ & $\begin{array}{l}-0.500 \\
(0.765)\end{array}$ \\
\hline Commitment & $\begin{array}{c}0.251 \\
(0.500)\end{array}$ & $\begin{array}{c}0.572 \\
(0.591)\end{array}$ & $\begin{array}{l}-1.044 \\
(0.756)\end{array}$ & $\begin{array}{l}-0.712 \\
(0.880)\end{array}$ \\
\hline Specificity & $\begin{array}{c}2.307^{* * *} \\
(0.658)\end{array}$ & $\begin{array}{c}2.286^{* * *} * \\
(0.635)\end{array}$ & $\begin{array}{c}1.689 \\
(1.133)\end{array}$ & $\begin{array}{c}1.619 \\
(1.143)\end{array}$ \\
\hline Institution & $\begin{array}{c}1.089^{* * *} \\
(0.421)\end{array}$ & $\begin{array}{c}0.986^{* *} \\
(0.451)\end{array}$ & $\begin{array}{c}2.186^{* * * *} \\
(0.648)\end{array}$ & $\begin{array}{c}2.083^{* * *} \\
(0.724)\end{array}$ \\
\hline Interdependence & $\begin{array}{l}-1.965 \\
(2.200)\end{array}$ & $\begin{array}{l}-1.355 \\
(16.17)\end{array}$ & $\begin{array}{l}-5.016 \\
(3.941)\end{array}$ & $\begin{array}{l}-32.68 \\
(31.53)\end{array}$ \\
\hline Sender Costs & $\begin{array}{c}-1.931^{* * *} \\
(0.443)\end{array}$ & $\begin{array}{c}-2.018^{* * *} \\
(0.456)\end{array}$ & $\begin{array}{c}-1.996^{* * *} \\
(0.461)\end{array}$ & $\begin{array}{c}-2.064^{* * *} \\
(0.461)\end{array}$ \\
\hline Target Costs & $\begin{array}{c}0.951^{* *} \\
(0.400)\end{array}$ & $\begin{array}{c}0.976^{* *} \\
(0.404)\end{array}$ & & \\
\hline Constant & $\begin{array}{c}-5.934^{* * *} \\
(1.124)\end{array}$ & $\begin{array}{c}-5.985^{* * *} \\
(1.157)\end{array}$ & $\begin{array}{c}-3.706^{* *} \\
(1.555)\end{array}$ & $\begin{array}{c}-3.555^{* *} \\
(1.519)\end{array}$ \\
\hline Observations & 783 & 772 & 375 & 363 \\
\hline
\end{tabular}

as above, the high costs models demonstrate that the effect is much more powerful when we are focus exclusively on cases where the target faces particularly painful damages if they do not choose to concede. Again, these probabilities are distinct from one another, according to post-estimation tests $(\mathrm{p}<0.01)$.

The dyadic results are again similar for CGV as BMR, as shown in Table B.4. Democracies continue to be the most likely issuer of sanction threats, with $84.1 \%$ of the total share, but the threats that are more likely to succeed has shifted to those between non-democracies, though inter-democratic threats remain a close second. In addition, we should probably be concerned about gleaning any significant findings from the threats between non-democracies given that there are so few compared to the other categories, as the addition of only two 
Figure B.1: CGV Target Measures - TIES
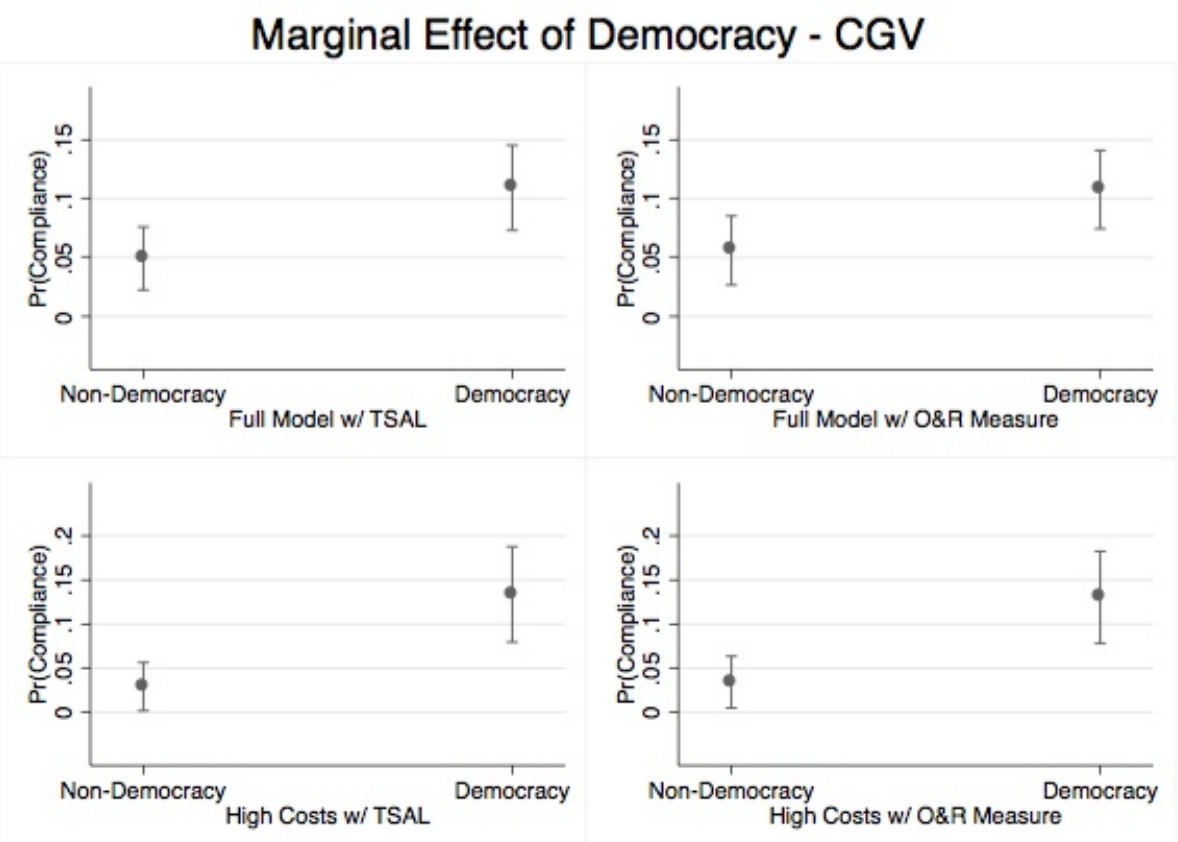

Table B.3: CGV Predicted Probabilities - TIES

\begin{tabular}{|l|c|c|}
\hline & Democracy & Non-Democracy \\
\hline Full w/TSAL & 10.9 & 4.9 \\
\hline Full w/Low Depend & 10.8 & 5.6 \\
\hline High Cost w/TSAL & 13.4 & 2.9 \\
\hline High Cost w/ Low Depend & 13.0 & 3.4 \\
\hline
\end{tabular}

more positive cases from the BMR figures was enough to cause the change.

In terms of the types of threats that are employed according to the CGV measure, we see roughly similar results as compared with the BMR and Polity indicators. Democracies contended with 87 "hard" types of threat in contrast to 767 "easy" ones, while non-democracies had 159 and 342, respectively. Again, this shows that non-democracies were generally dealing with threats that targeted their core interests more readily. However, just as with the BMR measure, the results also show that democracies comply slightly more often with these threats, at $6.9 \%$ compared to $5.0 \%$ for non-democracies. 
Table B.4: CGV Democracy - TIES Dyad

\begin{tabular}{|l|c|c|c|c|c|}
\hline & $\sim$ Demo/ Demo & Demo/ Demo & $\sim$ Demo/Demo & Demo/Demo & \\
\hline Compliance & $7(10.6 \%)$ & $32(8.0 \%)$ & $5(3.7 \%)$ & $67(10.1 \%)$ & $111(8.8 \%)$ \\
\hline Non-Compliance & $59(89.4 \%)$ & $369(92.0 \%)$ & $130(96.3 \%)$ & $598(89.9 \%)$ & $1156(91.2 \%)$ \\
\hline & 66 & 401 & 135 & 665 & 1267 \\
\hline
\end{tabular}

Pearson $\chi^{2}=7.3725 ; \operatorname{Pr}=0.061$

\section{Extended Chapter Tables}

The tables will proceed in order:

- Table 4.3: BMR Dichotomous Measure - TIES

- Table 4.4: Polity Dichotomous Measure - TIES

- Table 4.9: Dyadic Measures of Democracy, All Obs - TIES

- Table 4.10: Dyadic Measures of Democracy, High Target Cost Obs - TIES 
Table B.5: BMR Dichotomous Measure - TIES (4.3)

\begin{tabular}{|c|c|c|c|c|}
\hline VARIABLES & $\begin{array}{c}\text { (1) } \\
\text { TSAL } \\
\text { All Obs }\end{array}$ & $\begin{array}{c}(2) \\
\text { Low Depend } \\
\text { All Obs }\end{array}$ & $\begin{array}{c}(3) \\
\text { TSAL } \\
\text { High } T_{\text {Cost }}\end{array}$ & $\begin{array}{c}(4) \\
\text { Low Depend } \\
\text { High } T_{\text {Cost }}\end{array}$ \\
\hline Target Democracy & $\begin{array}{c}0.881^{* *} \\
(0.418)\end{array}$ & $\begin{array}{c}0.844^{* *} \\
(0.409)\end{array}$ & $\begin{array}{c}1.906^{* *} \\
(0.785)\end{array}$ & $\begin{array}{c}1.716^{* *} \\
(0.747)\end{array}$ \\
\hline Initiator Democracy & $\begin{array}{c}0.453 \\
(0.801)\end{array}$ & $\begin{array}{c}0.241 \\
(0.794)\end{array}$ & $\begin{array}{c}0.464 \\
(0.934)\end{array}$ & $\begin{array}{c}0.196 \\
(0.942)\end{array}$ \\
\hline Carrots & $\begin{array}{l}-0.537 \\
(0.930)\end{array}$ & $\begin{array}{l}-0.318 \\
(0.940)\end{array}$ & $\begin{array}{l}-0.638 \\
(0.786)\end{array}$ & $\begin{array}{l}-0.440 \\
(0.783)\end{array}$ \\
\hline Commitment & $\begin{array}{c}0.245 \\
(0.498)\end{array}$ & $\begin{array}{c}0.556 \\
(0.586)\end{array}$ & $\begin{array}{l}-1.071 \\
(0.779)\end{array}$ & $\begin{array}{l}-0.711 \\
(0.906)\end{array}$ \\
\hline Specificity & $\begin{array}{c}2.226^{* * *} \\
(0.664)\end{array}$ & $\begin{array}{c}2.217^{* * *} \\
(0.642)\end{array}$ & $\begin{array}{c}1.678 \\
(1.157)\end{array}$ & $\begin{array}{c}1.595 \\
(1.168)\end{array}$ \\
\hline Institution & $\begin{array}{c}1.128^{* * *} \\
(0.422)\end{array}$ & $\begin{array}{c}1.055^{* *} \\
(0.455)\end{array}$ & $\begin{array}{c}2.191^{* * *} \\
(0.640)\end{array}$ & $\begin{array}{c}2.089^{* * *} \\
(0.723)\end{array}$ \\
\hline UN Ideal & $\begin{array}{c}0.115 \\
(0.121)\end{array}$ & $\begin{array}{c}0.134 \\
(0.124)\end{array}$ & $\begin{array}{c}-0.000924 \\
(0.178)\end{array}$ & $\begin{array}{c}-0.0168 \\
(0.176)\end{array}$ \\
\hline Hard Issue & $\begin{array}{c}-0.860^{*} \\
(0.463)\end{array}$ & $\begin{array}{c}-0.815^{*} \\
(0.488)\end{array}$ & $\begin{array}{l}-0.796 \\
(0.598)\end{array}$ & $\begin{array}{l}-0.911 \\
(0.647)\end{array}$ \\
\hline CINC Ratio & $\begin{array}{l}-2.15 \mathrm{e}-06 \\
(1.72 \mathrm{e}-05)\end{array}$ & $\begin{array}{c}1.18 \mathrm{e}-05^{* * *} \\
(4.25 \mathrm{e}-06)\end{array}$ & $\begin{array}{c}9.44 \mathrm{e}-05 \\
(7.90 \mathrm{e}-05)\end{array}$ & $\begin{array}{c}0.000101 \\
(8.00 \mathrm{e}-05)\end{array}$ \\
\hline Interdependence & $\begin{array}{l}-1.630 \\
(2.199)\end{array}$ & $\begin{array}{c}-0.0796 \\
(16.35)\end{array}$ & $\begin{array}{l}-5.041 \\
(3.962)\end{array}$ & $\begin{array}{l}-33.21 \\
(31.63)\end{array}$ \\
\hline Sender Costs & $\begin{array}{c}-1.938 * * * \\
(0.452)\end{array}$ & $\begin{array}{c}-2.044^{* * *} \\
(0.468)\end{array}$ & $\begin{array}{c}-2.004^{* * *} \\
(0.474)\end{array}$ & $\begin{array}{c}-2.082^{* * *} \\
(0.475)\end{array}$ \\
\hline Target Costs & $\begin{array}{l}1.027^{* *} \\
(0.411)\end{array}$ & $\begin{array}{c}1.065^{* *} \\
(0.418)\end{array}$ & & \\
\hline Constant & $\begin{array}{c}-5.661^{* * *} \\
(1.122)\end{array}$ & $\begin{array}{c}-5.818^{* * *} \\
(1.165)\end{array}$ & $\begin{array}{c}-3.565^{* *} \\
(1.560)\end{array}$ & $\begin{array}{c}-3.389^{* *} \\
(1.527)\end{array}$ \\
\hline Observations & 754 & 743 & 357 & 345 \\
\hline
\end{tabular}


Table B.6: Polity Dichotomous Measure - TIES (4.4)

\begin{tabular}{|c|c|c|c|c|}
\hline VARIABLES & $\begin{array}{c}(1) \\
\text { TSAL } \\
\text { All Obs }\end{array}$ & $\begin{array}{c}(2) \\
\text { Low Depend } \\
\text { All Obs }\end{array}$ & $\begin{array}{c}(3) \\
\text { TSAL } \\
\text { High } T_{\text {Cost }}\end{array}$ & $\begin{array}{c}(4) \\
\text { Low Depend } \\
\text { High } T_{\text {Cost }}\end{array}$ \\
\hline Target Democracy & $\begin{array}{c}0.756^{* *} \\
(0.329)\end{array}$ & $\begin{array}{c}0.726^{* *} \\
(0.319)\end{array}$ & $\begin{array}{l}1.251^{*} \\
(0.645)\end{array}$ & $\begin{array}{l}1.095^{*} \\
(0.617)\end{array}$ \\
\hline Initiator Democracy & $\begin{array}{c}0.543 \\
(0.760)\end{array}$ & $\begin{array}{c}0.348 \\
(0.741)\end{array}$ & $\begin{array}{c}0.294 \\
(0.838)\end{array}$ & $\begin{array}{l}0.0487 \\
(0.822)\end{array}$ \\
\hline Carrots & $\begin{array}{l}-0.374 \\
(0.910)\end{array}$ & $\begin{array}{l}-0.143 \\
(0.925)\end{array}$ & $\begin{array}{l}-0.495 \\
(0.824)\end{array}$ & $\begin{array}{l}-0.290 \\
(0.801)\end{array}$ \\
\hline Commitment & $\begin{array}{c}0.357 \\
(0.666)\end{array}$ & $\begin{array}{c}0.716 \\
(0.844)\end{array}$ & $\begin{array}{l}-1.120 \\
(0.777)\end{array}$ & $\begin{array}{l}-0.816 \\
(0.894)\end{array}$ \\
\hline Specificity & $\begin{array}{c}2.012^{* * *} \\
(0.686)\end{array}$ & $\begin{array}{c}2.036^{* * *} \\
(0.692)\end{array}$ & $\begin{array}{c}1.532 \\
(1.178)\end{array}$ & $\begin{array}{c}1.383 \\
(1.179)\end{array}$ \\
\hline Institution & $\begin{array}{c}1.167^{* * *} \\
(0.434)\end{array}$ & $\begin{array}{c}1.042^{* *} \\
(0.474)\end{array}$ & $\begin{array}{c}2.131^{* * *} \\
(0.604)\end{array}$ & $\begin{array}{c}2.015^{* * *} \\
(0.678)\end{array}$ \\
\hline UN Ideal & $\begin{array}{l}0.0304 \\
(0.111)\end{array}$ & $\begin{array}{l}0.0534 \\
(0.112)\end{array}$ & $\begin{array}{c}-0.0988 \\
(0.183)\end{array}$ & $\begin{array}{c}-0.0930 \\
(0.180)\end{array}$ \\
\hline Hard Issue & $\begin{array}{c}-0.967^{*} \\
(0.504)\end{array}$ & $\begin{array}{c}-0.877^{*} \\
(0.526)\end{array}$ & $\begin{array}{l}-0.967 \\
(0.620)\end{array}$ & $\begin{array}{l}-0.998 \\
(0.669)\end{array}$ \\
\hline CINC Ratio & $\begin{array}{c}0.00157^{* * *} \\
(0.000578)\end{array}$ & $\begin{array}{c}0.00157^{* * *} \\
(0.000501)\end{array}$ & $\begin{array}{c}0.00294^{* * *} \\
(0.00100)\end{array}$ & $\begin{array}{c}0.00281^{* * *} \\
(0.000983)\end{array}$ \\
\hline Interdependence & $\begin{array}{l}-0.402 \\
(2.170)\end{array}$ & $\begin{array}{c}8.853 \\
(16.13)\end{array}$ & $\begin{array}{l}-3.192 \\
(3.872)\end{array}$ & $\begin{array}{l}-17.01 \\
(30.63)\end{array}$ \\
\hline Sender Costs & $\begin{array}{c}-1.799 * * * \\
(0.489)\end{array}$ & $\begin{array}{c}-1.884^{* * *} \\
(0.507)\end{array}$ & $\begin{array}{c}-1.754^{* * *} \\
(0.530)\end{array}$ & $\begin{array}{c}-1.805^{* * *} \\
(0.519)\end{array}$ \\
\hline Target Costs & $\begin{array}{c}1.053^{* *} \\
(0.437)\end{array}$ & $\begin{array}{c}1.063^{* *} \\
(0.451)\end{array}$ & & \\
\hline Constant & $\begin{array}{c}-5.682^{* * *} \\
(1.134)\end{array}$ & $\begin{array}{c}-5.927^{* * *} \\
(1.249)\end{array}$ & $\begin{array}{c}-2.914^{* *} \\
(1.442)\end{array}$ & $\begin{array}{c}-2.734^{* *} \\
(1.394)\end{array}$ \\
\hline Observations & 749 & 737 & 354 & 342 \\
\hline
\end{tabular}


Table B.7: Dyadic Measures of Democracy, All Obs - TIES (4.9)

\begin{tabular}{|c|c|c|c|c|c|c|}
\hline VARIABLES & $\begin{array}{c}(1) \\
\text { TSAL } \\
\text { BMR }\end{array}$ & $\begin{array}{c}(2) \\
\text { O\&R } \\
\text { BMR }\end{array}$ & $\begin{array}{c}(3) \\
\text { TSAL } \\
\text { CGV }\end{array}$ & $\begin{array}{c}(4) \\
\text { O\&R } \\
\text { CGV }\end{array}$ & $\begin{array}{c}(5) \\
\text { TSAL } \\
\text { Polity }\end{array}$ & $\begin{array}{c}\text { (6) } \\
\text { O\&R } \\
\text { Polity }\end{array}$ \\
\hline$\sim$ Demo/ Demo & $\begin{array}{c}-0.0428 \\
(1.137)\end{array}$ & $\begin{array}{c}0.0664 \\
(1.176)\end{array}$ & $\begin{array}{c}-0.404 \\
(1.086)\end{array}$ & $\begin{array}{c}-0.271 \\
(1.108)\end{array}$ & $\begin{array}{c}0.253 \\
(0.782)\end{array}$ & $\begin{array}{c}0.307 \\
(0.789)\end{array}$ \\
\hline Demo/ Demo & $\begin{array}{c}-0.987^{* *} \\
(0.429)\end{array}$ & $\begin{array}{c}-0.940^{* *} \\
(0.419)\end{array}$ & $\begin{array}{c}-1.050^{* *} \\
(0.434)\end{array}$ & $\begin{array}{c}-0.877^{* *} \\
(0.418)\end{array}$ & $\begin{array}{c}-0.988^{* * *} \\
(0.345)\end{array}$ & $\begin{array}{c}-0.951^{* * *} \\
(0.337)\end{array}$ \\
\hline$\sim$ Demo/Demo & $\begin{array}{l}-1.053 \\
(1.107)\end{array}$ & $\begin{array}{l}-0.805 \\
(1.103)\end{array}$ & $\begin{array}{l}-1.283 \\
(1.067)\end{array}$ & $\begin{array}{l}-1.038 \\
(1.059)\end{array}$ & - & - \\
\hline Carrots & $\begin{array}{l}-0.654 \\
(0.956)\end{array}$ & $\begin{array}{l}-0.435 \\
(0.974)\end{array}$ & $\begin{array}{l}-0.657 \\
(0.912)\end{array}$ & $\begin{array}{l}-0.458 \\
(0.928)\end{array}$ & $\begin{array}{l}-0.569 \\
(0.944)\end{array}$ & $\begin{array}{l}-0.319 \\
(0.963)\end{array}$ \\
\hline Commitment & $\begin{array}{c}0.228 \\
(0.500)\end{array}$ & $\begin{array}{c}0.536 \\
(0.588)\end{array}$ & $\begin{array}{c}0.232 \\
(0.501)\end{array}$ & $\begin{array}{c}0.552 \\
(0.592)\end{array}$ & $\begin{array}{c}0.337 \\
(0.671)\end{array}$ & $\begin{array}{c}0.692 \\
(0.853)\end{array}$ \\
\hline Specificity & $\begin{array}{c}2.230^{* * *} \\
(0.665)\end{array}$ & $\begin{array}{c}2.220^{* * *} \\
(0.644)\end{array}$ & $\begin{array}{c}2.313^{* * *} \\
(0.657)\end{array}$ & $\begin{array}{c}2.291^{* * *} \\
(0.634)\end{array}$ & $\begin{array}{c}2.026^{* * *} \\
(0.689)\end{array}$ & $\begin{array}{c}2.043^{* * *} \\
(0.693)\end{array}$ \\
\hline Sender Costs & $\begin{array}{c}-1.987^{* * * *} \\
(0.458)\end{array}$ & $\begin{array}{c}-2.078^{* * *} \\
(0.472)\end{array}$ & $\begin{array}{c}-1.958^{* * *} \\
(0.444)\end{array}$ & $\begin{array}{c}-2.031^{* * *} \\
(0.455)\end{array}$ & $\begin{array}{c}-1.920^{* * *} \\
(0.499)\end{array}$ & $\begin{array}{c}-1.970^{* * *} \\
(0.512)\end{array}$ \\
\hline Institution & $\begin{array}{c}1.161^{* * *} \\
(0.429)\end{array}$ & $\begin{array}{l}1.084^{* *} \\
(0.460)\end{array}$ & $\begin{array}{c}1.120^{* * *} \\
(0.428)\end{array}$ & $\begin{array}{l}1.013^{* *} \\
(0.456)\end{array}$ & $\begin{array}{c}1.234^{* * *} \\
(0.452)\end{array}$ & $\begin{array}{l}1.117^{* *} \\
(0.493)\end{array}$ \\
\hline UN Ideal & $\begin{array}{c}0.140 \\
(0.123)\end{array}$ & $\begin{array}{c}0.158 \\
(0.126)\end{array}$ & $\begin{array}{c}0.130 \\
(0.121)\end{array}$ & $\begin{array}{c}0.129 \\
(0.122)\end{array}$ & $\begin{array}{c}0.0856 \\
(0.110)\end{array}$ & $\begin{array}{c}0.110 \\
(0.111)\end{array}$ \\
\hline Hard Issue & $\begin{array}{c}-0.883^{*} \\
(0.463)\end{array}$ & $\begin{array}{c}-0.833^{*} \\
(0.489)\end{array}$ & $\begin{array}{c}-0.965^{* *} \\
(0.459)\end{array}$ & $\begin{array}{l}-0.929^{*} \\
(0.483)\end{array}$ & $\begin{array}{c}-1.025^{* *} \\
(0.505)\end{array}$ & $\begin{array}{c}-0.916^{*} \\
(0.527)\end{array}$ \\
\hline CINC Ratio & $\begin{array}{c}-3.00 \mathrm{e}-06 \\
(1.72 \mathrm{e}-05)\end{array}$ & $\begin{array}{c}1.15 \mathrm{e}-05^{* * *} \\
(4.27 \mathrm{e}-06)\end{array}$ & $\begin{array}{l}-4.41 \mathrm{e}-06 \\
(1.72 \mathrm{e}-05)\end{array}$ & $\begin{array}{c}1.12 \mathrm{e}-05^{* * *} \\
(4.14 \mathrm{e}-06)\end{array}$ & $\begin{array}{c}0.00160^{* * *} \\
(0.000595)\end{array}$ & $\begin{array}{c}0.00161^{* * *} \\
(0.000519)\end{array}$ \\
\hline Interdependence & $\begin{array}{l}-1.696 \\
(2.217)\end{array}$ & $\begin{array}{l}-0.190 \\
(16.42)\end{array}$ & $\begin{array}{l}-1.992 \\
(2.210)\end{array}$ & $\begin{array}{l}-1.531 \\
(16.22)\end{array}$ & $\begin{array}{l}-0.598 \\
(2.198)\end{array}$ & $\begin{array}{c}7.767 \\
(16.47)\end{array}$ \\
\hline Target Costs & $\begin{array}{l}1.052^{* *} \\
(0.415)\end{array}$ & $\begin{array}{c}1.081^{* * *} \\
(0.420)\end{array}$ & $\begin{array}{c}0.976^{* *} \\
(0.403)\end{array}$ & $\begin{array}{c}0.992^{* *} \\
(0.405)\end{array}$ & $\begin{array}{c}1.144^{* *} \\
(0.447)\end{array}$ & $\begin{array}{l}1.130^{* *} \\
(0.457)\end{array}$ \\
\hline Constant & $\begin{array}{c}-4.336^{* * *} \\
(0.640)\end{array}$ & $\begin{array}{c}-4.740 * * * \\
(0.740)\end{array}$ & $\begin{array}{c}-4.310^{* * *} \\
(0.644)\end{array}$ & $\begin{array}{c}-4.706^{* * *} \\
(0.742)\end{array}$ & $\begin{array}{c}-4.419^{* * *} \\
(0.722)\end{array}$ & $\begin{array}{c}-4.888^{* * * *} \\
(0.922)\end{array}$ \\
\hline Observations & 754 & 743 & 783 & 772 & 720 & 710 \\
\hline
\end{tabular}


Table B.8: Dyadic Measures of Democracy, High Target Cost Obs - TIES (4.10)

\begin{tabular}{|c|c|c|c|c|c|c|}
\hline VARIABLES & $\begin{array}{c}(1) \\
\text { TSAL } \\
\text { BMR }\end{array}$ & $\begin{array}{c}(2) \\
\text { O\&R } \\
\text { BMR }\end{array}$ & $\begin{array}{c}(3) \\
\text { TSAL } \\
\text { CGV }\end{array}$ & $\begin{array}{c}(4) \\
\text { O\&R } \\
\text { CGV }\end{array}$ & $\begin{array}{c}(5) \\
\text { TSAL } \\
\text { Polity }\end{array}$ & $\begin{array}{c}6) \\
\text { O\&R } \\
\text { Polity }\end{array}$ \\
\hline$\sim$ Demo/ Demo & $\begin{array}{l}-0.710 \\
(1.292)\end{array}$ & $\begin{array}{l}-0.593 \\
(1.309)\end{array}$ & $\begin{array}{l}-0.758 \\
(1.224)\end{array}$ & $\begin{array}{l}-0.624 \\
(1.239)\end{array}$ & $\begin{array}{c}0.199 \\
(0.862)\end{array}$ & $\begin{array}{c}0.245 \\
(0.857)\end{array}$ \\
\hline Demo/ Demo & $\begin{array}{c}-2.256^{* * *} \\
(0.832)\end{array}$ & $\begin{array}{c}-2.022^{* *} \\
(0.797)\end{array}$ & $\begin{array}{c}-2.337^{* * * *} \\
(0.861)\end{array}$ & $\begin{array}{c}-2.111^{* *} \\
(0.827)\end{array}$ & $\begin{array}{c}-1.987^{* * *} \\
(0.746)\end{array}$ & $\begin{array}{c}-1.763^{* *} \\
(0.721)\end{array}$ \\
\hline$\sim$ Demo/Demo & $\begin{array}{l}-1.287 \\
(1.308)\end{array}$ & $\begin{array}{l}-0.957 \\
(1.346)\end{array}$ & $\begin{array}{l}-1.356 \\
(1.235)\end{array}$ & $\begin{array}{l}-1.064 \\
(1.253)\end{array}$ & - & - \\
\hline Carrots & $\begin{array}{l}-0.862 \\
(0.849)\end{array}$ & $\begin{array}{l}-0.635 \\
(0.856)\end{array}$ & $\begin{array}{l}-0.879 \\
(0.817)\end{array}$ & $\begin{array}{l}-0.679 \\
(0.825)\end{array}$ & $\begin{array}{l}-0.929 \\
(0.928)\end{array}$ & $\begin{array}{l}-0.641 \\
(0.918)\end{array}$ \\
\hline Commitment & $\begin{array}{l}-1.043 \\
(0.786)\end{array}$ & $\begin{array}{l}-0.690 \\
(0.913)\end{array}$ & $\begin{array}{l}-1.035 \\
(0.751)\end{array}$ & $\begin{array}{l}-0.709 \\
(0.871)\end{array}$ & $\begin{array}{l}-1.077 \\
(0.798)\end{array}$ & $\begin{array}{l}-0.760 \\
(0.914)\end{array}$ \\
\hline Specificity & $\begin{array}{c}1.677 \\
(1.160)\end{array}$ & $\begin{array}{c}1.597 \\
(1.174)\end{array}$ & $\begin{array}{c}1.716 \\
(1.119)\end{array}$ & $\begin{array}{c}1.652 \\
(1.128)\end{array}$ & $\begin{array}{c}1.584 \\
(1.173)\end{array}$ & $\begin{array}{c}1.425 \\
(1.184)\end{array}$ \\
\hline Sender Costs & $\begin{array}{c}-2.109^{* * *} \\
(0.484)\end{array}$ & $\begin{array}{c}-2.144^{* * *} \\
(0.475)\end{array}$ & $\begin{array}{c}-2.084^{* * *} \\
(0.466)\end{array}$ & $\begin{array}{c}-2.113^{* * *} \\
(0.458)\end{array}$ & $\begin{array}{c}-2.068^{* * *} \\
(0.570)\end{array}$ & $\begin{array}{c}-2.014^{* * *} \\
(0.540)\end{array}$ \\
\hline Institution & $\begin{array}{c}2.274^{* * *} \\
(0.667)\end{array}$ & $\begin{array}{c}2.171^{* * *} \\
(0.748)\end{array}$ & $\begin{array}{c}2.276^{* * *} \\
(0.677)\end{array}$ & $\begin{array}{c}2.173^{* * *} \\
(0.750)\end{array}$ & $\begin{array}{c}2.293^{* * *} \\
(0.683)\end{array}$ & $\begin{array}{c}2.199^{* * *} \\
(0.762)\end{array}$ \\
\hline UN Ideal & $\begin{array}{l}0.0653 \\
(0.180)\end{array}$ & $\begin{array}{l}0.0391 \\
(0.179)\end{array}$ & $\begin{array}{l}0.0446 \\
(0.178)\end{array}$ & $\begin{array}{l}0.0224 \\
(0.177)\end{array}$ & $\begin{array}{l}0.0683 \\
(0.174)\end{array}$ & $\begin{array}{l}0.0560 \\
(0.176)\end{array}$ \\
\hline Hard Issue & $\begin{array}{l}-0.858 \\
(0.615)\end{array}$ & $\begin{array}{l}-0.948 \\
(0.659)\end{array}$ & $\begin{array}{l}-0.910 \\
(0.614)\end{array}$ & $\begin{array}{l}-0.991 \\
(0.662)\end{array}$ & $\begin{array}{c}-1.067^{*} \\
(0.634)\end{array}$ & $\begin{array}{l}-1.049 \\
(0.687)\end{array}$ \\
\hline CINC Ratio & $\begin{array}{c}8.75 \mathrm{e}-05 \\
(7.85 \mathrm{e}-05)\end{array}$ & $\begin{array}{c}9.54 \mathrm{e}-05 \\
(7.98 \mathrm{e}-05)\end{array}$ & $\begin{array}{c}8.87 \mathrm{e}-05 \\
(7.84 \mathrm{e}-05)\end{array}$ & $\begin{array}{c}9.62 \mathrm{e}-05 \\
(7.98 \mathrm{e}-05)\end{array}$ & $\begin{array}{c}0.00338 * * * \\
(0.00105)\end{array}$ & $\begin{array}{c}0.00323^{* * *} \\
(0.00104)\end{array}$ \\
\hline Interdependence & $\begin{array}{l}-5.597 \\
(4.209)\end{array}$ & $\begin{array}{l}-35.23 \\
(32.69)\end{array}$ & $\begin{array}{l}-5.511 \\
(4.196)\end{array}$ & $\begin{array}{l}-34.70 \\
(32.57)\end{array}$ & $\begin{array}{l}-4.462 \\
(4.357)\end{array}$ & $\begin{array}{l}-22.45 \\
(33.52)\end{array}$ \\
\hline Constant & $\begin{array}{l}-1.193 \\
(0.762)\end{array}$ & $\begin{array}{c}-1.502^{* *} \\
(0.720)\end{array}$ & $\begin{array}{l}-1.228 \\
(0.753)\end{array}$ & $\begin{array}{c}-1.534^{* *} \\
(0.720)\end{array}$ & $\begin{array}{l}-1.356 \\
(0.893)\end{array}$ & $\begin{array}{c}-1.668^{* *} \\
(0.845)\end{array}$ \\
\hline Observations & 357 & 345 & 375 & 363 & 333 & 323 \\
\hline
\end{tabular}




\section{Appendix C}

\section{Case Studies Appendix}

This appendix covers the additional materials from Chapter 5, the case studies of the $\mathrm{Mu}-$ nich and Suez Crises. Specifically, this appendix examines the application of the Weller and Barnes (2014) method of case selection, providing tables of the residuals developed through comparisons of the complete statistical models versus those where the key variables of interests are withheld. This section will begin by briefly recapitulating the basic logic of the case selection method, and providing the residual tables which were used to decide which cases I would examine in greater depth.

\section{Case Selection}

For this project, the goal was to provide some objective and measurable metric by which cases could be selected, rather than simply picking a case where the independent and dependent variables lined with the predictions of the theory. After examining the literature of case selection, I decided the follow the method suggested by Weller and Barnes (2014), which relies on using statistical methods to identify cases which are most relevant according to the criteria set forward by the researcher. In particular, their process focuses on how any 
given statistical model will identify how much uncertainty or noise there is associated with each observation, also known as the residual. The greater the residual for a particular observation is, the less capable the model is at "explaining" why the dependent variable of the observation ended up the way it did. Per Weller and Barnes, this can be used to the advantage of social scientists by running two different models, one fully specified while the other has the key variable of interest omitted, and thus comparing the residuals to identify those observations where the addition of the relevant variable better "explains" the value of the dependent variable. With these analyses performed, one can readily see which cases best fit the researcher's theory and which are ill-suited.

Using this methodology, I ran two separate analyses, one which omitted the democratic target variable while the second excluded the alliance indicator, in order to get their separate effects on the residuals compared to the fully-specified, baseline model. Tables C.1 and C.2 provide the complete list of cases with democratic targets and allies, respectively, in order from largest positive residuals to the smallest. While there are cases with negative residuals for both the targets and allies models, they have been excluded from the tables since the analysis indicates the addition of the variable actively increased the noise around the observation, making it ill-suited for further analysis.

I then further winnowed down my options to only include cases which appeared on both lists, which excluded observations with non-democratic or no major allies, non-democratic targets, and cases where only one of the target or ally achieved a positive residual score. Using this list of 17 observations, which is provided in Table C.3, I then selected those cases which are most well-known and studied, in order to ensure that, even if one were to oppose the contention that the cases provide external validity to my theory, they remain interesting in their own right and are worth examining. 
Table C.1: Democratic Target Residuals: All Positive Cases

\begin{tabular}{|c|c|c|c|c|}
\hline & Challenger & Target & Major Ally & Residual \\
\hline 1922 & Turkey & Italy & None & .8174 \\
\hline 1967 & Kenya & Somalia & None & .5839 \\
\hline 1920 & Albania & Turkey & None & .5782 \\
\hline 1940 & Germany & Denmark & None & .5453 \\
\hline 1922 & Turkey & U.K. & None & .4404 \\
\hline 1940 & Japan & U.K. & None & .3064 \\
\hline 1940 & Japan & France & None & .3014 \\
\hline 1956 & Soviet Union & France & U.S. & .2982 \\
\hline 1988 & Honduras & Nicaragua & U.S. & .2945 \\
\hline 1987 & Venezuela & Colombia & U.S. & .2945 \\
\hline 1939 & Japan & U.K. & U.S.S.R. & .2014 \\
\hline 1936 & Turkey & France & U.S.S.R. & .2013 \\
\hline 1923 & Italy & Yugoslavia & Czechoslovakia & .1983 \\
\hline 1939 & Hungary & Czechoslovakia & U.K. & .1978 \\
\hline 1938 & Hungary & Czechoslovakia & U.K. & .1977 \\
\hline 1938 & Poland & Czechoslovakia & U.K. & .1967 \\
\hline 1938 & Germany & Czechoslovakia & U.K. & .1929 \\
\hline 1958 & Tunisia & France & U.S. & .1864 \\
\hline 1964 & Cyprus & Turkey & U.S. & .1820 \\
\hline 1922 & Turkey & France & Poland & .1420 \\
\hline 1981 & Bangladesh & India & None & .1262 \\
\hline 1967 & Turkey & Greece & U.S. & .1168 \\
\hline 1961 & Indonesia & Netherlands & U.S. & .1001 \\
\hline 1939 & Germany & Czechoslovakia & U.K. & .0761 \\
\hline 1956 & Soviet Union & U.K. & U.S. & .0619 \\
\hline 1963 & Turkey & U.K. & U.S. & .0325 \\
\hline 1975 & Iceland & U.K. & U.S. & .0264 \\
\hline 1973 & Iceland & U.K. & U.S. & .0264 \\
\hline
\end{tabular}


Table C.2: Democratic Ally Residuals: All Positive Cases

$\begin{array}{lllll}\text { Year } & \text { Challenger } & \text { Target } & \text { Ally } & \text { Residual } \\ 1963 & \text { Dominican Republic } & \text { Haiti } & \text { U.S. } & .9477 \\ 1937 & \text { Japan } & \text { Soviet Union } & \text { U.K. } & .9257 \\ 1945 & \text { U.K. } & \text { France } & \text { U.S. } & .9035 \\ 1945 & \text { U.K. } & \text { Yugoslavia } & \text { U.S. } & .6299 \\ 1961 & \text { India } & \text { Portugal } & \text { U.S. } & .4810 \\ \mathbf{1 9 5 6} & \text { Soviet Union } & \text { France } & \text { U.S. } & .4483 \\ 1988 & \text { Honduras } & \text { Nicaragua } & \text { U.S. } & .3991 \\ 1987 & \text { Venezuela } & \text { Colombia } & \text { U.S. } & .3990 \\ 1923 & \text { Italy } & \text { Yugoslavia } & \text { Czechoslovakia } & .3807 \\ 1939 & \text { Hungary } & \text { Czechoslovakia } & \text { U.K. } & .3721 \\ 1938 & \text { Hungary } & \text { Czechoslovakia } & \text { U.K. } & .3713 \\ 1922 & \text { Turkey } & \text { France } & \text { Poland } & .3654 \\ 1938 & \text { Poland } & \text { Czechoslovakia } & \text { U.K. } & .3588 \\ 1964 & \text { Cyprus } & \text { Turkey } & \text { U.S. } & .3386 \\ \mathbf{1 9 3 8} & \text { Germany } & \text { Czechoslovakia } & \text { U.K. } & .3247 \\ 1958 & \text { Tunisia } & \text { France } & \text { U.S. } & .2780 \\ 1961 & \text { Indonesia } & \text { Netherlands } & \text { U.S. } & .2268 \\ 1994 & \text { U.S. } & \text { Haiti } & \text { U.S. } & .1984 \\ 1961 & \text { U.S. } & \text { Dominican Republic } & \text { U.S. } & .1865 \\ \mathbf{1 9 5 6} & \text { Soviet Union } & \text { U.K. } & \text { U.S. } & .1431 \\ 1963 & \text { Turkey } & \text { U.K. } & \text { U.S. } & .1182 \\ 1967 & \text { Turkey } & \text { France } & \text { U.S. } & .1120 \\ 1973 & \text { Iceland } & \text { U.K. } & \text { U.S. } & .0995 \\ 1975 & \text { Iceland } & \text { U.K. } & \text { U.S. } & .0994 \\ 1939 & \text { Germany } & \text { Czechoslovakia } & \text { U.K. } & .0916\end{array}$


Table C.3: All Positive Cases of Democratic Target and Ally, Chronological Order

$\begin{array}{llll}\text { Year } & \text { Challenger } & \text { Target } & \text { Ally } \\ 1922 & \text { Turkey } & \text { France }(.1420) & \text { Poland }(.3654) \\ 1923 & \text { Italy } & \text { Yugoslavia }(.1983) & \text { Czechoslovakia }(.3807) \\ \mathbf{1 9 3 8} & \text { Germany } & \text { Czechoslovakia }(.1929) & \text { U.K. }(.3247) \\ 1938 & \text { Hungary } & \text { Czechoslovakia }(.3721) & \text { U.K. }(.1977) \\ 1938 & \text { Poland } & \text { Czechoslovakia }(.1967) & \text { U.K. }(.3588) \\ 1939 & \text { Germany } & \text { Czechoslovakia }(.0761) & \text { U.K. }(.0916) \\ 1939 & \text { Hungary } & \text { Czechoslovakia }(.1978) & \text { U.K. }(.3721) \\ \mathbf{1 9 5 6} & \text { Soviet Union } & \text { France }(.2982) & \text { U.S. }(.4483) \\ \mathbf{1 9 5 6} & \text { Soviet Union } & \text { U.K. }(.0619) & \text { U.S. }(.1431) \\ 1958 & \text { Tunisia } & \text { France }(.1864) & \text { U.S. }(.2780) \\ 1961 & \text { Indonesia } & \text { Netherlands }(.1001) & \text { U.S. }(.2268) \\ 1963 & \text { Turkey } & \text { U.K. }(.0325) & \text { U.S. }(.1182) \\ 1964 & \text { Cyprus } & \text { Turkey }(.1820) & \text { U.S. }(.3386) \\ 1973 & \text { Iceland } & \text { U.K. }(.0264) & \text { U.S. }(.0995) \\ 1975 & \text { Iceland } & \text { U.K. }(.0264) & \text { U.S. }(.0994) \\ 1987 & \text { Venezuela } & \text { Colombia }(.2945) & \text { U.S. }(.3990) \\ 1988 & \text { Honduras } & \text { Nicaragua }(.2945) & \text { U.S. }(.3991)\end{array}$




\section{Bibliography}

Aldrich, John H., Christopher Gelpi, Peter Feaver, Jason Reifler and Kristin Thompson Sharp. 2006. "Foreign Policy and the Electoral Connection." Annual Review of Political Science 9(1):477-502.

Alvarez, Mike, José Antonio Cheibub, Fernando Limongi and Adam Przeworski. 1996. "Classifying Political Regimes." Studies In Comparative International Development 31(2):3-36.

Anonymous. 1938. "Nuremberg and Aussig.".

Bailey, Michael A., Anton Strezhnev and Erik Voeten. N.d. "Estimating Dynamic State Preferences from United Nations Voting." Journal of Conflict Resolution. Forthcoming.

Baker, William D. and John R. Oneal. 2001. "Patriotism or Opinion Leadership? The Nature and Origins of the "Rally 'Round the Flag" Effect." Journal of Conflict Resolution 45(5):661-687.

Baldwin, David A. 1985. Economic Statecraft. Princeton, N.J.: Princeton University Press.

Bapat, Navin A., Tobias Heinrich, Yoshiharu Kobayashi and T. Clifton Morgan. 2013. "Determinants of Sanctions Effectiveness: Sensitivity Analysis Using New Data." International Interactions 39(1):79-98.

Barbieri, Katherine and Richard Alan Peters. 2003. "Measure for Mis-Measure: A Response to Gartzke and Li." Journal of Peace Research 40(6):713-719. 
Baum, Matthew A. 2004. "Going Private: Public Opinion, Presidential Rhetoric, and the Domestic Politics of Audience Costs in U.S. Foreign Policy Crises." Journal of Conflict Resolution 48(5):603-631.

Baum, Matthew A. and Philip B.K. Potter. 2015. War and Democratic Constraint: How the Public Influences Foreign Policy. Princeton, N.J.: Princeton University Press.

Berinsky, Adam J. 2007. "American Public Support for Military Conflict." Journal of Politics 69(4):975-997.

Betts, Richard K. 1987. Nuclear Blackmail and Nuclear Balance. Washington, DC: Brookings Institution.

Boix, Carles, Michael Miller and Sebastian Rosato. 2012. "A Complete Data Set of Political Regimes, 1800-2007." Comparative Political Studies 46(12):1523-1554.

Borhi, Laszlo. 1999. "Rollback, Liberation, Containment, or Inaction? U.S. Policy and Eastern Europe in the 1950s." Journal of Cold War Studies 1(3):67-100.

Brooks, Stephen G. and William C. Wohlforth. 2008. World out of balance : international relations and the challenge of American primacy. Princeton, N.J.: Princeton University Press.

Bueno de Mesquita, Bruce. 1975. "Measuring Systemic Polarity." Journal of Conflict Resolution 19(2):187-216.

Bueno de Mesquita, Bruce, James D. Morrow, Randolph M. Siverson and Alastair Smith. 1999. "An Institutional Explanation of the Democratic Peace." American Political Science Review 93(4):791-807. 
Bueno de Mesquita, Bruce, James D. Morrow, Randolph M. Siverson and Alastair Smith. 2002. "Political Institutions, Policy Choice and the Survival of Leaders." British Journal of Political Science 32(4):559-590.

Bullock, Alan. 1972. Hitler and the Origins of the Second World War. In European Diplomacy Between Two Wars, ed. Hans W. Gatzke. Chicago, IL: Quadrangle Books, Inc. pp. 221246.

Cheibub, José Antonio, Jennifer Gandhi and James Raymond Vreeland. 2010. "Democracy and dictatorship revisited." Public Choice 143(1-2):67-101.

Chiozza, Giacomo and H. E. Goemans. 2003. "Peace through Insecurity: Tenure and International Conflict." Journal of Conflict Resolution 47(4):443-467.

Chiozza, Giacomo and Henk E. Goemans. 2004. "Avoiding Diversionary Targets." Journal of Peace Research 41(4):423-443.

Clark, David H. 2003. "Can Strategic Interaction Divert Diversionary Behavior? A Model of U.S. Conflict Propensity." Journal of Politics 65(4):1013-1039.

Cooper, Chester L. 1978. The Lion's Last Roar. New York: Harper and Row.

Correlates of War Project. 2008. "State System Membership List, v2008.1.". URL: http://correlatesofwar.org

Cox, Dan G. and A. Cooper Drury. 2006. "Democratic Sanctions: Connecting the Democratic Peace and Economic Sanctions." Journal of Peace Research 43(6):709-722.

de Tocqueville, Alexis. 2009. Democracy in America. Indianapolis, IN: Liberty Fund.

DeRouen, Karl Jr. 2000. "Presidents and the diversionary use of force: A research note." International Studies Quarterly 44(2):317-328. 
Downes, Alexander B. 2009. "How Smart and Tough Are Democracies? Reassessing Theories of Democratic Victory in War." International Security 33(4):9-51.

Downes, Alexander B. and Todd S. Sechser. 2012. "The Illusion of Democratic Credibility." International Organization 66(3):457-489.

Downs, George W. and David M. Rocke. 1994. "Conflict, Agency, and Gambling for Resurrection: The Principal-Agent Problem Goes to War." American Journal of Political Science 38(2):362-380.

Drezner, Daniel W. 2003. "The Hidden Hand of Economic Coercion." International Organization 57(03):643-659.

Dutton, David. 2001. Neville Chamberlain. New York: Oxford University Press.

Eubank, Keith. 1963. Munich. Norman, OK: University of Oklahoma Press.

Faber, David. 2008. Munich, 1938: Appeasement and World War II. New York: Simon and Schuster.

Farnham, Barbara. 1997. Roosevelt and the Munich Crisis: A Study in Decision-Making. Princeton, N.J.: Princeton University Press.

Fearon, James D. 1994. "Domestic Political Audiences and the Escalation of International Disputes." American Political Science Review 88(3):577-592.

Frankland, Noble, ed. 1959. Documents on International Relations, 1956. Oxford: Oxford University Press.

Fukuyama, Francis. 1980. Soviet Threats to Intervene in the Middle East, 1956-1973. Technical report Rand.

Fukuyama, Francis. 1992. The end of history and the last man. New York: Free Press. 
Furnia, Arthur H. 1960. Diplomacy of Appeasement: Anglo-French Relations and the Prelude to World War II 1931-1938. Washington, DC: The University Press of Washington, D.C.

Gartner, Scott Sigmund. 1998. "Opening Up the Black Box of War." Journal of Conflict Resolution 42(3):252-258.

Gartner, Scott Sigmund. 2008. "The Multiple Effects of Casualties on Public Support for War: An Experimental Approach." American Political Science Review 102(1):95-106.

Gartzke, Erik. 2007. "The Capitalist Peace." American Journal of Political Science 51(1):166-191.

Gartzke, Erik and Kristian S. Gleditsch. 2004. "Why democracies may actually be less reliable allies." American Journal of Political Science 48(4):775-795.

Gelpi, Christopher. 2010. "Performing on Cue? The Formation of Public Opinion Toward War." Journal of Conflict Resolution 54(1):88-116.

Gelpi, Christopher, Peter D. Feaver and Jason Reifler. 2006. "Success Matters: Casualty Sensitivity and the War in Iraq." International Security 30(3):7-46.

Gerring, John. 2008. Case Selection for Case Study Analysis. In Oxford Handbook of Political Methodology, ed. Janet M. Box-Steffensmeier, Henry E. Brady and David Collier. New York: Oxford University Press pp. 645-684.

Gibler, Douglas M., Steven V. Miller and Erin K. Little. 2016. "An Analysis of the Militarized Interstate Dispute (MID) Dataset , 1816-2001." International Studies Quarterly 60(4):719730.

Gowa, Joanne. 2011. "The Democratic Peace After the Cold War." Economics 8 Politics 23(2):153-171. 
Grieco, Joseph M., Christopher Gelpi, Jason Reifler and Peter D. Feaver. 2011. "Let's Get a Second Opinion: International Institutions and American Public Support for War." International Studies Quarterly 55(2):563-583.

Guisinger, Alexandra and Alastair Smith. 2002. "Honest Threats: The Interaction of Reputation and Political Institutions in International Crises." Journal of Conflict Resolution $46(2): 175-200$.

Hess, Gregory D. and Athanasios Orphanides. 1995. "War politics: An economic, rationalvoter framework." American Economic Review 85(4):828-846.

Homer, J. Robert. 1963. British Foreign Policy and Public Opinion: The Munich Week (September 23-30, 1938) Master of arts University of Massachusetts.

Horowitz, Michael C. and Idean Salehyan. 2015. "Joe Public vs. Sue Scholar: Support for the Use of Force.".

URL: http://politicalviolenceataglance.org/2015/07/27/joe-public-v-sue-scholar-supportfor-the-use-of-force/

Hufbauer, Gary Clyde, Jeffrey J. Schott and Kimberly Ann Elliott. 1990. Economic Sanctions Reconsidered: History and Current Policy. Peterson Institute.

Jervis, Robert. 1968. "Hypotheses on Misperception." World Politics 20(3):454-479.

Kant, Immanuel. 1932. Perpetual Peace. Los Angeles, CA: U.S. Library Association, Inc.

Kee, Robert. 1988. Munich: The Eleventh Hour. London: Penguin Group.

Kennan, George Frost. 1984. American diplomacy. Chicago, IL: University of Chicago Press.

Kingseed, Cole C. 1995. Eisenhower and the Suez Crisis of 1956. Baton Rouge, LA: Louisiana State University Press. 
Kroenig, Matthew. 2013. "Nuclear Superiority and the Balance of Resolve: Explaining Nuclear Crisis Outcomes." International Organization 67(1):141-171.

Kunz, Diane B. 1991. The Economic Diplomacy of the Suez Crisis. Durham, NC: University of North Carolina Press.

Kyle, Keith. 1991. Suez. London: Weidenfeld and Nicolson.

Lake, David A. 1992. "Powerful Pacifists: Democratic States and War." American Political Science Review 86(1):24-37.

Leblang, David and Steve Chan. 2003. "Explaining Wars Fought by Established Democracies: Do Institutional Constraints Matter?" Political Research Quarterly 56(4):385-400.

Lee, Dwight E. 1970. Munich: Blunder, Plot, or Tragic Necessity? Lexington, MA: D.C. Heath and Company.

Leeds, Brett Ashley, Jeffrey Ritter, Sara McLaughlin Mitchell and Andrew G. Long. 2002. "Alliance Treaty Obligations and Provisions, 1815-1944." International Interactions 28(3):237-260.

Lektzian, David and Mark Souva. 2007. "Sanctions Onset and Success." Journal of Conflict Resolution 51(6):848-871.

Lenway, Stefanie Ann. 1988. "Between war and Commerce: economic sanctions as a tool of statecraft." International Organization 42(2):397.

Levendusky, Matthew S. and Michael C. Horowitz. 2012. "When Backing Down Is the Right Decision: Partisanship, New Information, and Audience Costs." Journal of Politics 74(02):323-338. 
Levy, Jack S. 1989. Domestic Politics and War. In The Origin and prevention of major wars, ed. Robert I Rotberg and Theodore K Rabb. Cambridge, MA: Cambridge University Press pp. 79-99.

Lian, Bradly and John R. Oneal. 1993. "Presidents, the Use of Military Force, and Public Opinion." Journal of Conflict Resolution 37(2):277-300.

Lipson, Charles. 2003. Reliable Partners: How Democracies Have Made a Separate Peace. Princeton, N.J.: Princeton University Press.

Love, Kennett. 1969. Suez: the twice-fought war: a history. New York: McGraw-Hill.

Lucas, W. Scott. 1991. Divided We Stand: Britain, the US and the Suez Crisis. London: Hodder and Stoughton.

McDermott, Rose. 1998. Risk-Taking in International Politics: Prospect Theory in American Foreign Policy. Ann Arbor, MI: University of Michigan Press.

Meernik, James and Peter Waterman. 1996. "The Myth of the Diversionary Use of Force by American Presidents." Political Research Quarterly 49(3):573-590.

Miller, Steven V. and Douglas M. Gibler. 2011. "Democracies, Territory, and Negotiated Compromises." Conflict Management and Peace Science 28(3):261-279.

Mitchell, Sara McLaughlin and Brandon C. Prins. 1999. "Beyond Territorial Contiguity : Issues at Stake in Democratic Militarized Interstate Disputes." International Studies Quarterly 43(1):169-183.

Morgan, T. Clifton and Christopher J. Anderson. 1999. "Domestic Support and Diversionary External Conflict in Great Britain, 1950-1992." The Journal of Politics 61(3):799. 
Morgan, T. Clifton, Navin Bapat and Yoshiharu Kobayashi. 2014. "Threat and imposition of economic sanctions 1945-2005: Updating the TIES dataset." Conflict Management and Peace Science pp. 1-18.

Mousseau, Michael. 2013. "The Democratic Peace Unraveled: It's the Economy." International Studies Quarterly 57(1):186-197.

Mueller, John E. 1970. "Presidential Popularity from Truman to Johnson." American Political Science Review 64(1):18-34.

Nogueres, Henri. 1965. Munich: Peace for Our Time. New York: McGraw-Hill.

Oakes, Amy. 2006. "Diversionary War and Argentina's Invasion of the Falkland Islands." Security Studies 15(3):431-463.

Oneal, John R. and Bruce Russett. 1997. "The Classical Liberals Were Right: Democracy, Interdependence, and Conflict 1950-1985." International Studies Quarterly 41(2):267-293.

Pape, Robert A. 1997. "Why Economic Sanctions Do Not Work." International Security 22(2):90-136.

Potter, Philip B.K. and Matthew A. Baum. 2013. "Looking for Audience Costs in all the Wrong Places: Electoral Institutions, Media Access, and Democratic Constraint." Journal of Politics 76(1):167-181.

Poznansky, Michael and Matt K. Scroggs. 2016. "Ballots and Blackmail: Coercive Bargaining and the Democratic Peace." International Studies Quarterly 60(4):731-741.

Rasler, Karen and William R. Thompson. 1999. "Predatory Initiators and Changing Landscapes for Warfare." Journal of Conflict Resolution 43(4):411-433. 
Rauchhaus, Robert. 2009. "Evaluating the Nuclear Peace Hypothesis: A Quantitative Approach." Journal of Conflict Resolution 53(2):258-277.

Reiter, Dan and Allan C. Stam. 1998. "Democracy, War Initiation, and Victory." American Political Science Review 92(2):377-389.

Reiter, Dan and Allan C. Stam. 2002. Democracies at War. Princeton, N.J.: Princeton University Press.

Reiter, Dan and Erik R Tillman. 2002. "Public, Legislative, and Executive Constraints on the Democratic Initiation of Conflict." Journal of Politics 64(3):810-826.

Richardson, Louise. 1993. Avoiding and incurring losses: decision-making in the Suez crisis. In Choosing to Cooperate: How States Avoid Loss, ed. Janice Gross Stein and Louis Pauly. Baltimore, MD: Johns Hopkins University Press pp. 170-201.

Robbins, Keith. 1968. Munich, 1938. London: Cassell and Company Ltd.

Rucker, Laurent. 2001. Soviet Union and the Suez Crisis. In The 1956 War: Collusion and Rivalry in the Middle East. New York: Routledge.

Schultz, Kenneth A. 2001a. Democracy and coercive diplomacy. Cambridge, MA: Cambridge University Press.

Schultz, Kenneth A. 2001b. "Looking for Audience Costs." Journal of Conflict Resolution $45(1): 32-60$.

Scroggs, Matt K. and Michael Poznansky. 2017. "Targeting Their Wallets: Threats of Economic Sanction and the Limits of Democratic Peace (working paper).".

Sechser, Todd S. 2010. "Goliath's Curse: Coercive Threats and Asymmetric Power." International Organization 64(04):627-660. 
Sechser, Todd S. 2011. "Militarized Compellent Threats, 1918-2001." Conflict Management and Peace Science 28(4):377-401.

Sechser, Todd S. 2017. "Reputations and Signaling in Coercive Bargaining." Journal of Conflict Resolution 0(0).

Shaw, Tony. 1996. Eden, Suez and the Mass Media: Propoganda and persuasion during the Suez crisis. New York: Tauris Academic Studies.

Signorino, Curtis S. and Jeffrey M. Ritter. 1999. "Tau-b or Not Tau-b: Measuring the Similarity of Foreign Policy Positions." International Studies Quarterly 43(1):115-144.

Singer, J. David. 1987. "Reconstructing the Correlates of War Dataset on Material Capabilities of States, 1816-1985." International Interactions 14:115-32.

Singer, J. David and Melvin Small. 1966. "Formal Alliances, 1815-1939." Journal of Peace Research 3:1-31.

Skaaning, Svend-Erik, John Gerring and Henrikas Bartusevicius. 2015. "A Lexical Index of Electoral Democracy." Comparative Political Studies .

Smith, Alastair. 1996. "The success and use of economic sanctions." International Interactions 21:229--245.

Tarar, Ahmer. 2006. "Diversionary Incentives and the Bargaining Approach to War." International Studies Quarterly 50(1):169-188.

Tir, Jaroslav. 2010. "Territorial Diversion: Diversionary Theory of War and Territorial Conflict." Journal of Politics 72(2):413.

Tir, Jaroslav and Michael Jasinski. 2008. "Domestic-Level Diversionary Theory of War: Targeting Ethnic Minorities." Journal of Conflict Resolution 52(5):641-664. 
Trager, Robert F. and Lynn Vavreck. 2011. "The political costs of crisis bargaining: Presidential rhetoric and the role of party." American Journal of Political Science 55(3):526-545.

Trueman, C N. 2015. "Public Opinion And Appeasement In 1938.".

United States Government. 1949a. Documents on German Foreign Policy: 1918-1945. In Series D (1937-1938), Volume 2: Germany and Czechoslovakia, 1937-1938. Washington, DC: United States Government Publishing Office.

United States Government. 1949b. Documents on German Foreign Policy: 1918-1945. In Series D (1937-1945), Volume 1: From Neurath to Ribbentrop. Washington, DC: United States Government Publishing Office.

Vreeland, James Raymond. N.d. "The Return of Goldilocks in... Civil War and The Three Regimes!".

URL: http://faculty.georgetown.edu/jrv24/goldindex.html

Waltz, Kenneth N. 2000. "Structural Realism after the Cold War." International Security 25(1):5-41.

Weeks, Jessica L. 2008. "Autocratic Audience Costs: Regime Type and Signaling Resolve." International Organization 62(01):35-64.

Weeks, Jessica L. 2012. "Strongmen and Straw Men: Authoritarian Regimes and the Initiation of International Conflict." American Political Science Review 106(02):326-347.

Weiss, Jessica Chen. 2013. "Authoritarian Signaling, Mass Audiences, and Nationalist Protest in China." International Organization 67(1):1-35.

Weiss, Jessica Chen. 2014. Powerful Patriots : Nationalist Protest In China's Foreign Relations. New York: Oxford University Press. 
Weller, Nicholas and Jeb Barnes. 2014. Finding Pathways: Mixed-method Research for Studying Causal Mechanisms. Cambridge, MA: Cambridge University Press.

Werner, Suzanne and Douglas Lemke. 1997. "Opposites do not attract: The impact of domestic institutions, power, and prior commitments on alignment choices." International Studies Quarterly 41(3):529-546.

Wright, Quincy. 1965. A Study of War. Chicago, IL: University of Chicago Press. 